लिखिर दर

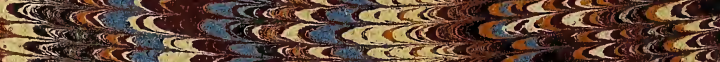

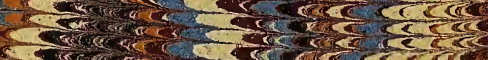

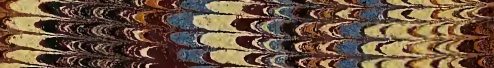

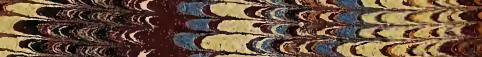

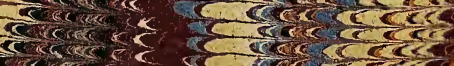

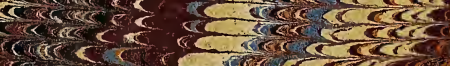 से क्राभा 15 है पोती लट से है है है हो ज्ञाता से प्रोटी \\ सि है पित्ये

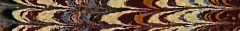

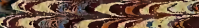

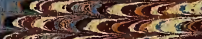

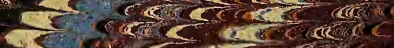

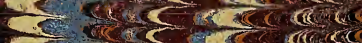

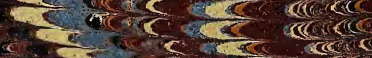

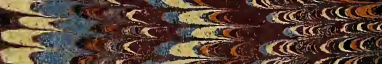

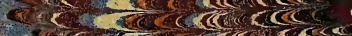

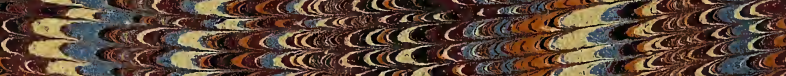

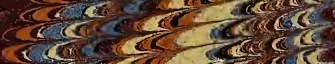

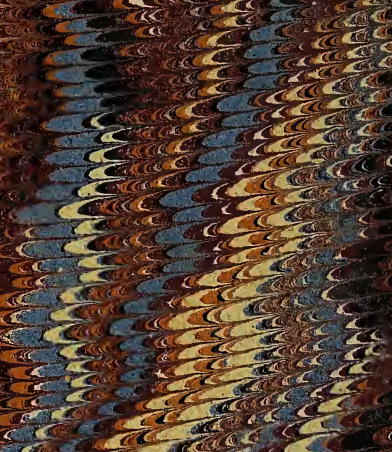
cicise

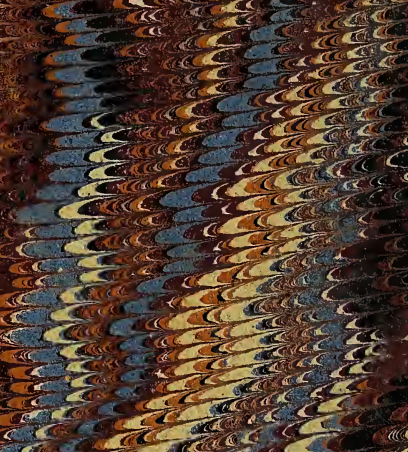
\& $x^{2}$ (1) Q60) स 更 ad

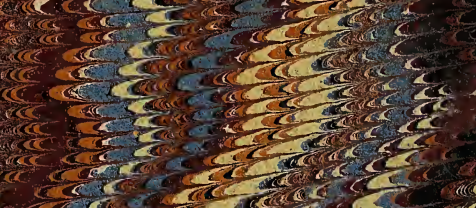

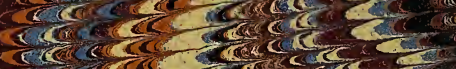

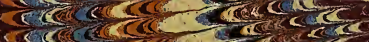

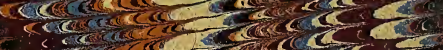

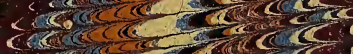

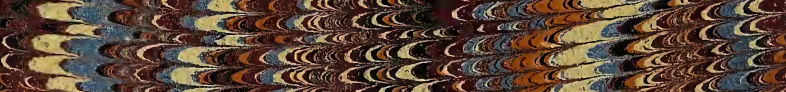
$52 \cos$

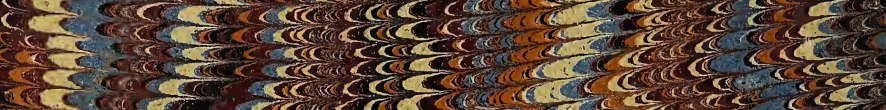

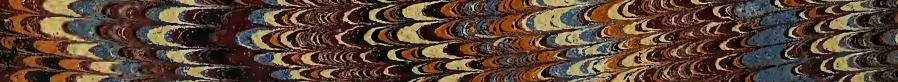
5. cesce

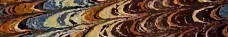

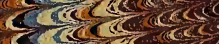
त. urencrar de

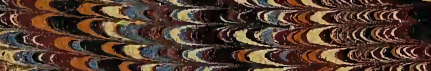

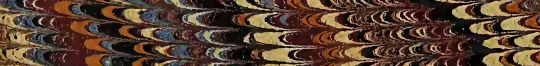
esecs GCC. \& e cer rescorn and

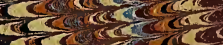

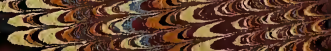

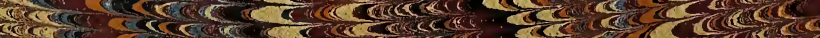
$\operatorname{cocec}$ Ca

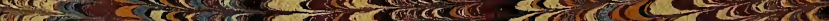


cos.ce

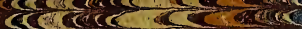

दो crats

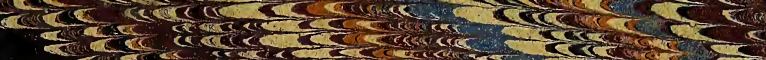

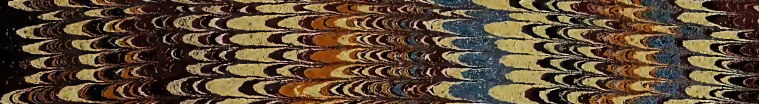

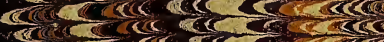

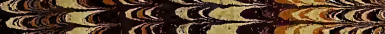

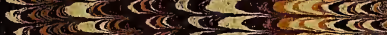

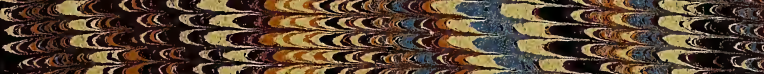

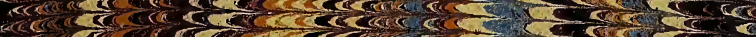

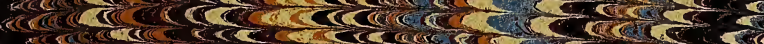

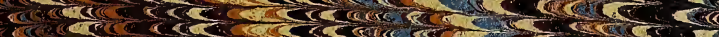

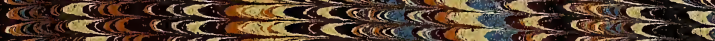

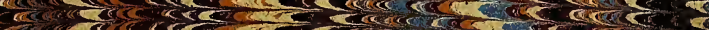

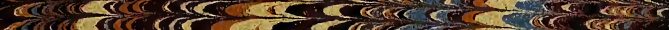

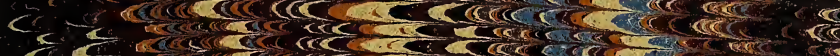

$\left\{\begin{array}{l}\xi \\ 2\end{array}\right.$

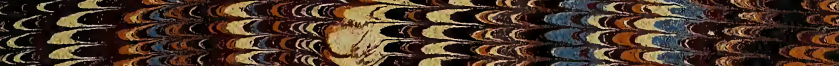

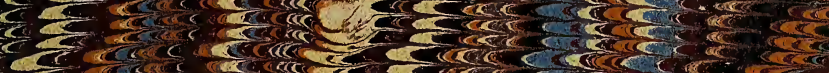
c.

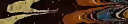

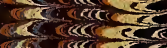

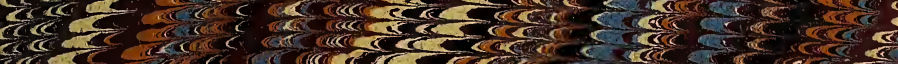

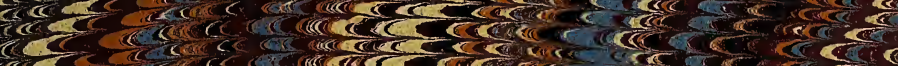

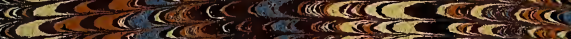

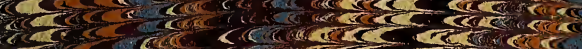

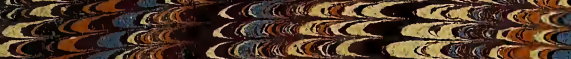

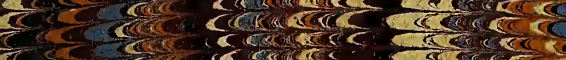
$\frac{\frac{5}{x}}{5}$

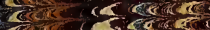

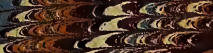

$\sin 2 \frac{12 \cos a}{20}$

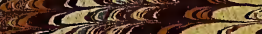

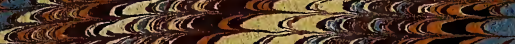

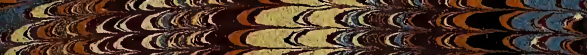

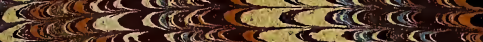

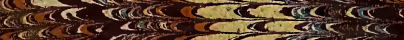

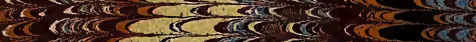

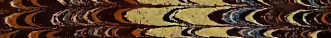

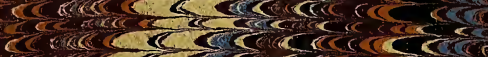

25

res $x$

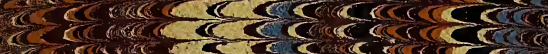

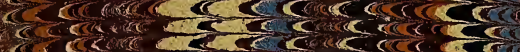

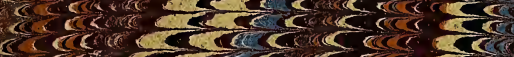

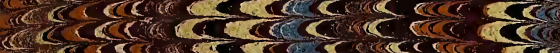

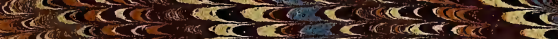

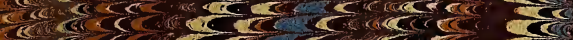

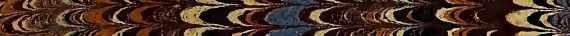

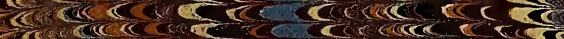

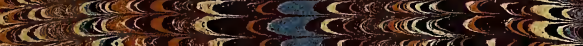

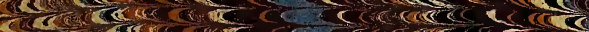

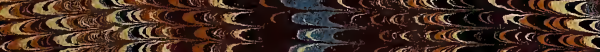
$x<$ Coces $x$ कर एक

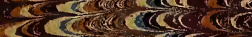

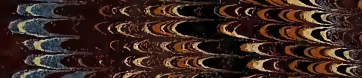

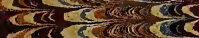
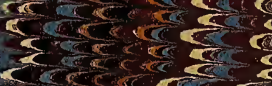

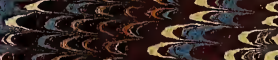

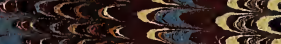
(ese cat <दर consicesen कर दोली कर

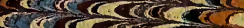

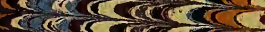

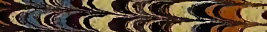
$\left.-\cos 2 \cos ^{2}\right)^{2}$

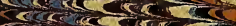
cosos C.C CC

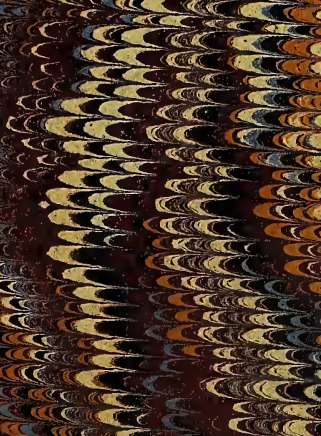


Gecrevo: H. Palmer D. 2

Howonir Caurâ Othawly Slow: tures . 0251 ? 
J.P.G. - Its just another chicken.

L.L.G. - Chicken! says you!

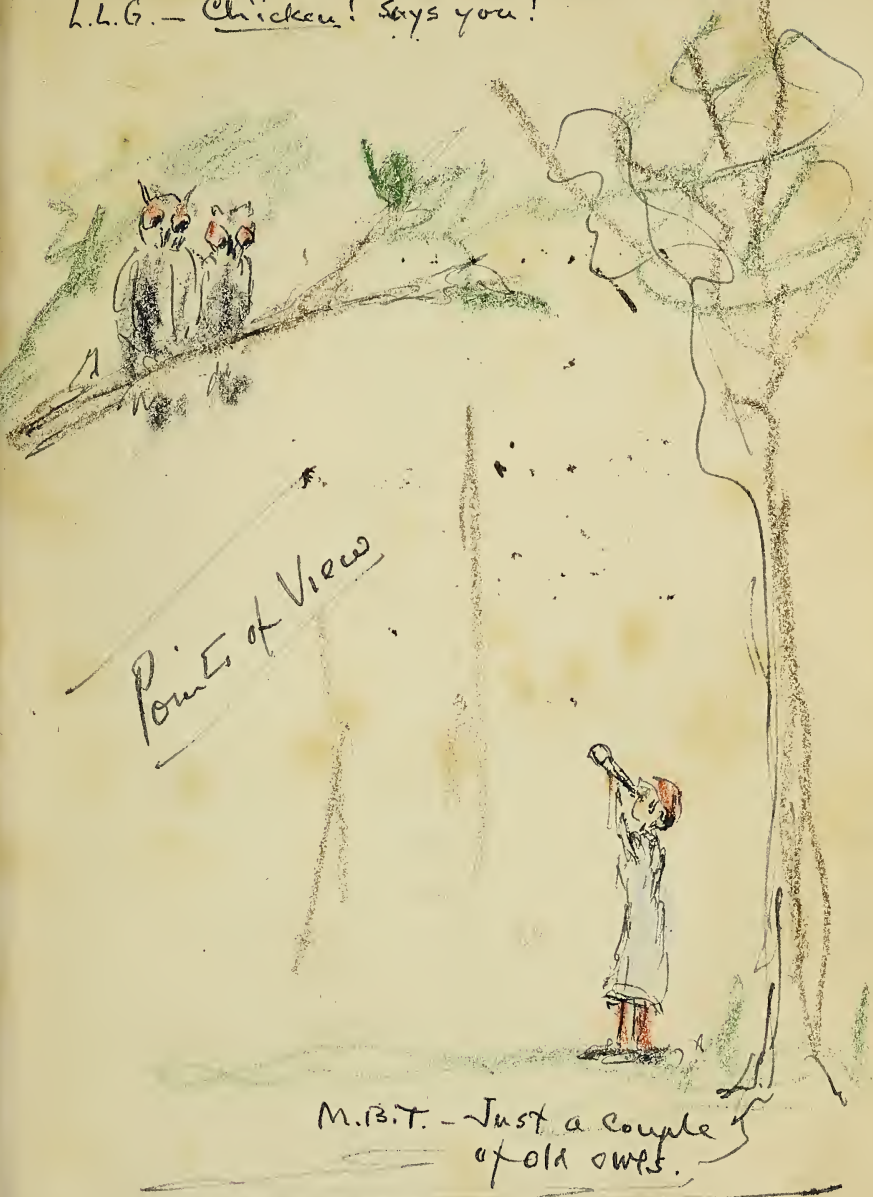

Just awolter old fire. book for Marcia Tucker is Collection

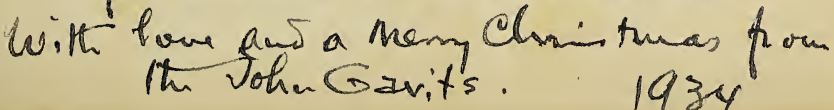
1934 




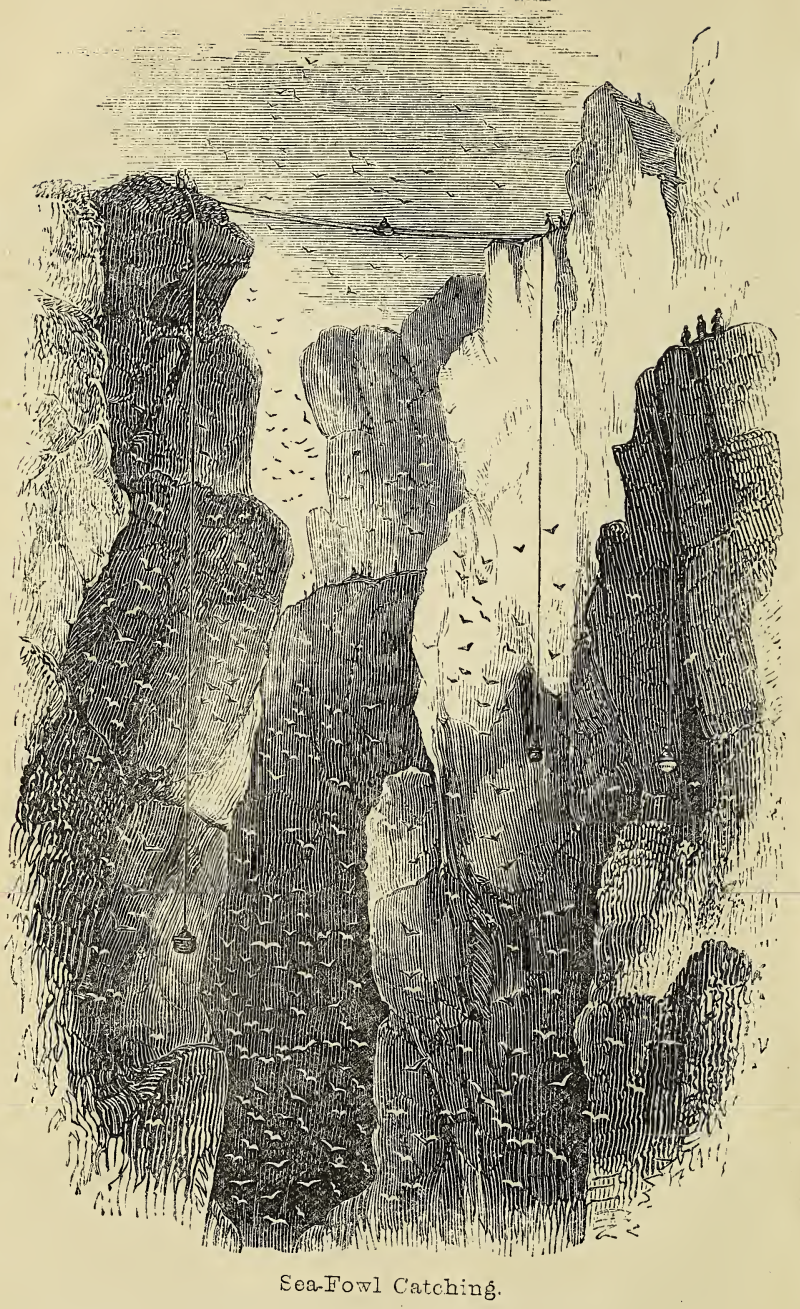




\section{A FAMILIAR HISTORY OF}

\section{B IR D S}

BY THE LATE

EDWARD STANLEY D.D. F.R.S.

LORD BISHOP OF NORWICH

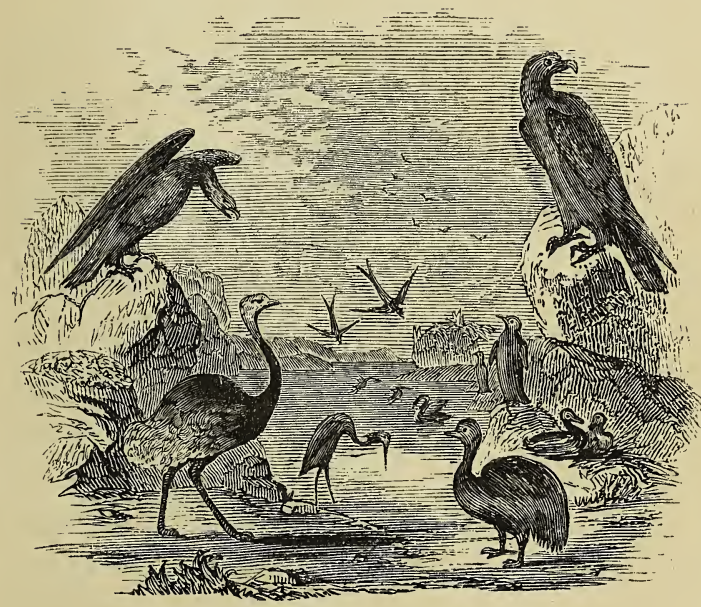

THE SIXTH EDITION

LONDON

JOHN W PARKER AND SON WEST STRAND M DCC்CLIV 
PUBLISHED UNDER THE DIRECTION OF THE COMMITTEE OF GENERAL LITERATURE AND EDUCATION APPOINTED BY THE SOCIETY FOR PROMOTING CHRISTIAN KNOWLEDGE. 


\section{ADVERTISEMENT.}

THIS work is intended for a class of readers to whom

1 mere scientific details would be unacceptable, if not unintelligible. Such, therefore, have been, as much as possible, avoided, and only alluded to as inducements to those who are interested in the subject, to make further progress in so attractive a department of Natural History.

There are few individuals who have it not in their power, occasionally, to remark the instincts and habits of Birds; and the many anecdotes collected from the Author's own observation, the information of friends, or various respectable sources, will, it is hoped, excite others to register any facts within their reach, which may illustrate the mysterious economy whereby this beautiful portion of God's creation is enabled, in so many instances, to surpass the highest efforts of man's ingenuity, foresight, or philosophy. 



\section{CONTENTS.}

PAGE

INTRODUCTION

Chapter I. Rank of Birds in the Animal Kingdom.Tables of Classification.-Directions for their Application . . . . . . . . . . . . . . . . 5

Chapter II. Structure of Birds.-External Structure.Skeleton.-Character of Beak. - Bones, their Lightness. - Solidity of Backbone.-Breastbone, Use of. -Wingbones.-Legs, Peculiarities of.-When resting on one leg, why Birds do not fall . . . . . . . . .

Chapter III. Internal Structure. - Digestive Organs. Gullet, Crop, Stomach-Adaptation of, to different habits of Birds. - Gastric Juice-Its use and properties. Gizzard, its grinding powers. - Respiration of Birds

Chapter IV. Organs of Sound.-Ducks, Crane, GoatSucker, Bell-Bird, \&c.-Distance at which Sounds may be heard.-Plumage.-Structure of Feathers.-GoosePlucking.-Summer and Winter Plumage . . . . 56

Chapter V. Flight.-Muscular power of Wings.-Peculiarity of, in different Birds.-Adapted to various habits. - Rapidity of motion, and rate of-How calculated.Long continuance of Flight accounted for.-Migration, causes of.-Tendency of most Birds to wander at particular times. - Why seldom seen in the act of Migrating -Instinctive power of finding their way . . . . . 70 
Chapter VI. Eagle and Hawk Tribe. - Wild Eagle Tamed - Muscular powers of - Carry off Children, Lambs, \&c.- Sometimes killed on the Wing by Weasels. -Battle between Cat and Eagle.-How caught when fishing - Voracity of-Nests - Singular mode of capturing their prey.-Bird of Washington. - Eagle Traps. -Feathers Prized . . . . . . . . . . .

Chapter VII. Vultures - Loathsome feeders - Strength of.-Snake-Eater.-Mode of killing Serpents.-Hawks - Character of.-Hawking for Bustards - Value of.Iceland Falcons much prized.-Falconry in former days. -Contest with Herons. - Modes of Catching.-The Sparrow-Hawk.-Anecdotes.-The Glede, or Kite.Herons. - Food of the Hawk Tribe.-Their disposition. -The Hawk sacred to the Egyptians and Turks . . 113

Chapter VIII. Owls - Superstitions respecting - Shorteared. - The Great Snowy Owl-White Owl-Mode of feeding-Attachment to young-Used in Bird-catching. -Burrowing Owl.-Dentirostral; Notch-billed Birds. Shrikes-Mode of foeding-Nests of-used in taking Falcons.-Puff-backed Shrike.-Thrush genus-Instinctive Habits of feeding.-Anecdote.-Thrush and young Cuckoo.-Fly-catchers. - Cotinga.-Tanagers - Beauty of. Sərratirostral, or Serrated Beaks.-Hornbills.-Plenirostral; Strong-Billed.-Grackles.-Paradise Birds . . . 145

Chapter IX. Ravens-Occasionally desert their YoungPredacious Habits. - Sagacity. - Various Anecdotes. Crows and Rooks-Characters of each. - Tame Crow.Meetings, or Councils, of Crows, Herons, Magpies, \&c. -Whether Rooks are beneficial or injurious to the Farmer.-Hard Winters favourable to Insects.-Rookeries. -Red-legged Crow._Jackdaws._Jays and Magpies . 179

Chapter X. Passerine Order continued. - Conirostres; Conical Beaks.-Orioles.-_tarlings.-Habits of.-Finch Tribe.-Goldfinch.-Anecdotes of. - Nests rapidly com- 
pleted.-Curious Nests in Africa.-Age of small Birds. -Canary Birds. - Trade in.-Bullfinches, Piping.-How trained.-Boldness of.-Affectionate and social Habits of-Also of Linnets.-Use of small Birds in destroying Insects .

Chapter XI. Subulirostres; Awl-shaped Bills.-Manakins: curious Nests of.-Tomtits.-Wagtails. - Redstarts.Robins, \&c. - Migration of this Tribe. - Nightingales.Whether they return to same nests.-Ear for Music.Night-Singing Birds. - Planirostres ; Flat-billed.-Swallow Tribe.-Whether occasionally Dormant ; instances of-Migration of.-Insects, number devoured by Swallows.-Spiders, high Flights of.-Curious Nests of Swallows.-Courage of . . . . . . . . . . 232

Chapter XII. Swallows' nests, continued.-Edible Nests, East Indies. - Goat-suckers.-Mode of seizing Moths.Cavern with their Nests, described. - Tenuirostres; Narrow-billed.-Nuthatch.-Tree-Creeper.-Bee-Eater. Hoopoe. - Kingfisher. - Humming Birds. - Climbing Birds.-Cuneirostres; Wedge-billed.-Jacamar.-Anis. Cuckoo.-Anecdotes and Habits of . . . . . 253

Chapter XIII. Cuneirostral, continued.-WoodpeckerTame one.-Wryneck-Tongue of.-Levirostral; Lightbilled. - Parrots. - Toucan. - Gallinaceous ; Poultry tribe.-Pigeons, American-Prodigious numbers ofRapid flight-Employed as Messengers - Mode of catching - Attachments of. - Cocks. - Pheasants Courage of.-On breeding Pheasants-Box for Feeding -Prized by Ancients.-Turkeys, Wild-Social Habits of.-Partridges, tamed-Nests of-Various sorts of.Quails - Immense Flights of. - Bustards.-OstrichNests of - Affection - Hunting - Strength of Cassowary and Emu .

Chapter XIV. Water Birds. - Waders. - Pressirostral; Narrow-beaked.-Water-Hens.-Anecdotes of - Nests of.-Coots-Nests of.-Jacanas-Singular Foot of.- 
Horned Screamers.-Rails.-Oyster-Catchers-Tamed. Cultrirostra; Cutting-billed.-Herons-Toothed-claw of Voracity of. - Storks and Cranes - Migrations of Respect paid to.-Gigantic Crane-Particulars respecting.-Jabiru,-Anastomus ; Open-beaked.-Tantalus . 305

Chapter XV. Latirostral - Flat-beaked. - Boat-bill. Spoon-bill.-Flamingo-Mode of Feeding-Nests of Watchful Habits.-Tenuirostral, or Longirostral; Long, Slender-billed Birds.-A voset.-Sand-Pipers.-Dotterel -Preservation of its young.-Dunlin's Nest and Eggs. -Plover-Mode of Catching.-Ibis-Mummies ofWhy held Sacred . . . . . . . . . . 329

Chapter XVI. Palmipedes; Web-footed - Serrated or Tooth-billed. - Geese - Flocks of - How managedPlucking - Singular attachment - Sagacity - Courage. -Tree Geese-Swans-Muscular Strength-Courage. —Black Swans._Trade in Swan-quills . . . . . . 349

Chapter XVII. Duck Tribe-Management of-Chinese mode.-Wild Ducks building in trees-Affection of.Eider Ducks - How caught.-Duck-shooters, Danger attending.-Decoys . . . . . . . . . . . 367

Chapter XVIII. Pinnipedes ; Swimming feet.-PelicanFable of drawing its blood explained-Mode of fishing.Sea-birds feeding on fish thrown up by Whales.-Cormorants-Voracity of-May be tamed-Fierceness of.Frigate-bird.-Solan Goose-Lightness and buoyancy of-Nests.-Anhingas, or Darters . . . . . . 383

Chapter XIX. Longipennes; Long-winged-SkimmersSingular bill. -Terns, or Sea-Swallows-Anecdote of.Gulls-Capacity for enduring cold-Voracious feedersBreeding-places.-South Stack described.-AlbatrossRoaming habits. - Tristan d'Acunha, Resort for breeding -Voracity.-Petrels-Nests-Feed at night-Superstition of sailors respecting.-Brevipennes; Short-winged. 
-Divers.-Crested Grebe-Great destroyers of fish.-

Guillemots._Razor-Bills._Puffins and Auks. . . . 396

Chapter XX. Penguins; Fin-winged.-King Penguin of the southern regions described-Breeding places-Valuable for oil.-Sea-fowler's perilous occupation-Description of, in Shetland, St. Kilda, \&c.-Singular escapesFatal accidents . . . . . . . . . . 429 



\section{INTRODUCTION.}

UR object being rather to furnish the reader with rational and interesting facts, than systematic arrangements, it is not intended to treat the subject of Ornithology* scientifically. But at a period when the education of every class of the community is rapidly improving, and when the minds of the rising generation are in a state of advancement, fitting them for that more perfect knowledge, which, in the preparation of elementary books, ought always to be kept in view, it is of importance that even the simplest work should be arranged and founded, in some degree, on scientific principles. We shall therefore commence with a few introductory remarks on those, peculiar features in the formation and habits of Birds, by which they are distinguished from other branches of the animal creation; evincing as they do, that uniform and beautiful adaptation of means to the accomplishment of certain ends, which characterize every branch of the creation; each in its respective perfection, proving beyond contradiction, that as "the works of the Lord are manifold, so in wisdom hath He made them all."

The visible creation, it has been well said, was Adam's library. There may be times, places, and occasions, in which a page out of a book in that library may impart not only instruction to the head, but consolation to the heart. When that persevering traveller, Mungo Park, was at one period of his perilous course fainting in the vast wilderness of an African desert, naked and alone, considering his days as numbered, and nothing appearing to remain for him but to lie down and die, a small moss flower of extraordinary beauty caught his eye. "Though the whole plant," says

\footnotetext{
* From ornis and logos, two Greek words, signifying the knowledge
} of birds. 
he, "was not larger than one of my fingers, I could not contemplate the delicate conformation of its roots, leaves, and capsules, without admiration! Can that Being who planted, watered, and brought to perfection, in this obscure part of the world, a thing which appears of so small importance, look with unconcern upon the situation and sufferings of creatures formed after his own image? Surely not. Reflections like these would not allow me to despair; I started up, and disregarding both hunger and fatigue, travelled forwards, assured that relief was at hand; and I was not disappointed."* And with the disposition to wonder and adore, in like manner, can no branch of Natural History be studied, without increasing that faith, love, and hope, which we also, every one of us, need in our own journey through the wilderness of life.

There are some points in which the structure and powers of the winged tribe demand more attention and admiration than those of any other class, inasmuch as the object to be obtained is a more extraordinary one, and the difficulties to be overcome, such as the utmost ingenuity of man has been found utterly unable to meet. Let us suppose a person to have grown from infancy to manhood, without ever having heard of a bird. He sees that the light snow-flake is unable to remain suspended in the air; that the still lighter thistledown, when no longer supported by the breeze, has a tendency to fall to the ground; and yet he is told, that there are tenants of the air, countless as those of earth and water; that some of considerable size and weight can journey on their way above the clouds, with a facility and speed far exceeding that of the swiftest footed animal. He may, indeed, from observing that cork and light bodies, when plunged in water, rise to the surface, conceive the possible existence of a lighter substance than air, capable, by the same laws of nature, of rising above the earth. If a philosopher, he may even discover the inflammable and lighter gas by which a balloon ascends, with the weight of a man attached; but

* PARK's Travels in Africa.

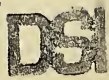


how shall he lift a substance heavier than the air? And how guide its progress through the air? Show him the weighty body of an Eagle or a Swan,* tell him their living history, and he may reasonably doubt your fact, and deny that these things could be.

There is one difficulty in the use of wings that any one may ascertain for himself. Let him take the smallest sized boy's kite by the narrow end, and wave it up and down at arm's length; he will instantly perceive how great is the resistance of the air, and how obvious the inability of his muscular strength to produce anything like the rapid motion of a wing. And yet, in order to possess the powers of a bird, he must be able to construct and move artificial wings, in superficial extent, in some cases measuring several of such kites; with the additional difficulties, which mathematical knowledge would prove to be proportionally increased at every step in his progress. How all these seeming impossibilities are accomplished is perhaps the most interesting part of the following pages.

But the study of Ornithology has other charms, in a great measure confined to itself, and recommending it to the attention of a large class of readers; namely, that of its being within the reach of all who take an interest in the proceedings of the natural world. Quadrupeds, generally speaking, are few in number, and so difficult of access, that in fact, beyond the limited families of our domestic menageries, few can have an opportunity of investigating their habits. Out of eighty genera of four-footed animals, about fifteen only are to be met with in the British islands; of these, many live so remote from man, that accident alone can gratify his curiosity, and of that greater portion scattered over the earth, few, comparatively speaking, ever fall under the observation of the most inquiring traveller. One-half of the characteristic features of the lion and tiger tribe we collect from the analogous habits of one of a similar genus, namely, the cat, which harmlessly purrs by our fire-side: while the

* The wild swan weighs $25 \mathrm{lbs}$. 
sheep and goat afford information respecting the numerous class of ruminating animals, which inhabit parched deserts, or the precipitous regions of rocks and mountains. But in the class of Birds the case is different: many, it is true, and perhaps some of the most singular as well as most beautiful, are seldom accessible; but of those which meet us at every turn, which cheer our solitary walk with their song, or display before us their various instincts and prominent occupations, the number is immense. Of about one hundred and twenty genera, about half are to be met with in this country, and frequently under circumstances favourable for ascertaining their habits and modes of life. Every field and garden, every tree and hedge-row, may prove the prolific source of delightful interest and information; for a trifling attention will enable an observer to distinguish, when on the wing, high in mid-air, or flitting from spray to spray, the genus to which every species belongs. In short, not a day passes but a lover" of nature may record in his journal, anecdotes and hints from whence a store of practical knowledge may be derived. In the country, an acquaintance with the feathered creation is like the acquisition of another sense, limited by neither season nor situation; their periodical journeys to and from regions far remote, their mysterious and wonderful instincts adapted to their respective situations, are all sources of inexhaustible interest. The spring, the summer, the autumn, and the winter, have each their corresponding interests: There is, moreover, a remarkable uniformity amongst Birds, which does not exist in Quadrupeds; for instance, a lion and an armadillo, a giraffe or a mole, are as different as living creatures can be conceived to be; but in Birds, excepting in size, and the natural division between the land and water families, a greater similarity is discoverable; a circumstance which enables us to treat more briefly the particular history of their several subdivisions. 


\section{CHAPTER I.}

Rank of Birds in the Animal Kingdom.-Tables of Classification. -Directions for their Application.

RIRDS form the second class in the great natural division $B$ of the Animal Kingdom. They resemble the first class, Mammalia (those that suckle their young), in some respects; such as the general form of the skeleton, the mode of breathing through lungs, \&c. They differ from them by being what is termed Oviparous, or producing their young enclosed in eggs; in their outward form, in their feathery covering, and in the structure of their mouths, which are furnished with a horny bill, instead of lips and teeth; but most particularly are they distinguished from other animals, by being provided with wings.

It is not our intention, as we have said, to treat the subject in what is called a scientific manner, by entering into details and particulars, more calculated for those who have made it' a matter of long study, than for the greater number, probably, of our readers, who may have paid little attention to it; but as it is our wish to be as extensively useful as possible, we have drawn up the following Tables, giving at a glance not only a general outline of the rules by which Birds are classed, but at the same time enabling an inexperienced person, with very little trouble, in most cases, to make out for himself the genus, or family, of any specimen which may be placed before him, and which he may wish to describe.

We are far from recommending these Tables as perfect, or even the best that could be drawn up, and an experienced student will, no doubt, find some of the subdivisions to be defective; but, when the difficulty of any mode of classification, so accurate and unexceptionable in all its details as to meet every case, is considered, an approximation to the truth is all that can be hoped for; and we trust that, tor 
practical purposes and general use, the annexed will be found, on the whole, simple and satisfactory. Whatever may be their imperfections, we can at least vouch, from experience, for their tending very materially to facilitate a learner's progress; and as they are founded on the authority of some of our most esteemed naturalists,* even the more advanced may, it is to be hoped, refer to them with advantage. $t$

* Chiefly from Cuvier and Dumeril.

$\dagger$ The best tables of classification and reference we have seen are those now published in large sheets with figures, at a very moderate price, by M. Achille Comte, illustrating CuviER's Règne Animal. 


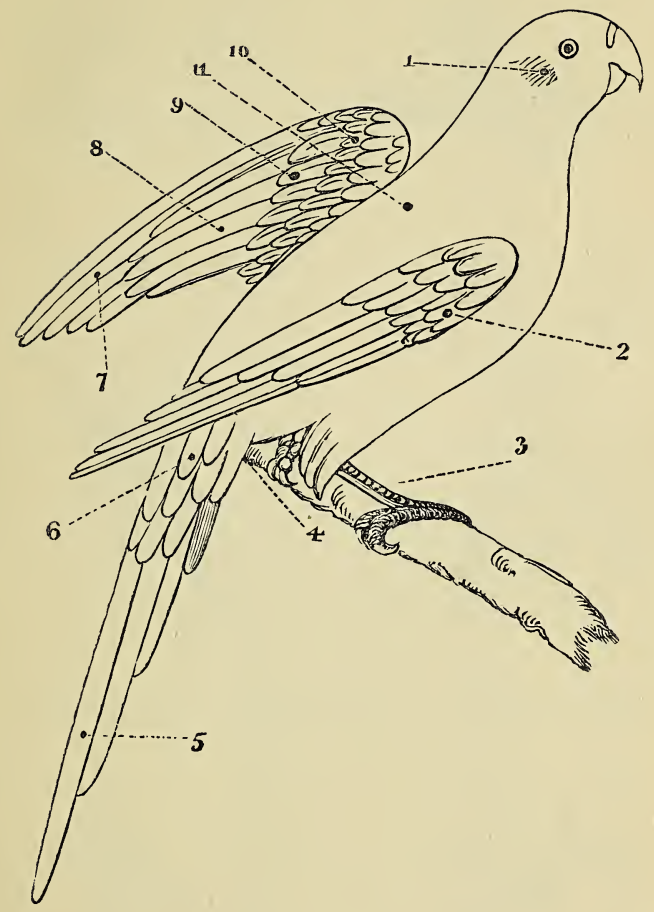

1. Ear-coverts. 6. Upper Tail-coverts. 11. Scapulars, feathers rising

2. Bastard-wing. 7. Primary Quills.

3. Tarsus.

8. Secondary Quills.

4. Vent feathers. 9. Greater Coverts.

5. Rectrices.
10. Lesser Wing-coverts. near the junction of the wing with the body, and lying along the sides of the back. 
1. Rapacious.

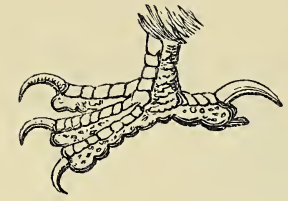

2 Passerine.

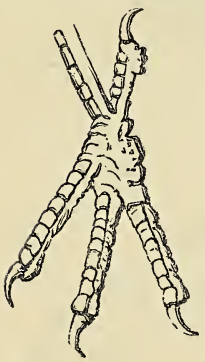

4 Gallinaceous

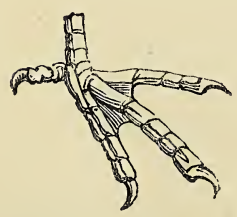

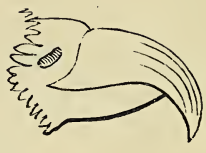

3. Scansores.

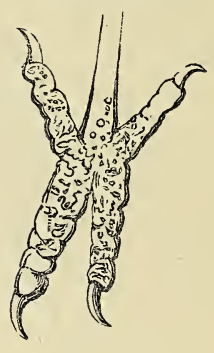

6 Web-footed.

5. Waders.*

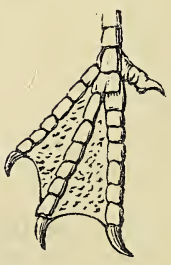

* Waders are readily distinguished by their length of leg. 


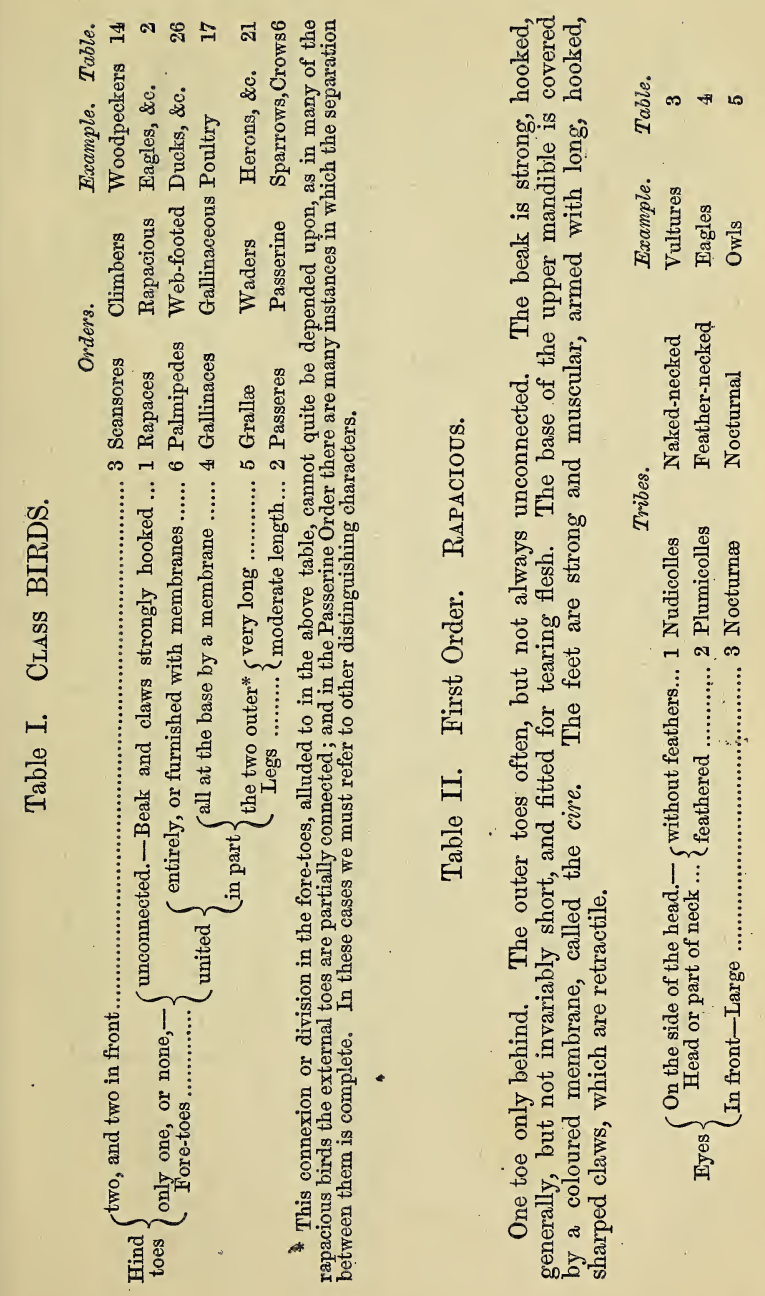


so

空富

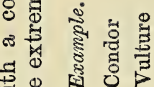
突

लै

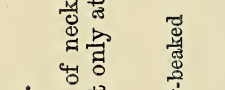

ชु

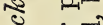

षे के

के वे

卷

艺

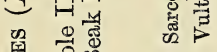

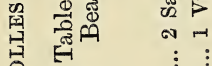

ठํํㅇ ह ह

只 4.

子 离害

$\exists$ ○े

范

क

ค月,

tै

范茟

体

ㅍ

†ै .

फै

o

है

=

密

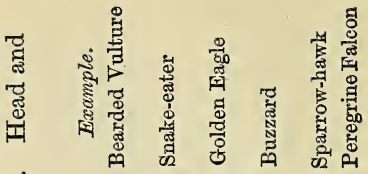

శ్తి

空

4

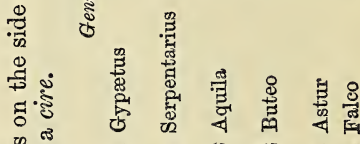

ชे

क

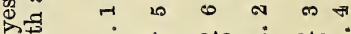

周落

is

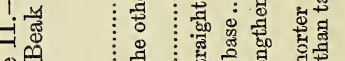

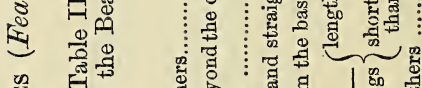

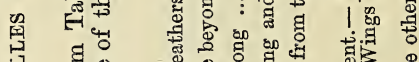

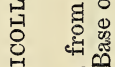

और

它

ह-

吾

5

密

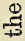

प्木

ह

융

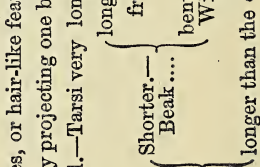

की ।

声

ह

蛋

क्ष

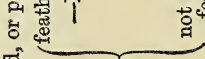

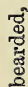

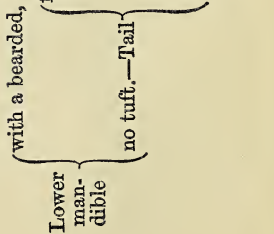




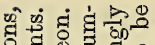
. 경 ${ }_{0} 0$ 웅

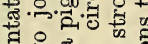
起 면 형 ฐँ 엉

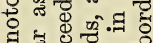
둥 舟

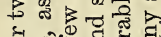

के of

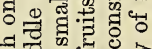
舟政 I

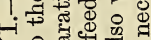
$>$ 연 क्ष

罂

궁.

产

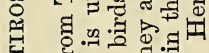

H

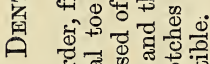
5.

过 突

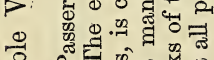

覆

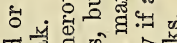

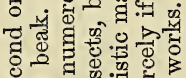

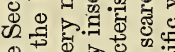
D 50 于4 당 . 울 $F$ 荡

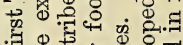

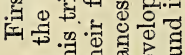

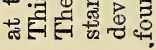

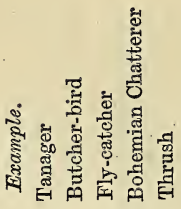

क्ष

今ं

1.

20 $\mathrm{H}$ का

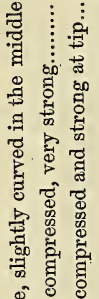

क्षे बी

\% 8

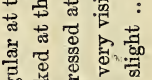

हू : का

.

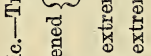

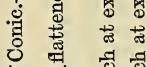

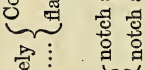

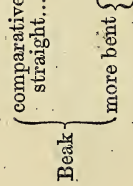

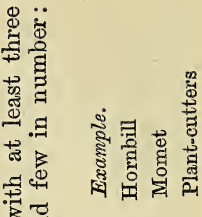

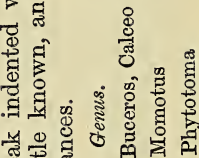

ल ब

उ ।

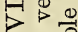

हैं

궁

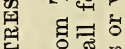

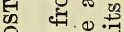

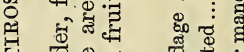

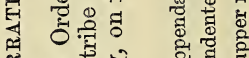

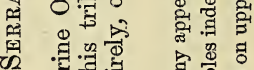

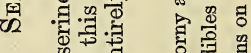

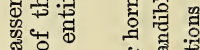

记

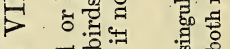

융 क人

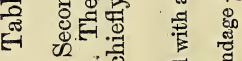

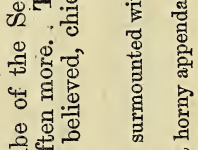

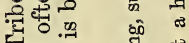

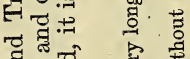

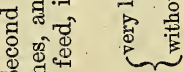

थ2 零 


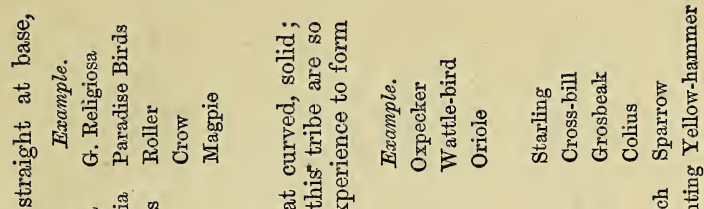

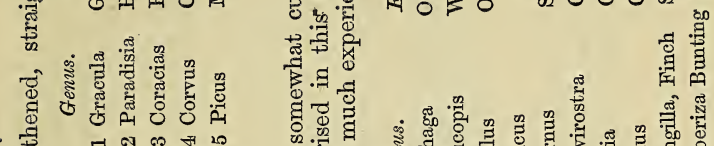

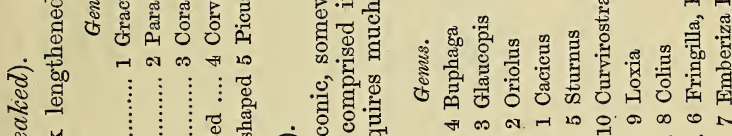
ปั้

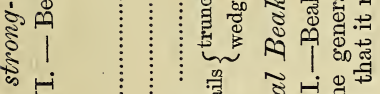
s.

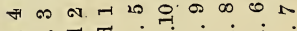

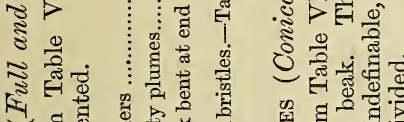

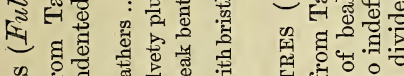

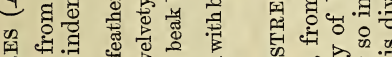

त्ञ

获

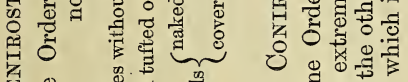

A

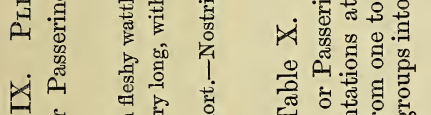

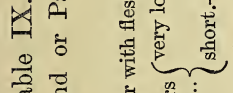

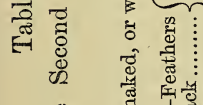

क वै

4

है द्वे क्षै

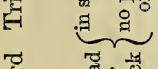

हृ

के कृ

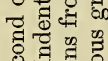

造.

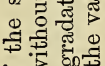

$4 \geqslant 50 \%$

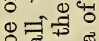

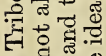

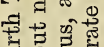

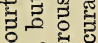

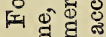

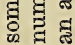

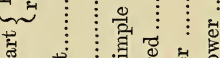

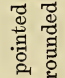

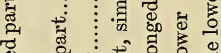

๙ लै

1. 0 क

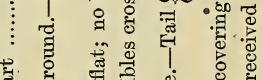

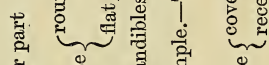

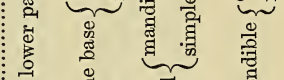

苗 营

量

.7

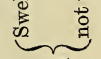

व్.

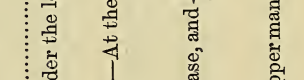



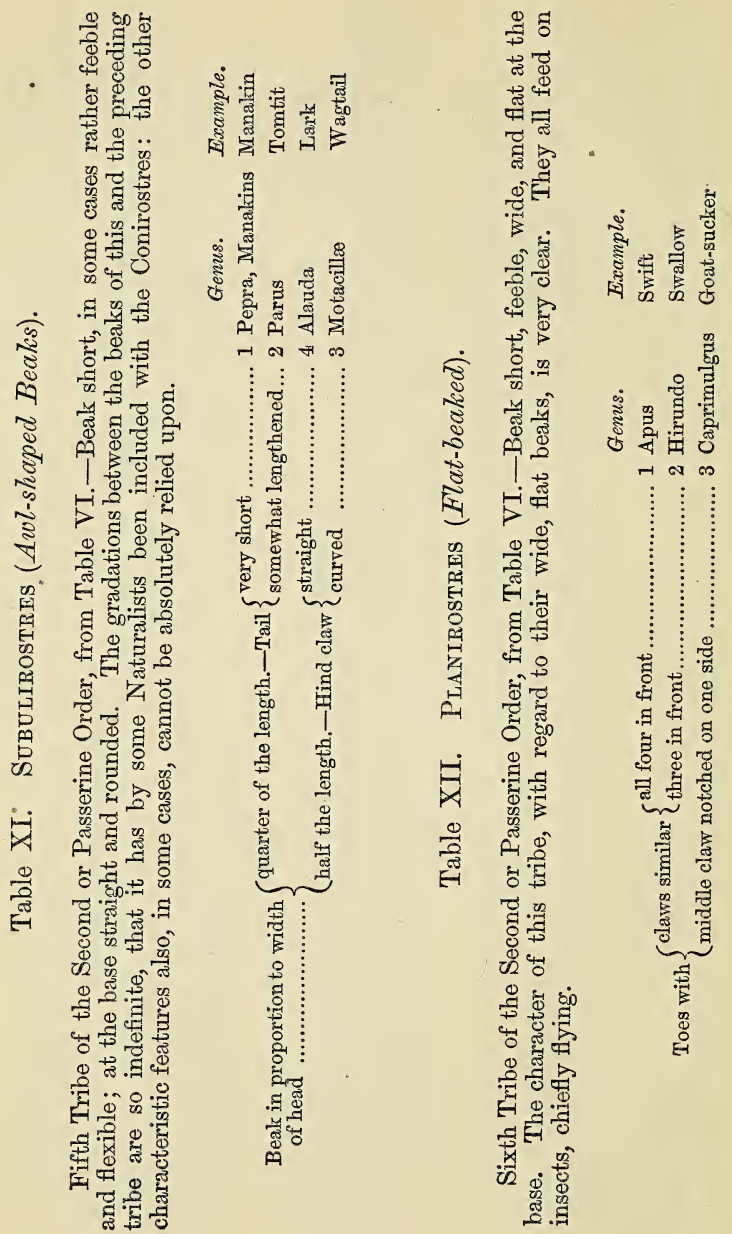


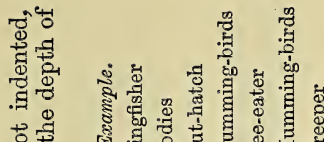

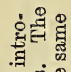

क्षेत्ञ

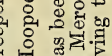

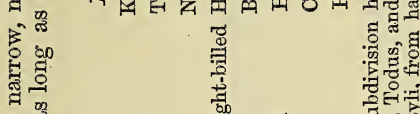

हैं

on

¿ิ

के

\$

8 ค

म $1+$ है

ธ $>$

है

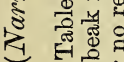

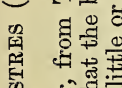

웍:

竞.

年

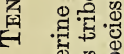

s.

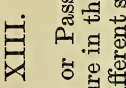

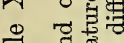

栗 कू से क्षे †. 月ुँ

岁总

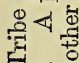

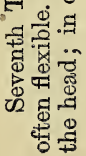

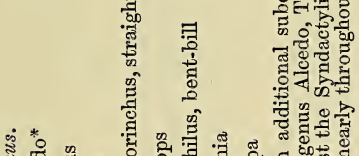

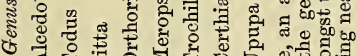

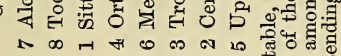

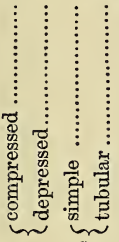

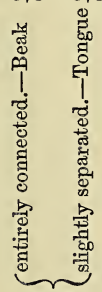

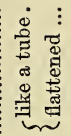

.

co 응

을

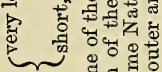

政

on

政

\%

ङ

o. on

a 34

롫

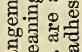

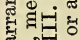

की

동융

空

डुका क्ञ

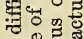

웎

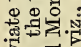

称害

얼 㐘

* ') 总萠
20 19

E.

है

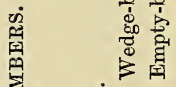

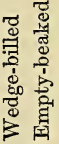

तु है

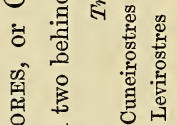

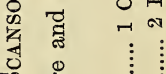

क्ष

$\stackrel{\dot{\Phi}}{\dot{0}}$

:

ro

ఖ

능

율

리 站

•

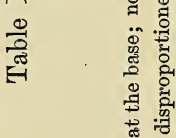

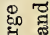

สำ

s

क

+롱

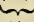

浆 
. 8

()

कू :

동

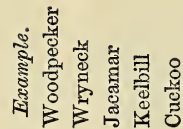

+ है.

है

:

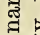

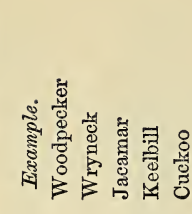

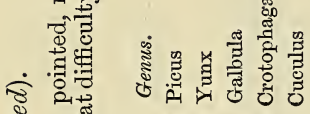

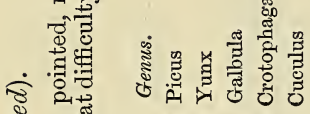

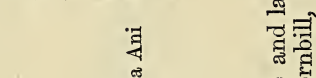

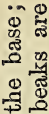

$+3$

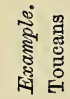

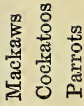

क.

สำ

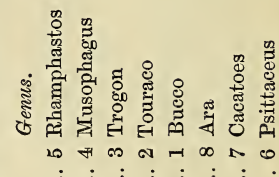

$\approx N \approx$

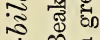

¿่ ตी

요

रक मा ल ल2 50

ชิ :

s.

ए

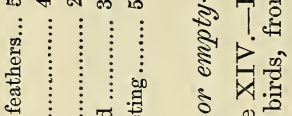

$\therefore H$

证

点

है

की $\mathrm{D}$ :

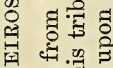

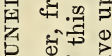

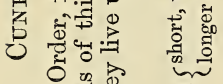

$p$. त्]

A

-

- 을

엉

क्ने क्षै

헝

बु

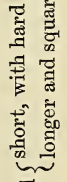

造

ते क

的

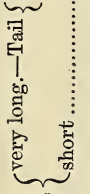

疍

स $ह$

प्रक्ष की

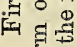

సू.

$\vdots$

리 हैं हैं

क क्षैं

की

寈

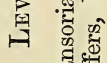

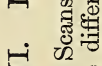

४

ली है है।

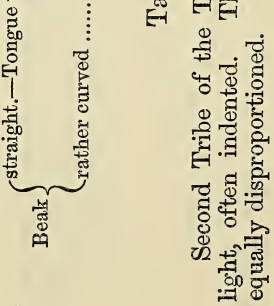

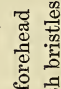

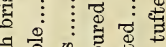

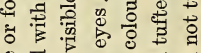

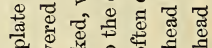

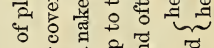

+

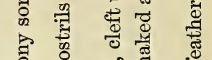

$\vdots \vdots$ 豆

당

$\vdots \vdots$

ॠ

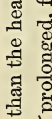

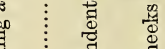

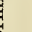

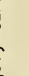

. म च

है।

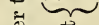

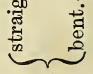

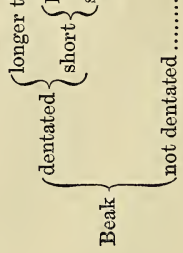




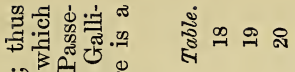
क्षेळ

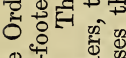
o t) o 20 겅 象递药 क $8 \ldots \ldots$ कृ : 月 붕

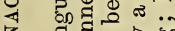

4 . 日 过 . .5. 密 0 D

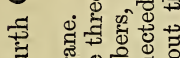
. 대응

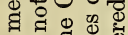
政

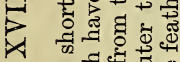
要 8 을

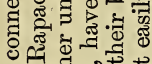
og $\$>$ ह

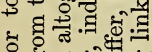
象是

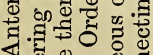
4 政 0 业.
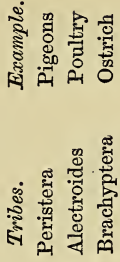

त 90

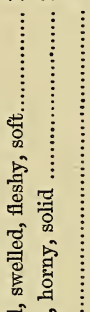

导

(2)

兵

용

से

ฐึ

ค

+

ज्ञ

क्ष

का कू

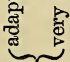

of

逍
용

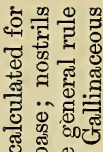
on . 的跑 $\ddot{0} \rightarrow$ 它 0

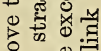
คำ

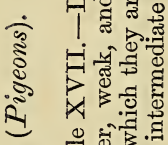

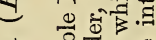

현

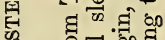
충 क्षे 5

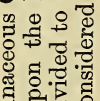
急

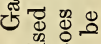
5. 연요 8 5 政 of ث

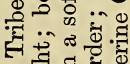
to 80 究 政

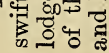



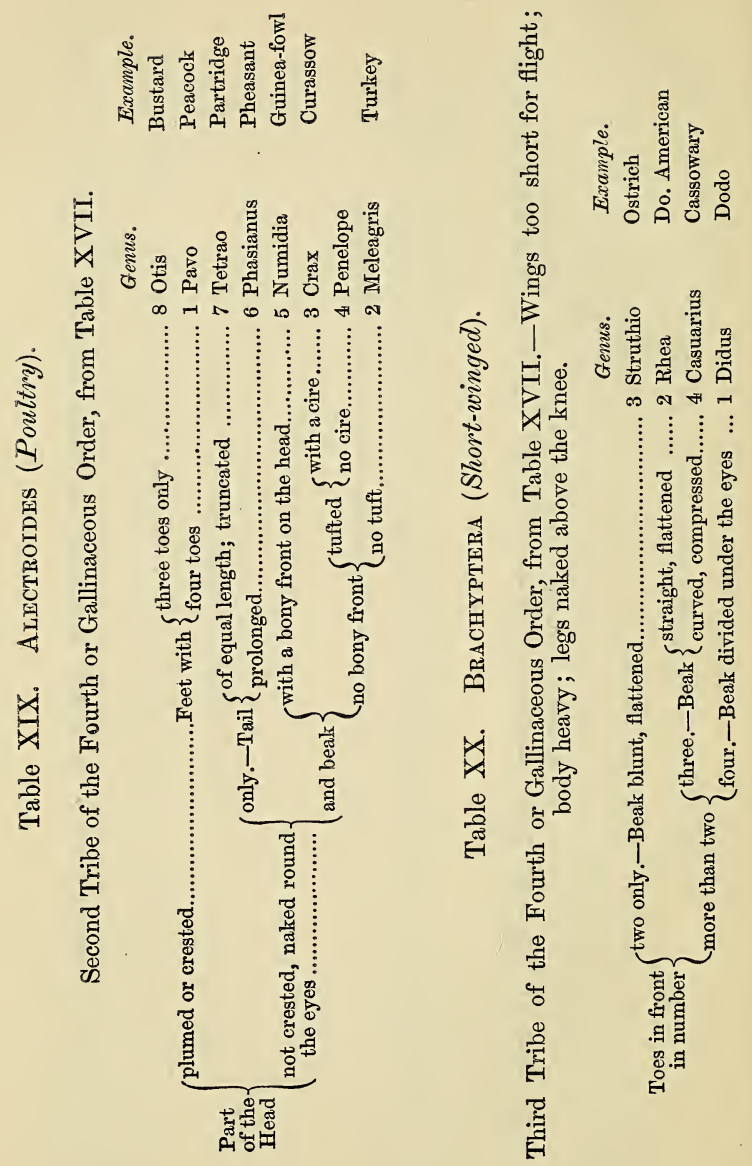


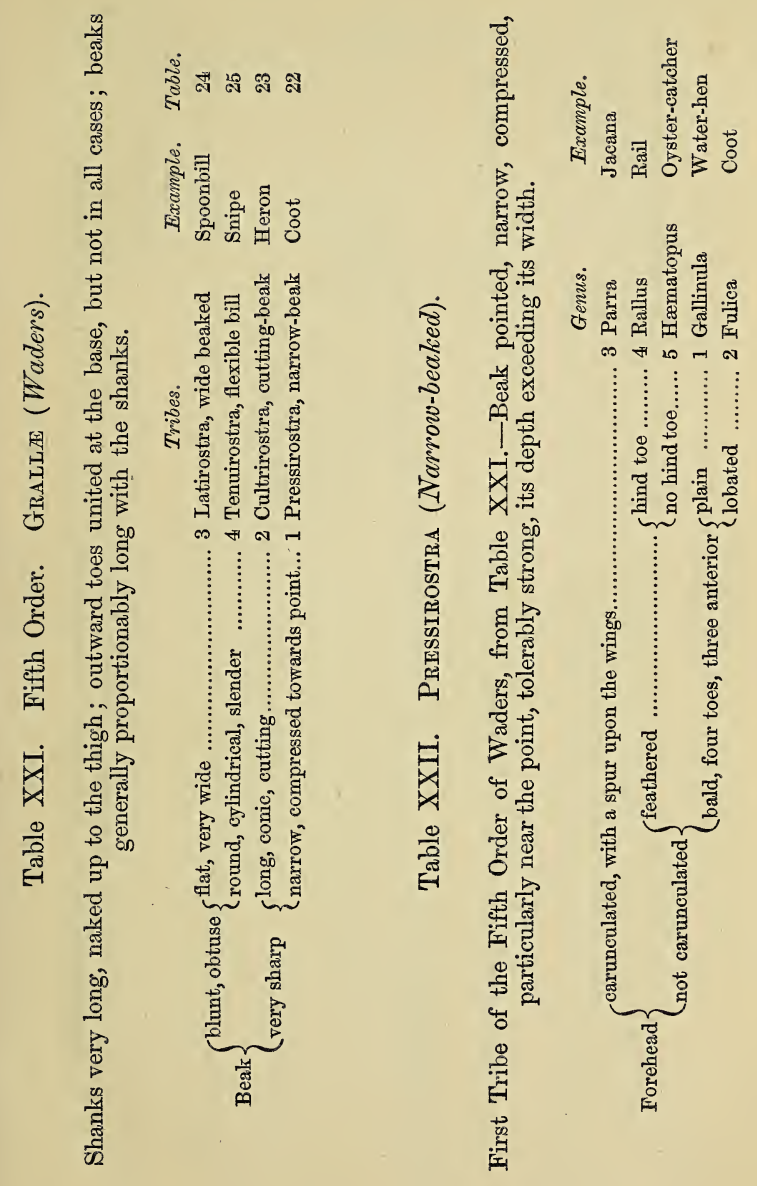




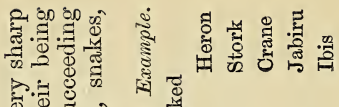
겅.

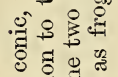
ही:

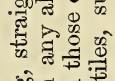

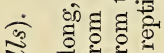

$\approx$ 我

규

คी

¿ -0.7 .7$

U $x$

सै $x \cong .0 .72$

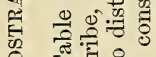

E

ह :

占

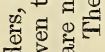

ह. हु ส

政

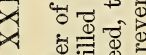

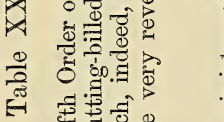

密考总

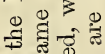

의

\&E요

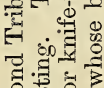

边

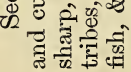

ङ

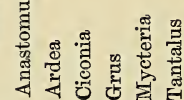

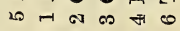

$\vdots$

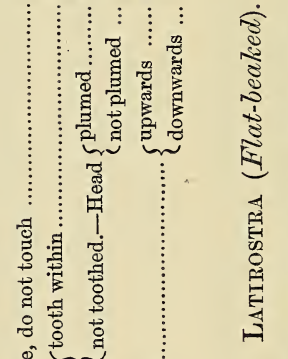

.
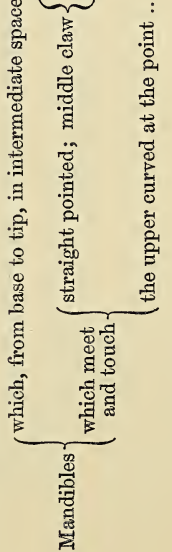

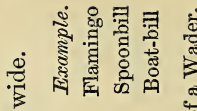

్ㅡㄴ

.हี

+ึ

की थี क्ष

อุด

+ $\vdots \vdots \vdots \vdots$

퓷

ถิก

ซึ

1.

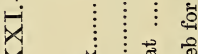

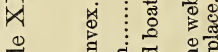

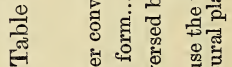

घ

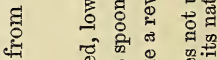

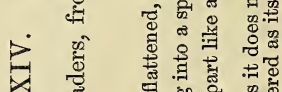

त्व

$\geqslant$ 유

ㄴ

㐘 छ्व

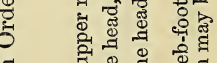

겨 용

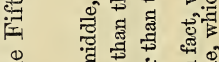

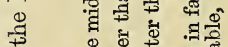

प क षै०

站 范

Е क्ष

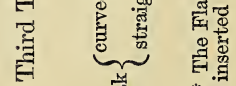




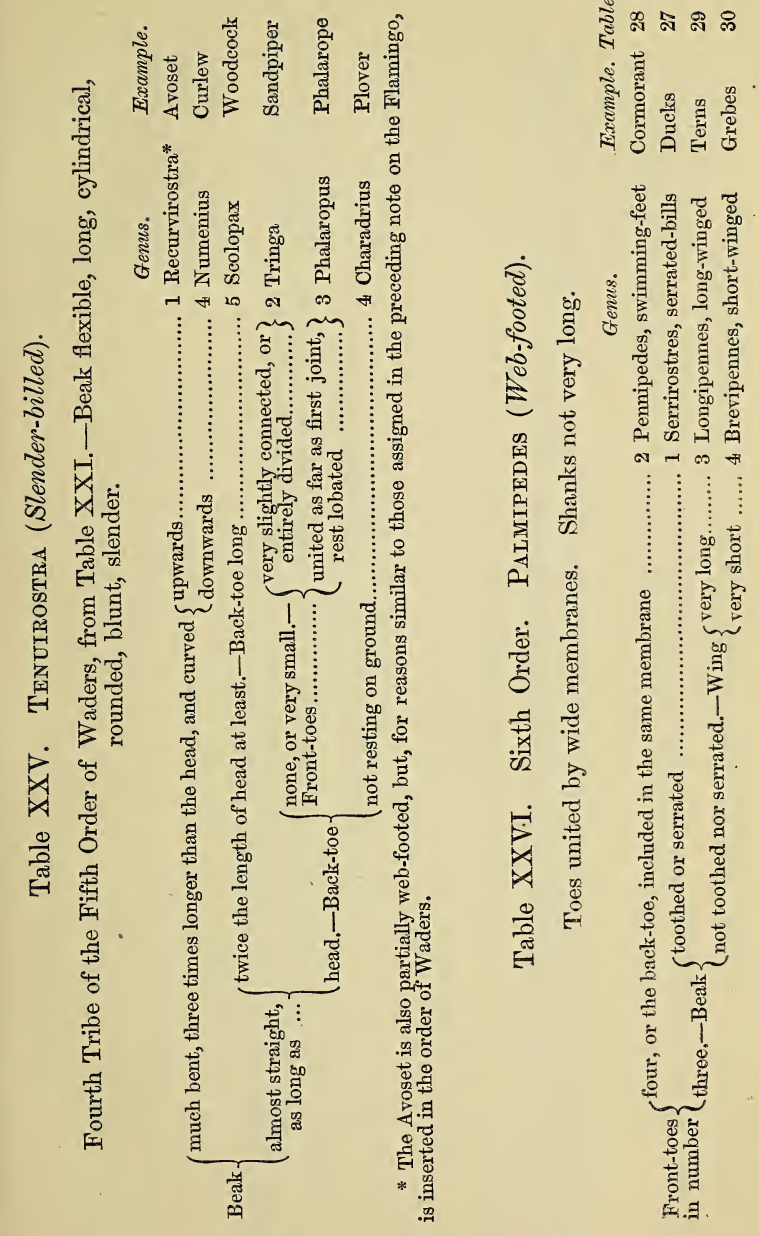




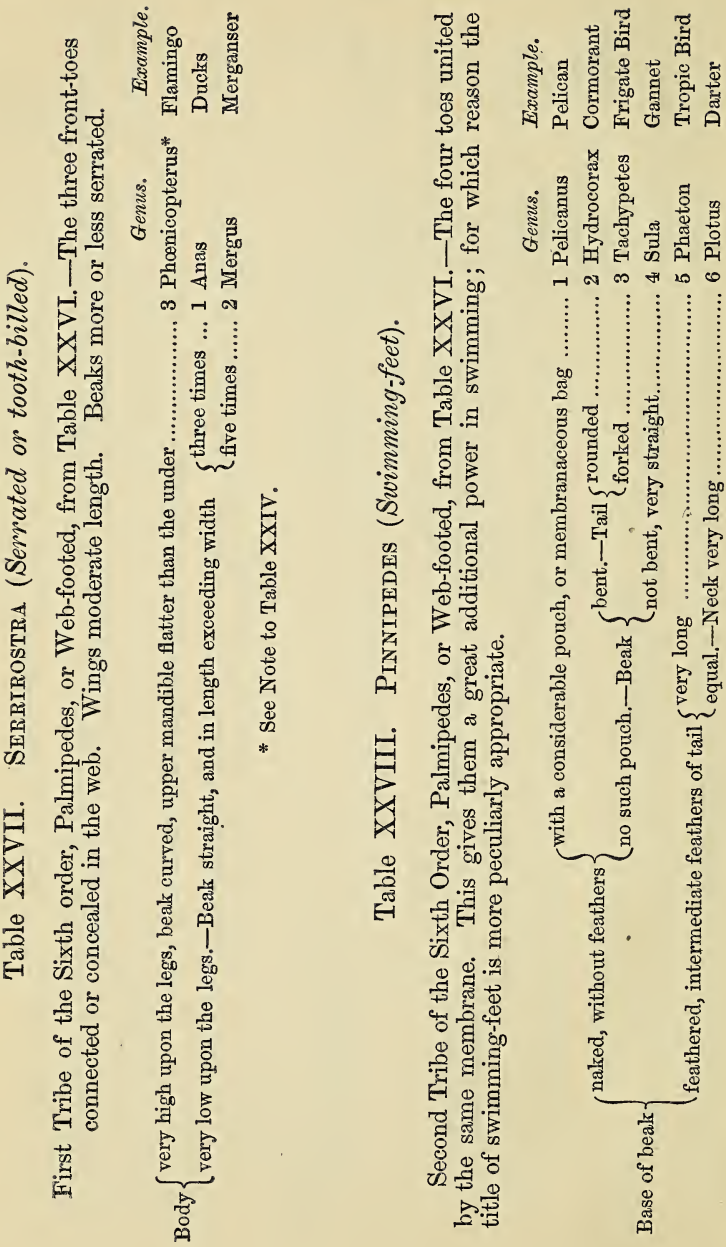


TABLES OF CLASSIFICATION.

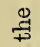

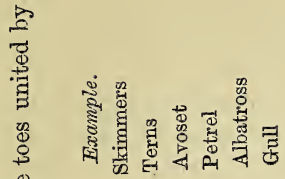

密

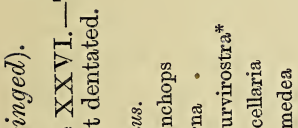

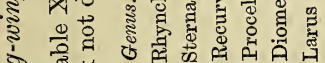

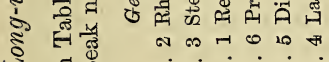

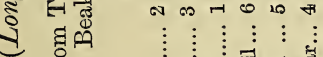

की

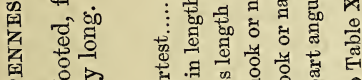

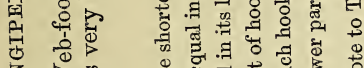

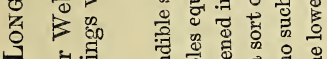

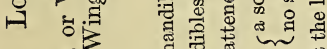

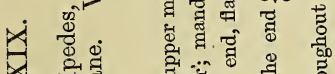

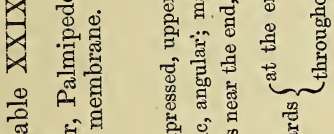

हा

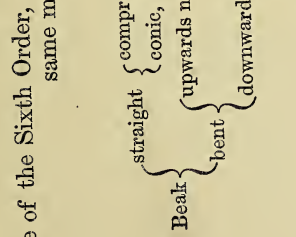

है

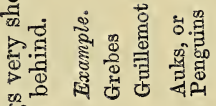

(1)

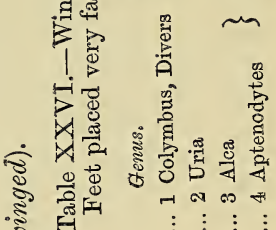

焉

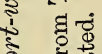

के

क्ष

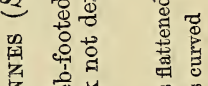

离势

है

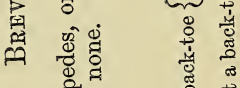

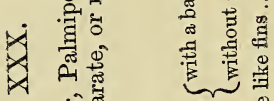

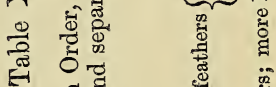

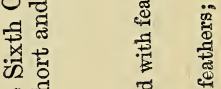

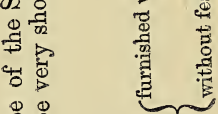

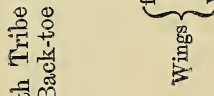


BY way of showing the utility of the preceding Tables, a B few instances, explaining the manner of applying them, may be acceptable.

Suppose, then, that a person entirely ignorant of Ornithology, finds a bird, and wishes to know its name or character. He will first turn to Table I., where the number of hind-toes appear as the distinguishing guide for further observation. His specimen, for instance, has only one hindtoe; he is then directed to the character of the anterior, or fore-toes, the two exterior or outer of which, in this case, he finds to be very slightly connected, and for a moment, without further rules to guide him, he might be at a loss whether to consider his specimen as belonging to the orders Rapaces, Grallæ, or Passeres: the character, however, of the claws and beak will at once point out the propriety of considering it as of the Rapacious Order, marked as No. 1. For further information, he is then referred to Table II., where the eyes are to be his guide. He finds them on the side of the head, and pursuing his line of direction, sees that it is feathered about the neck, and he accordingly turns to Table IV., where the lower jaw, or mandible, as it is called, of the beak, is the distinguishing feature. This lower mandible, in his bird, is not furnished with either bristles or tufts like a beard, neither is the tail considerably lengthened out by feathers projecting one beyond the other, like the Snake-eaters, or Magpies, for example.

Having proceeded thus far, his attention is turned to the first feather of the wing, which he finds to be shorter than the second. He next looks to the beak, which is not lengthened, and straight from its base, but is bent throughout, and hooked at the point. His bird must, therefore, be of the Buteo or Astur genus. But the wings do not extend beyond two-thirds of the tail; it therefore belongs to the Astur genus; and he has then only to ascertain the species, which he will easily do by consulting museums, or books with minute descriptions and plates.

Again: a bird is brought to him, which, on comparing 
with the characters given in the first Table, he finds to have no back-toe, and that the fore-toes are united by a membrane; he rightly, therefore, concludes that it belongs to the order Palmipedes, or Web-footed; and he is directed for further particulars to Table XXVI. Thus he perceives, that as his specimen has only three front-toes, that its beak is not toothed, or serrated like a file or saw, and that its wings are very short, it must be of the tribe Brevipennes, and he is referred to Table XXX. Then, as the wings are feathered, and it has no back-toe, it must be of the genus Alca; and he will have little difficulty, on referring to its colours, size, and a few other particulars, to ascertain its species.

In the above references, the birds for consideration were a Sparrow-hawk and Puffin, species more or less known to most of our readers. One more, however, shall be added, entirely foreign. Its colour a brilliant green, beautifully mottled and variegated on the upper part, the lower of the breast and leg-feathers being of a delicate lemon-colour; the size, rather smaller than a Thrush. On looking to Table I., the hind-toes are found to be two, and two before; it is therefore of the order Scansores, or climbers, and reference is made to Table XIV., when, as its beak is not very large at the base, and not toothêd, it must be of the Cuneirostral tribe, Table XV. On examining its beak, and finding it rather curved, with mandible rounded, and nostrils projecting, there can be no hesitation in pronouncing it to be a Cuculus, or Cuckoo. And so it is: the Golden Cuckoo, one of the most splendid ornaments of the South African forests, and not uncommon at the Cape of Good Hope; and in such a gorgeous garb, little likely to be taken by an ignorant observer for a bird belonging to the family of the grey and sober livery-clad class of Cuckoos, peculiar to our northern latitudes. 


\section{CHAPTER II.}

\section{STRUCTURE OF BIRDS.}

External Structure.-Skeleton.-Character of Beak.-Bones, their Lightness.-Solidity of Backbone-Breastbone, Use of. -Wing-bones.-Legs, Peculiarities of.-When resting on one Leg.-Why Birds do not fall.

$W^{\top} \mathrm{E}$ shall now proceed to give a few details concerning the structure and peculiarity of their forms and characters.

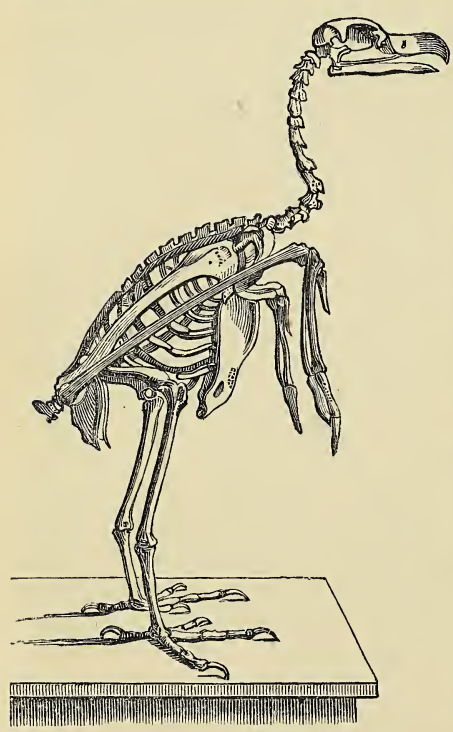

Skeleton of a Vulture

In examining the skeleton, we find the head terminating in a beak, composed of a horny substance, in form and structure and hardness, as intimately connected with the habits and general character of the bird, as jaws and teeth are with those of man and other animals. Thus in Eagles, Hawks, and all birds which tear their prey, as well as in Parrots, which have to bruise hard substances, or procure their food by piercing the bark of trees, as Woodpeckers, the bill is extremely hard and powerful. Whereas in thosewhich feed on worms, and substances equally soft, or live by suction, 
or swallow their food, as Woodcocks, Ducks, \&c., the hardness is gradually diminished.

A philosopher need not go further than this instrument, in search of a proof how well the providence of God fits the means to the end.

The hooked tip and sharp overhanging edge of the upper mandible, in the birds of prey, act like a dissector's knife, readily separating the flesh from the bones: a bill, hooked at the end with sharp edges, may indeed be considered as a characteristic of all birds of prey, that is, of all birds living on smaller birds, or quadrupeds, or fishes. Instead of a hook there is a sort of tooth at the extremity of the beak of certain birds of this class, which adds greatly to its strength; and it has been observed that those possessing it are more noble and courageous than others. Thus the Shrike, or Butcher Bird, although its usual food consists of beetles and insects, will not only bravely defend itself, but occasionally attack birds far superior in size; and is a perfect terror to the smaller species, who flutter round their assailant, uttering the most piercing cries, as if they wished to give

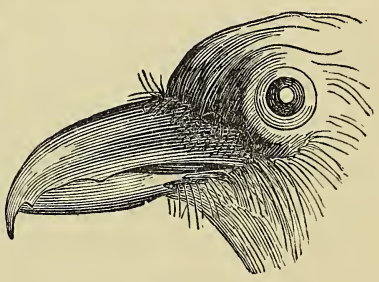

Vulture. notice of the intruder's approach. The bill of the Parrot is also hooked, but is at the same time unfitted for the uses to which it is applied by the birds just mentioned, curving and overlapping the lower bill so, much, that if the lower bill only had motion, the bird could scarcely open its mouth sufficiently wide to receive food; yet neither the hook nor the overlapping could be omitted, since it is by the beak that Parrots so readily climb; for which purpose it is therefore fitted, as well as for breaking nuts and other hard substances on which they feed.

The way by which the Parrot's beak is able to answer both purposes is this: the upper mandible, which in other 
birds forms one uniform piece or continuation of the skull, is united to the bone of the head by a peculiar membrane placed on each side of it, enabling the bird to lift or depress it at pleasure. The muscular power of this contrivance is very great, for the truth of which all who have incautiously exposed their fingers to the bite even of a Paroquet will readily vouch.

There is a bird, sometimes found in this country, called the Cross-bill, from the singular construction of its beak, the mandibles of which, instead of shutting together like those of other birds, cross each other; at first sight this might be supposed to be an accidental deformity, and that the poor bird must have great difficulty in picking up its food. But this is by no means the case, for as the bird lives upon the seeds or kernels of the hard fir-cones of pine-trees, it would never be able to crack them, and must soon die of hunger, if not furnished with a bill of more than ordinary strength and peculiarity of construction; exactly, in short, like the bill with which nature has provided it: with this it can instantly, and most dexterously, cut the hardest cones asunder. But as Divine Providence guards against every possible difficulty that might arise from any unusual conformation, so, in this case, it has been found that the muscles for closing the lower mandible were much larger and stronger on the side opposite to that where the lower mandible crossed the upper one; a highly necessary provision, to make amends for the increased quantity of power necessary to give the mandibles equal and uniform strength.

The Puffin is another bird with a strangely large and disproportioned bill, something like a Parrot's, whence it is sometimes called the Sea Parrot: it is also very powerful, and a bite from one of them would inflict a serious wound. When once they seize an object, they are with difficulty induced to leave hold of it; and, as they grasp it with great force, a singular mode of catching them is practised, which we shall notice when we come to speak of these birds.

Again, the longer tapering bill of the Snipe and Woodcock tribe is the precise instrument wanted, for penetrating 
deep into moist earth, from whence they extract their food. In this case strength is not requisite, and would have been quite out of character with the slender neck of this family, as well as unnecessary, for the purpose of collecting small worms; but length was indispensable, and nature has provided accordingly.

Woodcocks and Snipes are such shy birds, that their modes of feeding can rarely be observed; but sometimes opportunities have occurred which prove the truth of what is here said. A couple of Snipes were, by means of a good telescope, actually seen thus boring with their slender beaks in soft mire for their food. They were feeding close to the edge of a lake, pushing their bills into thin mud, by repeated thrusts, quite up to the eyes, then drawing them back again with great quickness, and every now and then shifting their ground a little.

The bills of Ducks and similar birds, which live partly by suction, and partly on small fish or aquatic animals, merit particular notice from their peculiar adaptation to that office. The inside of them, towards the edge, being thickly set with rows or lines of short, strong, sharp-pointed prickles. These might be mistaken for teeth: this, however, is not their purpose, which is merely to act as a sort of filter. Observe a Duck in a brook, crushing, with that quick motion of his head, soft weeds and other substances mixed with the mud. The operation is thus carried on: by plunging its flat bill into the oozy pulp, the finer portion is sucked up through these tooth-like lines; what it chooses is retained, the rest being thrown out and washed away by the rapid clattering motion of the flat bill. As a further help, enabling them to judge what is an agreeable and proper food, these birds are furnished with an additional supply of delicate nerves, extending to the very end of the beak; hence it has been conjectured that they have some sense of taste, of which birds in general are supposed to be destitute. That this is the use for which these additional nerves is designed, may be further gathered from the accurate examinations of a bill, much resembling a Duck's, belonging to one of the most 
extraordinary animals in the world, found only in New South Wales. It is called the "Duck-billed Platypus;" having the beak of a duck, the body of an animal, and the feet webbed, and furnished also with strong claws. As it lives underground generally, its eyes are like the mole's, so small as nearly to prevent its seeing. It depends, therefore, in great measure, upon the sense of feeling, and smelling, and tasting belonging to the beak, for its livelihood; and accordingly if is found, that throughout the whole beak, and more especially at its extremities, there is a fine nervous tissue which renders it as sensible as the tongue for the taste, or the fingers for the touch, and the nose for smelling.

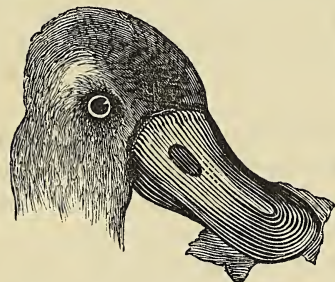

New Holland Shoveler.*

There is a Duck closely allied to our Shovelers, whose beak has a curious additioncertain flaps or loose projections - of which the annexed figure will give a better idea than any description. It is found in Australia, but its habits are little known.

In the Goosander, which in other respects partakes much of the nature of Ducks, these rows of tooth-like lines are harder, and very much resemble the teeth of a saw, extending along the edge of the beak; thus enabling it to secure even eels and fish, of which it destroys great numbers, and which would, but for this addition, make their escape and slip away from a surface unprovided with means of holding them fast. The bill of the Rhynchops or Skimmer, which collects its food floating on the surface of the waves as it swims across the ocean, is another very curious instance of contrivance. In most species it will be observed, that the upper part of the beak is much larger, and covers the lower part, but in this bird the contrary takes place; for the lower jaw or mandible of the beak is much larger than the upper, 
so that the bird can use it as a sort of spoon, dipping it into the water, and thus scooping up small fishes, or other light floating particles, on which it feeds. How different in its form is the beak of this bird from those of the Swallow and Goat-sucker tribe, which, feeding on the wing, adopt a somewhat similar course in catching the various flying insects on which they live. In their case the beak is short, and so weak as to be almost soft, but of vast width, proportioned to the size of the body. This may be easily seen in the common House Swallow, but more particularly in the Swift, or large Black Swallow; and Goat-sucker, whose heads may be said to be almost all composed of mouth, so wide and gaping are their large short beaks; consequently when the supply of insects is abundant, they have little more to do than fly with open mouth, and close their beaks upon the objects which cross their flight. This the Swallow does with a sharp clicking jerk, which may be heard by an attentive listener on a calm day, at a considerable distance.

In the Toucan, the beak forms a most prominent and unsightly feature, being quite a deformity in that otherwise beautiful and graceful bird;* and were it as heavy in proportion as the bills of other birds, it might prove a very serious weight, and materially impede its flight, if not quite weigh it down to the ground. It is, however, so remarkably light and hollow, as to be no inconvenience whatever, so that the bird can fly with such swiftness and certainty as to catch grapes and other fruit thrown to it before they fall to the ground. In its operation, too, it differs from those of other birds; seizing and acting upon the substances within its grasp, by a lateral or side-way rather than up and down or perpendicular motion. But they do not always confine themselves to fruits, their beaks being equally calculated by their muscular strength for crushing the bones of small birds; and in their native forests they are seen perched on high trees, watching the 
moment when old birds leave their nests, when down they pounce, and feed on the young ones, and even contest a prize with the monkeys. How skilfully, and at the same time how powerfully he can use this apparently awkward and cumbrous bill of his, we learn from the way in which a Toucan, which was for some years kept in the Museum of the Zoological Gardens in London, disposed of a small bird. The moment the owner of the Toucan introduced his hand with the small bird into the cage, the Toucan, which was on its perch, snatched it with its bill. The poor little bird was dead in an instant, killed by the violence of the squeeze. As soon as it was dead, the Toucan hopped with it still in its bill to another perch, and then placing it with his bill between his right foot and the perch, began to strip off the feathers. When he had plucked away most of them, he broke the bones of the wings and legs (still holding the little bird in the same position), with his bill, taking the limbs therein, and giving at the same time a strong lateral wrench. $\mathrm{He}$ continued this work with great dexterity, till he had almost reduced the body to a shapeless mass. He at first ate all the soft parts, leaving the larger bones to the last, which seemed to give him more trouble, particularly the beak and legs.
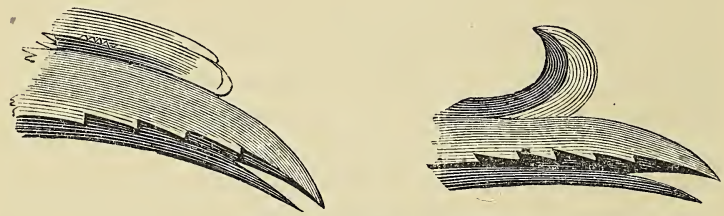

Beaks of Hornbills.*

In the Buceros or Hornbill, the beak is equally monstrous, and rendered still more hideously disproportioned by the addition of a large naked bony protuberance on the

* Buceros Violaceus, and Rhinoceros. 
forehead. As yet no satisfactory explanation has been given for these enormous protuberances. In the Toucan, indeed, it has been suspected that the bill is capable of feeling pleasure or pain, and not altogether insensible, like the horny bills of other birds, and the nails and claws of animals ; for the above-mentioned bird was frequently observed to scratch his beak with his foot, which he would not have done had it not produced an agreeable sensation.

The Pelican's beak is also very large, and the under jaw

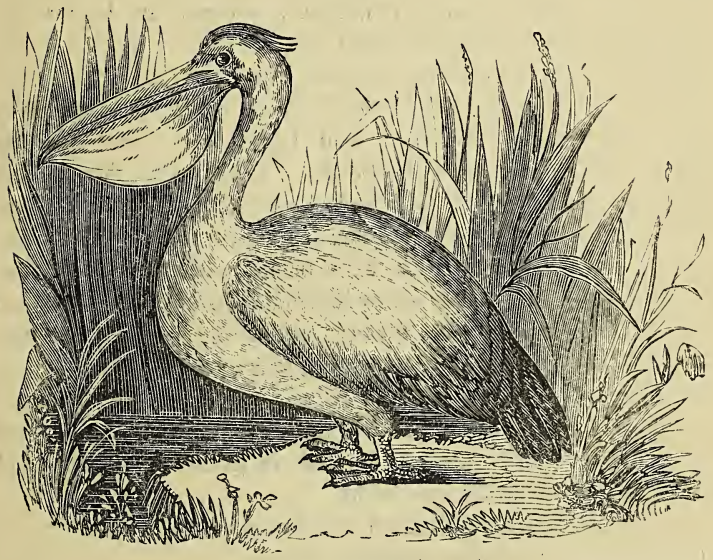

T'he Pelican.

or mandible furnished with a vast pouch, in which it can convey a considerably supply of food for its young. The Avoset, a bird of the wading tribe, which collects its food in shallow water, or moist sandy places, has a very different sort of beak, of singular construction, resembling flexible flat pieces of whalebone, and not bending downwards, as is usually the case, but turning upwards; with this it scoops up 
spawn, worms, or other soft water insects. One other beak only shall be mentioned,-namely, that of the Spoonbill, which, in its food, partaking of the nature of the Heron and Duck tribes, is provided accordingly ; its interior part being furnished with rough projections which prevent the escape of such slippery things as small fish, while its wide spoonshaped end enables it to crush and sift mud and weeds for worms or soft vegetable matter.

The bones of birds, like those of animals, are for the most part white, but in other respects, they differ materially from those of four-footed animals, being composed of a thin, firm, and partly elastic substance, formed in layers apparently fastened together, and almost always hollow; the cavities never containing marrow, but air, and communicating with the lungs by considerable openings; whereby they are rendered buoyant and light to a much greater degree than is generally supposed. Thus a portion of the leg of a Goose, about two inches in length, weighed about forty grains, while a piece of the leg of a rabbit (the marrow having been extracted, and both being perfectly dry, and as nearly as possible of the same thickness and length,) weighed. seventy-five grains, or nearly twice the weight of the similarly-sized bone of the goose, and yet so firm and strong was this latter, that although in diameter it was less than one-eighth of an inch, and the solid tubular part not more than one-hundredth part of an inch in thickness, it could not be broken asunder by the hand.

It is upon this principle mechanics and engineers act in constructing strong supports, knowing that if any quantity of material is to be fabricated into a rod of a certain length, the rod will be strong in proportion to its thickness; and that if the figure remains the same, that thickness can only be increased by making it hollow. Therefore hollow rods or tubes of the same length and quantity of matter have more strength than solid ones of less diameter. This is but one out of the hundreds of instances in which the wisdom of man has been perfected by studying the mode by which the great Creator accomplishes His purposes. 
It is evident that a creature thus furnished with bones so much lighter than those of other animals, must have a prodigious advantage in raising itself in the air. But, besides this superior lightness of the skeleton, these bones, from their hollow structure, act as pipes supplying air in abundance; and thus not only rendering the bird still lighter, but enabling it to breathe at heights, at which a human being would be gasping for breath. Travellers who have ascended very high mountains find, that when they get near the summits, the air becomes so rarefied and thin, that it is as much as they can do to proceed at a slow pace. Those birds, too, whose habits never lead them into the more elevated regions of the atmosphere, and are, therefore, not so abundantly provided with additional capacities for retaining air, have been observed to suffer severely, as was proved by a Mr. Robertson, who took two birds up with him in a balloon, one of which actually died at the height of 15,600 feet; whereas others better provided with air-cells appear to feel-no such inconvenience.

Mont Blanc, the most elevated mountain in Europe, is not quite three miles high; and yet on the top breathing is extremely difficult; nevertheless, the Condor of South America, the largest bird gifted with the power of flight, will dart upwards suddenly from the deepest valleys to a considerable height above the summit of even the lofty mountain of Chimboraço, which is one-fourth part higher than Mont Blanc. Humboldt, the celebrated traveller, who has given the best account of these regions, says, that he has frequently seen this enormous bird soaring without an effort, and enjoying itself at an elevation much higher than that of the clouds in our atmosphere.

In tracing the bones of the skeleton down the back, another remarkable difference is perceptible. In men and animals, the whole back-bone is more or less moveable, and can be bent; whereas in birds the parts more immediately connected with the back are either altogether consolidated or stiffened, so as to allow little or no play in the joints. 
In carving a fowl or any other bird at table, this peculiarity may easily be remarked. The want of motion in the back, however, is amply compensated by a greater number of bones in the neck, and greater power of moving them, which enables birds to turn their heads in all directions with extraordinary facility. These joints vary in number according to the necessities of the bird; thus, the Sparrow, which can perch and reach its food close before him, does not require such pliability or length of neck as the Swan, which floats on the water, and must seek its food at a considerable depth beneath; accordingly, we find that, whereas the Sparrow has only nine of these neck-joints, the Swan has twenty-three, - the advantages of which must be evident to all who have observed the ease and grace with which this stately bird turns its neck in every direction, or buries its head in sleep beneath the soft down of its wings.

The Toucan, the bird with the large beak mentioned in

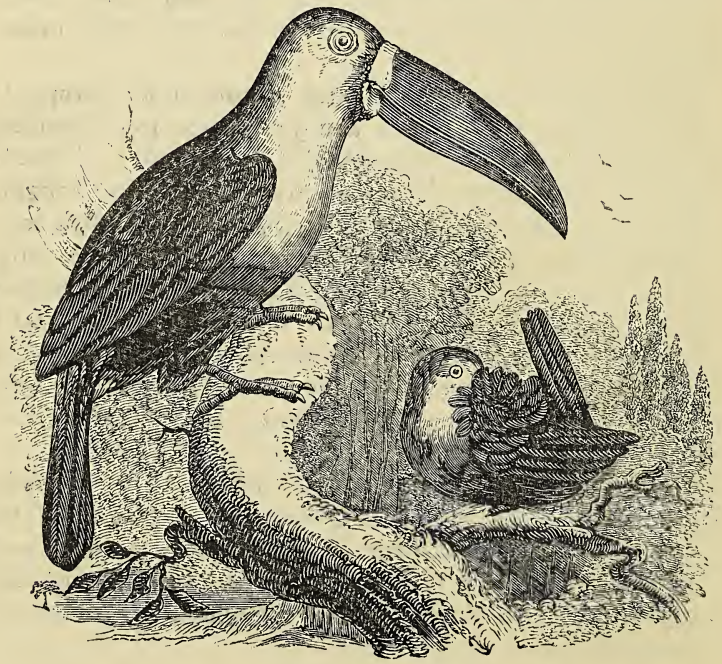

The Toucan. 
p. 31, affords a still more curious instance of this power of movement in the neck, nestling its head so completely among the feathers of its back, as entirely to conceal its enormous beak, and nearly assume the appearance of a ball of feathers: in which form, secured from all exposure to cold, it sleeps through the night. The reason of this deviation from the form of skeleton common to other animals, is that the stiffening or consolidation in the parts of the back-bone is essential in order to give strength and steadiness to the trunk in the violent muscular motion required by the act of flying; for in those birds which do not fly, as the Ostrich and Emu, the joints of the spine or back-bone are more or less moveable throughout. In the joints connected with the tail, (called the caudal vertebra,) certain other peculiarities in number and form present themselves, adapted to the habits of the bird. In the Martin and Swallow, where great freedom in the pliability of the tail is necessary, they are most numerous ; whereas in the Cassowary, which has no tail, the last joint only is found. This last varies also in form in different birds ; for instance, in the Peacock, whose beautiful, fanlike spread of tailfeathers is so well known, this last bone is oval, and placed horizontally.

Another striking feature in the skeleton of a bird is the breast-bone, or sternum, as it is called, which may be compared to the bottom part of a boat resting on a deep projecting keel. From the upper sides of the fore parts of this bone two others project, called clavicles, from the extremities of which a bone, in the form of the letter $\mathrm{V}$, is projected, called the furcula, though better known by the name of the merry-thought. Our attention is more particularly directed to these three bones, on account of their great importance in facilitating the powers of flight; since it is by the clavicles that the wings are connected with the breast-bone, and it is by the forked-like furcula, or merry-thought, that the wings are kept at a proper distance in flight. Accordingly, we shall find, that in proportion to the bird's necessities, will these bones be strong or weak. Thus in the Penguin, for 
instance, where the wings are little more than fins assisting in diving, or the Ostrich and Cassowary, where they are so small and insignificant as merely to assist in balancing their bodies when they run, the keel of the breast-bone is entirely wanting, or the furcula or merry-thought very imperfectly developed. On the other hand, in the Eagle and Hawk tribe, they are proportionably strong, conspicuous, and well defined.

The bones of the wings next come under observation; and these, as may be expected, in birds of prey, and some others, which have to carry their food frequently to a considerable distance, or live much in the air, are of great length; whereas, in domestic fowls, they are very small in proportion to the size of their bodies; and in the Penguins, which as has been observed, live almost entirely on the water, and, in diving, may be said to fly beneath its surface, they are remarkable for their flattened appearance, as if they had been pressed; approaching more to the form of a fin than a wing, much resembling the flappers of a turtle.

The last bones which remain for consideration, are those composing the legs and feet, which are the more worthy of attention, inasmuch, as to a certain degree, upon these, and of the feet more especially, depends the division or classification of birds.

It is not, however, our intention to enter into an explanation of what is called the anatomical structure of these limbs, further than to point out wherein they resemble or differ from our own, and correct a very common mistake into which inexperienced observers are apt to fall. We prefix two figures, No. 1 representing the leg of a man; No. 2, that of a bird; in which the corresponding divisions of each are marked by similar letters.

Here we see the legs both divided into three parts, exclusive of the actual foot. The first from $\mathbf{A}$ to $\mathbf{B}$; the second from B to C; the third from $\mathrm{C}$ to $\mathrm{D}$. Now, without attending carefully to these divisions, we might be apt to conclude that birds have one more division than human beings; but this is not the case. The mistake on our 

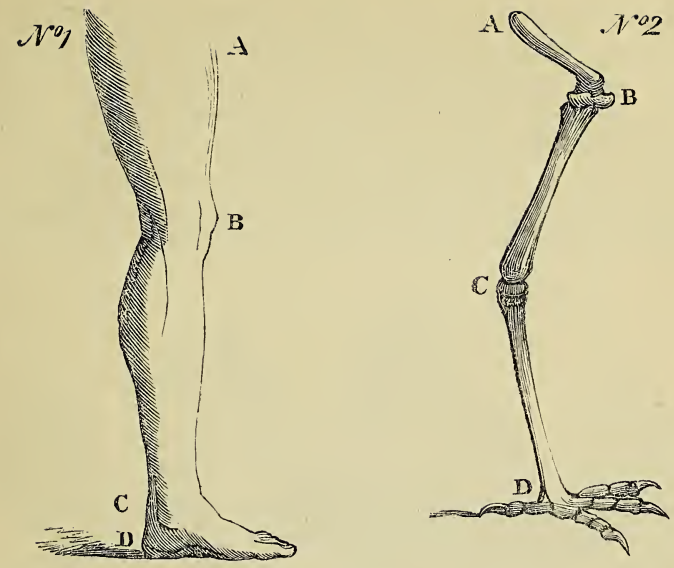

parts arising from the prevailing opinion that the part $\mathrm{C} \mathrm{D}$ in the bird's limb is the part which corresponds with what we usually term the leg, namely, B to $\mathrm{c}$, that is, from our knee to our ankle; whereas, the bone B $\mathrm{c}$ in the limb of the bird is, in fact, its real leg-bone. For its thigh we must look still higher, hidden as it usually is, amongst the feathers, and, probably, by many, scarcely known to exist. The great difference between the limbs of birds and human beings consists in this, that what we are apt to term the leg of a bird is, in fact, the part which answers to our ancle. This will be easily seen by a little closer examination. Let us look, then, at the joint $\mathbf{B}$ in the two figures: in the human figure it is at once seen to be the knee, and on referring to the same letter in the leg of the bird, we shall find that it is the true knee also; for supposing it to kneel, that is, to bend its leg, so that the fore part of the joint should touch the ground, it can only do so at the joint $\mathrm{B}$, it being as obviously impossible from the structure of the joint $\mathrm{c}$, that it could bend the part $\mathrm{C} \mathrm{D}$ forwards, so as to 
make the front part of the joint $\mathrm{c}$ touch the ground, as it would be for us to bend the leg-bone forward below the knee. The remaining portion, then, c D, of the bird's limb, when compared with the similar part in our own leg, ought to be called its ankle, and so in truth it is. This may be more easily understood by referring to a very extraordinarylooking bird, sometimes, though very rarely seen in England, called the Stilted Plover, (Charadrius himantopus,) from

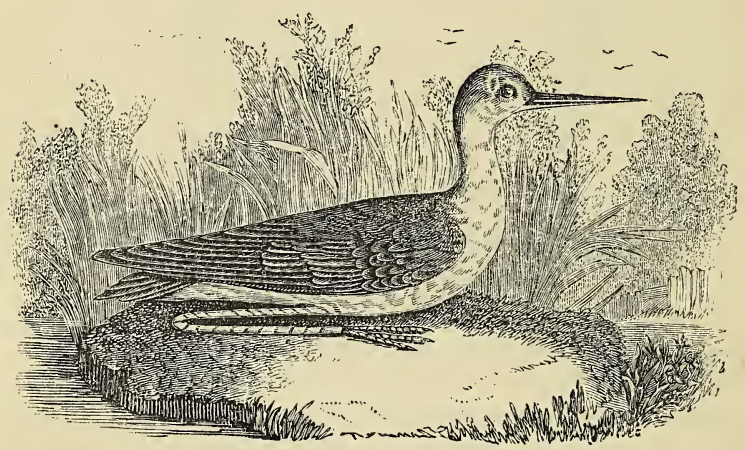

Stilted Plover.

the strange disproportion of its legs, a figure of which is annexed, and of which No. 2 may be considered as an illustration; in which an inexperienced observer will at first sight not easily persuade himself that $\mathrm{C} D$ is nothing more than the ankle, and the back part of the joint $\mathrm{c}$. its heel; yet so it is, as the reader will at once perceive in the above figure, where the bird is represented in its usual, and what may be called, kneeling position; the real knee, corresponding with B in fig. 2, of the leg, being partly hid in the feathers, and the bend of the leg beneath the tail corresponding with $\mathrm{c}$, the remaining part from that point to the claws answering to our foot and toes.

There are some other beautiful contrivances in the limbs 
of birds, which deserve attention. Look at a bird fast asleep with its head under its wing, resting usually on one leg, and that again resting upon a perch not thicker than one's finger. How apparently difficult and uneasy is such a position; and yet it is all made easy and safe to the bird by an admirable piece of internal mechanism, which may be briefly thus explained. Connected with the thigh-bone and leg, a set of muscles run down to the very extremity of the toes, so contrived and placed, that when, by pressure downwards, the limb bends, these fine muscles are pulled in, and therefore contract the toes, thus making them grasp more firmly whatever the bird is resting upon; just as if a set of fine strings ran over pulleys to certain hooks, and were acted upon at the other end by a weight or pressure, and thereby made to draw in the hooks.

But there are some birds, and very large ones too, such as Herons, Cranes, and certain other wading birds, which sleep standing on one foot, the leg being kept perfectly straight; and in these birds, as the foot rests upon the ground, any grasping power acting upon the toes would be useless. In this case, therefore, what is required is some contrivance to keep the leg firm, that it may not give way, in consequence of any swinging or balancing motion of the body, which would inevitably overset the sleeper. Accordingly, the upper part of what we shall call the heel bone, at $c$, is fitted in a very curious manner into the lower part of the leg bone above it, and precisely answers the purpose required of the bird, affording a sufficient degree of resistance by the bending of the leg, to counteract the effect of any overbalancing of the body. The bird, moreover, has a power over this well-contrived prop, and thus bends its leg or keeps it perfectly stiff, as best suits its convenience. 


\section{CHAPTER III.}

Internal Structure.-Digestive Organs. - Gullet, Crop, Stomach -Adaptation of, to different Habits of Birds.-Gastric Juice, its Use and Properties.-Gizzard, its Grinding Powers.Respiration of Birds.

HAVING briefly pointed out the most prominent features 1 of the skeleton, as influencing the general form of birds, we shall now proceed to give a short sketch of the structure and uses of some of the internal parts, commencing with those for the supply and consumption of food. The following figure may assist our explanation.

The gullet (oesophagus), $\mathrm{A}$, opens into the crop (ingluvies) $B$, which forms a sort of bag; on quitting this it extends to what is called the second stomach, c, (infundibulum, or ventriculus succinturiatus,) usually funnel-shaped, from whence

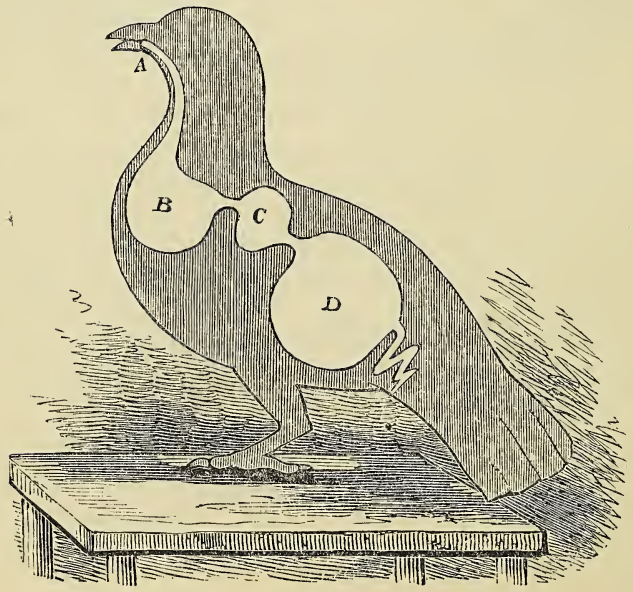


it opens into the third stomach or gizzard, D, (ventriculus callosus,) communicating with the intestinal canal or bowels, $\mathbf{E}$, which vary very much in length in different birds, though on the whole they are shorter than in the class of four-footed animals. The annexed plate is merely intended to convey a general idea of the stomachs of birds, and must by no means be depended upon as an accurate representation applicable to any particular family, since in each there is a marked variation with respect to the size, form, and other internal arrangements; a full explanation of which, though extremely interesting, from the beautiful adaptation to the habits of the bird, cannot in this little work be attempted; a few, however, may be briefly pointed out.

Thus, in what are called the carnivorous birds, feeding on flesh or fish, containing hair, feathers, or bony substances, which are of difficult digestion, the gullet is of a vast size and capacity compared with the other parts, often exceeding in width the stomach itself. In some of the water birds it is large enough to contain even a whole fish till the proper stomach is ready to receive it. In watching Cormorants at a distance with a telescope, they may be sometimes seen quietly reposing, with their mouths half open, and the tail of a fish hanging out, the remainder gorged in their capacious gullet: and Sea-Gulls will swallow bones of three or four inches in length; the lower end only reaching the stomach, whilst the rest continues in the gullet, and slips down gradually, in proportion as these lower ends are consumed.

The usual food of Gulls consists of fish; but when confined they will thrive very well on a diet with which they must be perfectly unacquainted by the sea-side. We may form, too, some idea of their voracity, from the quantity consumed by a Gull kept and fed in a garden, which devoured in one day fourteen mice and two rats. Another was seen to swallow an entire rat, - an operation, however, not accomplished without some difficulty, the bird making several efforts before it succeeded, and even then the tail remained visible for several minutes. But the voracity of Gulls is exceeded by some other fish-eating birds. Thus the Pelican, 
it is said, will at one repast, if hungry, devour as many fish as would suffice for half-a-dozen people; and, like the Gulls above mentioned, will in confinement snap up rats and other small quadrupeds. The Gannet, another fishing bird, has been known to swallow an entire cod of moderate size, and a Puffin kept in a menagerie to eat as much fish as its whole body weighed. Well might the eye-witness to such an extraordinary exhibition of gluttony declare, that " he never saw so unsatiable a devourer ;" and what was still more surprising, "that the body did not appear to swell the bigger."* Of the destructive character of Herons with regard to fish some idea may be formed, from no less than five eels having been found in the stomach of one which was shot. Voracity is not, however, entirely confined to the fishing tribe, for some that live upon fruits can dispose of an equally surprising quantity. For instance, the Cedar Bird of America, a sort of Jay, will devour every fruit or berry that comes in its way; and will gorge itself to such excess, as sometimes to be unable to fly, and may be taken by the hand. Some, indeed, although wounded and confined in a cage, have eaten apples until suffocation deprived them of life in the course of a few days; and when opened, they were found to be crammed to the very mouth.

Very frequently in woods, or solitary places, round balls, or lumps of semidigested substances, composed of small bones, claws, feathers, hair, \&c., may be found on gateposts or rails. These are the discarded remnants of food thrown from the gullets of Hawks, Owls, \&c., which, if allowed to pass into the stomach, might remain so long in an undissolved state as to prove injurious to the living bird. To defend the tender lining of this inner passage, the sides and under-surface of the tongue, and the upper part of the gullet, are furnished with numerous glands, supplying a slimy moisture which softens the gullet and smooths the way for the admission of the hard substances which are occasionally introduced.

In the upper and back part of the palate of the Ostrich, * Evelyn's Memoirs. 
there are two remarkable reservoirs from which a very tenacious mucus may be expressed of infinite importance to the bird: for it is so little choice in its food, that in the stomach of one belonging to the King, which died at Windsor, and was forwarded to the Zoological Society for dissection, some pieces of wood of considerable size, several large nails, and a hen's egg, entire and uninjured, were discovered; and in another, in addition to some long cabbage-stalks, were masses of bricks of the size of a man's fist.

This large space and capacity of the gullet is clearly intended to counterbalance the disadvantages of uncertain subsistence. Thus, Herons and Cormorants will devour as much fish at once as will last them for a long time.

There is another peculiarity, too, in the gullet of fishfeeding birds, that it is usually wider near the mouth, thus enabling them to gulp down their slippery food in an instant, without giving them an opportunity of escaping. In all these birds the width and space of the gullet does away with the use of the crop, which is accordingly, in this class of birds, exceedingly small, or altogether wanting.

The crop is furnished with a number of vessels secreting an oily fluid, something similar to the liquid in the gullet just mentioned. In such birds as feed their young from the crop, these vessels are observed to swell considerably at that particular time, in order to provide a great increase of this unctuous liquid. Those who have kept Turtledoves or Pigeons, must be familiar with the manner by which the young birds receive their food, almost thrusting their heads down the very throats of the old ones, to reach the nourishment provided in the enormous crops of their parents, where this lubricating liquid is provided in great quantity when the nestlings are young; but decreases in abundance as they grow older, and require less nourishing food.

This portion of the digestive organs is the most capacious in what is called the gallinaceous or poultry tribe, which feed chiefly on grain, requiring much softening; and there, accordingly, we find the food retained, till it is sufficiently softened to pass onwards to the stomach. And in this tribe 
it almost forms a distinct bag, as may be easily seen on examining a fowl,- the gullet opening into it at the upper part, and quitting it about the middle. Its texture is very fine and thin; so much so that the craw of a full-sized Turkey will contain nearly a quart, and when scraped and varnished, is sufficiently light to form small air balloons, for which purpose they are now prepared and sold in London.

We next come to the part called the second stomach, which, like the rest of the digestive organs, varies very much in size and internal arrangement. In some birds it is extremely small; in certain cases, as in the Kingfisher, it is actually wanting; whereas in the Ostrich it considerably exceeds even the real stomach, being capable of holding several pints of water. It is in this cavity that the grand business or process of digestion is carried on, it being abundantly supplied with a number of glands or vessels secreting that very curious liquid, called the gastric juice, which acts most powerfully on every variety of food. They are called the solvent glands on this account; and as birds generally require a more rapid digestion, they are larger, and more distinct from the other organs of digestion, than in other animals.

There may also be another reason why this liquid may be more essentially necessary for birds, which seem to require greater warmth than other animals, since it is found that their blood circulates more rapidly, and is warmer than the blood of the human body. For instance, the heat of the human body will raise the mercury in the thermometer to about 95 or 96 degrees, the true blood-heat being 98 ; but if the same thermometer is placed under the wing of a Parrot, or a Canary, it will raise it to 100 or 101; of a Fowl, to 103; of a Sparrow or Robin, sometimes to 110 or 111; and no doubt, if tried on certain other birds, requiring additional warmth, it would be found to rise still higher. Now the gastric juice, from some very ingenious experiments,* is supposed to contain a much

* Spallanzani. 
stronger principle of life and warmth than other liquids; thus when water, salt and water, and gastric juice were exposed to great cold, the gastric juice was the last to freeze, and the first to thaw. The greater portion of this juice, therefore, found in birds, may be an additional means by which the wisdom of God furnishes them with more warmth, and enables many of them to resist very strong degrees of cold. In proof of their endurance of cold, at the bird-market of St. Petersburgh, in Russia, during the intensity of those dreadfully cold winters, several thousand cages, containing birds of every description, are hung on the outside of about eighty shops; in a part of each cage, a small quantity of snow is placed, which is said to be necessary to keep them alive. That birds, originally from warm climates, suffer from the colder regions of the North, is, to a great degree, true; but by far the greatest number of birds, found dead in our severe winter, perish not from the inclemency of the weather, but the deficiency of food; for instance, our little Wren is just as active and cheerful in the severest frost as the warmest summer's day, - his supply of food, consisting of small insects concealed under the bark of trees, never failing him.

As a proof that small birds are not affected so much by temperature as want of food, Captain King* observed the lesser Redpoll existing without apparent inconvenience in a climate, and at a season, when the thermometer was not unfrequently at seven degrees below zero; and in the inclement atmosphere of Cape Horn, on the desolate shores of Terra del Fuego, Humming-birds were constantly seen hovering over the blossom of a species of Fuchsia, when the jungle composed of this shrub was partially covered with snow.

There is another singularity in this mysterious liquid, namely, the different force with which it acts on the various substances used for food by different birds. Thus the gastric juice in the stomach of those birds which live on flesh acts very sparingly on vegetable substances. On examining the castings or pellets of some Eagles, which had been occasion-

* KING's Narrative, vol. i., p. 199. 
ally fed with dead Pigeons, it was found that the vegetable food, peas, wheat, and barley, which had been swallowed by these birds of prey, enclosed within the crops of the Pigeons, remained entire, being only somewhat enlarged by heat and moisture; though the fleshy substances, even to the very bones, were entirely consumed.*

Again, it has been observed, that this juice will not act upon the grain swallowed by poultry and other granivorous birds while it remains whole and entire.

This fact has been further proved by actual experiment. Some gastric juice was poured into a cup containing some whole seeds, but it produced no effect upon them till they were crushed. Hence it has been found, that if oats and barley given to horses are previously killed by heating, and crushed, the animal only requires half the quantity, and yet thrives equally well.

In considering the real stomach or gizzard, by which name it will be more familiarly known, we shall find additional cause for admiration in the mode by which Providence, with reference to the food introduced, so nicely balances the grinding powers of the gizzard with the dissolving or melting powers of the gastric juice. This third or real stomach differs, like the gullet, crop, and second stomach, very materially in different birds; but, generally speaking, the action of the gizzard may be compared to that of a coffee-mill, grinding down the various substances introduced into a pulpy matter. In those which feed on flesh and insects, substances of no very hard texture, this stomach appears as a thin membranous bag in comparison with the thick muscular globes or gizzards of the grain-devouring class; and the reason is evident; for the animal matter on which they feed requires no actual grinding to reduce it, the action of the gastric juice being sufficient for the purpose of dissolving it; whereas, without the powerful working of this grindingmachine within its body, a fowl, for instance, without a gizzard, would receive no sustenance from the grains on 
which it depends chiefly for support, since we have seen that until these grains are bruised and crushed, the gastric juice will not act upon mealy or nourishing matter contained within the husk. And there are reasons for supposing, that in this process, nature acts according to certain wise laws, in most cases suiting the quantity and quality of the gastric juice to the necessities of the bird. One of our ablest anatomists,* indeed, concluded that the stomach became more and more fitted to economize the food, as the country to which the bird belongs became less fertile, or less able to provide the requisite supply. In some cases, where the gizzard is imperfect, and is unfitted to act the part of a grinder, the bird is led by instinct to provide itself with a singular substitute.

We have alluded to the strange matters found in the stomach of the Ostrich which died in this country. Now, the reason why these birds and some others, such as the Emu and Cassowary, which move over the ground by running instead of flying, swallow such strange hard substances, is this: their digestive organs are, generally speaking, weak; accordingly, their well-known propensity for swallowing glass, iron, and other such substances, is an instinctive remedy for this deficiency, which is further assisted by their habits of running; this motion producing such an increased shaking or rubbing together between these hard substances which they swallow, and their natural food, as to render the strong action of a gizzard in a great degree useless. Those who take an interest in poultry are aware that they are in the constant habit of picking up small stones. Many persons consider this as an accidental occurrence; but it is by no means so: they do it, like the Ostrich, for the purpose of assisting the powers of the gizzard in grinding the shells and outer coats of the grains, so as to render them fit for final digestion. In the stomach of a Turkey-hen, nearly one hundred stones have been counted, and in that of a Goose, a still larger number; but these are nothing to the extra-

* Sir E. Home. 
ordinary contents of a common fowl's stomach, in which were found three pieces of flint, three metal buttons, fourteen nails, several of which were very sharp, in addition to a great number of small stones.* The coat of the bird's stomach, with the exception of some slight scratches on the inner membrane, was in its natural state; probably, however, if the gizzard had been closely examined, it would have been found diseased or defective in its operations, thus inducing the fowl to make up its deficiency by so unnatural an addition. Sir James Ross, in his interesting voyage of discovery towards the South Pole, mentions having found in the stomach of one of the "Great Penguin," (Apterodytes Forsteri, the frequenters of high southern latitudes, from two to ten pounds weight of pebbles, consisting of granite, quartz, and trappean rocks, swallowed,' no doubt, to assist them in digesting the various species of crustaceous animals on which they feed.

But the best way of understanding its curious mode of working, will be, to follow the progress of a meal swallowed by a fowl, between whose stomach and that of a corn-mill, naturalists have traced a very close resemblance. The grain is first passed by the gullet into the craw, which may be compared to the hopper of the mill, through which the grain is gradually emptied on the grinding-stones. There, as we have seen, it remains a certain time, till it is considerably softened; and then,-not all at once, but in very small quantities, in proportion to the progress of trituration, just as the hopper allows the grain to dribble into the central hole in the upper mill-stone,--does it pass onwards to the gizzard, where it is thoroughly bruised and reduced. Many experiments have been made to ascertain the precise manner in which the gizzard acts; but we are still much in the dark respecting it. We may learn, however, a good deal by examining a very lean young fowl, when, on removing the feathers from the side of the belly nearest the gizzard, its motion can be both felt, seen, and heard. On pressing with

* Edinburgh Philosophical Journal, No. III., p. 206. 
the finger, the muscles will feel to the touch as hard as stones; when they relax, the grain, upon which they were then working, passes on, and a further supply, as in the case of the mill, passes under these natural rollers. These alternate actions succeed each other slowly but regularly; and on placing the bird close to the ear, as the food and stones roll under the pressure of the muscles of the gizzard, a sound not unlike the noise of the tide rolling upon a shingly shore, may be distinctly heard at intervals, as if the waves were ebbing and flowing; and during all this process, the gastric juice slowly flows in from the lower part of the guilet or second stomach, and mingles intimately with the digesting food.

We have stated that the fowl best calculated for this examination should be a full-grown young one; but although, in this almost immature state, the gizzard is fully developed, if we were to dissect a chick, we should find not a vestige of a gizzard, but merely a thin pellicle or skin. And it is for this reason, that whereas the young fowl is nevertheless old enough to live entirely on grain, and therefore requires the assistance of a gizzard, the little chick, on emerging from its shell, for a short time lives on soft food, and requires no such aid. As it advances in age, however, the pellicle gradually thickens, till at last, by pressure and rubbing, it becomes a hard and grinding membrane.

From the different construction and digestive powers of the stomachs of birds, it must be evident that some are able to continue a much longer time without food than others. An Eagle has been known to fast for three weeks; those who had the charge of it having forgotten to provide its usual supply of food. It soon, however, recovered its strength, and did not appear to suffer from its extraordinary abstinence. How long other birds can sustain hunger, we can have few opportunities of learning, but probably it will be found ihat such as are most likely, from their habits and particular sort of food, to be more exposed to a precarious and doubtful supply, are, generally speaking, best provided against the chance of suffering. But this is not always the case, for 
Geese and Fowls, which are rarely without the means of supplying themselves, have been known to remain a surprising length of time in a fasting state. A favourite hen, which had been missed for upwards of four weeks, was fortunately found at the bottom of a deep well, by a person who went down to repair it: the poor bird, when discovered, was perched on a small piece of timber floating on the water, and when taken up was in a very exhausted state, but soon recovered.

A Goose was accidentally shut up in a shed, and supposed to have been carried away by a fox, when, at the expiration of three weeks, it was discovered alive; for a few days it continued in a weak state, but gradually resumed its strength.

Having taken a short view of the frame-work and internal construction of a bird, with reference to the disposal of its food, we shall next consider some other of the vital functions, commencing with those of breathing and voice. The lungs of men and animals occupy, as is well known, a large portion of the chest, whereas, in birds, the space occupied is not only much smaller, but the lungs themselves are of a more firm and compact texture. At the same time they are most plentifully supplied with air-cells, communicating with other cells, profusely distributed over every part of the system, by which their bodies are in a manner blown up and rendered buoyant; a considerable portion of the skeleton, moreover, as we have shown, being formed into receptacles for this light and elastic fluid, of which birds partake in so much greater a degree than most other portions of the creation. In fact, a bird, destined as it is to live in air, may be almost called an absolute air-vessel, so completely does air fill up and circulate throughout its whole frame. While men and other land animals breathe-in air through the nostrils alone, a bird respires through a variety of other channels. A wounded Heron was observed to live a whole day, breathing solely through a broken portion of the wing-bone.* Other experi-

* See Linncean Transactions, vol. xi., p. 11. 
ments have confirmed the fact; the fractured portion of a bone that had been separated, when immersed in soap-andwater, was observed to emit bubbles from the part nearest the body, proving, beyond a doubt, that it contained air in considerable quantities.

The quills of the feathers are also air-vessels, which can be emptied and filled at pleasure.

There is a bird called the Gannet, or Solan-Goose, which is a beautiful instance of this wonderful provision; it lives on fish, and passes the greater part of its time either in the air or on the water, even in the most tempestuous weather, when it may be seen floating like a cork on the wildest waves. To enable it to do so with the least possible inconvenience, it is provided with a greater power of filling and puffing itself with air than almost any other bird. It can even force air between its skin and its body, to such a degree, that it becomes nearly as light and buoyant as a bladder. This buoyancy, however, entirely prevents its diving after fish: Nature, therefore, has applied a remedy by giving an extraordinary force and rapidity of flight, in enabling the creature to dart down on a shoal from a great height. This velocity is so prodigious, that the force with which it strikes the surface of the water is sufficient to stun a bird not prepared for such a blow, or to force the water up the nostrils. But the Gannet has nothing to fear from either of these causes, the front of its head being covered with a sort of horny mask, which gives it a singularly wild appearance; and it has no nostrils, a deficiency amply remedied by the above-mentioned reservoirs of air, and capacity for keeping them always filled. Some notion may be formed of the rapidity of their descent by a curious mode of taking them, occasionally practised by the fishermen in the North. A board.is turned adrift, on which a dead fish is fastened. On seeing it, the Gannet pounces down, and is frequently killed or stunned by striking the board, or is secured by its sharppointed beak being actually driven into the wood like a nail, and holding it fast. 
There is another bird even more copiously supplied with air than the above, called the Chavana Fidele, in which the skin is entirely separated from the flesh, and filled with an infinity of small air-cells, the legs and even toes partaking of the same singularity, so that it appears much larger than it really is, and when pressed by the finger, the skin sinks in, but resists pressure like a foot-ball, or other elastic body. The air, in this case, is supposed to assist in producing a powerful screaming voice, the bird being a wader, and not calculated for lengthened flights.

Generally speaking, the bones of birds, excepting when young, are without marrow, the gradual absorption of which, till the bones become a hollow tube, is most easily perceptible in young tame Geese, when killed at different periods of the autumn and winter. From week to week the air-cells increase in size, till, as the season advances, the air-bones become transparent. Towards the close of the summer and beginning of autumn, although in external appearance the young Goose resembles the parent, no trace of air-cells can be discovered in its bones,- - the interior being still filled up with marrow, which does not entirely disappear till about the end of the fifth or sixth month.

In the Eagle, Hawk, Stork, Lark, and other birds in the habit of soaring, the air-cells are very large, particularly those in connexion with the wing. On the other hand, in Ostriches, or those birds which either never or seldom fly, those of the wing are comparatively small; but as a compensation, it has been remarked, that as great strength as well as lightness is desirable to enable them to run swiftly, their bones are almost all of them remarkably hollow. Such are some of the advantages derived from this abundant supply of air.

We have alluded to the additional warmth possessed by birds, in comparison with other animals, to which this greater quantity of air must essentially conduce. We may here again refer to the Gannet, which, passing so much of its time in the depth of winter, exposed to the severest weather, 
would, if not provided with additional means of keeping itself warm, often perish from cold; but having, as we have observed, a power of filling up the space between its flesh and outward skin with air, it is thus furnished with a light, but at the same time admirable coat, which effectually prevents it from feeling the effects of cold, however severe. 


\section{CHAPTER IV.}

Organs of Sound.-Ducks, Crane, Goat-Sucker, Bell-Bird, etc.Distance at which Sounds may be heard.-Plumage.-Structure of Feathers. - Goose-Plucking. - Summer and Winter Plumage.

HROM the organs of breathing we naturally proceed to 1 those of voice. The striking difference existing between those of birds and other animals, may, perhaps, be best explained by comparing them with the organs of sound in the uman species. We utter sounds, and speak, through a certain tube, communicating from the mouth to the lungs, called the trachea or windpipe, which is furnished with very beautiful contrivances for the purposes of sound. In like manner, birds are provided with windpipes; but, unlike men and animals, they have a double set of instruments, if they may be so called, one at the upper, and the other at the lower end of the windpipe; and as it is in the lower part of the windpipe chiefly that the peculiar contrivance for uttering sounds is to be found, which may be compared to a clarionet, or similar musical instrument, it so happens, strange to say, that a bird might utter notes even after its head was cut off. It is astonishing what powers and varieties of notes this simple pipe is capable of producing. A good deal depends

1
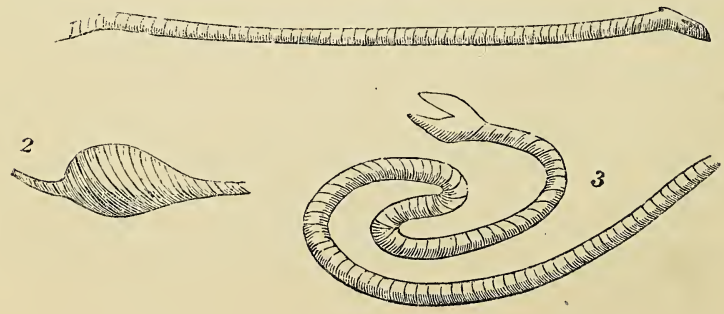
on the construction of the windpipe itself; and several, as the Duck tribe, are very curiously formed. It usually consists of a straight tube, of a stiff horny character, sometimes of uniform diameter throughout, at other times gradually swelling towards the middle, or with roundish enlarged cavities, as in the tufted and golden-eyed Ducks, though these enlargements are more frequently at the end of the tube. The first of the annexed figures represents the tube, the second the horny cavity, and the third, twisted windpipe, is that of the Crane, which is singularly bent, as it enters within the breast bone; the cleft end is the internal termination; the other, its junction with the mouth.

It would be needless to dwell upon the infinite variety of notes of birds, but a few of the most striking deserve notice.

In this country, we find, indeed, few peculiarities; but, nevertheless, there are some. -Thus, everybody knows that Jackdaws, Starlings, and Magpies, may be taught to speak words, like Parrots; but near a clergyman's house, in Northamptonshire, a blackbird

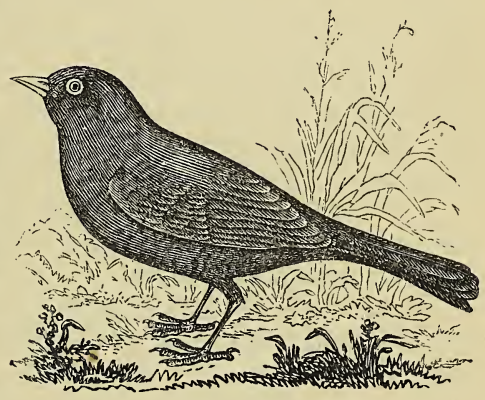

The Blackbird. was in the habit of crowing constantly, as accurately as a common cock, and nearly as loud. Perched upon the top bough of an ash-tree, it might be seen crowing away; occasionally indulging in its natural song, but this only for a second or two; for it soon began again to crow; and when the cocks from a neighbouring poultry-yard answered it, the little bird seemed delighted, and seemed as if it was trying to rival them in the 
shrillness of its note. It was supposed that it must have been bred near the spot, and learned the cry from hearing the cocks.*

The Goat-sucker, Night-jar, Hawkmoth, (or, as it is better known in many places, the Wheel-bird, owing to its making a sound much resembling a spinning-wheel,) is another bird not uncommon in this country during the summer months, frequenting heaths and commons. The best time to hear it is about dusk, when it may be cautiously approached, and discovered sitting with its head downwards, repeating, for a considerable time, its rough jarring cry.

In foreign countries, however, there are birds possessing a far greater power of imitation. We need scarcely mention the Mocking-bird of North America at the head of the list; so widely spread over the world is its character, not only having the power of imitating the note of every bird it hears, but also that of animals, and other sounds. It can bark like a dog, mew like a cat; then all of a sudden make the exact noise of a trundling wheelbarrow; sometimes it will call the hens together by screaming like a wounded chicken; or entice the house-dog from the fire-side by whistling for it in its master's well-known summons.

There is a species of Crow in India, (Corvus leucotophus,) which assembles in flocks of about twenty or thirty, in the recesses of forests, and whose note so exactly resembles the human voice in loud laughing, that a person ignorant of the real cause would fancy that a very merry party were close at hand.

There is also a species of Skylark, in India, whose powers of imitation are described as astonishing. One of these birds had so completely learned the wailing cry of a Kite soaring in the air, that although the Lark's cage was in a room, and within a few feet of the listener, he could scarcely persuade himself that the cry he heard did not, in reality, proceed from a distant Kite. They are taught by being carried daily to the fields and groves, in close-covered cages,

* See Mag. Nat. Hist., vol. iv., p. $34 \delta$. 
and are so prized, that a fine, well-instructed bird, has been known to sell for $4 l$.

We have spoken of our English Goat-suckers, but there are many of this family never seen in our island, and far more interesting. In South America there are several sorts, whose notes are so singular, that the natives look upon them with a degree of awe and reverence, and will never kill them. They have received names from the different words they are supposed to speak, and absolutely bewilder strangers on first arriving in those parts. Thus, one of the most common will alight close to the door, and, on a person going out, will flit, and settle a few yards before him, crying out, "Who are you? who, who, who are you?" another calls out, "Work away, work away, work away !" a third, in a mournful tone, says, "Willy come go; Willy, Willy, Willy come go !" while another, which is also a very common one, is known by the name of Whip-poor-Will, from constantly repeating these words. But the most extraordinary note yet remains to be mentioned, that of the Campanero, or Bell-Bird, found in South America, and also in Africa (Cotinga carunculata). A traveller in the first-mentioned country speaks of it as never failing to attract the attention of a passenger, at a distance of even three miles, when it may be heard tolling, like a distant church-bell. When every other bird, during the heat of the day, has ceased to sing, and all nature is hushed in midnight silence, the Campanero alone is heard. Its toll sounds, then a pause for a minute, then another toll, then another pause, and then a toll, and again a pause. In Africa, two travelling missionaries have given nearly the same account, but at somewhat greater length. They were journeying onwards, in the solitude of the wilderness, when the note of the Campanero fell upon their ear. " 'Listen,' said my companion, 'did not you hear a church-bell ?' We paused, and it tolled again; and so strong was the resemblance, that we could scarcely persuade ourselves that we did not hear the low and solemn sound of a distant passing bell. When all was silent, it came at intervals upon the ear, heavy and slow, like a death-toll; all again was then silent, and then 
again the Bell-Bird's note was borne upon the wind. We never seemed to approach it, but that deep, melancholy, distant, dream-like sound, still continued, at times, to haunt us like an omen of evil."

How the Bell-Bird utters this deep loud note is not known, though it is supposed that a fleshy protuberance on its head, which, when inflated with air, stands up like a horn, is, in some way, the cause; but the Goat-suckers, in all probability, are indebted to their peculiar width of mouth and throat for this power of voice; for many other birds, in uttering loud notes, are observed to puff and swell out their throats in a very extraordinary manner. For instance, our little summer visitant and sweet songster, the Blackcap, when warbling forth his finest notes, distends his throat in a wonderful degree; and those who have chanced to see a Brown Owl in the act of hooting, will have noticed, that they swell up their throats to the size of a Pigeon's egg. And persons who have fine ears for music, have ascertained, by comparing their notes with a pitch-pipe, that their variations are according to certain rules, most of them hooting in B flat, though some went almost half a note below A. This strain upon the throat is sometimes carried to a pitch which endangers the bird's life. The bird-fanciers in London, who are in the habit of increasing the singing powers of birds to the utmost, by training them, by high feeding, hot temperature of the rooms in which they are kept, and forced moulting, will often match one favourite Goldfinch against another. They are put in small cages, with wooden backs, and placed near to, but so that they cannot see, each other: they will then raise their shrill voices, and continue their vocal contest till one frequently drops off its perch, perfectly exhausted, and dies on the spot. This will even happen sometimes to birds in a wild state. In the garden of a gentleman in Sussex, a Thrush had for some time perched itself on a particular spray, and made itself a great favourite from its powerful and constant singing; when one day it was observed, by the gardener, to drop suddenly from the bough, in the midst of its song. He immediately ran to pick it up, but found it 
quite dead: and, upon examination, discovered that it had actually broken a blood-vessel by its exertions, and thus perished.

That the notes and cries of birds serve them instead of language, there can be little doubt; one person indeed is on record, who having passed much of his time in boyhood alone, in lonely situations, had by close attention acquired such a knowledge of this language, that from the song of the parents he knew where the nests were situated, whether they contained eggs, or whether the brood was hatched, knowing even the number of young birds, and their age, before he saw them.* In fact, a common observer may, in some instances, understand their different notes, and all their different wants and emotions, as well as the birds themselves do.

Thus, while walking in a wood, if we happen to get sight of a flock of Jays before they chance to notice our approaching, they will be seen enjoying themselves, and chattering in seeming confusion. Suddenly, one will be heard to utter a peculiar short deeper-toned note, when in an instant all is silent, and they may be seen skulking off one by one, only to be heard again when they have sheltered themselves at a considerable distance. Crows and Fieldfares, with many others of what are called congregating birds, or those that live together, act in the same manner. Every sportsman knows how difficult it is to get within gunshot of a large flock of these birds, though they appear to be so busily employed in picking up their food in a meadow, that it might be supposed they saw nothing else.

The fact is, they very often do see nothing, and think of nothing, beyond the food they are in search of; because, on the bough of some neighbouring tree, a good look-out is kept by one of the party, and the moment the sentinel Crow, or Rook, gives out his well-known caw of alarm, or the Fieldfare its peculiar jarring cry, away go the main body beyond the reach of the fowler, who thought he could

* See Quarterly Review, on Lord Holland's Life of Lope de Vega; vol. xviii., p. 36 . 
escape observation, by lurking behind a tree, or stealing behind a hedge-bank. A person familiar with the notes of birds has no difficulty whatever in distinguishing between the sounds of pleasure and alarm. If he hears the Swallows screaming in a certain note, he is as well aware that cats or Hawks are about, as if they could tell him so in common language. We once happened to hear a loud outcry amongst a parcel of Sparrows, Tomtits, and Chaffinches; the noise was evidently not their usual note of pleasure, neither was it the clamorous scream they utter when fighting. The bustle occurred within a yard of our window, too near for a Hawk to venture; neither was there a cat within sight,-nothing of the sort; but still the din increased, and the bush shook again with flutterings of wings and clacking of tongues; when, at last, we espied a pair of inquisitive eyes, and a little sharp snout poked out from the twigs, at the bottom of the bush. It was a weasel, which on seeing that it was discovered, took to its heels ; and in an instant the cries of the Sparrows ceased, and the whole party dispersed.

It is scarcely necessary to remind the reader of the language so well known in the poultry-yard. The cluck of the Hen, when she calls her chickens together; her shriek, if a Hawk is seen flying over the brood, and the rapid rush of chickens under her wings; and her cackle of pride or pleasure, when she announces to the whole farm-yard the important fact of her having laid an egg. Even a young chicken has a power of language easily understood. Take, for instance, one of four or five days old, and hold it up to a window where there are flies, and it will immediately seize them, with a little twittering note of pleasure ; but if a wasp or bee is placed before it, at once its note becomes harsh, expressing its dislike as well as fears.

Nobody can doubt, who sees a bird singing, clapping its little wings, turning from side to side, and glancing its bright eyes in all directions, as if courting attention and admiration, that it feels delight and satisfaction. Did we require further proof, we have but to recollect that the songbird is most on the alert with the music of his voice when 
its affection and interests are awakened by attention to its mate, during the time of rearing its young. The male may then be generally seen on some twig or bough, at no great distance from the nest; in most cases becoming silent if aware of a stranger's approach, or exchanging the note of pleasure for another of anger and complaint, which too often produces the very evil it dreads. Thus, the Nightingale, one of our shyest and most timid birds, will frequently discover its nest, by making a jarring noise, and also a snapping and cracking, at the same time pursuing people along the hedges, as they walk, when its young are in a helpless state. The male Blackcap is still more incautious, for it will commence and continue its song, even when sitting on its nest, and thus too frequently become the innocent cause of the capture of its brood.

The loud cries of other birds, however, particularly of many of the migratory water-birds, which fly by night, are evidently intended for the purpose of keeping them together. Few have been without opportunities of listening in the silence of the night to the incessant cackling of a flight of wild Geese, on their way to some distant spot, high in the air. In the Northern seas, sounds of this sort are more frequently heard, from birds which never come so far to the southward. Of these is the red-breasted Diver, which seldom quits the water by day, but during the night may be known to be on the wing, at a vast height, by a peculiarly melancholy and distressing scream, exactly resembling that of a young child suffering from agonizing pain. We have listened by the hour together to the repeated and successive wailings of these wild, melancholy birds ; first, the scream is faint, and so distant as scarcely to reach the ear; then it increases as the bird passes nearer,- - till, as it continues its flight, the sound gradually dies away. Soon another scream from another quarter is faintly heard; and so on, till the dawn appears, when they betake themselves to the element on which they pass the day.

The distance, too, at which some birds may be heard is very extraordinary. The brown Crane of North America, 
which soars to an amazing height, when almost out of sight utters a note which is so distinctly heard, that an experienced sportsman would imagine it to be close at hand.

From the notes and voice of birds, we will next proceed to their feathers and wings. A more beautiful, light, and compact piece of machinery, or more perfectly adapted for the purposes for which it is intended, cannot be conceived, than a feather. For beauty, look to the colours and shades presented by the glossy plumage of our Peacocks and Pheasants, with which everybody is familiar; but their colours, beautiful and brilliant as they are, shrink into insignificance compared with the dazzling coverings of many others, found only in the hotter climates of the globe. It is difficult to make a selection amongst the splendid variety which might be named; but perhaps the Ptiloris Paradiscus, a bird of New Guinea, little known, is one of the most beautiful. It is impossible for any written description, or even coloured representation, to give an accurate idea of this most splendid creature. Its size is about that of a small pigeon, and its general colour is a deep velvet black, glossed on the upper parts with rich brownish lilac, which in some lights leaves the margin of each feather black, and gives them a scale-like appearance. The whole back part of the head is covered by a crown of smaller scale-like feathers, of a splendid metallic green; each colour alternately preponderating, as the direction of the light is varied. The middle of the throat is occupied by a large patch of the same colour, which, as it approaches the breast, divides and forms a stripe on each side. The chin and breast appear to be of an intense velvety black, but when held in certain lights, become glossed with the most beautiful reflections of lilac and purple. The feathers on the body are yet more changeable; in some directions, they seem entirely black; in others, this apparent black is mingled with a rich olive green; while in another position it is brilliantly reflected and relieved by shades of lilac, purple, and the most vivid green. All this gorgeous apparel, however, is confined to the males, the female being clothed in a homely and russet-brown attire, attracting little notice. 
Of a feather's lightness, we may form some idea when we find that the largest quill of a Golden Eagle weighs only sixty-five grains, and that seven such quills do not weigh more than a copper penny-piece; that the feathers of a common fowl which weighs thirty-seven ounces, weigh only three ounces; and that the entire plumage of an Owl weighs only one ounce and a half. Meant as they are, some for covering and some for strength, we shall find them, on examination, very differently put together. The light downy part, when examined through a microscope, will be found to bear little resemblance to the flat part or blade of the quill. If it were not so, a bird would scarcely be able to fly at all; for when the flat of the wing was pressed down, the air would pass through it, and yield no resistance. The fibres of the downy part, we see, have little connexion with each other; they have short and loose side shoots, just sufficient to mat them together when pressed close to the skin; whereas, the side shoots of the quill-feather hook and grapple with one another, so as to make one firm and united surface. Some idea of this may be formed from the annexed figures, the second of which represents a piece of the finest down magnified.

But others there are, much stronger and stiffer than the wing quill-feathers, as those, for instance, forming the tails of the Woodpecker tribe. And the reason would be evident to any person who watched a Woodpecker on the stem of a tree feeding. Its food consists of grubs, usually concealed in the wood. In order to get them, he must therefore remain fixed on the bark, and make a hole with his beak, a tedious, if not an impracticable operation, were it not for the wiry stiffness of the tail feathers, which press against the tree, and act like an additional limb. The tail, however, has another use, applicable more or less to all birds; it is to them, what a rudder is to a boat, and in many cases acts like a third wing. If we look at a Hawk hovering in the air, when he remains in one spot we shall see that the tail is spread out like a fan, and is in a constant state of 

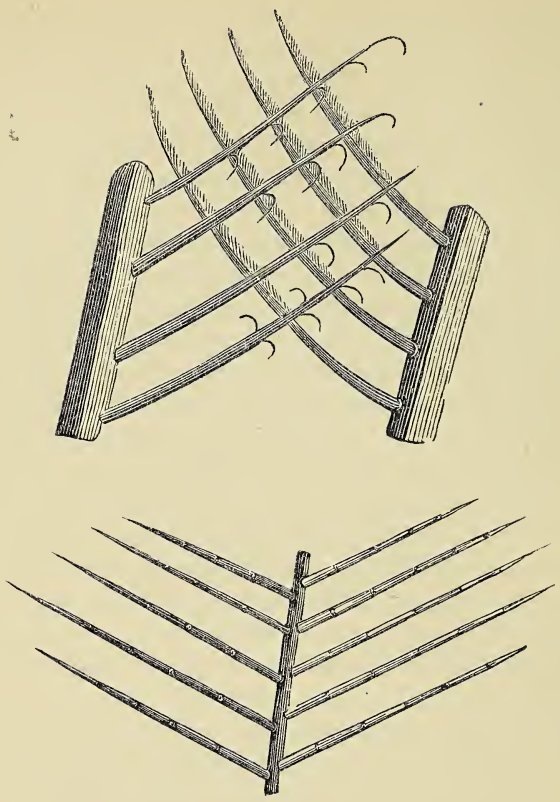

quivering motion, balancing the bird, while the wings are keeping it afloat.

It is clear, that if water could soak into the soft feathery covering of a bird, every shower of rain would be the death of thousands, inasmuch as it would increase their weight considerably, and at the same time, by destroying the fine elastic nature of the feathers, entirely disable them from flying, and they must remain in a helpless state upon the ground, either to perish from hunger, or become the prey to men or animals, who would catch them without trouble. But against such a possibility they are guarded by an abundant oily covering, which is constantly renewed; so that the rain, instead of 
sinking in, runs off, without remaining an instant; and we all know, that if we take up a Duck, or any swimming bird, we shall find, though it might have been diving just before, that it is perfectly dry, and free from all damp. But this principle of life, if it may be so called, in a feather, ceases with the life of a bird; for if we were to throw a dead Duck into the water, we should find that its coat had lost all power of resisting water, and become a spongy mass of moisture. But besides this, some birds, certain Eagles, Hawks, Owls, and Herons, for instance, are furnished with a very fine dust or powder, which is supposed to be of use in preserving their plumage, though in what way is not at present exactly known.

The growth of feathers in young birds in hot and favourable weather is very remarkable. It has been ascertained by attending to nestlings, that in eight days after their appearing from the egg in a helpless, naked state, they have acquired a full coating of feathers, and are able to make some use of their wings.

That feathers are essential to a bird in its wild and natural state there can be no doubt; but they are not, it would seem, in all cases absolutely necessary, for a featherless, naked Canary-bird was once actually reared, and continued living in good health for upwards of three years. In this case, the featherless state of the bird was accidental; but the fact of a bird's being able to exist without this, its natural clothing, is proved by a most cruel and barbarous custom, which cannot be too strongly reprobated, practised in some parts of England, where extensive flocks of Geese are bred and reared mainly for the value of their feathers. The season of sheep-shearing does not return more regularly than that of Geese-plucking. It is chiefly performed by women; and of course the torture of the poor bird is greater in proportion to the want of skilfulness in the operator, those new to the employment often tearing and lacerating the skin in such a manner as to occasion the bird's death. But even when performed with the utmost expertness, the poor birds pine for a considerable time afterwards, losing their flesh and 
appetite; their eyes become dull, and they betray symptoms of weariness and weakness. In some birds this growth of feathers is always going on; and they may be said to be in a perpetual moult; while in others again, and those chiefly water birds, the process of moulting or changing plumage occurs only twice in the year, in autumn and in spring; and here again we shall find that Creative Wisdom is at work in acting for the best.

That there is a great difference in the summer and winter plumage of many birds is known to almost everybody; but it requires a closer examination to see that much of this difference consists in a great increase of warmth, to meet the severity of the latter season, which is thus produced. In the autumnal moult, when the summer feathers fall off, the new feathers which take their place will be found to be fringed. This fringe is generally of the same texture, though almost always of a warmer and more downy character, and often of a different colour, which will account for the variety of tints often observed in birds at these different seasons of the year. As the spring advances these little fringes break off, and leave the edge of the feather sharp and defined, but of course shorter; in this very simple manner is the bird divested of a quantity of winter clothing, when the weather is warmer, and a superfluity of apparel no longer required. In the case of two species of Partridges, called the Wood and Rock Partridge of North America, which, in winter, burrow underneath the snow, a still warmer covering is provided, the growth of feathers being actually doubled; so that they have nearly twice as warm a coat, when they most require it, as they had during summer, when it was unnecessary.

Generally speaking, the colour of the plumage in different species is the same; there are, however, some constant exceptions, as, for instance, in the Ruffs and Reeves, in which no two birds are ever found exactly alike. The Ptarmigans, again, vary considerably; the Cross-beak also has the same peculiarity, and it is almost needless to point out the constant variety observable in our common barn-door fowls; but, 
exclusive of these, which may be called natural variations, there are occasional departures from the usual rule, of an unnatural character. Thus Blackbirds are not unfrequently found very considerably mottled with white. Woodcocks are now and then shot, of a delicate and uniform fawn colour. We have also seen white Swallows, and a few other small birds; and amongst Crows and Rooks, one or two interlopers may be occasionally observed, with more or less white feathers peeping out from their glossy wings. Closer observations may probably throw additional light upon this singular peculiarity, and we suspect that it will be generally found that it extends through several generations of birds reared by the same pair. In one instance we know, indeed, that this was the case. A pair of Rooks were in the habit of building in a wild spot near Ruthin, where there were few trees affording shelter for others. The attention of the tenant on the farm was soon attracted by the singular appearance of two white young ones, and, to his surprise, for three or four years, the same phenomenon occurred, two white Rooks being the invariable and sole nursery establishment of this solitary sable pair of old birds. This year (1837) the young ones were taken and reared. A change of plumage has also been observed to take place occasionally by limiting the bird to a particular sort of food; thus bird-catchers say, that by the use of hemp-seed, Bullfinches and some other kinds of birds will frequently assume a darker colour. Fright, again, (as in the case of human beings, whose hair has been known to change under great excitement or alarm,) it is said, will produce similar effects on birds; in proof of which, we have been assured on the authority of a friend, that a Bullfinch in his possession turned black in a few hours after having been terrified by the approach and attack of a cat upon its cage. 


\section{CHAPTER V.}

Flight.-Muscular power of Wings. - Peculiarity of, in different Birds.-Adapted to various Habits.-Rapidity of Motion and Rate of, how calculated.-Long continuance of Flight accounted for.-Migration, causes of.-Tendency of most Birds to wander at particular times. - Why seldom seen in the act of migrating. - Instinctive power of finding their way.

HAVING described the light and airy frame-work of birds 1 intended to pass more or less of their time in the air; and having shown how beautifully, in every particular, an all-wise Creator has fitted them for such a life, we are naturally led to follow them in their flight, and see how they are still further prepared to turn their lightness of form to the greatest advantage ; and, in pursuing this inquiry, the more shall we be constrained to acknowledge, that "wondrous are the works of God, and that in wisdom he hath made them all,-giving unto the Stork in the heaven to know. her appointed time, and the Turtle, and the Crane, and the Swallow, to observe the seasons for their coming." No human ingenuity or skill could ever have devised so perfect an instrument as a bird's wing for its intended purpose; so light, and yet so powerful; so spacious when spread out, and yet so compact, and gathered into so small a compass when not wanted.

We may form some idea of the extraordinary strength of a bird, from knowing that the great muscle, which chiefly regulates the movements of its wing, weighs more than all the other muscles of its body put together, constituting not less than one sixth-part of the weight of the whole body; whereas, those of the human body are not one-hundredth part as large in proportion.

Some birds have to seek their food on the wing, consisting of such very small insects, that many hundred must 
be swallowed for a meal, and in these we accordingly find a spread and power of wing truly astonishing. We cannot take a better example than our common Swift, the largest of our Swallow tribe, whose well-known scream and rapid flight must be familiar to every one. It has to seek its livelihood solely in the air, on insects so small that we can with difficulty perceive them, even if slowly passing before our eyes. It could not, therefore, live a day, unless gifted with extraordinary powers of flight; it must not only be able to move rapidly forward in a straight line, but also be able to turn as quick as thought to the right or left, upwards or downwards, to catch its minute prey. And such is the case; the bird is so light that it weighs little more than an ounce, and yet the spread of its wings, from tip to tip, is not less than eighteen inches. But extraordinary as these proportions are, in length of wing, compared with weight, in this our British species, they are exceeded in a newly discovered species in the East Indies, called the Javanese Crested Swallow,* whose uncommon length of wing indicates a speed far beyond that of our Swift. Other birds, again, there are, which require additional powers, not in the air, but under water, their food consisting entirely of the fish they are enabled to catch, by diving after them with greater speed than the fish can swim. Here it is evident a long, widespreading wing, like the Swift's, would be very inconvenient; accordingly, in birds of this tribe, we find the wings much smaller, and so formed that they can be used as oars or fins, which in one division of the Penguin tribe they very much resemble, the short feathery covering upon them having much the appearance of scales. Of the true Penguins we have none in this country, but we have, however, many species, even in England, which live on fish, having wings, if not so much like fins as those of the Penguins, at least so very small, comparatively speaking, that we may refer to them as illustrations of the subject before us, - we mean the Divers or Grebes,-one of the most beautiful of which, and at the same 
time the most common, called the crested, or eared, or tippet

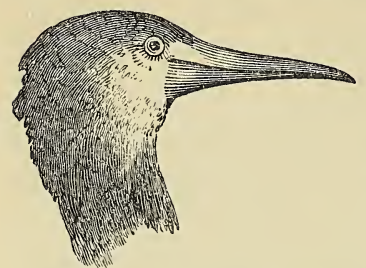

Head of the Crested Grebe. Grebe, from a feathery ornament like a tippet and ears, weighs two pounds and a half, or nearly forty times the weight of a Swift, and yet its spread of wing is only thirty inches, being six inches less than twice the spread of the Swift's wing. Sometimes, by carefully watching these birds in clear water, opportunities occur of observing their progress beneath the surface, when they may be seen flapping with their short wings, as if flying, thus acquiring a much greater speed than they could by the use of their webbed feet alone.

There is one bird, however, the Water Crow (Turdus cinctus), in size, shape, and wings very similar to the Blackbird, which also dives; but as it does not pursue fish, living on spawn, or such sort of food as may be collected without effort, the Diver's form of wing is not necessary, and accordingly the only use of its wing, under water, is by flapping or jerking it upwards, to prevent its rising; for as, like all other birds, it is much lighter than water, it must of course use some power to keep itself beneath the surface, and this it does by means of its wings. These birds are chiefly found in wild parts of the country, abounding in streams rushing over rocky beds. There they may be seen perched upon a stone on the edge or middle of the water, from whence they wade beyond their depth, and continue their course along the bottom, where they may be observed struggling, to preserve a footing, and prevent themselves from rising, by a strange tumbling sort of motion of their bodies, accompanied by quiverings of their wings, which, acting upon the water above, helps to keep them down.

Before we proceed to speak of migration, or that instinct which induces birds to visit and retire from certain countries 
at particular times of the year, it is necessary to say a little on the speed with which they can pass through the air, and their capacity for continuing on the wing without being fatigued. Few people, we believe, are aware of the very great rapidity of a bird's flight, and many will doubtless be surprised when they are informed, that even our slower birds can most of them make their way at the rate of thirty miles an hour, without any extraordinary effort; but that, if pressed, they can considerably exceed that speed. There is an easy way of ascertaining with tolerable accuracy the rate of a bird's flight, which from experience we can recommend as equally amusing and interesting. It is this:-

Suppose any bird, a Partridge, for instance, rises in the middle of a stubble, and flies in a straight line over a hedge; all the observer has to do is to note by the seconds hand of a watch (and those who not have seconds-hand watches may easily learn, at least sufficiently for practical purposes, to count them), the number of seconds between the moment of the bird's rising and that of its topping the hedge ; and then ascertain the distance between the point from whence it rose and the hedge by stepping and counting the number of paces; when, supposing each pace to be a yard, we have a common Rule of Three sum. Thus, if a Partridge, in three seconds, flies one hundred yards, how many yards will it fly in 3600 seconds, or one hour? or seconds yards seconds

as $3: 100::$ 3600: the number of yards required, which will be $\frac{3600 \times 100}{3}$ or 120,000 yards, which will amount to (as there are 1760 yards in a mile) about sixty miles an hour.

Again, suppose some Starlings are seen feeding in a field at A, at no great distance from a church tower, B C, in which they are building; or a Crow flies from a certain spot to the top of a tree; we may proceed in the same manner : for the height of the tower or tree will, in most cases, be too inconsiderable to make any material alteration in the result, though, if greater accuracy is required, it may 


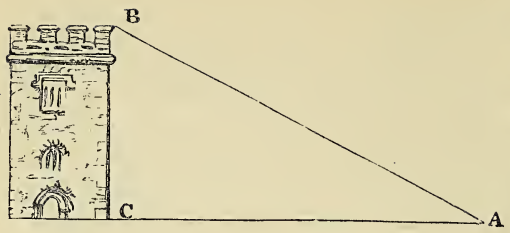

be obtained by the usual mode of measuring triangles. Thus, let $\mathrm{B} \mathrm{C}$ be the height of the tower, and $\mathbf{A}$ the point from whence the Starling rose, flying to the point $\mathbf{B}$. Knowing the height of the tower and the distance $\mathrm{A} \mathrm{C}$, we have to calculate $\mathrm{A} \mathbf{B}$, which is easily learned, since by the well-known problem of Euclid, $\mathbf{A} B^{2}=\mathrm{A} \mathrm{C}^{2}+\mathrm{B} \mathrm{C}^{2}$; by extracting the square root, we therefore find the exact length of $\mathbf{A} \mathbf{B}$.

It was by an application of this simple rule that the flight of an eagle was ascertained to be little short of one hundred and forty miles an hour. The bird was seen hastening on its way over a valley in the Pyrenees, and the number of seconds was observed which elapsed between its passing from the summit of one high point till it reached the brow of a mountain on the other side, the space between which was known by reference to a good map, in which the distances were well laid down. Such a rapid progress, we are aware, will scarcely be credited; but a celebrated naturalist, in speaking of the large white Fishing Eagle of North America, gives reasons for suspecting that its speed is still greater : he says, that, from an immense height, on perceiving their prey, they glide downwards with such rapidity as to cause a mighty rushing sound, not unlike that produced by a violent gust of wind passing among the branches of trees; and that the fall of this bird, enormous as it is, can on such occasions be scarcely followed by the eye.* Those who ride over commons of fine turf may often have witnessed a quickness of flight, probably not much inferior to these Eagles; for they will, even at their fullest speed on the fleetest horse, have seen Swallows skimming in all directions, pursuing the small 
insects which the horse puts up in its course over the grass, sometimes leisurely keeping at an equal pace, then shooting ahead, and not unfrequently actually flying round the rider in wide circles, with an ease and facility betraying neither effort nor labour in so doing.

The flight of the common Swallow has been computed at 90 miles, that of the Swift has been conjectured to be nearly 180 miles per hour. We can scarcely, indeed, calculate or limit the speed which can be produced by the effort of a wing's vibrations. That a small insect can with ease accomplish forty or fifty miles an hour, and probably much more, we know to be a fact, from our own experience on the Liverpool and Manchester Railroad; for, when rolling along, at the rate of about thirty miles an hour, we saw bees and flies, sometimes hovering round the carriages, sometimes settling, then, when disturbed, flying to the right or left, in an irregular course, but still keeping up, without the slightest appearance of extra exertion; and often when tired of continuing with the train, shooting forward, and in an instant leaving us far behind, and this, too, in opposition to a fresh breeze heading them.

Another mode of ascertaining the flight of birds has been by Carrier Pigeons. These are a particular breed, which can be so trained, that when carried to great distances from the place of their usual abode, and turned out, they will find their way back. A short time ago, fifty-six of these birds were brought over from a part of Holland where they are much attended to, and turned out from London about halfpast four in the morning: they all reached their dove-cotes at home by noon; but one favourite Pigeon, called Napoleon, arrived about a quarter after ten o'clock, having performed the distance of 300 miles at the rate of above fifty miles an hour, supposing he lost not a moment, and proceeded in a straight line; but as they usually wheel about in the air for some time before they start off, and then probably deviate more or less from the direct course, this first bird must have flown, most likely, at a much quicker rate; of which we have an instance which occurred at the fair of Ballinasloe in 
Ireland, in 1842, where a bird of this species belonging to Thomas Bernard, Esq., was let go in the town at eleven o'clock in the forenoon, with a note appended to it, directing dinner to be ready at his residence af Castle Bernard at a given time, as he purposed being home that day, which message reached the appointed destination in eleven minutes, having travelled 23 miles Irish in that wonderfully short space of time, or, in other words, at the rate of $125 \frac{1}{2}$ miles an hour. These pigeons, of which Mr. Bernard had a large flock, were so domesticated, that he could handle them as he pleased, and so very tractable were they, that whenever he called, they attended promptly.

A curious way of guessing at the speed of a Pigeon's flight has been noticed in America. Birds have been shot, which, on opening them, were found to have fed on coffeeberries, so fresh, that they could not have been in the stomach above four or five hours; but, as the nearest part of the country known to produce coffee was some hundreds of miles distant, it was calculated that they must have flown at the rate of sixty or seventy miles per hour.

But besides this great speed, many, even of those apparently least calculated for continued flight, can remain on the wing for a much longer time than we are apt to imagine, from seeing them slowly and heavily waddling, as in the case of farm-yard Ducks and Geese, or of a Sparrow, hopping leisurely from bough to bough, or flitting from thence to the house-top. Thus the tame domestic Geese, belonging to several Cossack villages, near the river Don, in Russia, leave their homes in March or April, as soon as the ice breaks up, and take flight in a body to the more northerly lakes, the nearest of which must be five or six hundred miles off, where they breed and constantly reside during the summer; but in the beginning of winter, the parent bird returns with their young ones, each alighting with its brood at the door to which it belongs. That flights of this sort are not confined to Russia, we may learn from the following instance, corroborating the fact just mentioned. A gentleman walking near Aberdeen, in Scotland, one morning, during a heavy 
gale which blew from the north-west, was attracted by a loud cackling overhead; from the awkward motion of their wings, he was certain they were not wild Ducks, and they seemed to him to be helped on as much by the wind as their own exertions. He next day heard that the duck-pond of a person in the neighbourhood had been deserted the morning before, about the time he saw them, by thirty Geese, which had all taken flight, and not been since heard of.

An instance of uncommon flight, though not to the extent of the above, occurred not long ago in Yorkshire. A person had a large flock of Geese, which fed on high ground not visible from the house. They were lessened, as occasion required, to about six; these were fetched.home, every night, for some weeks; and very frequently, on seeing the house from the top of the hill, they would take wing, and fly homewards, making a circuit of about a mile. On one occasion they were on the point of alighting on a pond of water, near the next farm-house, instead of a smaller one near home; they soon, however, discovered their mistake, and raised themselves in the air, to nearly as great a height as before, alighting on their own water ; and were there long before their driver, notwithstanding that he went mostly in a direct line. These flights were considered as particularly remarkable, because the Geese were at the time quite fat and heavy. We have a similar instance of a common tame Duck, in Hertfordshire, which was in the constant habit of taking flights, with the same power, and at the same height, as a Crow, or as if in its wild state. The people of the village were all aware of its singular propensity, asserting that it would often rise and take the circuit of a mile.

As to our smaller species, there is scarcely a part of the wide ocean, in the usual route of navigators, over which some of the little land-birds have not been seen flitting, blown off, in many instances, possibly, from their native shores, by gales of wind, and no doubt often perishing in the waters, but still leaving survivors enough to give evidence of their uncommon strength of wing. Thus our well-known cheerful little bird, the Tomtit (Parus major), has been met with in 
latitude $40^{\circ}$ north and longitude $48^{\circ}$ west, about 920 miles from land.* But a still more extraordinary instance, both as regards distance from land and situation, is that of a common Titlark (Alauda pratensis) having alighted on board a vessel from Livierpool, in latitude $47^{\circ} 4^{\prime}$ south, longitude $43^{\circ} 19^{\prime}$ west, in Sept. 1825, at a distance of at least 1300 miles from the nearest main land of South America, and about 900 from the wild and barren island of Georgia. The poor little traveller was taken, and brought back to Liverpool, where it was seen by Dr. Traill, one of our most eminent naturalists. An Owl has been also seen gliding over the midst of the Atlantic Ocean, with as much apparent ease as if it had been seeking for mice amongst its native fields. To the distant voyages of this bird, we can indeed bear our testimony, when sailing in the Mediterranean. At daylight a brown Owl was observed on the main-top-gallant yard, and secured by an active sailor : for three or four days it was detained, but as it appeared to pine, it was again turned adrift. At first it seemed bewildered, but after wheeling round the ship twice or thrice, it steered, direct as an arrow from a bow, for the nearest land, distant about eighty miles.

We cannot, after this, be surprised to hear, that certain seafaring birds are constantly found at a thousand miles, or often at greater distances, from land. Three of the most remarkable of these wild wanderers are the Albatross (Diomedea exulans), the Tropic-Bird (Phaeton Phoenicurus), and the Frigate-Bird (Tachypetes aquila). The first of these, the Albatross, the largest of the aquatic tribe, with plumage of the most delicate white, except the back and tops of its wings, which are of a dark grey, floats in the air, borne up by a vast expanse of wing, measuring fourteen feet, or even more, from tip to tip. The air and the water, indeed, seem to be far more natural to it than the land, where it is so helpless, owing to its enormous length of wing, which prevents it from rising, unless it can launch itself from a steep precipice or projecting rock, that it is completely at the

* Foster's North America, vol. i. 
mercy of those who approach, and one blow on the head generally kills it instantly,

The Tropic-Bird is the very reverse of the heavy, gigantic Albatross, and might fairly be called the fairy of the ocean; seen as it is in the genial latitudes of the warmest climates of the globe,-now a stationary speck, elevated as far as the eye can reach, contrasted with the dark blue of the sky, like a spangle in the heavens; then. suddenly descending like a falling star, and as suddenly checking its course, to hover for a while over the topmost point of a vessel's masts, and then darting like a meteor, with its two long projecting tailfeathers streaming in the air downwards, on a shoal of flyingfish; and then rising gracefully with its prize, again to soar aloft and take its rest above the clouds.

But light and airy as is the Tropic-Bird, what shall we say to the Frigate-Bird, which surpasses all others in its powers of flight, inasmuch as, excepting at the breeding season, it seldom visits the land; and, still more extraordinary, is never seen to swim or repose upon the waters! Its very structure, indeed, renders its living on either land or water a matter of difficulty; its wings are so long, that, like the Albatross, unless perched upon the pinnacle of a rock, or projecting point of a branch, it cannot take flight. Neither is it adapted for a life upon the waves; as its feet are but partially webbed, and in addition to its length of wing, which renders it as difficult to rise from a flat-water surface as from the level ground of the land, its feathers are not of that close and downy texture peculiar to aquatic birds; whereas, its whole form and internal arrangements are calculated for, it may be almost said, eternal flight. Its length of wing, ten or twelve feet from tip to tip, forked tail, and short legs, (the thighs or tarsi not exceeding an inch in length,) bear a close resemblance to those of our common Swift, of whose wonderful powers of flight we have said so much; but nature has provided the Frigate-Bird with still more surprising means, for not only floating for a time, but for ever, without fatigue, in the regions of air, and even sleep without risk of falling. We shall endeavour to explain this 
(at first sight) most improbable capacity, so as to render it no longer a matter of doubt or difficulty, but merely an additional instance of the beautiful arrangement adopted by the providence of God in all his wondrous works.

On examining it, we shall find just beneath the throat a large pouch communicating with the lungs, and with the hollow and particularly light bone-work of its skeleton. Suppose, then, that the bird wishes to rest in the air; -in the first place, it avails itself of its large wings, which it is enabled by constant habit to keep expanded, and which are in themselves nearly sufficient to sustain its weight and float its light body in the air. But in addition to the wing, suppose the bird fills its large pouch with air, and from thence forces it into all its bones and cavities between the flesh and the skin, what will happen? That the heat of its circulation (and it is well known that the heat of a bird's circulation is considerably beyond that of other animals) will rarefy the internal air; which will therefore puff up, not only the pouch, but every cavity, and thus give the bird a surprising additional buoyancy or power of floating, even in the higher regions of the atmosphere. And that this is the case may be presumed from its habits; for when the lower currents of air are stormy and disagreeable, up goes the Frigate-Bird to a higher and calmer current, where, just as we see the light fleecy clouds in the sky, it remains, suspended with outspread wing, motionless, and at rest, till, roused by hunger, it expels the rarefied air, and emptying its pouch, descends towards the waves; but as it never either dives or swims, on approaching within a few feet, it instantly stops, and changes its direction, so as to skim along and catch the flying-fish with its hawk-like bill or talons, or both together. So averse are they, in fact, to diving, or even touching the water, that, instead of dashing downwards head foremost, like the Gannet and other diving birds, the Frigate-Bird holds its neck and feet in a horizontal direction; striking the upper column of air with its wings, then raising and closing them one against the other above its back, it darts on the flying-fish with such skill and certainty, as almost invariably to insure success. 
Most travellers who have visited Constantinople by the passage of the Dardanelles and the Sea of Marmora, may have noticed a bird not quite so large as a Pigeon, abundant in that neighbourhood, though occasionally seen in other parts of the Archipelago, as at Napoli and Vourla, which must have excited their curiosity and surprise. "Every day," says one of the many authors who have noticed it, "they are to be seen in numerous flocks, passing up and down the Bosphorns with great rapidity. When they arrive either at the Black Sea or Sea of Marmora, they again wheel about, and return up the channel, and this course they continue, without a moment's intermission, the whole day. They are never seen to alight, either on land or water; they never for a moment deviate from their course, or slacken their speed; are never known to search for, or take any food; and no visible cause can be assigned for the extraordinary and restless instinct by which they are haunted. They fly very near the surface of the water; and if a boat meets a flock of them, they either rise a few feet over it, or it divides them like a wedge. Their flight is remarkably silent; and though so numerous and so close, the whirr of their wings is scarcely ever heard. They are so abundant in the Sea of Marmora that near twenty flocks have been counted.in the passage of a few miles. One reason why they have escaped the close attention of naturalists is, that no person is permitted to kill any bird upon the Bosphorus without incurring the displeasure of the Turks, who although very indifferent as to the lives of human beings, are extremely averse to take away the lives of animals." "**

Such is the singular account given by an intelligent traveller, to which we are enabled to add a few particulars, partly confirming and partly contradicting it. The bird is called by the Turks, Armidau, and has been, hitherto, erroneously considered a Kingfisher, $\uparrow$ from which species it is, however, far removed, proving, on examining a beautiful

* WALSH's Constantinople. See also Sketches in Greece.

t In Andreossi's work, Sur le Bosphore, it is termed Halcyon Voyageur. 
specimen in our possession, to be of that family of birds well known to sailors by the name of Mother Carey's chickens, and named the Cinereous Petrel (Procellaria cinerea.)* Agreeably to the habits of the Petrel tribe, this species is rarely seen to settle, though it does sometimes repose for a few moments on the waves, or alight when attracted by food,an officer of H.M.S. "Actæon" having actually caught one which seized his bait hung over the stern, at the extremity of a long line. A couple more were taken in a still more singular manner. Two flocks flying with their usual rapidity, in opposite directions, did not divide, but came in contact, immediately above a boat belonging to the same ship, with such violence, that a brace fell senseless into the boat. An additional reason for the respect in which they are held by the Turks is, that, in consequence probably of their restless life, they are supposed to be bodies animated by condemned souls, thus doomed for ever to frequent the scenes of their former existence.

From this superstition, in addition to the prevailing opinion that they are Halcyons or Kingfishers, our classical readers may be reminded of the fable of Ceyx and Halcyone.

Percutiensque levem modò natis aëra pennis, Stringebat summas ales miserabilis undas.

* * * * * * *

Hos aliquis senior circum freta lata volantes Spectat.

Ovid, Metam., b. xi. 731.

We cannot quit the subject of the flight of birds, without entering a little more at large upon one so closely connected with it as migration, to which we have already briefly alluded; for certainly, there is no instinct which seems to act upon them more forcibly, or which, after all, is so deeply involved in mystery.

* It is so closely allied to our Shearwater, that it might easily be mistaken for it. 
A careless observer will probably urge that there is no difficulty in accounting for the periodical journeys and voyages of birds. He will say that it is for the sake of food, no longer to be found in the particular spot in which the bird has been dwelling for a few previous weeks or months; or, that it is for the purpose of breeding in more favoured situations, or for some other less ostensible cause. But none of these reasons will hold good when closely examined. Is it for the sake of rearing its young that the Woodcock leaves us early in the spring for the marshes or heaths of Norway, when England and Scotland, even now, might provide spots as solitary and appropriate as the most timid bird could desire? Is it to feed on our comparatively scanty supply of gnats and midges, and other small insects of the air, that a certain number of the Swallow tribes tarry in Britain during the summer season, when Sweden and Norway could provide, in tenfold quantities, insects of this sort for every Swallow, and Martin, and Swift in Europe? When the Redwing and Fieldfare quit this country, it often abounds with that food which they prefer to any other, and at the time of their departure they are in the finest condition. Again, the younger birds, in many cases, do not depart at the same time; and when they do, it has been ascertained that they frequently do not go so far as the old ones. Other birds, again, which in some places are constantly to be found, will in others disappear for a certain time, and then return without any discoverable cause. Thus, the Kingfisher, which in the northern part of England may be seen all the year round, on some parts of the southern coasts only makes its appearance in October in considerable numbers, and as regularly departs in the following spring. Few would suspect our constant and lively companions, the Jays and Chaffinches, to be at times travellers, but so it is ; there is proof of the fact.

Some gentlemen near Tunstall, in Suffolk, who were out shooting, about five miles from the sea, observed an extraordinary flight of Jays passing in a single line from seaward towards the interior. The line extended further than the eye could reach, and must have consisted of some thousands ; there 
could be no doubt of their being Jays, as several were killed as they passed. But the noise of the guns did not occasion the rest to deviate from their line of flight: these birds, to all appearance, were then coming from the Continent. We have before noticed the occasional wandering tendency of that steadiest of all birds, the barn-door Goose; in fact, all birds seem, either at certain seasons, or under certain circumstances, to be seized with travelling propensities which they cannot resist. If any of our regularly migratory birds are kept in an aviary or cage, when the usual time arrives for the departure of the rest of their species, these prisoners, without having any communication with their companions, will nevertheless manifest great uneasiness, and often die if detained. We have seen this repeatedly in the Redstart and Flycatcher, which, though carefully supplied with the same food on which they have thriven for weeks before, and been quiet and apparently satisfied with their lot, will, early in September, begin to show great impatience, flying about and striking against the bars of the aviary, and usually dying after a few days spent in ineffectual endeavours to escape.

This year (1837) an instance came under our observation, rather at variance with what has been stated, in the case of a Nightingale, reared from the nest in the spring of 1835 . It soon became tame, and was kept in a cage till May, 1837, singing always in the winter from Christmas till April, and feeding readily upon minced pieces of meat and meal-worms, and showing no symptoms of impatience at the usual period of migration. It was silent the rest of the year. Last May it was permitted to go out of its cage, which was hung up, open, at the door of the offices. At first it returned regularly in the evening to its cage, and was taken into the pantry, and released again next morning. As the season advanced, it sometimes stayed out all night, in the shrubberies and pleasuregrounds, but if called by any of the servants, whose voice it knew, would return, and feed out of their hand. For a day or two, towards the close of summer, it seemed rather uneasy, getting into the coal-hole and cellar; but this soon wore off. As the evenings got cool, in the autumn, it returned again to 
its cage before nightfall, and was taken as usual into the house. As the season still farther advanced, it was to be permanently housed, and was expected to sing again at Christmas.

Other facts deserve attention, proving that mere climate is by no means, in all cases, the cause of these periodical visits. Thus, some birds will, on the introduction of a new system of cultivation, make their appearance in countries where they were never seen before. The Crossbill (Loxia curvirostra) has followed the apple to England. Glenco, in the Highlands of Scotland, never saw the Partridge till its farmers of late yearsintroduced corn into theirlands. The Sparrow again extended its range with the tillage of the soil. Thus, during the last century it has spread gradually over Asiatic Russia, towards the north and east, always following the progress of cultivation. It made its

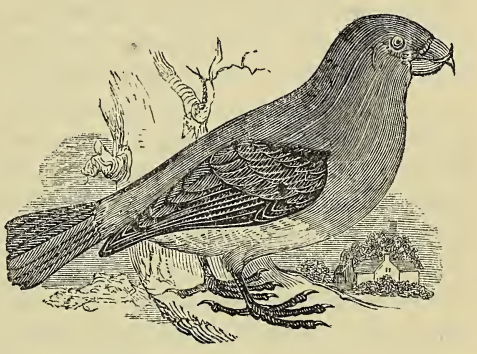

Cross-Bill first appearance on the Irtisch, in Tobolsk, soon after the Russians had ploughed the land. It came, in 1735, up the Obi to Beresow, and four years afterwards to Naryn, about fifteen degrees of longitude farther east. In 1710, it had been seen in the higher parts of the course of the Lena, in the government of Irkutzk. In all these places it is now common, but it is not yet found in the uncultivated regions of Kamtschatka.* From certain entries in the Hunstanton Household Book, from 1519 to 1578, in which Sparrows (or, as they are there written, Spows, or Sparrhouse) are frequently recorded, it would appear that these birds took their place in the larders 
of the nobility as delicacies with other game, from which we may infer that they were at that time as rare in Norfolk as they still are in some parts of Russia, owing probably to the same cause, viz., the limited state of tillage and growth of corn.*

The Rice-Buntings, natives of Cuba, after the planting of rice in the Carolinas, annually quit the island in myriads, and flying over wide seas, land, to partake of a harvest introduced there from distant India. It is, however, only the female Ricebird that migrates ; for of the numbers visiting Carolina, it is said not a single male is ever found.

The foregoing instances, while they assure us (if assurance was necessary) that birds at wonted times change their habitations, still add to, rather than remove, the difficulties as to the real causes. But if of these we must for the present remain in ignorance, we have enough left in the actual facts of migration to call forth all our wonder, in considering the regularity, order, and discipline with which these unaccountable journeys are conducted, and the unknown compass placed within the bosoms of these airy travellers, enabling them to go, and return from, points thousands of miles apart, with as much certainty as the sailor steers his ship across the wide ocean by his skill in navigation, and that mysterious needle ever pointing to the north. Neither is this instinct confined to birds; it has been observed in turtles, which cross the ocean from the Bay of Honduras to the Cayman Isles, near Jamaica, a distance of 450 miles, without the aid of chart or compass, and with an accuracy superior to human skill; for it is affirmed, that vessels which have lost their reckoning in hazy weather, have steered entirely by the noise of the turtles in swimming. The object of their voyage, as in the case of birds, is for the purpose of laying their eggs on a spot peculiarly favourable.

It is, indeed, this instinctive power and stimulus which is the real point to excite our astonishment in the migration of

* See Household and Privy-purse Accounts of the L'Estranges of Hunstanton, communicated to the Society of Antiquaries by Daniel Gurney, Esq., F.S.A. 
birds; for when we take into consideration what has been said of their rapid flight, which would enable an Eagle in nine days, allowing him sixteen or seventeen hours for repose, to go round the world, there is nothing so very extraordinary in the journey of a Swallow from the shores of England to those of Sierra Leone in Africa, where a person, who resided there for seven years, constantly observed our three species, many of them remaining all the year, but their numbers much diminished from spring to autumn, when they were supposed to be absent, spending their summer in Europe.

On looking at the map, it will be seen that without further peril by sea than simply crossing the short space of the British Channel and Straits of Gibraltar, (either of which, at their narrowest parts, even a barn-fed Sparrow might easily do in an hour or two,) a bird might make almost a direct course to Sierra Leone, a distance of about 3000 miles, which space a Swallow would without effort traverse in three days, including time for roosting at night, and which even a Sparrow could perform at leisure, and without the least fatigue, in less than a fortnight. The above calculation is made on the supposition that the airy travellers keep over the land as much as possible: but if the straightest course were preferred, they might, by crossing the Bay of Biscay, perform it in less time. And that Swallows do, at least occasionally, take this line we know, from the very curious fact of one settling on the rigging, and caught on board a vessel bound to the French port of Havre, beneath the wing of which was found a very small slip of paper, on which was written in French, " The ship Armide, Captain Borgnet, going to Martinique, latitude $48^{\circ} 33^{\prime}$ north, longitude $10^{\circ} 39^{\prime}$ west." On reference to the map, it will be seen that this point is nearly in a straight line, drawn from the Land's End in England to the western coast of Africa.

It might be supposed, taking place as these journeys do with Swallows twice in the year, that frequent opportunities would occur of seeing their arrival or departure in flocks, but, with the exception of straggling parties of ten or twelve at a time, few have been fortunate enough to see them either come 
or go; whence it has been inferred, that they pursue their course at night. And that this is the case we can give tolerably good evidence from actual observation. Happening to be at Fecamp, a seaport at the foot of the highest cliffs in France, immediately opposite the English coast, on the 14th of September, 1833, we had ascended the heights to visit the ruins of an old chapel before sunrise. On looking towards the sea, the first object presenting itself was a flight of about one hundred Swallows, evidently just making the land, and whirling in a hurried manner over the upper ledge of the precipice. On the supposition that these birds had quitted the British shores about an hour before dawn, they would naturally have arrived at the point where they were thus seen landing : others probably had come in before; as in the course of the morning we saw, on the roof of a large building in the town, which was exposed to the full force of the sun's rays, an infinitely greater number of Swallows collected together than we had observed throughout the whole of the season.

That this is the practice of many other birds indeed is well known, particularly of those which are in the habit of feeding at night. In the fen countries, for instance, which, on account of their ditches and marshes, are favourite haunts for waterbirds, in almost every still night, more especially about the time of their usual journeys either to or from the fens, the whistling sound of thousands of wings, or the shrill notes of call by which these vast flights are kept together in the darkness of night, may be heard overhead.

Birds too, in their longer flights, no doubt avail themselves of different currents in the air ; for we know that often, when the lower stream of air is blowing from the west, another stream far above may be blowing from another direction; this may be frequently seen by the motion of the upper clouds moving in contrary directions from those at a lower level. Those most beautiful of all the feathered race, the Birds of Paradise, (not only distinguished by their brilliant plumage, but from their being singularly decorated with tufts or trains of light, loose, fringy feathers, which render it difficult for them to fly, excepting against the wind, which 
smooths them down,) are chiefly natives of a few islands in the Indian Ocean, and when sailing between these islands, flocks of them are often seen crossing, and always flying against the wind: but as in that climate sudden squalls often occur from an opposite quarter, the birds, when caught by them, are observed immediately to dart upwards till they ascend beyond the reach of the gale, and are then seen to pursue their course as before.

One other very remarkable fact connected with these long journeys undertaken by birds over seas and lands, is that they are gifted with some secret power, enabling them not only to find their way to and from the distant countries they visit, but actually guiding them to the very same place from whence they came, and the very same spots for building their nests. This has been proved by marking the claws of Swallows, which were in the habit of building in sheds or outhouses, where they could easily be retaken on their return in the spring, and examined. An instance came under our own observation, of a pair of Swallows returning to build for three years in a small closet in a school-house, entering by a broken pane in the casement, and forming their nest in a corner above the window; and as they were never disturbed, the female would remain sitting, and the male fly in and out in our presence. But though several broods were hatched, the old birds allowed no intruders, and not a single young bird was ever seen to return to the place of its birth after it had once quitted the nest.

Another instance of confidence placed in man by these little birds, when unmolested, occurred at a nobleman's house in Scotland. A pair of Swallows, a few years ago, built their nest upon the top bar of a clothes-screen in the porter's lodge, which was hung up against the wall; the young ones were hatched and flew away; the nest was suffered to remain; and upon the first appearance of Swallows, the year after, a male bird again entered the apartment, and took a survey of the premises. Having satisfied himself, he went off, but soon returned with a companion, which at first appeared very shy and timid, but in a short time acquired as much assurance 
as its mate. They both forthwith set about building a new nest on a small ledge, which had been prepared for them, as near as possible to the place where that on the clothes screen had been built, and which had been destroyed; as, while it remained, the screen was of course useless to the family.

In this nest three broods were reared as before, notwithstanding the almost constant presence of the porter and his wife, who lived and slept in the room. In the spring of the third year, the male again made his appearance with another mate, evidently much younger than its predecessor. The old nest on the ledge was examined, but for some reason the birds were not satisfied with its situation, and as the clothes-screen was hanging in the same situation it had occupied the first year, after a couple of days' hesitation they constructed a new nest on the favourite screen, and the business of hatching and rearing the young ones went regularly on. The male bird, indeed, seemed to have acquired increased confidence, never manifesting alarm at the number of visitors which so curious a circumstance attracted to the lodge; whereas the female continued very shy, and was on the alert, and ready to take wing when anybody approached too near. It was remarked in this, as in the preceding case, that no young birds, from the moment of their taking wing, ever returned to the house, either for the purpose of forming nests of their own in so safe and comfortable an asylum, or disputing possession with the old ones for the tenement in which they were born and bred. But, besides these regular migratory birds, others seem to possess a similar instinctive power; for instance, a Robin which frequented a greenhouse was caught, and a piece of silk being tied round its leg, it was put into a bag, and carried to a distance of some miles, and then turned loose. In three days it was found in the greenhouse.

One other peculiarity in the periodical visits of birds to their breeding stations, is the punctuality of their arrival. There is seldom the difference of a week, and frequently not that of a day, in the time of the appearance of some particular species. Of course we cannot be accurate in most cases, from not being able to fix on the exact moment of a bird's 
arrival; but in some instances, circumstances afford us the means of speaking more positively. Thus, on a well-known rocky island, called the South Stack, near Holyhead, the Lighthouse keepers assured us that the Gulls, which seldom visit the island for two-thirds of the year, arrive on the same night, namely, February 10th, for the purpose of breeding. They are regularly warned of the arrival of their summer guests, about midnight, by a great noise, as it were a mutual greeting and cheering; and from that moment they remain till their broods are reared, and the business for which they resorted thither entirely at an end.

The light-keepers spoke with pleasure of the arrival of the birds, saying that they looked to their return as that of so many old acquaintances after a long absence, announcing the spring to be at hand, and the winter to be over and gone.

In alluding to light-keepers, we may mention a curious circumstance connected with birds of passage, namely, that during their migrations in the night, they frequently fly with such force against the strong plate-glass reflectors of lighthouses, as to be killed on the spot. Instances of this have occurred at Flamborough Head, where, we have been informed, that Ducks, Woodcocks, Starlings, Fieldfares, Redwings, and in short every species of the migratory tribes, have fallen victims to the attractive but unintentional decoy. The astonishing number of seventeen dozen of Starlings were, at the latter end of 1836, picked up near the above-mentioned light-house, having been killed, maimed, or stupified by flying against the dome of that brilliant light.

It has been observed that the time of departure of certain birds is by no means so exact as that of their arrival; which may be accounted for by a natural disinclination on the part of the old ones to desert the nests of young ones still requiring their care. But even this most powerful of all instincts, the attachment of a parent to its young, is not in all cases strong enough to conquer the still stronger impulse for migration; for Swallows will actually desert their nests, and leave helpless little ones to perish by hunger, rather than remain long 
after their companions. A pair of Martins, which had deserted their family in the autumn, on returning in the spring, were observed to draw out the dead bodies of three nearly full-fledged nestlings. Another pair acted in a different manner; after vainly endeavouring to drag out the bodies, which had most probably formed a dried mass with the wool and feathers in the interior, they entirely closed up the opening of the nest with clay, and leaving them thus entombed, proceeded to build another nursery.

As much interest and amusement may be derived from watching and expecting the arrival and departure of our migratory birds, we annex a list of a few of the most common, with the earliest and latest dates which have come under our observation.

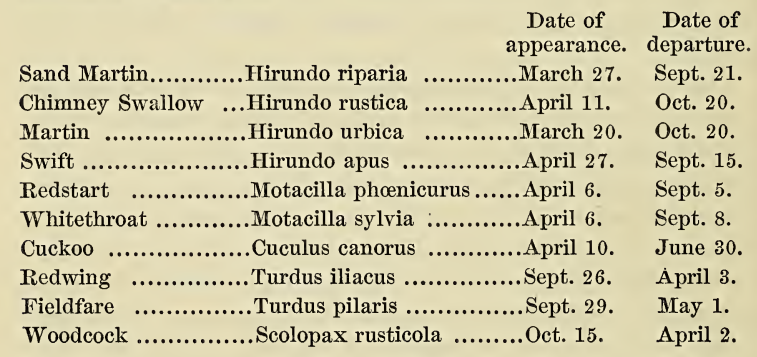

Having thus noticed, as extensively as our limits would allow, some of the most prominent external as well as internal peculiarities of birds, we shall now proceed to the consideration of the various species in detail, following pretty nearly the arrangement already given in the Tables of Classification, and inserting additional observations and anecdotes to illustrate those subjects on which we have already touched. 


\section{CHAPTER VI.}

Eagle and Hawk Tribe. 1-Wild Eagle; Tamed-Muscular Powers of-Carry off Children, Lambs, etc.-Somtimes Killed on the Wing by Weasels. - Battle between Cat and Eagle.How caught when Fishing.-Voracity of.-Nests.-Singular mode of Capturing their Prey.-Bird of Washington.-Eagle Traps.-Feathers of, Prized.

\section{Table II. Order I.-Rapacious Birds.}

\section{EAGLES AND HAWKS.}

WE have classed Eagles and Hawks together; for though not exactly similar in their form and habits of life, there is still a great resemblance; they are for the-most part wild, savage birds, and may be compared to the Lions, Tigers, and all that family of four-footed animals, preying upon others, and tearing them to pieces for their food.

The Eagle stands first and foremost amongst them, for though one or two of the Vulture tribe are a little larger, none can compare with the well-named King of Birds. Those who have only

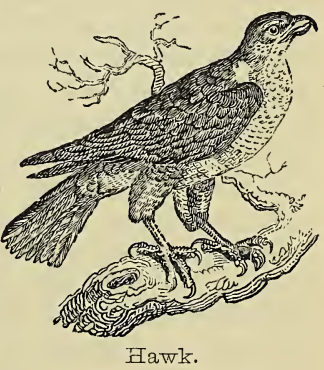
seen an Eagle in confinement, can form little idea of what he is in his natural state, amongst the rocks and mountains in which he takes up his abode-a situation in which we were once fortunate enough to be very near one of these noble birds. In climbing some high precipices in the volcanic district 
of Auvergne, in France, near a great waterfall which dashed downwards with a thundering noise, in the midst of the loud roar of waters, a short, shrill cry met our ear, coming, as it were, from the clouds. On looking in the direction from whence it came, we soon perceived a small dark speck moving steadily on towards us. It was a Golden Eagle, evidently coming from the plain countries below; on drawing nearer, we could see that his wings scarcely ever moved; he seemed to float or sail in mid-air, rather than fly; though now and then, indeed, they slowly flapped, as if to steady him. As he was approaching in a direct line, we hid ourselves behind a rock, and watched his motions through a telescope. When first seen he could not have been at a less distance than a mile, but in less than a minute he was within gun-shot; and after looking round once or twice, he darted down his legs, slightly quivered, and alighted on a rock within a few yards. For a moment he gazed about with his sharp bright. eyes, as if to assure himself that all was safe; he then, for a few moments more, nestled his head beneath one of his expanded wings, and appeared to plume himself. Having done this, he stretched out his neck, and looked keenly and wistfully towards the quarter of the heavens from whence he came, and uttered a few rapid screams; then stamping with his feet, we saw him protrude his long-hooked talons, at the same time snapping his hooked beak with a sharp jerking noise, like the crack of a whip. There he remained for about ten minutes, manifesting great restlessness, not a single instant quiet; when suddenly he seemed to hear or see something, and immediately rising from the rock on which he stood, launched himself into the air, and floated away as before, uttering the same shrill cry; and looking round, we beheld the cause of his emotion; he had seen his mate approaching. He rose to meet her, and after soaring in a circle a few times, they went away, and were soon invisible to the naked eye.

This was the large Golden Eagle, a species occasionally found in England and Scotland, but more frequently in 
Ireland, where, notwithstanding its wild and apparently untameable character, one was taken even after it had attained maturity. It soon became domesticated, and firmly attached to the place, where it continued till it died, though perfectly at liberty, it never having been chained, or put under any restraint. Its wings had, indeed, been cut when first brought thither, but they

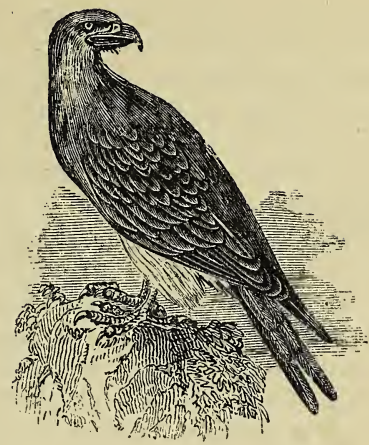

Golden Eagle. were allowed to grow again; and the noble bird, on recovering the use of them, would repeatedly soar away, and absent himself for a fortnight or three weeks. It became very much attached to those who were in the habit of feeding or caressing it. On its first arrival it had been placed in a garden, situated on a slope overhanging a lake; a house or shed had also been built for its accommodation; but it generally preferred a perch of its own finding out, in the branch of a large apple tree, which grew in nearly a horizontal position from the stem. Its food was chiefly crows, which were shot for it, sometimes, however, it attempted to procure them for itself, but never successfully, as their agility in turning short and rapidly enabled them to elude its superior strength of wing; latterly, therefore, it contented itself with eyeing them wistfully as they flew or perched securely over its head. It was never suspected of committing any havoc among the sheep or lambs in the adjoining fields; but now and then, when from some accident it had not been regularly supplied with its accustomed food, it would seize upon and kill young pigs. Children, who constantly met it as it walked about the garden, were never molested; but on one occasion it attacked its master with some violence, in consequence, as it was supposed, 
of his having neglected to bring it some bread or other food it was accustomed to receive from his hand. At length, after having lived about ten or twelve years in this way, it was killed by a powerful and ferocious mastiff. Nobody saw the battle, but it must have been long and bravely contested, for the dog, though victorious, was so severely wounded that it died almost immediately afterwards.

The weight of a large Eagle is abont twelve pounds, though some (as the Bird of Washington) weigh fourteen pounds and a half, rather more than an average-sized Goose. But in order to transport this weight with their extraordinary occasional speed of 140 miles or more per hour, which it has been proved these birds can accomplish, there is a prodigious spread of wing, from seven to upwards of ten feet from tip to tip, in addition to a muscular power almost incredible.

An Eagle has been known to strike and kill its prey with a stroke of its pinions before it touched them with its claws. Many people have, however, doubted whether they have sufficient strength to carry off children and lambs; and if such belief rested only on one or two instances, it might be reasonably questioned; but so many well authenticated cases have been mentioned as having occurred in places widely distant, that we do not see how the fact can be denied.

Bishop Heber, in his travels in India, passed through a mountainous district where sad complaints were made of their carrying off infant children; and we remember some years ago, in the Alps, that on a high-pointed pinnacle of inaccessible rock, jutting out from a peak of snow near the summit of the Jung Frau, one of the highest of the Alpine range of mountains, there might be seen the tattered remains of the clothing of a poor child, who had been carried up by a Læmmergeyer, or Bearded. Vulture, from a valley below, in spite of the shouts of some peasants who saw the bird pounce upon its prize. It is called the Bearded Vulture from the tuft of bristles on each cheek, as represented in the figure at p. 27. 
A more fortunate fate awaited a child in the Isle of Skye, in Scotland, where a woman having left it in the field for a short time, an Eagle carried it off in his talons across a lake, and there deposited his burden. Some people herding sheep perceived it, and hearing the infant cry, hurried to the spot and found it uninjured. The name of the child was Niel, but he was afterwards distinguished and called by a Gaelic word, signifying Eagle. In Sweden a deplorable circumstance occurred to the mother of a child; she was working in the folds, and had laid her infant on the ground, at a little distance; soon after an Eagle darted down, and carried it off. For a considerable time the wretched woman heard the poor child screaming in the air, but there was no help. She saw it no more; in a little time she lost her reason, and is, we believe, still living, confined in the lunatic asylum of the town near which it happened.

An instance, it is said, occurred in the spring of 1847 , of an Eagle carrying off a boy of ten years of age, in the Commune of Hery sur Alby, in the Canton of Geneva. The little fellow had just riffed a nest, from which he had taken the young Eaglets, thereby probably irritating the old birds, and more powerfully exciting them; for he was immediately seized by one of them, and deposited on the summit of a rock about 600 yards above the spot from which he was raised; and luckily before any further violence was offered, he was rescued by some shepherds who were engaged at no great distance. He had sustained no other injury than a rather severe laceration from the Eagle's claws.

On Tirst Holm, one of the Feroe Islands, situated between the north of Scotland and Iceland, a similar fact occurred; an Eagle caught up an infant lying at a little distance from its mother, and carried it to its nest, situated on a point of high rock, so steep that the boldest bird-catchers had never ventured to attempt to climb it; the mother, however, ascended and reached the nest, but alas! too late: the child was dead, and its eyes torn out. But the most striking story 


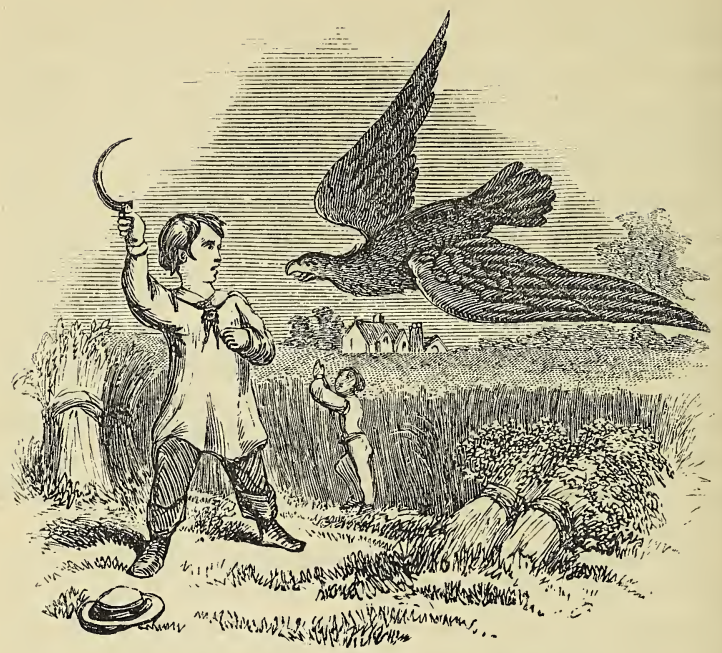

Contest between a Boy and an Eaǵle

we have met with, is the brave behaviour of a little boy in America : it occurred in the parish of St. Ambrose, near New York. Two boys, the one seven and the other five years old, were amusing themselves by trying to reap, while their parents were at dinner. A large Eagle soon came sailing over them, and with a sudden swoop attempted to seize the eldest, but luckily missed him. The bird, not at all dismayed, alighted at a short distance, and in a few moments repeated his attempt. This bold little fellow, however, gallantly defended himself with his sickle, which he fortunately held in his hand, and when the bird rushed upon him, resolutely struck at it. The sickle entered under the left wing, and the blow having been given strongly, went through the ribs, and piercing the liver, proved fatal. $\mathrm{On}$. opening the bird's stomach, it was found entirely empty, 
which may explain in some degree the cause of so unusual an attack. The brave little boy did not receive a scratch, though there can be little doubt that had the bird not been weakened by hunger, a blow or two from its sharp strong beak would have penetrated through the skull into the brain, and caused instant death.

Eagles of this particular sort are very common in that part of the country, and are often known to carry off a Turkey, or even a Goose, but this was the first instance of their attacking children, though in New South Wales a celebrated navigator, Captain Flinders, met with something of the same sort. He was walking with some of his officers when a large Eagle, with a fierce aspect and outspread wing, was seen bounding towards them; but stopping short at about twenty yards off, he flew up into a tree. Soon after, another bird of the same kind discovered himself, and flying above their heads, made a sudden pounce downwards, but checked himself before he actually" touched them. Captain Flinders supposed that they took him and his party for kangaroos, which, when sitting up on their hind-legs, according to their usual habit, are about the height and form of a man. On these animals the Eagles were observed to feed, having been seen watching quietly in the trees till a kangaroo made its appearance, when down they flew, and tore it in pieces in an instant. Probably this was the truth; for the country was very desolate, and, as far as they could judge, uninhabited, so that the Eagles might never have seen men before.

The well-known crest of the Eagle and Child, borne by the Stanley family, is supposed to have been founded upon a tradition of one of their ancestors, when a child, having been carried off by an Eagle; and a story is told in a very old book on English History, which, whether true or not in all its particulars, proves at least the prevailing belief, that Eagles occasionally flew away with children; indeed, there was an ancient Act of Parliament " anent the slaying of the Erne," that is, concerning the slaying of the Erne, the name of a particulpr species of Eagle, in which, on account of its 
being " a terror to farmers, from fowls to children," a reward was granted to the person who should destroy a nest or a bird. The story alluded to from the above-mentioned old book* is as follows : "Alfred, king of the West Saxons, went out one day a hunting, and passing by a certain wood heard, as he supposed, the cry of an infant from the top of a tree, and forthwith diligently inquiring of the huntsmen what that doleful sound could be, commanded one of them to climb the tree, when in the top of it was found an Eagle's nest, and lo! therein, a pretty sweet-faced infant, wrapped up in a purple mantle, and upon each arm a bracelet of gold, a clear sign that he was born of noble parents. Whereupon the king took charge of him, and caused him to be baptized; and, because he was found in a nest, he gave him the name of Nestingum, and, in after time, having nobly educated him, he advanced him to the dignity of an earl."

In all the above instances of carrying away children, it does not appear that the Eagles were able to fly with them to any great distance; but in Ireland a large Eagle was seen to alight and take up a lamb, and carry it away in a straight direction towards the high range of the Morne mountains. The men who saw it pursued and kept it in view, when at length, having in vain attempted to soar upwards to the summit of one of the highest mountains, it dropt its burden at the edge of a wood, quite unhurt. The distance it had flown was judged to be upwards of two miles.

They frequently attack smaller animals, but often suffer severely in consequence, from the struggles of the prisoners to escape, and several instances have occurred of their being killed by weasels and stoats, which they had incautiously pounced upon. One was related by the gamekeeper of a Scotch nobleman, who, when out on the moors, observed an Eagle rise from the ground with something it had seized as its prey. For a time it flew away steadily, when suddenly it became evidently much agitated, and after irregularly fluttering for a short time, spired upwards in a 
straight line to a vast height, and then ceasing to flap its wings, fell headlong to the ground. Struck with so unaccountable an occurrence, the keeper made what haste he could to the spot, and found the Eagle quite dead, and a wounded stoat struggling by its side. On examining the body of the Eagle, he soon discovered the cause of its fall. The stoat when in the air had contrived, according to its usual custom in attacking rabbits, hares, rats, and other small animals, to open an artery or vein, and kept firm hold of the wound it had inflicted.

Another such case occurred to a gentleman in America; he, like the gamekeeper, saw an Eagle seize its prey and fly off, and soon afterwards rise spirally to an immense height till nearly out of sight, and then fall to the earth like a stone. As he approached, he saw a weasel running away from the body, and, on further examination, found that the little animal had got under the Eagle's wing, and sucked the blood until the bird fell from exhaustion. Another case is on record, of one of these birds attacking a cat, when a battle actually took place in the air, and lasted some minutes. The cat, aware, it may be supposed, of her danger, clung with her claws to the Eagle, and prevented him from letting her drop. At length, tired of struggling, and impeded by the clinging of the cat, he descended to the earth, where the fight still continued; and in the end some lookers-on captured both the combatants. A cat, however, if once within the fair grasp of an Eagle on firm ground, has but a poor chance. One, tempted probably by some pieces of raw meat, was seen to make its way through the lattice-work of a large hut, in which a fine Golden Eagle had been long kept. In an instant, the bird was observed to pounce from its perch, and seize poor puss so rudely and suddenly with its claw, that, notwithstanding the vivacious nature of the cat species, she was killed in a moment, without an appearance of struggling, or even quivering of her limbs. The entire claw seemed to have been plunged in a moment into the tenderest part of her body. Having secured his victim beyond the power of escape, he remounted his perch to pause and look 
about him, and then, again descending, proceeded to tear the flesh from the bones, and devour the carcase at leisure.

But, besides warm-blooded animals and birds, most, if not all, the Eagle tribe will readily feed on fish; some sorts indeed, prefer them, and live in the neighbourhood of large lakes on the sea-shore.

Some of these birds are gifted with such extraordinary clearness of sight, that from a great height in the air, they will distinguish fish swimming near the surface, and, shooting down with the speed and straightness of an arrow's course, will plunge into the water, and seize them with their talons. Often, however, they have no reason to boast of their success, for, when carrying off their prize, a larger Eagle, generally on the look-out, gives chase, and forces them to drop the fish, which the other catches before it reaches the water. This larger bird, however, is himself sometimes made prisoner by the singular mode he practises of providing for his meals. The following is not the only instance with which we are acquainted, but as it is sanctioned by the authority of a respectable Scotch clergyman, we give it at full length, in preference to others we have met with. The anecdote

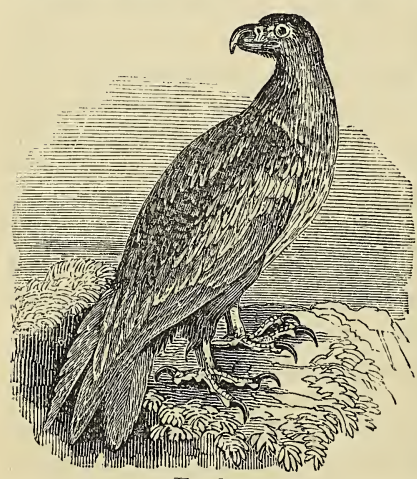

Eagle. is told of the Erne, or White-headed Eagle. A halibut, a large flat-fish, resembling a turbot, reposing on or near the surface of the water, was perceived by an Erne, which immediately pounceddown and struck his talons into the fish with all his force. Should the halibut be too strong, the Eagle, it is said, is sometimes, but rarely, drowned in the struggle. In this case, however, 'as more freqently happens, he overcame the fish; on which he re- 
mained as if floating on a raft, and then spreading out his wide wings, he made use of them as sails, and was driven by the wind towards the shore. On landing, their first object is to disengage their claws by eating the flesh in which they are buried, but before the Erne, of which we are speaking, could effect this, some lookers-on rushed in, and took him alive.

The Vulture, too, floats on a prey of a very different description. In the rivers of the East, says a traveller,* one is constantly shocked with the sight of a floating corpse,

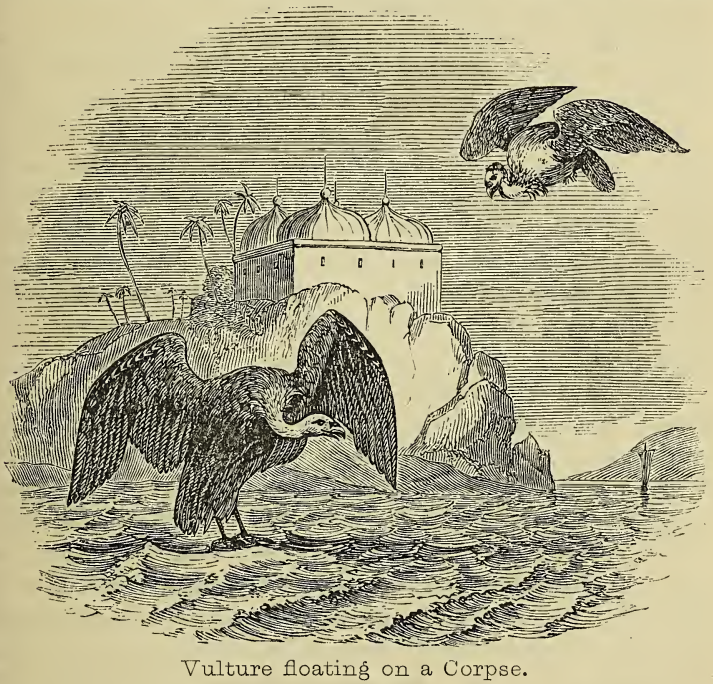

with a vulture perched upon it, and expanding its wings to cause it to land, that it may devour its horrid meal in leisure.

From what has been said, it will be readily believed that they are most voracious in their appetites. These large fisheaters have been known to consume a bucket-full a day; and,

* Transatlantic Sletches, vol. ii. 
as if aware at the same time of the uncertainty of always insuring a supply, particularly when they have, in addition to their own wants, their young to provide for, they are in the habit of collecting an over-abundance on the high rocks where their nests are situated, so as to have an ample stock in hand. And so well aware are the North American Indians of these stores, that an Eagle's nest is familiarly called an Indian's larder; from which the wild hunters can readily supply themselves, at least during the breeding and rearing season, from May to September, with a plentiful store of hares, ducks, and geese, besides fish.*

In England, though large Eagles are now very rare, naturalists have met with similar instances. Mr. Willoughby, an excellent authority, mentions a nest which he saw in the woodlands, near the river Derwent, in the Peak of Derbyshire, about 150 years ago. He described it as about two yards square, formed of great sticks, resting one end on the ledge of a rock, and the other on two birch-trees, upon which was a layer of rushes, and over them a layer of heath, and upon the heath rushes again, upon which lay one young one, and an addle egg, and by them a lamb and a hare, and three heath-poults.

But the most particular and curions account of one of these Eagle-nest larders, is related by a gentleman who was visiting at a friend's house in Scotland, near which he went to see a nest, which for several summers two Eagles had occupied; it was upon a rock or a hill. There was a stone within a few yards of it, about six feet long, and nearly as broad, and upon this stone almost constantly, but always when they had young, the gentleman and his servants found a number of grouse, partridges, hares, rabbits, ducks, snipes, ptarmigans, rats, mice, \&c., and sometimes kids, fawns, and lambs. When the young Eagles were able to hop the length of this stone, to which there was a narrow road hanging over a dreadful precipice, the Eagles, he learned, often brought hares and rabbits alive, and placing them before their young, 
taught them to kill and tear them to pieces, as a cat brings live mice to her kittens, and teaches them to kill them. Sometimes, it seems, hares, rabbits, rats, \&c., not being sufficiently weakened by wounds, got off from the young ones while they were amusing themselves with them; and one day a rabbit escaped into a hole, where the old eagle could not find it. The parent bird another day brought to her young ones the cub of a fox, which, after it had fought well, and desperately bitten the young ones, attempted to make its escape up the hill, and would, in all probability, have accomplished it, had not the shepherd, who was watching the motion of the Eagles with a view to shoot them, which they do with bullets (Swan-shot not being able to penetrate their feathers), prevented it.

As the Eagles kept what might be called such an excellent storehouse, whenever visitors came unexpectedly, the owner said he was in the frequent habit of sending his servants to see what his neighbours the birds had to spare; and that they scarcely ever returned without some dainty dishes for his table, game of all kinds being rather the better than the worse for being kept a certain time. When the gentleman or his servants carried off things from the shelf or table near the nest, (for it was a work of great hazard to approach the nest itself,) the Eagles lost no time in bringing another supply; but when they did not take them away, the old ones loitered about, and were very inactive, amusing themselves with their young, till the stock of food had nearly come to an end.

While the hen Eagle was hatching, the table or shelf on the rock was generally kept well furnished for her use : and when she was in that state, or the Eaglets very young, the male-bird generally tore a wing from the fowls for her, or a leg from the animals captured. These Eagles, as is generally the case with birds that are not gregarious, that is, which do not live together, or assemble in flocks, were faithful to each other, and would not permit even their young, after they had grown up, to build a nest, or live near them, but drove them off to a considerable distance. This gentleman 
did not learn whether these Eagles were in the habit of sparing lambs, kids, \&c., in their own immediate neighbourhood, which it has been said they do in some places. Thus, in the Shiant Islands, a cluster of wild and retired rocks, situated amongst the Hebrides, or western islands of Scotland, the natives assert that the Eagles, which are, or rather were, very numerous there, particularly in the breeding season, scrupulously abstained from providing their young ones with animals belonging to the island in which they had taken up their abode, invariably transporting them from neighbouring islands, often some miles distant. Their mode of catching the mountain deer was by pouncing down and fixing their talons between the poor animal's horns, flapping at the same time with their powerful wings, which so terrified the deer, that they lost all command over themselves, and setting off at full speed, usually tumbled down some rock, where they were either killed, or so disabled as to become an easy prey to the Eagles.

Probably this instinctive mode of catching running animals is common to all large birds of prey, and may have led to the introduction of it in some parts of India, where the natives are very fond of hawking, and train their hunting Hawks so well, that one particular Falcon, called the Chirk, is taught to strike an antelope, a beautiful species of small deer, and retard its speed, by fastening on its head, till the greyhounds come up.

But a still more extraordinary mode, by which the Eagle contrives to kill even oxen, is mentioned as often witnessed in Heligoland, a small and now deserted rocky island in the German Ocean, off the coast of Denmark. Persons resident there state that it first flies away to the sea, and then plunging into the waves, returns to land, where it rolls itself on the shore till its wings are quite covered with sand. It then rises again, and hovers over its victim. When close to it, it shakes its wings, and thus scatters the gravel and sand into the eyes of the ox, while it adds to the fright of the animal by blows with its powerful wings. The blinded animal becomes stupified, and runs about quite raving, and, at length, 
falls down wholly exhausted; or, like the deer in the Shiant Islands, dashes itself to death by falling over some cliff; when the Eagle mangles undisturbed the fruits of its victory.*

There is a remarkably fine Eagle in North America, called the great Sea Eagle, or Bird of Washington : it is very rare, confining itself usually to lonely situations, occasionally, however, following the hunters, to feed on the entrails of the animals they kill, when excluded by ice from its favourite water-haunts, where in open weather it dives for fish.

A naturalist, who was extremely anxious to meet with one, had long laboured in vain, when one day, as he was engaged in collecting cray-fish, near the Ohio, a large river in North America, he chanced to observe on the rocks, which at that place were nearly perpendicular, a quantity of white droppings, which led him to conclude that Owls resorted thither; but, having been assured by a more experienced companion, that they must have fallen from a nest of one of their long-lookedfor Birds of Washington, and that the old ones caught fish on the river, he determined to watch for them, and in high expectation seated himself, with his friend, about a hundred yards from the foot of the rock. For two long hours he waited with great impatience and curiosity, when the approach of the old Eagles was announced by loud hissings, which was soon perceived to be uttered by two young ones crawling from the extremity of their hole to receive a fine fish presented by the parent, as it held itself to the projecting rock, something after the manner of a House Swallow, its tail spread out, and its wings partly so. That they might not be observed, or frighten the birds away, they crouched down, and kept perfect silence, not whispering a single word. In a few minutes the other parent joined its mate : it also had brought a fish, but being not so bold, or more suspicious, before it ventured to alight, it glanced its quick and piercing eye around, and instantly catching sight of the spectators, dropped the prey, and with a loud shriek communicated its alarm to the other, which, loosening its hold, hovered over their heads, keeping up a sort of growling threatening cry of intimidation.

* Annals of Philosophy, vol. i. 
At the same moment, the young birds, as if aware of some danger, shrunk back, and buried themselves in the chink of the rock; and, as further waiting would have been unavailing, the observers went to the bottom of the precipice, and picked up the fish that had fallen; it proved to be a sort of large perch, weighing about five pounds and a half; the upper part of the head was broken in, and the back much torn by the talons of the Eagle. The sport being over, as they journeyed home, they agreed to return, and endeavour to procure, dead or alive, both the old and young birds.

Accordingly, on the third day following, they assembled with some additional hands, well provided with guns, and materials for ensuring success, and proceeded to post themselves, some at the foot and some at the top of the rock; but all in vain. The eagles had been beforehand, and proved too cunning for them. The young birds had disappeared, and they passed the whole day without seeing or hearing anything of either them or the old ones. It appeared from their observations, that the old ones had actually removed their young to fresh quarters, but as they did not seem sufficiently grown to use their wings, how they could accomplish such a removal was a mystery not to be solved.

Two years afterwards, the same person was fortunate enough to shoot one dead on the spot, as it sat upon a low tree, attracted, as was supposed, by the scent of some slaughtered hogs. The bird in this case seemed to be perfectly fearless, not only allowing the sportsman to approach within easy gunshot distance, but looking at him all the time with an undaunted eye.

Having had, since first seeing one of this species, other opportunities of observing their habits, he has given some very interesting details. In its flight it differs from another sort of Eagle for which it is often taken. When looking after fish in the water below, it makes very wide circles, and when it sees one, it falls gradually in a circuitous, spiral manner, as if with an intention of checking any retreating movement of its prey. When within a few yards, however, it darts down like a shot, and seldom misses its object. As it is so con- 
stantly exposed to the water, its feathers are provided with a greater portion of that oily substance common to many birds, and they shine as if covered with a thin coating of clear gum. An anecdote is related by Dr. Richardson,* who accompanied that enterprising traveller, Sir John Franklin, as current on the plains of Saskatchewan in North America, of a half-bred Indian, who was vaunting his prowess before a band of his countrymen, and wishing to impress them with a belief of his supernatural power. In the midst of his harangue, an Eagle was observed suspended as it were in the air directly over his head; upon which, pointing aloft with his dagger, which glistened brightly in the sun, he called upon the royal bird to come down. To his own amazement, no less than to the consternation of the surrounding Indians, the Eagle seemed to obey the charm, for instantly shooting down with the velocity of an arrow, it impaled itself on the point of his weapon.

Fierce and savage as these birds usually are, they notwithstanding appear in some instances to lay aside these habits, and manifest a kind and protecting disposition, particularly towards little birds. Thus it has been observed that an African Eagle (Falco halbescens), though it will suffer no bird of any size to come near its haunt, will nevertheless permit small ones not only to reside near it, but even to perch upon its nest without offering them any violence, and still more, will protect them against the attack of other rapacious birds which might be disposed to devour them. The Osprey, or Fishing Eagle of North America (Falco haliatus), allows the Grakle, or New England Jackdaw, as it is termed, to take the same liberty, these birds building their nests among the loose sticks forming the base of the Eagle's nest, apparently neither dreading nor inconvenienced by the bird of prey which rears its young above them. $\dagger$

However cunning and sagacious we have seen them to be in their modes of providing for their own wants, and entrapping other birds and animals, they are occasionally overreached

* Pichardoson's Fauna Americana.

† KING's Narrative, vol. ii., p. 217. 
by well-contrived plans, and at times have been made prisoners by animals not surpassing them in size and power. Thus, about ten years ago, as a gentleman's groom in Nottinghamshire was early one morning exercising his master's horses, a terrier dog which accompanied him put up from a bush a fine Eagle, measuring from tip to tip of his wings nearly eight feet. It flew slowly over the hedge into a neighbouring field, pursued by the dog, who came up with and attacked it before it could fairly rise; a sharp oontest took place, during which the dog was severely bitten, but gallantly persevered in maintaining his hold; when at length, with the assistance of the groom, and a person accidentally passing by, the bird was finally secured. It is not improbable that the Eagle had, during the night, been gorging itself with food, after which birds of prey usually become lazy and dull, and unwilling to fly, unless roused. Aware of this, in Scotland, the people adopt a mode of eatching them, which is attended with general success; or at least was in former times, when the country was less inhabited, and eagles more abundant.*

Four walls are raised to the extent and height of a small house or hut, on some heath or common where Eagles abound, and one opening left at the foot of the wall, sufficiently large to admit of the bird's walking in or out. To the outside of this opening, a bit of strong cord is fixed, with a noose formed at one end. When this has been arranged, a piece of carrion is thrown into the enclosure, which the Eagle in his range finds out and devours. Having eaten voraciously, it becomes stupified, and unwilling or unable to fly at once upwards, and consequently walks slowly and leisurely out at the opening left for it; and the cord with its noose being fitly contrived, and well placed for the purpose, catches hold of and strangles it.

In North America, they are much sought after and prized by the Indians, who are constantly on the look-out for them. Sometimes a hole is dug and slightly covered, and there, in a manner buried, a hunter will patiently watch, day after day, 
with a bird in his hand, to entice an Eagle within reach. At other times a deer is killed, and a covert made near it, where equal patience is displayed, till a successful shot secures the prize; and a prize indeed he is to these Indians, who hold him in such veneration, from the qualities they esteem above all others amongst their own renowned warriors and chieftains, namely, unwearied perseverance, activity, watchfulness, undaunted courage, and, lastly, patience in suffering privations. There is something, too, in his appearance, which strikes the untutored minds of these savages as denoting superiority over all other birds ; his look and movements so dignified, and his rapid and downward flight attended with a sound which is heard at a considerable distance, and is a signal to all other birds to disappear from his presence; or when floating magnificently above on his motionless expanded wings, they listen to the rattling of his pinions as he now and then shakes his quills with a noise which has been compared, by those who have heard it, to the fluttering or rustling of a silken flag in a gale of wind: accordingly, to his very feathers they attach a respect amounting almost to religious veneration.

There is an instrument called the Calumet, or pipe of peace, which is used in their most solemn meetings, when they hold councils respecting peace or war; and when offered and accepted by contending parties, has the effect of the most solemn treaties and oaths of Christian people. This instrument is, in a part of America called Louisiana, ornamented with the feathers of a particularly beautiful and rare species of White Eagle, called the Conciliating Eagle.* In another part of America, called California, and indeed amongst many other tribes of that vast continent, the Indians, when in their full dress, wear an Eagle's feather fastened to the top of their heads as a mark of nobility; and singularly enough a similar custom prevailed, and, on occasions of ceremony still prevails, amongst the Highland chiefs of Scotland, handed down from time immemorial: the plume of the Erne, or great Sea Eagle, $\uparrow$ being the distinguishing mark of the head 
of a clan, and even of the kings of Scotland. Many of our readers will, doubtless, remember the beautiful passage of Sir Walter Scott, in the Lady of the Lake, when

Fitz James alone wore cap and plume,

And Snowdown's knight was Scotland's king.

These plumes, too; were also valued for another purpose,* that of garnishing their arrows; the feathers of the Eagle never being injured by rain or water as others are, but remaining always durable, firm, and incorruptible.

* See Lord Somers' Tracts, vol. iii.

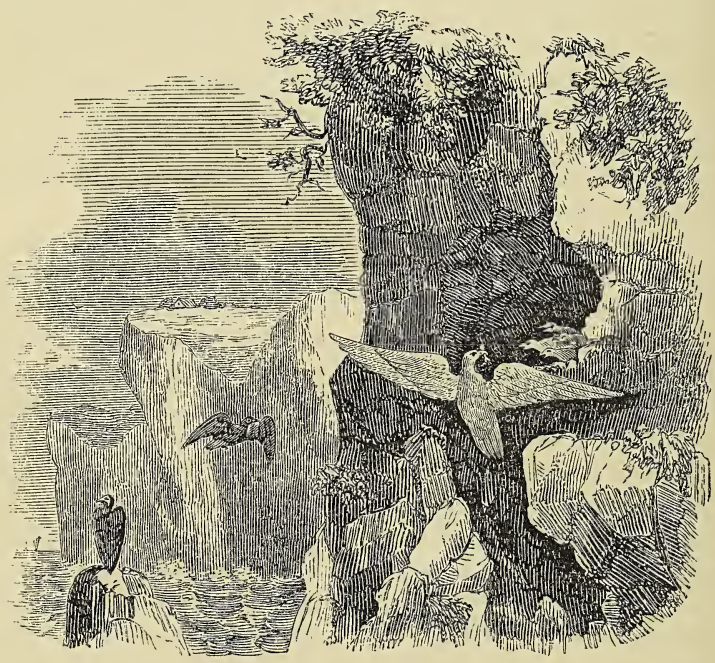

Great Sea-Easle, or Bird of Washington, feeding its Young 


\section{CHAPTER VII.}

Vultures.-Loathsome Feeders.-Strength ot.-Snake-Eater.Mode of Killing Serpents._-Hawks. - Character of.-Hawking for Bustards.-Value of.-Iceland Falcons müch prized.Falconry in former days.-Contest with Herons.-Modes of Catching. - The Sparrow-Hawk.-Anecdotes.-The Glede, or Kite.-Herons. - Food of the Hawk Tribe. - Their Disposition. -The Hawks sacred to the Egyptians and Turks.

VULTURES are nearly allied to the Eagles in point of size and some of their habits; they,yet differ from them considerably in others : generally speaking, they may be easily distinguished by the head and part of the neck being either

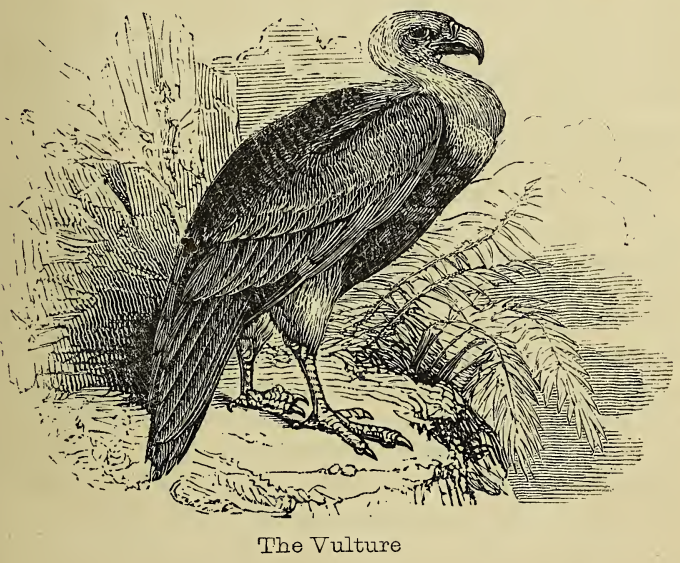

quite naked or covered with a short down. Instead of ranging over hill and valley in pursuit of living game, they confine their search to dead and putrefying carcases, which 
they prefer: and justly merit, by the voracity with which they devour the most offensive carrion, the name of Scavengers, in some countries, where they are never destroyed, in consequence of the good they do, by consuming the bodies of animals that might, but for the assistance of the Vultures, breed a pestilence in the hot climates where they most abound. A traveller in Africa having killed two buffaloes, and directed his party to cut them up piecemeal, and hang the various joints on the branches round their tents, that they might be dried up under the scorching beams of a burning sun, found himself suddenly surrounded by a flight of these birds, who actually carried off the flesh, notwithstanding the efforts made to drive away or destroy them by shouting, throwing, or even shooting at them. As fast as one dropped, another supplied his place. Another English traveller, who marched for some days with an army in Abyssinia, in a different part of Africa, speaks of their numbers as to be compared to the sand of the sea, extending over the troops like a black cloud; they were also more courageous than some other species; for he once saw one strike an Eagle to the ground, which had accidentally straggled into a host of Vultures, assembled to feed on the dead soon after a battle.

They are, however, sometimes more dainty in their choice of food ; as in Egypt, where, during the season when crocodiles and alligators lay their eggs in the sand, these cunning birds will sit, hid in the leaves of the trees, watching the females coming on shore to lay their eggs, which, when laid, they cover carefully with sand, thinking, no doubt, that they are thus safe from all danger, and sure to be hatched in regular course of time by the warmth of the soil, heated as it is by the sun; but no sooner does she retire, than the concealed birds glide down, and with claws, wings, and beak, tear away the sand, and quickly devour the hidden treasures.

A dead crocodile or alligator is equally acceptable; but as these reptiles are furnished with strong horny or scaly coats, like armour, much too strong to be opened and broken into, by either beaks or claws, the Vultures are often obliged to :wait for a long time until the hide of the carcase loosens, and 
affords them an opportunity of tearing it off; but they are then as often disappointed of their expected feast, for the flesh, when in a very decayed state, becomes almost fluid and runs off, to the great disappointment of the hungry birds.

Naturalists are a good deal divided as to the faculty by which these birds are enabled to discover, in a most surprising manner, a dead or dying animal at the distance of even many miles.

In travelling over the immensely wide deserts of Africa, where there is not a blade of grass to tempt a living bird or animal, and no inducement therefore for birds of prey to scour those vast wildernesses in search of game, should a camel or other beast of burden drop under its load in the train of a caravan, in less than half an hour there will be seen, high in the air, a number of the smallest specks, moving slowly round in circles, and gradually growing larger and larger as they descend in spiral windings towards the earth; these are the Vultures, but whence they come, or by what sign or call they are collected at a height beyond the reach of the human eye, is still a mystery; though we are much inclined to suspect that they derive their information from an indiscriminate use of both these senses, possessed of an acuteness far beyond our experience or comprehension.

Instances without number might be mentioned, in which the gifts of sight and smelling seem to rival each other. We will add the following respecting the power of each, related by an intelligent observer of nature in Jamaica : two relating to the sense of smelling, the two others to that of sight, and a third including both, with the addition of hearing. A poor German emigrant, who lived alone in a detached cottage, rose from his bed, after a two days' confinement by fever, to purchase in the market some fresh meat for a little soup, but before he could do more than prepare the several ingredients of herbs and roots, and put his meat in order for the preparation of his pottage, the paroxysm of fever returned, and he laid himself on his bed exhausted. Two days passed in this state of helplessness, by which time the mess of meat and pot-herbs had putrefied. The stench becoming very per- 
ceptible in the neighbourhood, Vulture after Vulture, as they sailed past, was observed always to descend to the cottage of the German, and to sweep round, as if they were aware of some putrid carcase, but could not find out where it was. This at length led the neighbours to suspect that the poor man lay dead in his cottage, as no one had seen him for the last two or three days. His door was therefore broken open, when he was found in a state of extreme feebleness, but the room was most insufferably offensive from something putrefying, which could not for a length of time be found, for the fever having nearly deprived the poor man of his senses, he had no recollection of his uncooked mess of meat and herbs, and as no one thought that the kitchen pot could contain anything likely to produce putrefaction, search was made everywhere but in the right place. At last, however, the pot-lid was lifted, and the cause of the insupportable stench discovered in the corrupted soup-meat. Here we have then clearly proved that the sense of smelling directed the Vultures, without any assistance from the sense of sight, and discovering unerringly the locality of the putrid matter, when even the neighbours themselves were unable for some time to detect it.

A few days succeeding this occurrence, after a night and morning of heavy rain, in which the streets had been inundated to the depth of a foot, and flood after flood had been sweeping to the river the drainage of the whole town, a piece of fresh offal had been brought down from some of the yards where an animal had been slaughtered, and lodged in the street. A Vulture, beating about in search of food, dashed down in a slanting direction from a considerable height, and just resting, without closing her wings, snatched up the fresh piece of flesh, and carried it off. Here was the sense of sight clearly unassisted by that of smelling, for the meat was too fresh to communicate any taint to the morning air, and the Vulture stooped to it from a great distance.

On another occasion, very near to the time when the above two facts occurred, a dead rat had been thrown out early in the morning into the street, having been caught in the night. 
Two Vultures sailing over-head in quest of a morning meal, descended at the same time, stooping to the dead rat, the one from the north, the other from the south, both seizing the object of attraction at the same moment.

In the last instance, the three senses of smelling, seeing, and hearing, were comparatively equally concerned, though not under the influence of the usual appetite for carrion food, as the object was a living, though wounded, animal. A person having had his pastures much trespassed on by intrusive hogs, resorted to his gun to rid himself of the annoyance. A pig which had been mortally wounded, and had run squalling and trailing in blood through the grass, had not gone far before it fell in the agonies of death. And at the very moment the animal was perceived to be unable to rise, three Vultures at the same instant pounced down upon it, attracted, no doubt, by the cries of the dying pig, and by the scent of its reeking blood, which was also visible on the ground: and while it was yet struggling for life, began to tear open its wounds and devour it.

Some idea, indeed, may be formed of their voracity, when we are assured that at one meal a Vulture contrived to devour the whole body, bones and all, of an Albatross, the large seabird which we have already described.

The natives of South America avail themselves of the gluttonous greediness of this bird to catch it. A dead carcase of a cow or horse is laid out for a bait, on which they gorge themselves to such a degree, that they become quite drowsy and stupid. When in this plight, they are approached by the Indians, who easily throw a noose over them; on finding themselves prisoners they are usually for a time sullen and shy: but this is not always the case, as the following story will prove, related by Captain Head, and told to him by one of his attendants, a strong English miner from Cornwall, when exploring the mining districts of South America.

The man, when riding along the plains, saw several Condors, or largest sized Vultures, (described in Table III., p. 10, under the genus "Fleshy Beaked,") of which the annexed figure 1 represents the head; and guessing that they were 
attracted by some dead animal, rode up, and found a numerous flock round the carcase of a horse. One of the largest was standing with one foot on the ground, and the other in the horse's body, exhibiting a singular force of muscular power, as he lifted the flesh and tore off great pieces, sometimes shaking his head, and pulling with his beak, or sometimes pushing with his leg. As the man approached, one of them, which appeared to be gorged, rose up, and flew about fifty yards off, when it alighted, and he rode up to it, and then jumping down, seized the bird by the neck. The contest was severe, and never probably was such a battle seen before, as a Cornish miner and a Condor. The man declared he never had had such a trial of strength in his life, that he put his knee upon the bird's breast, and tried with all his might to twist its neck, but that the Condor, objecting to this, struggled most violently, and he fully expected that several others which were flying over his head would take part against him, and assist their companion. At length, however, he succeeded, as he supposed, and carrying off the pinionquills in triumph, left the bird for dead; but so tenacious are they of life, and so difficult to kill, that another horseman who passed the spot some time after, found it still living and struggling.

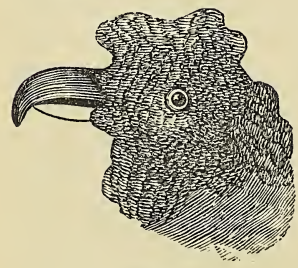

Figure 1

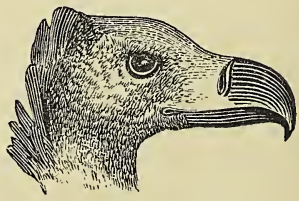

Figure 2

Feeding, as Vultures do, on carrion, plunging their beaks into putrid masses of decayed flesh, were they covered with feathers like Eagles and Hawks, about their heads and necks, they would soon become clotted with gore, and be an incum- 
brance to the bird; accordingly the head and lower part of the neck, in all the tribe, are more or less covered either with . down or wattles, or the skin is left almost naked, as in the accompanying figure 2 .

As may be well conceived from the nature of their food, these birds are very disgusting in various ways, much more so than we can form an idea of, from seeing them when kept in clean cages, and fed sparingly, on comparatively fresh and wholesome meat. In their wild and natural state, no one who has once been near them, would willingly approach too closely a second time, as their smell, increased by a greasy sort of perspiration, drawn out by the heat of the sun, is dreadfully offensive; and their appearance very different from the bold fine Eagle, perched on his pinnacle of a rock.

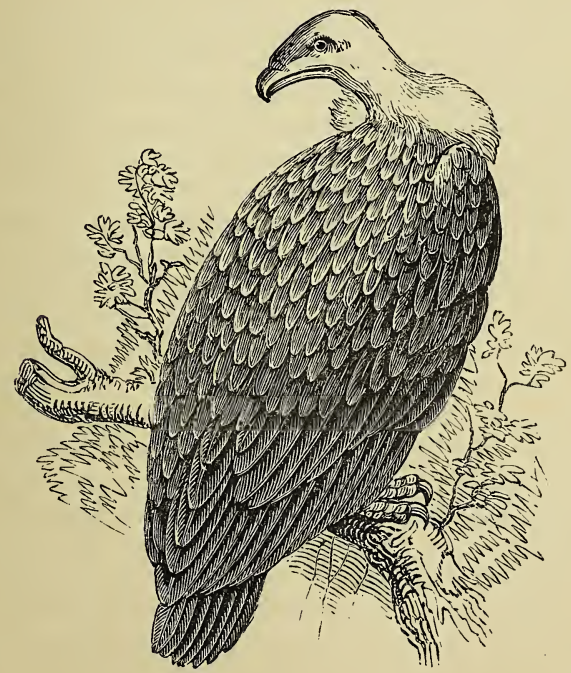


They sit in a sort of moping, slouching manner, with their heads buried within their shoulder-bones, as if torpid, or roosting, many of them together, on tall dead pines, or cypress-trees, where in the morning they often continue for hours, with their wings, measuring from eight to ten feet from tip to tip, spread open, as some believe, that the air may blow upon and purify their filthy bodies, though more probably, that it may gradually dry up a portion of that greasy moisture, which might, if very abundant, impede their flight,-which is at times prodigious.

There is one exception to this inactive character of Vultures, in a bird which is now classed with them, though more from certain peculiarities in his plumage and beak, than those closer points of resemblance which would fairly entitle him to be placed in such bad company. This bird is called the Snakeeater (Vultur serpentarius), a native of Africa, and of some parts of India; and it is here noticed, on account of its singular manner of destroying serpents, on which it feeds. An eyewitness thus describes it. He was one day riding, when he observed a Snake-eater, while on the wing, make two or three circles at a little distance from the spot on which he then was, and suddenly descend to the ground. On observing the bird, he found it engaged in examining and watching some object near the spot where it stood, which it continued to do for some minutes. After that, it moved with considerable apparent caution, to a little distance from the spot where it had alighted, and then extended one of its wings, which it kept in continual motion. Soon after this, the observer saw a large snake raise its head to a considerable distance from the ground, which seemed to be what the bird was expecting, and waiting for ; at the moment the snake reared its head, he instantly struck a sharp blow with the end of his wing, by which the snake was knocked flat on the ground. The bird, however, did not appear confident of having slain his enemy, or gained the victory, but kept his eye fixed on the reptile for a short time, when the snake reviving again, lifted up its head, and the bird as before repeated his blow; after this second blow he appeared to gain 
more confidence; for, almost the moment it was inflicted, he marched boldly up, and struck at the snake with his feet; after which, finding it disabled, though not quite dead, he rose almost perpendicularly to a very great height, when he let it drop, and as it fell with great violence to the ground, he seemed satisfied that there was no more danger to be feared, and accordingly he followed it to the earth, and commenced his hardly-earned meal.

Vultures are chiefly natives of the hotter regions of the globe, such as South America, Africa, and other similar warm climates. Some sorts are, however, not uncommon in the southern parts of Europe; and even in England, a few have been seen and killed. In June, 1826, near Bridgewater, in Somersetshire, a strange unknown bird was observed walking on a road, which, on being pursued, flew about a mile towards the sea, and alighted on the beach, where it was shot. It had just been gorging itself with a putrid lamb, which was most likely the cause of its allowing itself to be approached within gunshot. On opening it for the purpose of stuffing, the smell was excessively offensive. Another bird, apparently of the same species, was seen near the place where this was killed, but evaded pursuit. It was of the smallest kind, measuring only, from the tip of the beak to the end of the tail, two feet three inches; and from the tip of one wing to the tip of the other, five feet six inches and a half; whereas the great Condor of South America is sometimes found to measure nearly twelve feet from tip to tip of the wings, when spread out.

We next come to the Hawk tribe, which includes a great variety of species of different sizes, from the largest, not much less than an Eagle, to the smallest, not much larger than a Blackbird. They differ, too, very greatly in disposition; some, like the Eagles, being all fire, spirit, and courage, while others are dull and cowardly, and, compared with the first mentioned, are what Vultures are to Eagles. The chief distinguishing marks between the really called Falcons and Hawks and true Eagles, are in the form and shape of the beak, and length of the outer feathers in the wing. 
The beak of an Eagle is comparatively long, terminating in a hook; whereas, that of the Falcon or Hawk tribe is short, and begins to bend from its base. In an Eagle, the first, second, and third feathers of the wing are shorter than the fourth and fifth: whereas, in the common Hawk the second

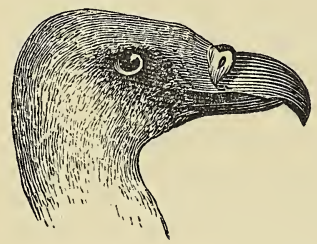

Beak of Eagle

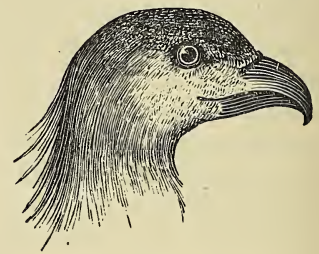

Falcon, or Hawk Tribe

feather is the longest, and the first and third of equal length; but in the true Falcon, the first feather is the longest. There may be some exceptions to the strict letter of this rule, but generally speaking, it is sufficiently correct for practical purposes. Owing to the greater docility of several of the Hawk and Falcon species, they have been made useful to mankind by being trained to catch game of various sorts ; and accordingly people of all nations, from very early days, have taken pains in rearing and training them. Above two thousand years ago, ancient writers speak of hawking as a common sport. People used to go out into the marshy grounds, and beat amongst the reeds and bushes for small birds which harboured there; and as they flew away, Hawks were let loose in pursuit, and when the game fell to the ground, either through fright, or struck by the Hawks, the men ran up and secured them. Others were so well taught, that they not only returned to their owners when called, but brought whatever they might have captured in their flight. Some North American Indians understand the art of taming these birds, and are equally fond of the sport; but it has been remarked, 
that when the hard winters set in, the birds, if not confined, take wing, and are never seen again. In China, it is a favourite amusement with some of the Mandarins, or great people, to hawk for butterflies and other large insects, with birds trained for that particular sport. In India,

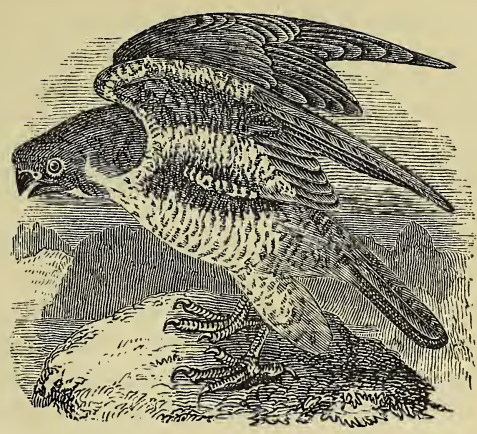

The Falcon.

the Goshawk, and two other species, are taught to keep hovering over the hunters' heads, and when deer or other game starts up, they dart down, as has been before stated, and fix their claws upon its head; and thus bewilder it, till the pursuers come up.

Near Tripoli, in Africa, on the wide plains, Bustards are very common, - - large bird, once plentiful in some parts of England, though now, in consequence of the increase of population, and enclosure of the waste tracts of land, no longer to be seen; they are larger than Turkeys, and though their wings are so short as to be of little use to them in flying, they enable them to use their long legs with a speed equal to that of a greyhound, and afford excellent sport when pursued by Hawks; and Bustard-coursing is therefore a favourite amusement with persons of rank in that country. Hawking, however, to any extent, is at the present day nothing, compared with what it was a few hundred years ago in England, and many parts of Europe, when it was followed with an eagerness and a degree of expense far beyond the cost of foxhunting, racing, or any of the field sports of modern times. Of the value and importance attached to birds of the right breed (for all Hawks were far from being equally good), we 
may form some idea from the attention paid by the king of Denmark, in procuring and preserving certain Falcons which were in the highest estimation, from the island of Iceland, and were then, and still are, known by the name of the Iceland Falcon (Falco icelandicus, Falco gyrfalco). Next to the Eagle, it was reputed the most formidable and active, as well as the most prompt and intrepid of our birds of prey.

In the winter, whole flights of these birds come over from Greenland and the Arctic regions, where they probably breed and pass the summer, as Captain Sir Edward Parry saw them frequently in his last voyage. These Icelandic Falcons were always considered the best for sport, lasting ten or twelve years; whereas, those from Norway, not above two or three years ; they are also superior in size, and gifted with extraordinary qualities. So much were they indeed prized, that an ancient Danish law inflicted the punishment of death on any person found guilty of destroying them; and those engaged in taking them were bound, under heavy penalties, to deliver them to no other person whatever but the king's own falconer; and even so late as 1758 , the spirit of the law was not much changed, judging from the following account of a writer on Icelandic history. He tells us that the king of Denmark sends every year a falconer, with two attendants. On landing, they repair to a house called the king's falconhouse, for the purpose of receiving the birds caught by persons who are licensed, and are native Icelanders. About midsummer, these catchers bring their birds on horseback, holding a pole, with another fixed across it, on which ten or twelve sit, all capped, that is, with their heads covered with caps or hoods. This pole is held in their hand, and rested on the stirrup. The falconer examines them very carefully, and returning those that are of an inferior sort, sends off the best to Denmark. During the voyage, they are arranged between the decks, tied to poles, two rows of a side; these poles are covered with coarse cloth over a stuffing of straw, and lines are strung from one side to the other, pretty close, that they may have something to catch hold of in case of 
the ship's rolling. The catchers receive a written testimony of their respective good qualities, by virtue of which they are paid by the king's receiver-general, about three pounds for the best, which are white; about two pounds for the second best, and from eight to ten shillings for the remainder : latterly, the prices have been raised, but in former days, when they received rather more, and money was not so plentiful, this price may be considered as very great. But this price is nothing in comparison with the sums quoted by historians, as given about two hundred years ago in England, when a Goshawk, a bird far inferior to these Iceland Hawks, was sold for one hundred marks, or nearly seventy pounds sterling. It is further said, that a certain Sir Thomas Monson, about that period, gave no less than a thousand pounds for a cast of Hawks, consisting of two birds.

In the Orkney Islands, a little to the north of Scotland, where excellent Hawks are bred, there was an act of parliament claiming them " to be reserved to his Majesty, with the falconers' salaries, according to ancient custom ;" and in some parts there is still an old custom observed of claiming a hen from each house or from a certain number of houses in each parish, as due to the royal falconers. They were said to have been originally taken as food for the King's Hawks.*

No amusement seems to have been followed with so much eagerness as hawking in almost every country in Europe; and from the earliest times, even before William the Conqueror's days, it was the favourite pursuit of the royal families and nobility of England. The training and flying of Hawks formed part of the education of every young man of rank. King Alfred is said to have written a treatise upon the subject; and even ladies followed it as eagerly as the gentlemen. The amusement was occasionally followed on foot, but generally, particularly on downs and in open countries, it was pursued on horseback. In woods and covers, however, or where horses could not easily follow, the sportsmen were furnished with long stout poles for leaping over ditches, which we learn from a story told of King Henry the Eighth, who, one day,

* Barki's Orkney. 
when pursuing his Hawk at Hitchen, in Hertfordshire, attempted, with the assistance of his pole, to jump over a wide ditch, full of muddy water, but the pole unfortunately breaking, the king fell head over ears into the thick mud, where he might have been suffocated had not one of his attendants, seeing the accident, leaped into the ditch after his royal master, and pulled him out.

No pains were spared in breaking-in the Hawks, as much of their value depended on their docility, derived from good and careful training. The young birds, when taken out of the nest, or sometimes caught by traps, as soon as they began to fly, were put into linen bags, with openings for the head and tail, that they might be brought home without injury. A hood or cap was then placed over its eyes, and for a day or two the bird was left to itself. After which it was placed quietly on the fist, carried up and down the whole day, and gently stroked with a feather. Having been, in some degree, tamed by this treatment, and accustomed to handling, the hood was taken on and off quickly, till it was willing to feed. Meat was then offered, and the hood removed, the falconer making a particular call at the same time, which was invariably used whenever it was fed, but on no other occasion, that it might become acquainted with the voice of its feeder. It was then taught to alight upon the fist from a perch, being still hood-winked, and receive its food; this was called luring the Hawk. When it was so far tamed as to come readily when called, it was allowed to remain unhooded, and then put to the lure, an artificial bird, made of feathers and leather, thrown up into the air. To this a live Pigeon or dead Chicken was fastened, part of which it was permitted to seize and eat; during this part of training it was prevented from escaping by a long string. When quite familiar with the lure, it was taught to fly at live game, chiefly by means of a Duck, which was blind-folded that it might not escape. The natural disposition of the Hawk would induce it to carry off its game, when caught, but this was checked by the skill and kind treatment of the falconer, so that the 
Hawk, as soon as it had taken the live lure, always returned to its master, knowing that it was sure to be well fed as a reward.

Having completed its education, when at home it was placed on a perch without a hood. Straps of leather or silk, called jesses, were put about its legs, for the purpose of holding it, and bells were also attached, so small as not to impede its flight; besides this part of the Hawk's furniture, the person who carried it was provided with thick gloves, to prevent its talons from hurting the hand, and these were often very costly and highly embroidered.

Attached as were our ancestors to this sport, it was by no means confined to England. In Denmark, we have seen, from the attention paid to their importation, how highly good Hawks were prized. In France, too, it was as eagerly and expensively pursued, and even the Turks followed the example of Christendom.

A certain Sultan, called Bajazet Ilderim, maintained a corps of 7000 falconers, about the time it was so fashionable in Europe; and to this day, in the plains of Turkey, travellers may meet with parties of falconers, with Hawks upon their wrists, in pursuit of hares, and a particularly large kind of Lark, at which their Falcons are trained to fly.

Wild and shy as Hawks are, it will scarcely be credited, that at one time, the common Gledes or Kites were numerous in London streets. This happened in the time of Henry VIII., when it seems that they were attracted by the offal of butchers' and poulterers' stalls; and as, on account of their use in removing so offensive a nuisance, they were not allowed to be killed, they became so fearless as actually to mingle with the passengers, and take their prey in the very midst of the greatest crowds. Few people are, indeed, aware of the numbers of Hawks existing at this day in London. On and about the dome of St. Paul's, they may be often seen, and within a very few years, a pair, for several seasons, built their nest and reared their brood in perfect safety between the golden dragon's wings which formed the weather-cock of Bow Church, in Cheapside. 
They might be easily distinguished by the thousands who walked below, flying in and out, or circling round the summit of the spire, notwithstanding the constant motion and creaking noise of the weather-cock, as it turned round at every change of wind.

In consequence of the disappearance of wastes and commons, by enclosures and hedges, which rendered it no easy matter to follow the amusement without danger and delay, and also, ever since the introduction of guns, hawking has gradually declined, and may be now said to be nearly at an end; though within late years, some attempts have been made to revive it.

The following account is from an eye-witness of a day's hawking, which occurred in June, 1825, in Norfolk, in the flat fen-country, near a heronry. The party assembled in the afternoon, the wind blowing towards the heronry. There were four couple of Hawks, all females, of the breed known by the name of the Peregrine Falcon, one of the most esteemed of the British Hawks in the ancient days of falconry. They were carried by a man to the ground, upon an oblong kind of frame, padded with leather, on which the birds perched, and to which they were fastened by a thong of leather. Each bird had a small bell on one leg, and a leather hood, with an oblong piece of scarlet cloth stitched into it over each eye; on the top of this hood was a small plume of various-coloured feathers. The man walked in the centre of the frame, with a strap from each side, over each shoulder; and when he arrived at the spot fixed upon for the sport, he set down the frame upon its legs, and took off all the Falcons and tethered them to the ground in a convenient shady place.

There were four foreigners, probably from Falconsward, a village in North Brabant, much famed for its Falcons, under whose particular care the birds were placed, each having a bag, somewhat like a woman's pocket, tied to his waist, containing a live Pigeon, called a lure, to which was fastened a long string.

After waiting awhile, some Herons passed, but at too 
great a distance; at length, one appeared to be coming within reach, and preparations were made to attack him. Each falconer wore a brown leather glove on his right hand, to prevent the Hawks' talons from scratching the wrist; and there was a small bit of leather attached to the leg of the bird, held by the falconer between the thumb and the finger. Each of the men being now ready, with a Falcon on his fist, and the bag with the lure tied to the waist, and mounted on horseback, proceeded slowly in the direction from whence the Heron was flying: and as soon as the Heron was nearly opposite, though at a very considerable height in the air, they slipped the hoods from off the heads of the Falcons, holding them to the fist by the bit of leather, till they caught sight of the Heron, when the sport commenced in earnest.

For the moment they were let loose, off they went, straight as arrows, towards the Heron, which by this time had gone a considerable distance ahead. As they were dashing away towards it, an unfortunate Crow happened to cross their course, when one of them instantly darted at him, but he contrived to escape by striking into a plantation, where the Falcon followed, but did not take him. The other Falcon soon overtook the Heron, which began to prepare for the threatened attack, by disgorging its ballast, consisting of two or three fishes; while the Hawk, after flying round for a short time in circles, at length soared above him, and then pouncing downwards, struck him on the back, when they both came tumbling down together from a great height to the ground. The other Falcon having lost some time in chasing the Crow, was now flying with all speed to assist her companion, and was coming up just as the first Falcon and Heron were falling. At this instant, a Rook happened to fly across, when the disappointed Falcon struck at him, and they both fell together, within twenty yards of the other Falcon and Heron. No sooner had they reached the ground than each of the Falcons began to pull its victim to pieces; but as soon as the falconers could come up, the lures were thrown out, and the Falcons were allowed to make 
a meal upon the Pigeons, having been kept fasting for some hours before.

The Pigeons were placed for them on the body of the Heron; and after they were satisfied, they were again hooded and put up for the day. The next cast of Hawks consisted of two younger birds; and when let loose at another Heron, they flew up to it very well. But the Heron was an old one, and was supposed to have been attacked before; for the moment he saw his enemies below, he began to soar into the air, and set up a loud croak, and the two young Falcons, not so experienced as the two first older ones, would not attack the Heron, but after flying about for some time left him. Upon this one of the falconers set up a peculiar call, to which the birds were accustomed, when one of them, from a great height in the air, immediately closed his wings, and darting down to the man who called him, was taken in hand. The other Falcon, however, was not so well trained and obedient, but continued to sail about in the air.

At length a Heron approached, and she attacked it, but without success, and soon left it; at last a third Heron crossed, which she attacked, and, after a short struggle, succeeded in bringing to the ground in the same manner as in the first case. This last Heron had its wing broken, and the falconer killed it, but the other was taken alive, and afterwards turned out before a single Falcon, which struck it down in a minute. It was said, that if a Heron had been once taken by a Falcon, it would néver afterwards show sport by soaring and endeavouring to escape. It was the case with this one, for as soon as it saw its enemy approaching, it appeared to lose all its powers, and merely made a trifling and awkward defence on the ground, where the Falcon would speedily have killed it, if the lure had not been thrown in her way.*.

It will be observed that in the above instances the Hawks either obeyed the call, or were secured by their keepers on 
the capture of the game, but this does not always follow, and they are occasionally lost; of which there is a curious proof in a Hawk having been taken, a few years ago, in the month of August, with bells on its thighs, and a silver ring to its leg with the owner's name engraved thereon. It flew on board a vessel bound from North Shields to Quebec, in latitude $44^{\circ}$, longitude $25^{\circ}$ west, nearly midway between the coasts of Europe and America, and died after being on board twenty days. From the inscription on its silver ring, this bird must probably have escaped from England or Ireland, from the nearest point of which it was, when taken, about 700 miles. Knowing as we do the speed of a bird's flight, this distance appears less extraordinary, and might have occupied but a short time in its accomplishment. For instance, the bird might have taken its departure from the nearest land, and with ease, and by no means at its extreme speed, have reached the vessel in six or seven hours; and as it lived for twenty days on board, we have no grounds for believing that it had suffered from excessive fatigue or hunger during its flight.

In the above cases of hawking for Herons, and some other birds, it is observable that the Hawk's object is to disable its prey in the air, and force it to fall to the ground, by the infliction of a severe wound; and it is remarkable that welltrained Hawks, and probably all, from natural instinct, aim at the back, and for this curious reason, that the Heron frequently, indeed, whenever it can, on finding the Hawk above it, and ready to pounce down, turns itself on its back, with an intention of piercing its assailant through with its longs sharp beak; and in ancient pictures of hawking, the Heron is often represented falling with its back downwards, and occasionally with the Hawk transfixed by its beak in the moment of descent.

All Hawks, however, do not fly at their game with an intention of taking it in the air, while others, so far from avoiding the head, make it their particular point of attack, as the Kestrel (Falco tinnunculus), which was invariably observed by a person who kept one for some time to crush 
the head of the animal given it for food, with its beak, before it began to devour it.

Those who are in the habit of catching Hawks avail themselves of their knowledge of the different ways in which they provide themselves with food, in order to capture them; a description of a few of these modes may be useful to some of our readers. The manner of catching the celebrated Icelandic Falcons was thus. So anxious were the inhabitants to secure them, that almost every nest was known, and the Falcon-catchers in the neighbourhood watched them with the greatest care. When the old ones had reared their young, and the latter were full grown, two posts were stuck into the ground, at a little distance from each other; to the one was tied a Partridge or a Pigeon by a small line, two or three yards long, that they might have room to flutter about and attract by their motion the eye of the Falcon; to the leg of the Partridge or Pigeon, they tied another string, in length about a hundred yards, which ran through a hole in the other post, in order to draw the bait to that post, where a net, like a fishing-net, was fixed, with a hoop in a semicircle of six feet in diameter. This being pulled down, it went over, and covered the post, for which purpose there was another string fastened to the upper part of the hoop, which went through the first post, to which the bait was tied. These two strings the Falcon-catcher held in his hand, that he might pull the bait when he pleased, and at the proper moment draw the net over his prize. These nets were fixed in the neighbourhood of some nest, or in situations known to be frequented by Falcons. As soon as one of them happened to notice the lure fluttering on the ground, after taking a few sweeps in the air, just over the spot, as if to discover any hidden danger, he pounced down with such violence and certainty, that the bait's head was taken off, as clean as if with a knife. The moment he had thus despatched his supposed prey, he generally flew up again, unless very hungry, to be reassured that there was no danger near. Availing himself of this pause, the Falcon-catcher pulled the string and dead bait to the other post, close under the net, which 
the Falcon observing, on again pouncing down, the other string was pulled, when the net fell over and secured him. He was then taken out with the greatest care, for fear of injuring any of his feathers, particularly those of the wings and tail, and a hood placed on his head, and drawn over his eyes. It is most likely in consequence of the persevering pursuit and capture of them, that this fine breed of birds is becoming exceedingly scarce in Iceland; a late traveller, during a visit of some months, not being fortunate enough to see one, even at a distance.

We may form some opinion of the rapidity with which Hawks fly upon their prey, from the singular manner in which the Lanner, a small Hawk about the size of a Pigeon (Falco lanarius), is often taken, or as often killed, in the Feroe Islands, between Iceland and the north of Scotland, where they are abundant, and are considered as the tyrant of the smaller birds. The Starlings are in such fear of it, that, when pursued, they will take shelter in a church, or a house, and often seek refuge in the presence of men. They often escape by what is called a wind-house, a building made for drying meat or fish, the sides of which consist of laths placed at a very small distance from each other, just wide enough, however, to admit the body of a Starling, through which, when pursued, the frightened bird contrives to slip, leaving the Lanner, eagerly following close behind, jammed quite fast between them.

There is a Hawk called the Ringtail, or Goshawk (Falco palumbarius), now rare in England, though formerly plentiful, and much valued for hawking, which committed sad devastation amongst Partridges. Its mode of hunting was to beat a field, and when a covey was sprung to fly after them, and observe where they settled; for as it was not a fast flyer, the Partridges could outstrip it in speed: it then sprung the covey again, and after a few times the Partridges became so wearied that the Hawk generally succeeded in securing as many as it pleased. To catch it, a trap or two was set in its regular beat, baited with a small rabbit, or the stuffed skin of one; but a surer bait, particularly in open, 
unenclosed countries, was by preparing what were called birdbushes, about half a mile from each other. A large stake was driven into the ground and left standing, about seven feet in height; bushes and boughs were then laid round this post and kept loosely open, and hollow at the bottom, to the extent of ten or twelve yards round the post, for the Partridges to run into when pursued by the Goshawk, which they usually did after being disturbed two or three times. The Goshawk, finding itself disappointed, and unable to follow them with its long wings amongst the bushes and briars, after flying round them for some turns, was sure to perch upon the top of the post, as the only resting-place at hand, and was there as sure to be taken by a trap set there for the purpose.

The beautiful, and at the same time, very common little Hawk, called the Kestrel ( $F$. tinnunculus), when in search of its prey, may be seen hovering high in the air in the same spot, with its head towards the wind. It has been asserted by some naturalists that it lives only upon insects and mice, and will not touch small birds. This, however, is untrue; the Kestrel will not only kill small birds, but others nearly as large as itself, as the following fact will prove. One of them was observed to seize a young Blackbird just able to fly, which it was in the act of carrying off in ts talons. The old Blackbird gave chase with loud cries, and apparent determination to rescue her young one, when the Kestrel, having allowed her to approach unmolested, in an instant dropped the young bird, and as instantaneously caught up the screaming parent, and carried her clear away. The habit of hawking on the wing has been further proved by its having been seen on summer evenings, darting amongst a swarm of cockchafers, seizing one in each claw, and eating them on the wing, and then again darting amongst them.

That birds possibly may by their swifter flight often escape, is not unlikely; but exclusive of the above instances, bird-catchers know to their cost, while patiently watching their nets, how often the Kestrel, hovering over the field, will pounce down and destroy their most valuable call-birds; 
accordingly they contrive a suitable trap for catching them, which rarely fails. A white napkin is spread upon a meadow, and fastened down at the corners with little hooked sticks; on the middle of the napkin a live sparrow is placed, and kept there by means of a string, three or four inches in length; slender twigs are stuck up round the four sides of the cloth, to prevent the Kestrel from attacking the Sparrow, excepting from above. Two long slender twigs of weeping willow, well covered with bird-lime, are then stuck in the ground, one at each end of the napkin, both forming an arch over the Sparrow, but at such a distance that it cannot touch them with its wings while fluttering, but still so near as to render it impossible for any Hawk to reach the Sparrow without touching the lime-twigs. The use of the white cloth is merely to attract the attention of the Hawk to the Sparrow at a greater distance. The lime-twigs must be placed so lightly in the ground, that if the Hawk, on finding himself entangled, should struggle, they would still adhere to his feathers, and rise with him into the air if he took flight: for

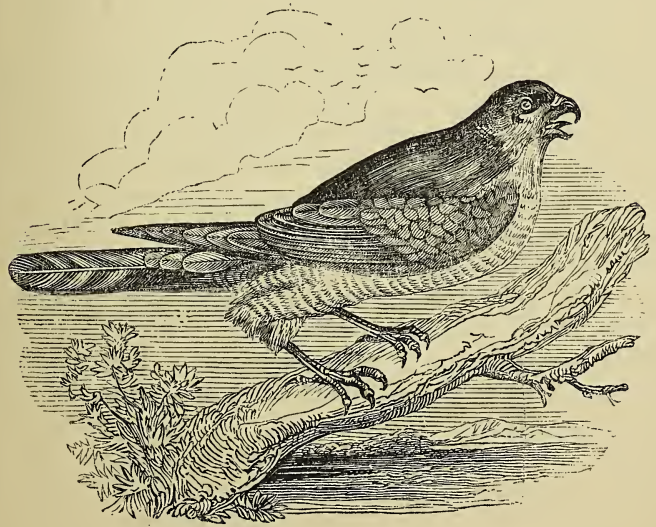

The Sparrow-hawk 
it has been observed, and should be known to bird-catchers, that twigs covered with bird-lime, if long and very slender, will stop the flight of the strongest bird, if fixed so as to pass off with him when touched by his feathers, for they become like a chain binding the wings to the body.

Sparrow-hawks may be caught by similar means; there is, indeed, a great resemblance between these birds in many of their habits, though the latter may be considered as the more shy and untractable of the two. When in pursuit of prey, however, they will not unfrequently evince great boldness. We know of one which darted into an upper room, where a Goldfinch was suspended in a cage, and it must have remained there some time, and continued its operations with great perseverance, as on the entrance of the lady to whom the poor bird belonged, it was found dead and bleeding at the bottom, and its feathers plentifully scattered about. The Kestrel is, on the other hand, rather more tractable, and will manifest, if not attachment, at least no shyness on the approach of those who feed it, particularly if carefully attended to.

We have noticed several instances of Eagles carrying off such considerable weights as children, lambs, \&c., and we have noticed the death of some of these larger birds by their imprudent attacks upon stoats, and similar small animals; but the power of wing is more decidedly shown by the fact of so small a bird as the Kestrel, weighing only six ounces and a half, and having an expansion of wing of only twentyseven inches, having been known to dart upon a weasel, an animal its equal nearly in size and weight, and actually mount aloft with it. As in the case of the Eagle, it suffered for its temerity, for it had not proceeded far when both were observed to fall from a considerable height. The weasel ran off unhurt, but the Kestrel was found to have been killed by a bite in the throat.

The following is a strong corroboration of the truth of the story just mentioned, as far as the powers of a Hawk to raise comparatively heavy weights, but is more curious, as exhibiting the courage displayed in one of the most timid 
animals, in defence of its young. It occurred in Yorkshire. In the spring, a gentleman walking in the fields saw a small Hawk attempting to fly off with some prey it had just pounced upon, but evidently prevented by the weight of its capture from rising to any height above the ground. It was pursued by a hare, which, whenever it came within her reach, attacked it with her paws, and at last succeeded in knocking it down, when it dropped its prey. At this moment the gentleman ran forward, and the Hawk and its pursuer both made their retreat; upon his reaching the spot where the prey had been dropped, he found it to be a fine leveret, which at once explained the cause of the parent hare's gallant attack on the Hawk. It was wounded on the side of the head, and was bleeding, but the gentleman left it in a furrow, hoping that the wound might not prove fatal, and that the mother might find it, and reap the reward of her maternal attachment.

It may seem extraordinary that they should presume to meddle with living things of their own size and weight, but it is still more remarkable that they should occasionally wage successful warfare with birds still larger than themselves, as, for instance, with the Jay. Not long ago, some boys observed a Hawk flying after a Jay, which, on reaching, it immediately attacked, and both fell on a stubble-field, where the contest appeared to be carried on; the boys hastened up, but too late to save the poor Jay, which was at the last gasp; in the agonies of death, however, it had contrived to infix and entangle its claws so firmly in the Hawk's feathers, that the latter, unable to escape, was carried off by the boys, who brought it home, when, on examination, it proved to be a Kestrel. The Sparrow-hawk of North America (Falco sparverius), which is more nearly allied to the Kestrel than ours, is often known to attack the Blue Jay of that country. No wonder that Jays have a great dislike to this Hawk, and never fail to annoy it by every means in their power. Sometimes they will follow in order to plague it, and at other times, they, by imitating its note, will deceive and draw it from its haunts. In return for all this abuse, the Hawk now 
and then revenges itself by killing and eating the fattest of its persecutors.

Rapid as is the flight of these birds of prey, and accustomed as they are to pounce at once on their game, and if disappointed leave it, and continue their search elsewhere, they will at times follow a devoted bird for a length of time with great perseverance. Not long ago, some fishermen belonging to Newhaven, when about five miles from the Bass-rock, off the coast of Scotland, observed a Hawk in close pursuit of a small bird. Apparently exhausted by its numberless sudden turns, spiry circles, and various efforts to escape, it was just on the point of falling into the claws of its pursuer, when the fishermen gave a loud shout by way of frightening the Hawk, on which the little bird flew down for protection, and perched, quite exhausted, in the midst of them. It proved to be a fine Lark. The Hawk approached within a few yards of the boat, and after hovering about for a short time, turned his course towards the shore.

The Glede or Kite was a well-known bird, and much oftener seen in former days, even in towns, as we have shown, than at present; but for some reason or other they are getting every year more scarce. Still they may now and then be observed soaring in wide circles over woods, easily distinguished from other birds by their length of wing and forked tails. There is a very curious story told by a gentleman, of a strange manner in which not less than fifteen were caught at the same time: he says he remembers when a boy, that several of them happened to be roosting on some lofty elmtrees in winter, when a fog came on, which, freezing as it fell, completely glued their feet to the boughs; and they were all taken. The truth of this extraordinary anecdote has been often questioned by naturalists, who maintain that there is a sufficiency of internal warmth in a bird's foot to thaw any moisture which might produce the effect above mentioned; but when we consider the power of sudden frosts, and the comparatively small circulation of blood in a bird's claw, we see no reason to doubt the fact, which is in a great degree confirmed by some other instances of the effect of frost, of an 
equal if not more extraordinary nature. Thus, a writer who kept a journal in 1658, in speaking of the winter of that year, alludes to it as the severest ever known in England, and, amongst other things, adds, that Crows were taken with their feet frozen to their prey.* In Scotland, also, during a severe frost, a Heron was found struggling on the ice; it seems the foot on which it had been standing, had been during the night completely frozen up; probably when first it settled on the previous evening, the surface was in a fluid state, but a severe frost setting in, the foot was soon encrusted with ice, and the bird fettered to the spot. Again, in one of Captain Sir Edward Parry's Northern Expeditions, the hand of a marine was so dreadfully frost-bitten, that it was found necessary to amputate some of the fingers; previously to which, by way of restoring circulation gradually to the parts which had not been frost-bitten, the man's hand was dipped in cold water, when to the great surprise of the medical attendants, the water was seen to congeal round the frozen joints for a considerable length of time after its immersion. In another of his expeditions, it was observed that the Ravens which were seen on the wing had a white circle round their neck like a collar, which was at last discovered to be a regular coating of frozen breath, that had thus collected on the feathers, as it escaped from the bird's mouth. But a still more curious instance, and very similar to that of the Kites, occurred near Windsor. One morning a person was employed in a yard adjoining to his house, when his attention was attracted by the growling of his cat, who seemed to be in violent agitation, though confined to the spot on which she stood. On examining the cause of her distress, it appeared that she had been making her breakfast on some offal scraps of meat, which had been thrown there; and the place being wet, and the thermometer at the time being fifteen degrees below freezing, her feet had actually frozen to the ground, and a minute or two elapsed before she could extricate herself from her unpleasant situation. One other instance we have 
met with, which is stated by the writer to be a positive fact, and as in our view of the case it is by no means unlikely to have occurred, we give it. A peasant in the mountainous part of the South of France, observing a great number of wild Ducks settled on the ice of a small river that was frozen over, fired into the midst of them, and was surprised to find that not one of them took to flight. On going up, he found, that owing to the severity of the frost, they were not only completely fastened to the ice by their feet, but that nearly onehalf were frozen to death. The above anecdotes will appear less improbable, when we consider how rapidly, under favourable circumstances, even in our comparatively temperate winters, ice is formed, and how unexpectedly birds or animals unaware of it, might in consequence be imprisoned. It is easy to form ice to a considerable extent, in a few minutes, if water is poured over a level surface so that none shall escape; for instance, over a wide floor or plain, smoothed with Roman cement, flooded to the depth of less than a quarter of an inch. A thin coating of water thus applied, will, even if the thermometer is scarcely lower than the freezing-point, almost immediately become a sheet of ice, and if repeated two or three times, will form a covering, capable of bearing the heaviest weight without giving way. This was actually practised with success on three successive days in November, near Glasgow, for the purpose of preparing a perfectly smooth sheet of water on a roughly-frozen pond, for a game, called, in Scotland, a curling match. One-eighth of an inch in thickness was found sufficient; it immediately froze, and when the game was over at night, a similar additional coating was poured over it, for fresh use.

We have seen that the common food of the Hawk tribe consists of animals or birds, dead or living, with the exception of the Kestrel, which preys with equal satisfaction on beetles ; but there is one particular Hawk, called the Honeybuzzard (Falco apivorus), rather rare at present in England, whose favourite food is bees and wasps, (and not the honey of the former, as has been erroneously supposed from its name,) which it devours greedily, apparently without ever suffering: 
from their stings. There can be no longer any doubt as to the truth, one having been lately shot in the parish of Stoke Nayland, in Suffolk, by a person who saw it first on the ground near several wasps' nests, and who, on dissecting it, found both in its craw and stomach a quantity of wasps and their grubs, with a few small beetles. As nobody has had the good fortune to see one of these birds in the act of feeding, it is impossible to ascertain how it makes its way without being injured into the interior of the wasps' nest, which it must do in order to get at the grubs, which are concealed in the very middle of the combs. The head and throat are surrounded with a clothing of remarkably thick, and rather stiff feathers, which may probably be intended as a protection. From the date named, October 12, when this bird was shot, it might be imagined that it attacked those nests only which had been partly destroyed, or deserted by the wasps, which so late in the season were beginning to get feeble; but this is not correct, as they have been seen just as busy about hives and wasps' nests in the breeding season, when these insects are in full strength and vigour. How the Hawk contrives to make his way into the comb is also difficult to understand, though as the legs and claws of this bird were very dirty even to the knee, he most probably uses them as fowls do in dunghills, to scratch away the soil.

Bold, and apparently savage and cruel as is the disposition of the Hawk tribe, occasional instances are to be found of their manifesting something like kindness and good-will towards birds, where such a disposition might be little expected. Even the Sparrow-hawk, which by some has been considered of so savage and wild a nature, as to render all means for taming it hopeless, has, nevertheless, in the hands of more able or patient guardians, proved not only docile, but amiable in its disposition. About four years ago, a young Sparrow-hawk was procured and brought up by a person who was fond of rearing a particular breed of Pigeons, which he greatly prized on account of their rarity. By good management and kindness, he so far overcame the natural disposition of this Hawk, that in time it formed a friendship with the 
Pigeons, and associated with them. At first the Pigeons were rather shy of meeting their natural enemy on such an occasion, but they soon became familiarized, and approached without fear. It was curious to observe the playfulness of the Hawk, and his perfect good-humour during feeding-time; for he received his portion without any of that ferocity with which birds of prey usually take their food, and merely uttered a cry of lamentation when disappointed of his morsel. When the feast was over, he would attend the Pigeons in their flight round and round the house and gardens, and perch with them on the chimney-top or roof of the house, and this voyage he never failed to take early every morning, when the Pigeons took their exercise. At night he retired and roosted with them in the dovecot; and though for some days after his first appearance, he had it all to himself, the Pigeons not liking such an intruder, they shortly became good friends, and he was never known even to touch a young one, unfledged, helpless, and tempting as they must have been. He seemed quite unhappy at any separation from them, and when purposely confined in another abode, he constantly uttered most melancholy cries, which were changed to tones of joy and satisfaction on the appearance of any person with whom he was familiar. The narrator of the above concludes his account by adding, that he was as playful as a kitten and as loving as a dove. In Egypt and Turkey too, a particular species is often domesticated, and may be seen in the farmyards and gardens, like the Sparrow-hawk just mentioned, in company with Pigeons, without showing any inclination to injure them; and in the course of 1833, a Hawk, which we believe to be of a similar species to that domesticated in Turkey, namely, the common Buzzard, not only sat upon the eggs of a common barn-door fowl, but instead of devouring them when hatched, according to its natural habit, actually paid them considerable attention, as long as they were allowed to remain in the place where they were hatched, though when removed to another more spacious enclosed situation, with the brood, notwithstanding she showed no inclination to kill them, 
she avoided them altogether, and incessantly struggled round the enclosure in hopes of escaping.

Another instance has been noticed near Lichfield. A female of the same species, domesticated and kept in a garden, was set with some eggs of the common poultry, which she hatched at the usual time. When the chickens were freed from the shell, this strange stepmother defended them in the most furious manner, scarcely allowing any person to approach the wooden box in which they were hatched and kept, and to which they retired whenever they chose; and no dog or cat could venture near without being stoutly assailed by the Buzzard. Its fury far surpassed that of a common Hen, as long as the chickens were young and helpless, but gradually slackened as they grew older; the habits of affection, however, never entirely ceased, for the chickens, after they became fullgrown fowls, remained with it, and all lived together in the same garden in perfect harmony. A single instance of so extraordinary a deviation from the general habits of birds, might have been received with hesitation, but when corroborated by similar occurrences, on record in other places, its truth scarcely admits of a doubt. We have heard, indeed, a still more extraordinary circumstance, namely, that of an Eagle, at an inn at Uxbridge, which also hatched and brought up several broods of poultry.

The attention of the Turks and Egyptians to certain Hawks, most probably arises from the respect paid to them in ancient times, when the Hawk was held sacred, and when even accidentally to kill one was punished by a heavy fine; and designedly to deprive it of life was a capital offence, and the culprit suffered death. Various reasons are mentioned by old writers for this veneration. Thus the Eagle was worshipped, as a royal bird, and the favourite of their god Jupiter. The Hawks were worshipped for different reasons; some because they were supposed to destroy scorpions, serpents, and divers dangerous reptiles. Others again were deified, or held sacred, because the priests, or augurs as they were called, made use of their swift flight in their divinations, or pretended fore- 
tellings of events which were to happen. And others, again, looked upon them as sacred, from an ancient tradition, stating, that once upon a time, a book, bound about with a scarlet thread, was brought to the priests of Thebes, by a Hawk, on which was written all the secret rites and customs of the divine worship of the Egyptians. This extraordinary respect was not only shown to the living birds, but was even more marked by the funeral attention paid to them when dead. Their bodies were wrapped up in linen folds, steeped in perfumed and precious oils, in order to preserve them; and in this state, they are still frequently found in what are called the mummy-pits of Egypt. A celebrated traveller, Mr. Salt, in his account of Abyssinia, a country bordering on Egypt, speaks of a certain species of Hawk, respecting which the people entertain a singular superstition. When they set out on a journey, if they happen to meet with one of them, they watch it very attentively, and draw good or evil omens, or signs, from its motions ; if it sits still, with its breast towards them, till they have passed, they consider it as a fortunate sign, and everything is expected to go on well during the remainder of their journey; whereas, if its back is turned towards them, it is considered an unfavourable sign, but not sufficiently so as to create serious alarm; but should it happen to fly away hastily on their approach, some of the most superstitious among them will immediately turn back, and go home again, and wait for a more favourable opportunity for undertaking their journey. Mr. Salt was so much struck with the resemblance of this species to the sacred Hawk, so often seen inscribed on the ancient picture-writings, or hieroglyphics, as they are called, of Egypt, that he considered it to be the same which was formerly held sacred and worshipped. 


\section{CHAPTER VIII.}

Owls. - Superstitions respecting. - Short-Eared. - The Great Snowy Owl.-White Owl.-Mode of Feeding.-Attachment to Young.-Used in Bird-catching.-Burrowing-Owl.-Dentirostral.-Notch-billed Birds. - Shrikes. - Mode of Feeding. Nests of.-Used in taking Falcons.-Puff-backed Shrike.Thrush Genus.-Instinctive Habits in Feeding.-Anecdote.Thrush and Young Cuckoo. - Fly-catchers. - Cotinga.Tanagers, Beauty of. - Serratirostral, or Serrated Beaks. Hornbills. - Plenirostral. — Strong-Billed. - Grackles._Paradise Birds.

THERE is still another family to be classed amongst the 1 rapacious birds, and forming a natural link in the chain after Eagles and Falcons, namely, Owls. Everybody who has once examined them must have been struck with the leading points of resemblance. An Owl's bill is almost like a Hawk's, short, hooked, and like its claws, evidently intended for the purpose of seizing and tearing to pieces its favourite food. An Owl's eye, too, is bright and clear, like a Hawk's, but, by being larger and more full, is better calculated for the twilight or midnight hours, preferred for prowling abroad in quest of prey. The chief peculiarities of the tribe consist in the advantages afforded them by

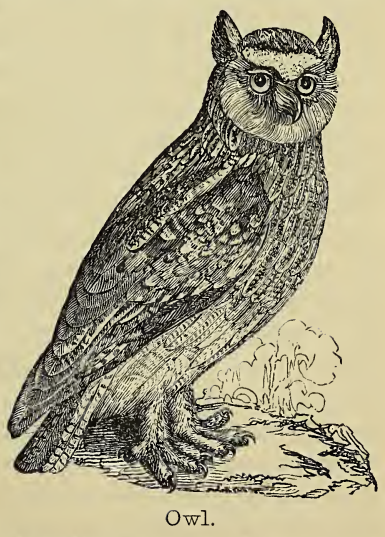
nature respecting their mode of flight, and sense of seeing and 
hearing. It is evident that, in order to make a prize of mice, and other small animals, which easily hide themselves in the ground, or under grass or heath, great silence and clearsightedness are necessary, as well as a very acute sense of hearing. Accordingly, the wing of an $\mathrm{Owl}$ is provided with feathers so remarkably soft and pliant, that in striking the air they make no resistance or rushing noise; and the bird is therefore enabled to steal along silently, in a manner very different from many other birds, such as wild Ducks, the whistling of whose wings may, particularly in a still night, be heard at a great distance; or even as the Plover, whose large soft flapping wings, at first sight, much resemble an Owl's; but which produce a well-known whirring sort of sound, as they wheel round and round in airy circles.

There is something so peculiar in the solemnity and secluded habits of this tribe of birds, that they have in all ages been regarded with a degree of superstitious feeling. Amongst the North American Indians it is customary for the priest or conjuror, on their most solemn meetings, to cover his head with the snowy skin of the great White Northern Owl; and by the ancients parts of its body were foolishly supposed to possess a sort of magical power; for instance, they imagined that the heart of a Screech-Owl, laid upon the breast of a sleeping person, would cause him to divulge secrets ; or that, if carried into battle, it would inspire courage and avert danger. In this country, people of former days always considered it as a bird foreboding mischief, and it was customary to hunt them on Christmas-eve; and even in later times superstitious persons have thought that the sudden appearance of an Owl, during the sickness of any member of the family, was a sure forerunner of death. These conceits wiser people have long since thrown aside; but nevertheless there is something so mournful and dismal in its night-shriek, and such a ghostly sort of motion in its silent gliding movements, when seen glancing through the twilight, or hunting for food in a bright moonlight night, that we can scarcely be surprised at the strange opinions and prejudices of ignorant or superstitious people. Generally speaking, however, a more 
harmless, we may say a more useful race of birds does not exist; since, with the exception of one or two of the larger and rarer species, their food consists entirely of vermin and insects very prejudicial to our crops, and which, but for these nocturnal hunters, might do serious mischief. A striking instance of their utility occurred some years ago in the neighbourhood of Bridgewater, in Somersetshire, where, during the summer, such incredible numbers of mice overran the country as to destroy a large portion of vegetation; and their ravages might have extended to an alarming degree, had it not been for a sudden assemblage of Owls, which resorted from all parts to prey upon them. Short-eared Owls (Strix brachyotos), to the number of twenty-eight, have been counted in a single field, collected together, no doubt, by swarms of mice, which in a favourable season had been bred there. This particular Owl only frequents England between the months of October and April, migrating in the spring to the northern islands of Scotland, where they breed. Its usual and favourite food is, as we have observed, field-mice; but they are bold, powerful birds, and, when their young are to be provided for, will chase Pigeons, and even larger birds, in the open day, particularly if the weather is gloomy. In a nest containing only two unfledged young ones, the remains of a Grouse and two Plovers were found, besides the feet of several others.

During their visits to this country, they are usually to be met with on wild heaths and commons, concealed in rushy places or long grass : a pair, and sometimes more, possibly the brood of the preceding spring, are usually found frequenting the same haunts. When first disturbed, they seldom fly far, but either hover over the dog, if there be one, or alight, and raising their two odd feathery horns (from whence they are called Eared $O w l s$ ), they fix their large round eyes intently on the object of their alarm. As a specimen of these Eared Owls we insert a figure representing the head of the largest of the family, the Long-eared Owl.

Their note is a singular snapping noise, not issuing from the throat, but occasioned entirely by a smart clicking of the bill ; so rapid, indeed, is this motion, that it is with difficulty 
the opening or shutting of the mandibles can be observed. As it is a bird of courage, the sportsman must be cautious how he attempts to handle it, for it has been known to spring up in the fiercest manner, and offer a most desperate resistance.

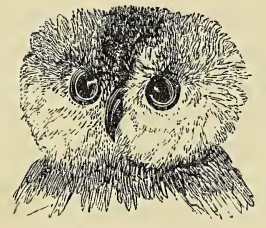

Fye and Bill of Owl.

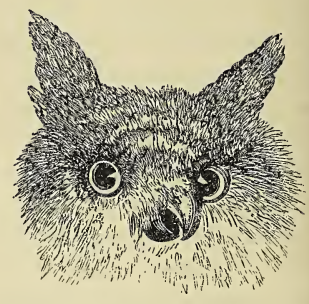

且ead of Long-eared $\mathrm{O}^{\dot{\mathrm{w}} \mathrm{l}}$

There are upwards of sixty species of Owls, widely spread over almost every part of the known world: of these, we may count not fewer than eight as more or less frequenting this country; of which by far the most beautiful is the great Snowy Owl (Strix nyctea), which may fairly, from its size and noble appearance, be called the Golden Eagle, or very king of Owls. It is a rare visitant, indeed, in England, chiefly confining itself to the wildest and most desolate regions of the north, where amidst almost perpetual snows, it passes its solitary life. When in perfection, its plumage is of the most dazzling snowy white, with a few darker spots, chiefly about the head. Its thick feathery coating is most admirably adapted for the countries in which nature has appointed it to live.

During the three summer months in those inhospitable regions, the temperature of the air is little above the freezingpoint, and during the remainder of the year far below it: were it not, therefore, for the mass of thick down and feathers in which its body is shrouded, it must soon perish under the intensity of cold; but as it is, it has nothing to fear; for with the exception of the tip of its beak and the extremities 
of its long black claws, no part is exposed. And again, were it not for its colour, which renders it almost invisible, as it silently skims over the snowy plains, the hares and other animals on which it preys would see its approach, and be prepared for escape.

Of course the habits of a bird so seldom coming under human observation can be but little known; but the few particulars we have been able to collect completely justify the above remarks. Thus, that its snowy plumage is essential to its means of existence, may be gathered from circumstances relating to a couple that were shot in the severe winter of 1823, in Northumberland. They had, for some days before they were killed, been observed in the wild and rocky parts of an open moor, either perched upon the snow, or on some large solitary stone projecting from it, from whence, without attracting notice by any contrasting colour, they could look out for their prey, and be prepared to seize it, as it incautiously approached. As the smaller species hunt for mice, so does this search for hares and rabbits, on which it pounces, and in a similar manner swallows them, when possible, whole; a fact ascertained in the case of one shot at and wounded in the island of Balta, which, on being approached, disgorged an entire young rabbit; another, when taken, had a Sandpiper, with the whole plumage, in its stomach. As they were often found dead by Captain Sir Edward Parry, who spent so many months in their most frequented neighbourhood, it is concluded that they frequently perish from want of food; indeed, their eagerness to partake of the hunter's fare, and carry off the spoil in his presence, is a proof that they must often be severely pressed by hunger. Sportsmen in the north* assure us, that they keep watch on some high tree or lofty rock, and the moment the gun is fired and the game killed, they descend, and skimming rapidly down, secure the prey before the shooter is able to get near it.

Ptarmagans are a favourite food of these birds, and are well aware of their danger. Their mode of escape is, on perceiving the Owl about to pounce upon them, to dive instantly into 
the loose snow, and make their way beneath it to a considerable distance.*

Our well-known White Owl is a very different bird in its habits : so far from wandering far from the abodes of man, it is always near or about our dwellings; the constant frequenter of our barns and outhouses, and one of the farmer's best friends ; for to it we are indebted for the destruction of the shrew-mice, a species which, but for the good service of our Barn-Owls, might prove a great annoyance to our gardens and fields, since, owing to a peculiar flavour or smell, neither cat nor dog will eat them. On the approach of twilight, they sally forth from their roosting-places, and hunt the meadows and hedge-banks with the regularity of a pointerdog; every now and then they may be seen to drop suddenly down, with great rapidity and unerring aim, on their game, which is seized on and swallowed at once, without any attempt to tear it in pieces with its claws. If, however, they have young ones, they carry off the prize in their claws; and here a curious piece of address is practised. It is evident, as long as the mouse is retained by the claw, the old bird cannot avail itself of its feet, in its ascent under the tiles, or approach to their holes; consequently, before it attempts this, it perches on the nearest part of the roof, and there removing the mouse from its claws to its bill, continues its flight to the nest. Some idea may be formed of the number of mice destroyed by a pair of Barn-Owls, when it is known that in the short space of twenty minutes the old birds carried food to their young twelve times, thus destroying at least nearly forty mice every hour during the time they continue hunting; and as young Owls remain long in the nest, many hundreds of mice must be destroyed in the course of rearing them.

If taken young they may be tamed, so far as to eat out of the hand, and become to a certain degree familiar; but in their wild state even, they seem to be sensible of kindness, and lose much of their shyness if never disturbed. A gentleman in Yorkshire, Mr. Waterton, who has paid great attention to their habits, gives a very interesting account of their mode

\section{* King's Narrative, vol. i. p. 126.}


of life. He made a sort of dwelling for them about four feet square, on the ruins of an old gateway, and trained some ivy round about, which soon concealed it. In the stone-work he fixed a thick oaken stick for them to perch upon. In about a month after everything was ready, a pair of Barn-Owls came and established themselves there. This succeeded so well, that he formed some other similar places, all of which were in like manner soon occupied by pairs of Owls. That in the old gateway was so contrived, that he could examine it whenever he pleased; and as they were never injured, the Owls soon grew confident, and betrayed no fear when strangers mounted a ladder to look in. One rather unexpected piece of information was learned from constant inspection, namely, that these birds, unlike others, seem to breed at all seasons, as he found a young brood hatched in September, and another in December; and he adds, that he considers himself as amply repaid for the pains he has taken in protecting and encouraging his Barn-Owls ; conceiving that it pays him a hundred-fold by the enormous quantity of mice destroyed throughout the year. Many, however, condemn them on account of the ravages they commit in pigeon-houses, by carrying off the young ones ; but this seems to be an unfair charge ; their real reason for entering pigeon-houses being rather for the purpose of picking up the vermin that are constantly harbouring there, than injuring the inmates.

Mr. Waterton observes, that when farmers complain that the Barn-Owl destroys the eggs of their Pigeons, "they put the saddle on the wrong horse." It ought, he says, to be put upon the rat; stating from his own experience, that his increase of Pigeons was inconsiderable till the rats were effectually excluded from the dove-cote, since which time they have increased abundantly, though the Barn-Owls frequent it, and are encouraged all about it. And he reasons very correctly, by saying, that if they were really enemies, the Pigeons would be in commotion as soon as the Owl began its evening flight, and entered their premises; but they heed him not. Whereas, if a Hawk should make its appearance, the whole community of Pigeons would be in confusion and 
alarm. We have another testimony in favour of the Owls with regard to pigeons. A person who kept Pigeons, and had often a great number of his young ones destroyed, laid it on a pair of Owls which visited the premises, and accordingly, one moonlight night, he stationed himself, gun in hand, close to the dove-house, for the purpose of shooting the Owls. He had not taken his station long before he saw one of them flying out with a prize in its claws; he pulled his trigger, and down came the poor bird, but instead of finding the carcass of a young Pigeon, he found an old rat nearly dead. Mr. Waterton met with a similar proof. He was one evening sitting under a shed, watching for rats, when he killed a very. large one as it was coming out of its hole, about ten yards distant. He did not immediately go to take it up, hoping to get another shot; when in a short time a Barn-Owl pounced down and flew away with it.

But there is another food of which Owls partake, little guessed at, we suspect, by many, namely, fish. The great Snowy Owl above mentioned is known to be a regular fishingbird. Motionless as the rock on which he sits, he waits patiently till a fish passes, when with the rapidity of a shot, he seizes it with his claws; but, although asserted by some naturalists, it had never been quite proved that the common Owls were also fish-catchers; but the fact has been now confirmed by the testimony of more than one credible witness. Some years ago several young Owls had been taken from a nest, and placed in a yew-tree near a gentleman's house. In this situation it was observed that the parent birds repeatedly brought them live fish, such as bull-heads and loaches, which had evidently been taken from a neighbouring brook, in which these species abounded. At subsequent times, bones of the same fish were frequently found lying under the trees on which the young Owls were observed to perch after they had left the nest, and where the old ones were accustomed to feed them. How they caught them was not then known; and the report of some labourers, employed to watch a fish-pond in the flower-garden, was not believed. This pond contained several gold and silver fish, which were observed to diminish in 
number, and it was suspected that the pond had been poached, and other persons were therefore appointed to watch; when lo! the poachers proved to be Owls, which alighted on the edge of the water, and there waited the approach of the fish; as soon as these came within reach, they were captured and devoured. This testimony has since been corroborated by another witness, who at twilight in July, happened to be standing on the middle of a bridge, watching an Owl carrying mice to its nest, when suddenly he observed it to drop perpendicularly into the water. At first he thought it had met with an accident, or had been seized with some sort of fit, but before he could reach the end of the bridge in search of a boat, he saw it rise out of the water with a fish in its claws, and convey it to its nest. It has been conjectured by some, that as fish are attracted by a light or any shining substance, there may be a luminous appearance in the large round and bright eyes of an Owl, like those of a cat, which are known to all for their glaring in the dark, by which the fish are attracted within reach of its beak or claws. How far this conjecture may be true we know not, but it is worthy of consideration, on account of a very singular power possessed by one of the American Bitterns, which has been confirmed by several witnesses whose veracity it would be impossible to doubt. This bird, which lives almost entirely on fish, when in pursuit of prey, decoys them within reach by a light from its breast of considerable brilliancy, described by those who have seen it, " as equal to the light of a common torch." Whether it has the power of increasing or diminishing, or entirely putting out this light, is not known, but its use to it as a fishing-bird is very great, for it not only attracts the fish within reach, but when they are there, enables the Bittern to see them without difficulty.

Owls have been noticed for an extraordinary attachment to their young; whether, however, it exceeds that of other birds or animals may be difficult to say, but they will certainly visit and feed them long after they have been separated from the nest. Some young Owls, which had been so far tamed as to take food from the hand, were observed to lose all their fami- 
liarity on being hung out during the night, in consequence of renewed visits from the supposed parent birds, who fed them with as much eare and attention as if they had been with them without interruption.

Another instance in point was witnessed by a Swedish gentleman who resided several years on a farm, near a steep mountain, on the summit of which two Eagle-Owls (Strix bubo) had built their nest. One day, in the month of July, a young bird, having quitted the nest, was caught by the servants. This bird was, considering the season of the year, well feathered; but the down appeared here and there between those feathers which had not yet attained their full growth. After it was caught it was shut in a large hencoop, when, to his surprise, on the following morning, a fine young Partridge was found lying dead before the door of the coop. It was immediately concluded that this provision had been brought there by the old Owls, which no doubt had been making search in the night-time for their lost young one. And such was, indeed, the fact; for night after night, for fourteen days, was this same mark of attention repeated. The game which the old ones carried to it consisted chiefly of young Partridges, for the most part newly killed, but sometimes a little spoiled. On one occasion a Moor-fowl was brought, so fresh, that it was actually warm under the wings; a putrid stinking lamb was at another time deposited. It was supposed that the spoiled flesh had already been some time in the nest of the old Owls, and that they brought it merely because they had no better provision at the time. The gentleman and his servant watched several nights, in order that they might observe, through a window, when and how this supply was brought; but in vain-for it appeared that the Owls, which are very quick-sighted, had discovered the moment when the window was not watched, as food was found to be placed before the coop on those very nights. In the month of August, the attention on the part of the old birds ceased; but it should be observed that this was the usual period when all birds of prey abandon their young to their 
own exertions, and usually drive them off to shift for themselves in distant haunts.

It may be readily concluded, from this instance, how much game must be destroyed by a pair of these large Owls, during the time they rear their young. Our Barn-Owl is, by many, accused of being equally injurious to game, but experienced sportsmen are most of them of opinion, that game is rather preserved than destroyed by them: the great destruction, exclusive of poaching, proceeding from weasels, stoats, rats, \&c., which suck the eggs, and in one night will destroy a whole brood. Now Owls, although they may occasionally kill a bird or two, of which, however, we have considerable doubts, (for by night, young Partridges and Pheasants are in safe keeping under their mothers' wings,) live chiefly on small vermin, as we have seen; and in proportion as the Owls are destroyed, these noxious animals may be expected to increase.

That small birds, generally speaking, have a great dislike to Owls is clear, from the uproar that takes place if an unfortunate $\mathrm{Owl}$ is disturbed in the day-time, and compelled to appear in broad day-light; pursued, as it is sure to be, by a host of them, who persecute it by every means in their power. And we may therefore conclude, that they either take it for their real enemy, the Hawk, or that it does, now and then, when it can, feast upon any of them which may, by accident, fall into its clutches.

Of this antipathy, the bird-catchers in Italy know how to take advantage, it being customary with them to decoy small birds to lime-twigs, by tethering an $\mathrm{Owl}$ by the leg with a long string, which is thus kept hopping, and beating the ground, without being able to escape. The bird-catcher then hides himself behind a tree, and makes a chirping, which calls the small birds together, and on seeing the Owl they gradually approach nearer, and finding him unable to resist, become so bold, that they at length come within the line of twigs, and are made prisoners themselves.

Though apparently cowardly birds, and never the first to 
dispute with others of their own size, yet when pressed, they show considerable spirit and skill in defending themselves. One, which had been slightly wounded in the wing, was, when cured, placed in a large pen with a Sparrow-hawk, which had been some time confined there, and with whom, it was hoped, a new companion might live on friendly terms; but no sooner were they left to themselves, than the Hawk fell upon the $\mathrm{Owl}$, and a furious battle began. But the $\mathrm{Owl}$, so far from showing fear, defended itself most gallantly. He threw himself on his back, and awaited the charge of his enemy with patience and preparation, and by dint of fighting and scratching, preserved himself from injury. As long as they remained together, these battles were frequently repeated, and further acquaintanceship did not seem likely to ripen into friendship. Whether they would in the end have come to better terms cannot be known, as, after a time, the Owl's wing having gained strength, it took advantage of a favourable opportunity, and contrived to escape, leaving the Hawk in full possession of their joint prison.

One other species of Owl only shall we notice, which has a very different way of living and lodging, from those already alluded to. It is called the Burrowing Owl (Strix cunicularia). It is widely spread over the American continent, both North and South, though only to be met with in particular parts of each, where circumstances combine to make its residence convenient. It gets its name of Burrowing Owl, from the singular retreat it invariably prefers. Other birds of this family resort to solitary recesses in woods and forests, or ruined buildings, but this delights to dwell in open plains, in company with animals remarkable for their social disposition.

Lucien Buonaparte, the brother of Napoleon, who for many years lived in North America, and became a celebrated naturalist, thus speaks of it:- " Instead of sailing heavily forth in the obscurity of the evening or morning twilight, and then retreating to its abode, this bird enjoys the broadest glare of the noon-day sun, and fiying rapidly along, searches for food or pleasure, during the cheerful light of the day; and then 
returns to its underground dwelling, which consists of the burrows of the marmot, or prairie-dog, an animal abounding on the vast plains of the western part of the United States. These burrows are called by the natives marmot villages, and are so numerous and extensive, that they will sometimes spread over the face of the country for miles together. If disturbed, the Owls, which are usually seated near the burrows, either fly off a little way, and settle again, or descend into the holes, from whence it is no easy matter to dislodge them."

Another traveller, Captain Sir Francis Head, when travelling over some immense plains in South America, called the Pampas, fell in with them in company with the biscachos, an animal much resembling the above-mentioned prairiedogs, of very singular appearance, nearly as large as badgers, but their heads not unlike a rabbit's, except that they have large bushy whiskers. In the evening, they sit outside these holes, looking very serious, as if moralizing, thoughtful, and grave. These holes were guarded in the day-time by two of the above-mentioned little Owls, who were never an instant away from their post. As strangers gallop by, there, the Owls continue to sit, looking at them, first full in the face, and then at each other, moving their old-fashioned heads in a manner which was quite ridiculous, when, as the riders pass close to them, fear gets the better of their dignified looks, and they both run into the biscachos' holes.*

The next order which offers itself to our notice in the tables of classification, is the Passerine, subdivided into seven tribes, the first of which is the Crenirostral, from two Latin words, signifying notchbilled, as they are all more or less indented or notched to-

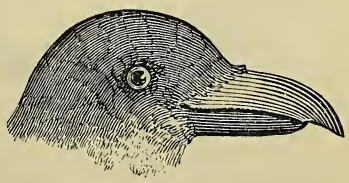
wards the extremity, as in the annexed figure.

In the preceding order the same peculiarity, indeed, exists, 
but in the crenirostral tribe the beak is, generally speaking, of a very different character, though in some cases there is a resemblance. In fact, the more we examine the arrangements of nature in its orders of created beings, whether in animals, birds, fishes, or insects, the more shall we be struck with the beautiful connexion between the several classes into which they are divided, and the utter impossibility of drawing up rules which shall, without exceptions, accurately define the marks of distinction. The works of God, in short, whether in the animal, vegetable, or mineral world, may be likened to

The letting down a golden chain from high ;

a chain of innumerable uninterrupted links, visible to us only in the intermediate portions, and each attesting the wisdom and power of its great Contriver. Thus, in the subject under our immediate consideration, we find that from the gigantic Condor or great Vulture of the Alps, to the small Humming bird, not exceeding in size a humble bee, there is a regular scale; that one class and family slides imperceptibly into another, till the most intelligent naturalist feels himself at a loss to define accurately where the one ends and the other begins. Of this we have an example in the link connecting the Eagle, Hawk, and Owl tribes with the first of the numerous families which remain for consideration. This link consists of a small but interesting division, called the Shrikes.

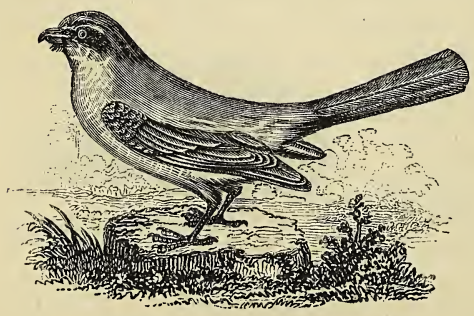

Shrike. (Table VII.,see page 12.) As many of them live chiefly, if not entirely, on beetles, grasshoppers, \&c., they have been considered as the Falcons of the insect world, pursuing and destroying vastnumbers of those countless multitudes that 
swarm in hot climates; and have also been named Butcherbirds, from a fierceness and cruelty of disposition which seems to lead them to kill and slay from mere wantonness, together with a singular habit of impaling their victim on thorns or cleft branches, where they are left.

In this savage character they resemble the birds of prey we have just noticed. In the form of their beak, too, there is a close resemblance, it being short, arched, and furnished with a strong projecting tooth near the tip, which is acute, and very analogous to the true Falcons. But they, at the same time, differ so essentially in other points, that some modern naturalists have removed them into a distinct class. Their limbs, for example, are very different from the Eagle and Hawk tribe, the toes being slender, and the claws comparatively weak. But although slender, their pressure is nevertheless powerful, and the bite they can inflict with their bill extremely severe, and capable of drawing blood from a man's finger in an instant. The uses of the separate qualities of the claws and bill are seen from the mode in which they seize their prey ; if, for instance, it is an insect, they pounce down, secure it with their sharp notched bill, and then press it under their feet to eat it; but when coming down on a bird or a mouse which they have pursued for some distance, they settle their feet on the head of the object pursued, at the same moment that they strike it with their bill; and in this manner one was seen carried a very considerable distance by a dove, on which it had fastened itself by its beak and feet. They differ again from the Eagles and Falcons respecting the treatment of their young; the Falcon tribe invariably driving them off to shift for themselves as soon as they are full grown, and capable of getting their own living, whereas the Shrikes, although cruel to a degree in theirgeneral habits, show a marked attachment, and of long continuance, to their young; and are indeed, in all respects, as far as concerns each other, the most amiable birds imaginable. They never drive them off, but live together on the best terms till the following season, when they separate by the instinctive laws of nature, each to procure its mate. This, we are sorry to say, is the only redeeming good 
quality we can point out in the character of the Shrike genus ; for in all other respects their whole lives seem to be spent in dealing out death and terror to their fellows of the feathered creation. A London bird-catcher, not long ago, caught one of them (Lanius excubitor) in his clap-net, in the act of pouncing down upon a valuable decoy linnet. At first he thought himself fortunate in capturing so rare and valuable a prize; but in a very short time he was glad to get rid of it at any price, for though it fed well on small birds and raw meat, and seemed tolerably accustomed to confinement, the moment it opened its mouth, and uttered its well-known note, his whole collection of singing birds were put to silence. All small birds indeed have the strongest antipathy to the Shrike, either betraying anger, or moaning, or expressing signs of fear when it approaches their nests. They will also mob, attack, and drive it away as they do the Owl, as if they were well aware of its plundering propensities; and with good reason, for it will conceal itself in a bush, or perch itself on some upper spray, to look out for prey : and no doubt avails itself of the absence of the parent birds, in order to pillage their nursery of nestlings; for a gamekeeper, who was in the habit of rearing Pheasants, observed, that if any of his brood were weak or sickly, a Shrike would occasionally contrive to draw them out through the bars of the breeding-coops; and a gentleman who lived in a part of North America where several of them harboured, actually discovered them taking his favourite singing-birds out of the cages which hung by his window.

Their usual food is however insects; but whether birds, mice, or insects, the same singular propensity has been remarked, that of frequently impaling the object they have caught on a thorn or pointed stick. That it thus destroys, when opportunity occurs, a far greater quantity of living subjects than it can possibly consume, is unquestionable; for they have been seen to be all day long seizing insects, as if actuated by a desire of destroying life, rather than procuring a store of food. This apparently wanton cruelty may, however, be turned to good account; for we have no doubt, that it was by a species of this bird called the Collared Shrike 
(Lanius collaris) that the following check was given to a plague of locusts. The account was sent from the Cape of Good Hope in 1829. During the spring of that year, the locusts abounded to such a degree on the southern coasts of Africa, that the whole country was completely ravaged, and the most serious apprehensions were entertained for any renewal of vegetation which the rains might promote, when the locust-birds made their appearance in vast flocks and successfully interfered. The writer adds, that their mode of attacking, and destroying, and impaling these destructive insects, was quite extraordinary, and far surpassed all human efforts.

Mr. Selby, a celebrated English naturalist, was fortunate enough to see the whole process of pinning a Hedge-sparrow by one of these Butcher-birds. Having seized his victim, he immediately killed it, and then hovered with it in his bill for a short time over the hedge, apparently occupied in selecting a thorn suited to his purpose. Upon disturbing it, and advancing to the spot, he found the Sparrow already firmly fixed by the tendons of the wing, at the selected twig. In another instance, a Shrike was observed busily occupied near a thorn hedge; on examination, three frogs, and as many mice, were found regularly spitted on thorns. With the design of catching this Butcher-bird, six very small steel traps were set, baited with mice. On the following day two of the traps were found to be sprung, and the baits gone. As it was not an easy matter to accomplish this without being caught, the traps were then watched. At length, the Shrike approached, and darting down, was rising perpendicularly with his prize; but in this instance, notwithstanding the celerity of his movements, the teeth of the trap caught his claws and secured him by two of the toes. The bird was put in a room, in which a thorn-bush was placed, and some dead mice provided, one of which he was soon observed to seize, and spit on a thorn with the greatest quickness and dexterity.*

That one of the reasons for thus transfixing their prey is 
for the purpose of more conveniently feeding on it, there can be no doubt; for if confined in a cage, they evince a similar propensity, and if not provided with a thorn, will invariably fasten it to the wires before commencing their repast. It has however been suggested, that as the quantity destroyed, particularly of insects, so far surpasses the wants of the destroyer, they may be placed on the thorns as baits. This seems to be a prevailing opinion in America, where one species of this bird, called the Nine-killer, is very abundant, for on spots frequented by it, the thorn-bushes may be seen furnished on the naked thorns with grasshoppers, transfixed precisely in the same manner; all regularly, and in their natural position as when on the ground, not one of them having his back downwards. After the frost sets in, there they still remain unconsumed; the Shrikes, at the same time, watching the smaller birds, and catching them near these hedges.

Of the two sorts visiting England, one only, we believe, breeds here, namely, the Red-backed Shrike, (Lanius collurio.) It is one of our latest birds of passage, probably coming from a great distance, as it is found in the southern part of Africa, as well as South America, and also probably because the insects it prefers are not abundant till late in the spring-season. There is another peculiarity worthy of notice; that it is, generally speaking, very rare in most parts, confining itself to particular districts; such as parts of Essex, the Sussex downs, Wiltshire, and Gloucestershire, where it is by no means uncommon. May not this be attributed to something in the soil, or other local causes favourable to the production of its favourite food? If so, it might be desirable to ascertain to what species of insect it gives the preference, which might lead to some curious inferences in natural history,--throwing light on the remarkable locality observed so often in the animal as well as vegetable world; for, notwithstanding the greatest care and attention, although not the slightest difference of soil, climate, or situation, can be pointed out, it has been often remarked, that an insect, or a plant, abundant in one place, is not to be found in another, at no great distance. 
A few years ago, a naturalist, for curiosity, removed to his garden several webs-full of the larvæ of the brown-tail moth (Ph. phaorrheus), which, from its numbers and voracity, had been looked upon as a perfect scourge where it abounded. For a time, the caterpillars seemed to feed and thrive, and finally spun themselves up. In the next season, however, few came forth; and at the season when the hedge might have been expected to swarm with the newly-hatched eggs, not one appeared.

But to return to our Shrikes : in the parts of England frequented by them, no great difficulty or acute observation is requisite for finding them out. In the first place, the bird announces its arrival by a croaking and most unmusical voice, from the summit of some tree; then it builds a large and ill-concealed nest, which, if not found out by actual detection, the male will usually discover by its own imprudence, manifesting great uneasiness and clamour when any one approaches. No sooner are the eggs hatched, than the female lends her aid to the discovery of her brood, uniting her vociferations to those of the male. And should the nest, by extraordinary good luck, continue undiscovered, no sooner are the young ones capable of making a noise, than they all join in the cry upon any approach to their bush. We have noticed the lengthened kindness existing between the old and young birds; this begins from the moment of their issuing from the egg; for no birds can be more assiduous in their attentions to their offspring than the old Shrikes; feeding them most carefully, long after they have left the nest,-an instinctive precaution, probably more necessary in these than most other birds, as, for a long time, in consequence of their being heavy and inactive when young, they would be unable to pursue and capture those winged insects which constitute their chief food. If taken early, they may be easily tamed; but their pugnacious disposition, which does not appear in their own family circle when wild, is often fatally conspicuous when they are confined in a cage. Mr. Montague, who kept several, found, that at about the end of two months, violent battles ensued, to such a degree, that he was obliged to 
separate the survivors, and chain them in the manner Goldfinches are frequently confined, when they became very docile, - would come when called, for the sake of a fly, of which they were remarkably fond, though they would also eat mice or birds, spitting, or fastening them, or pieces of raw flesh, on their cage, in order to tear them ; disgorging the feathers, fur, and bones, in pellets, like Hawks and Owls.

Of two, thus kept for some time, the deaths were rather singular; one choked itself by swallowing too large a quantity of mouse-fur, which it could not disgorge,- the other, by eating to such a degree, that it actually died of fat and repletion; expiring in Mr. Montague's hand, in a fit, when in the act of feeding on insects. In some countries, the young of the species of Shrike found there, are trained for hawking or other purposes.

In Russia, they are sometimes used for the former amusement; in Bengal, they are taught to fight,-a cruel diversion, - one being held up opposite to another, in the hand of a man, to whose finger the bird is fastened by a string, sufficiently long to enable it to fly at and peck its adversaries. By others, it is so well trained, that, at a given signal, it will seize and carry the small golden ornament usually worn on the head of young Indian females, and convey it to its master. It will also, with wonderful celerity, follow the descent of a ring, purposely thrown down a deep well, catching it in its fall, and returning it to its owner.

In parts of Holland and Germany, it is used for catching Hawks, in rather a curious way; showing some other of its peculiarities. The Falcon-catchers generally make their preparations in October and November, when the Hawks are on their passage towards the southern parts of Europe. The falconer constructs a low turf hut, in an open part of the country, with a small opening on one side ; at about a hundred yards' distance from the hut, a light-coloured Pigeon is placed in a hole in the ground, covered with turf, with a string attached to it, which reaches to the hut; another Pigeon is placed in a similar situation on the opposite side, at the same distance. At ten yards' distance from each Pigeon, a small 
bow-net is fixed in the ground, so arranged as to be pulled quickly over by means of a small piece of iron, made fast to the net, and reaching to the hut; the string by which the pigeon is held passes through a hole in a piece of wood driven into the ground, in the centre of a bow-net. The falconer has also a decoy Pigeon, in a string, at a short distance from the hut; and several tame Pigeons at liberty on the outside, which, on sight of a Hawk, immediately take shelter within. The Butcher-bird is fastened by a leather thong on a hillock of turf, a yard in height, and a few yards distant from the hut; a small hole is made, and a piece of turf laid over, for a place of retreat in case of danger.

The falconer has some quiet and sedentary employment in hand, to occupy his time, which does not prevent his observing every motion of this his little watch-bird; and it is almost incredible at how great a distance he will perceive a Hawk in the air. If it comes near, he shows symptoms of alarm,drawing in his feathers, and fixing his eyes in the same direction : on its approaching still nearer, he screams aloud; the Hawk being then, perhaps, not less than three or four hundred yards distant; on its closer approach, he retreats under the turf, and quite conceals himself. It is then the falconer draws out the Pigeons where the nets are fixed, which, fluttering round, generally tempt the Hawk to make a stoop at one of them, which if he takes, he is inevitably ensnared. While the Hawk is near, the Shrike continues in his hidingplace, hardly daring to show his head at the entrance of his retreat: should the Hawk be taken, or pass over without touching the Pigeons, he cautiously creeps out, yet almost afraid to trust himself on his hillock, looking on every side, and does not for some time recover from his alarm. There is one Hawk, the Goshawk, of which he is particularly afraid, screaming louder than ever, and making every attempt to escape, as if aware that this Hawk will even seize him in his hiding-place, should it catch sight of him, which the other Hawks will not do. $\mathrm{He}$, on the other hand, shows less alarm at the sight of the Kite or Buzzard, unless very near indeed; so that, by the motion of the Butcher-bird, the falconer can 
tell, almost to a certainty, what species of Hawk is approaching, without running the risk of discovery, by looking out from his retreat. Were it not for the penetrating and keen eye of this his watch bird, he would sit many dreary hours to no purpose, as he would not know when to pull the Pigeons out to lure the Hawk. Like most other birds, they appear constant to particular spots for breeding.

A bird-collector, in the island of Anglesea, mentioned his having, for many seasons, found a few in, or near, a certain field: his mode of catching them was by watching the twigs on which they perched, on returning to their nest; these he prepared with bird-lime, and seldom failed capturing several specimens.

Some of the foreign species of Shrikes have an addition of plumage, of a fanciful character. The annexed engraving is a representation of the Puff-backed Shrike; the light downy tuft bears a close resemblance to a powder-puff; it must add either to the comfort or convenience of the bird, though in

what way we can form

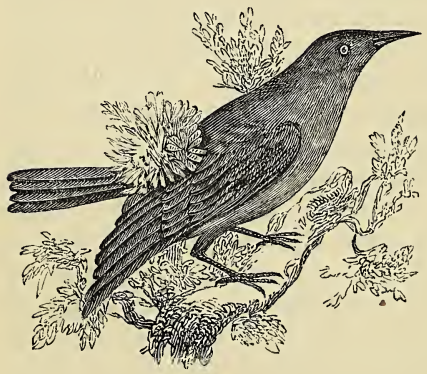
no opinion.

After the Shrikes, we find in the tables the Thrush genus (see Table VII., page 12), of which we have in England seven species, viz.,-1. Missel-Thrush; 2. Fieldfare; 3. SongThrush; 4. Redwing; 5.Ring-Ousel; 6. Blackbird; and 7. WaterOusel or Dipper.

The first of these, the Missel-Thrush, is not only the largest, but the finest and boldest of the family, and has some claims to our esteem, from its being the earliest song-bird of the year; often favouring us with its notes, at a season when every other bird slinks away to its hiding-place, glad to escape the inclemency of the weather. In the height of a 
heavy gale of wind, the Missel-Thrush may be seen braving the blast, perched on the quivering branch of some tall tree; hence it has gained the name of the Storm-Cock. It is, moreover, a gallant bird; and during the breeding season, woe be to the Jackdaw or Magpie that ventures to cast a wistful eye at its eggs : nay, more, we have known it attack even a Hawk, and fairly drive him from the neighbourhood.

The Redwing and Fieldfare are but visitants: their summers are passed in far-distant northern regions, where they rear, unmolested and unseen by man, those immense flights which frequent our fields and forests in the winter season. It is generally supposed that they are hardy birds; but the very reverse is the case, for, in severe weather, should there be a dearth of food, they are the first to suffer. In hard winters, when sudden falls of snow have deprived them of their usual supply, thousands have been known to perish on the coast, unable, through weakness, to take flight for a more southern climate. In January, 1815, when a heavy fall of snow fell on the 19th, and remained one deep white mantle over the face of the country till the 29th, during which time the thermometer, even at noon, rarely rose above the freezingpoint, we recollect finding dead Redwings in greater numbers than any other birds. They are naturally remarkably shy, but hunger soon makes them tame, as many a Christmas school-boy knows; when, if the weather is mild, he in vain endeavours to get a shot at a chattering party, temptingly perched on a naked bough; whereas, should a severe frost set in, they seem to invite his approach, and allow him to take a steady aim within a few yards. Our common Song-Thrush, however, is a more social bird, and, if unmolested, will build its nest frequently almost within sight of our windows. Instances have, indeed, occurred of still greater confidence. Thus, a short time ago, in Scotland, some carpenters working in a shed adjacent to the house, observed a Thrush flying in and out, which induced them to direct their attention to the cause, when, to their surprise, they found a nest commenced amongst the teeth of a harrow, which, with some other farming tools and implements, were placed upon the joists of 
the shed, just over their heads. The carpenters had arrived soon after six o'clock; and at seven, when they found the nest, it was in a great state of forwardness, and had evidently been the morning's work of a pair of these indefatigable birds. Their activity throughout the day was incessant, and when the workmen left off in the evening, and came again in the morning, they found the female seated in her half-finished mansion, and, when she flew off for a short time, it was found that she had already laid an egg, though the bottom of the nest was the only part plastered and completed, evidently to meet the pressing necessity of the female bird. When all was finished, the cock took his share in the hatching; and, though he did not sit so long, he was very attentive in feeding her when on the nest. In thirteen days the young birds were out of their shells, which the old ones carried off. It is generally supposed that the usual food for nestling thrushes consists of grubs and worms, quantities of which they may be constantly seen collecting on lawns, particularly after showers have moistened the earth; and, to those who have opportunities of observing them, nothing can be more interesting than the way they, as well as Blackbirds and some other birds, set about it.

Watch an old Thrush pounce down on a lawn moistened with dew or rain. At first he stands motionless, apparently thinking of nothing at all; his eye vacant, or with an unmeaning gaze. Suddenly he cocks his ear on one side, makes a glancing sort of dart with his head and neck, gives perhaps one or two hops, and then stops, again listening attentively, and his eye glistening with attention and animation; his beak almost touches the ground,-he draws back his head, as if to make a determined peck. Again he pauses; listens again; hops, perhaps, once or twice, scarcely moving his position, and pecks smartly on the sod; then is once more motionless as a stuffed bird. But he knows well what he is about; for, after another moment's pause, having ascertained that all is right, he pecks away with might and main, and soon draws out a fine worm, which his fine sense of hearing had informed him was not far off, and which his hops and previous peckings had 
attracted to the surface, to escape the approach of what the poor worm thought might be his underground enemy, the mole. But to return to the young Throstles in the shed. In this case the food was not worms, but snails. The old ones brought them in their shells, from which they cleared them, by breaking the shell with a smart knock on the tooth of the harrow, catching the snail, without, in one instance, letting it fall. They now and then varied the feast with a few worms, and occasionally with butterflies and moths. As is usual with almost all birds, the old ones were invariably seen to carry away the dung of the young birds, which might otherwise, by its accumulation, be a great inconvenience. They would, however, be unable to do this, were it not for a curious natural precaution, namely, that the dung of young birds is voided in a thin tenacious bladder or bag, which can be removed without breaking. As the young grew, and required greater supplies, the entrance and retreat of the old ones through the door was so rapid, that it could scarcely be seen, but was only known by the sound, as they darted over the heads of the men; another proof of the rapidity of flight, of even the slower flying birds, when urged by necessity.

The above fact of Thrushes feeding on shell-fish, has been corroborated by the observations of a naturalist, who, on the shores of the Hebrides, on the western coast of Scotland, found small heaps of shells belonging to two particular species, whelks and periwinkles, always broken, but without the animal, although many appeared quite fresh. On frightening away a Throstle, which he had seen engaged in breaking something which it held in its beak against a stone, he found one of the small heaps of whelks, among which was a fresh one, newly broken, and containing the animal. As the shell of the whelk and periwinkle is much harder than that of the common snail, it was a matter of considerable surprise how so tender an instrument as the beak of a Thrush could accomplish it, but we see in the above case that the bird was instinctively taught to avail itself of a power which accident placed within its reach.

Here we have a curious instance of a Thrush's confidence 
in man: but a more singular instance, considering the nearness of the parties concerned, fell under our observation a season or two ago: namely, a Blackbird's nest on the ground, in a tuft of grass or rushes close to the seat of a rabbit, the tail, in fact, of the rabbit being in contact with the nest. As the seat as well as the nest were both occupied, these two companions must have sat meditating together for many a day, in perfect peace and good fellowship. We do not know whether the Blackbird ever sings on its nest, which might have been a very gratifying attraction to the rabbit; but the Thrush unquestionably sometimes does. Few birds, indeed, seem to be more liberal in the use of their voice; we have heard it repeatedly, on fine nights, in the latter end of May, singing till after dark, and have been roused from our slumbers by a repetition of the same well-known song by two o'clock in the morning. The following anecdote connected with the intelligence of Thrushes, in alluding to their modes of feeding, may not be out of place. Not long ago, in the city of Norwich, a gentleman had a young Thrush and equally young Blackbird, both in fact nestlings, which he kept in the same cage. The Thrush soon learned to feed itself, not so, however, its companion the Blackbird, which no doubt would soon have died from exhaustion, had not the Thrush undertaken the office of nurse, which it perseveringly continued for ten days, regularly feeding the starving bird, until at the expiration of the above time, it was competent to feed itself.

Those who have seen a young Cuckoo fed by its unsusspicious step-mother, seated on a bough or rail, opening its wide-gaping mouth, as if ready to swallow the poor little bird that hung over it with fond attachment, fluttering its little wings as it dropped a caterpillar down the monster's greedy throat, will be the less surprised at the following anecdote, of what may be called unnatural attachment between Thrushes and birds of a very different character.

We know nothing of the strange ways by which Providence brings about some of the apparently singular contradictions in its established rules; but knowing for a certainty, that by 
some strange delusion, a small Hedge-Sparrow is persuaded to look upon an enormous Cuckoo as its own beloved young one, may we not suspect that the Cuckoo has some instinctive mode of gaining the affections, or attracting the attention of those birds from whom it requires assistance? The case was this,-A young Cuckoo was taken from the nest of a HedgeSparrow, and a few days afterwards, a young Thrush, scarcely fledged, was put into the same cage. The latter could feed itself, but the Cuckoo, its companion, was obliged to be fed with a quill; in a short time, however, the Thrush took upon itself the task of feeding its fellow-prisoner, and continued so to do with the utmost care, bestowing every possible attention, and manifesting the greatest anxiety to satisfy its continual craving for food.*

The following is a still more extraordinary instance, corroborating the above, and for the truth of which we can vouch in every particular. A young Thrush, just able to feed itself, had been placed in a cage ; a short time afterwards, a young Cuckoo, which could not feed itself, was introduced into the same cage, a large wicker one, and for some time it was with much difficulty fed; at length, however, it was observed that the young Thrush was employed in feeding it, the Cuckoo opening its mouth and sitting on the upper perch, and making the Thrush hop down to fetch food up. One day, when it was thus expecting its food in this way, the Thrush seeing a worm put into the cage could not resist the temptation of eating it, upon which the Cuckoo immediately descended from its perch, and attacking the Thrush, literally tore one of its eyes quite out, and then hopped back: the poor Thrush felt itself obliged to take up some food in the lacerated state it was in. The eye healed in course of time, and the Thrush continued its occupation as before, till the Cuckoo was full grown.

The Fly-Catchers form the third genus of the notch-billed

* In dissecting a young Cuckoo, killed August 20,1833, about twenty full-grown caterpillars, of the peacock butterfly (Pap. Io), were found undigested. The stomachs of these birds are remarkable for having a coating of hair, which, when dried and turned inside out, looks very similar, in colour, size, and form, to a mouse's head. 
birds; we have but two sorts in our country; and one of these, the Pied Fly-Catcher (Muscicapa atricapilla), is so rare as to be seldom seen; the other, however, known by the name of the Beam-bird, is common enough, building very frequently upon the ends of beams, or rafters in gardenhouses, from whence it probably takes its name. They act the part of Hawks amongst flies, feeding on them alone, and always on the look-out. In summer-time, it is very interesting to watch a Beam-bird, perched on some prominent twig, commanding a view all round. In an instant it may be seen to dart, like a little shot, upon a fly passing often at so great distance, that it would quite escape our powers of vision; but by no means that of this keen-sighted bird, for the fly is no sooner seen than caught, and brought back with equal rapidity to the twig on which the bird was before

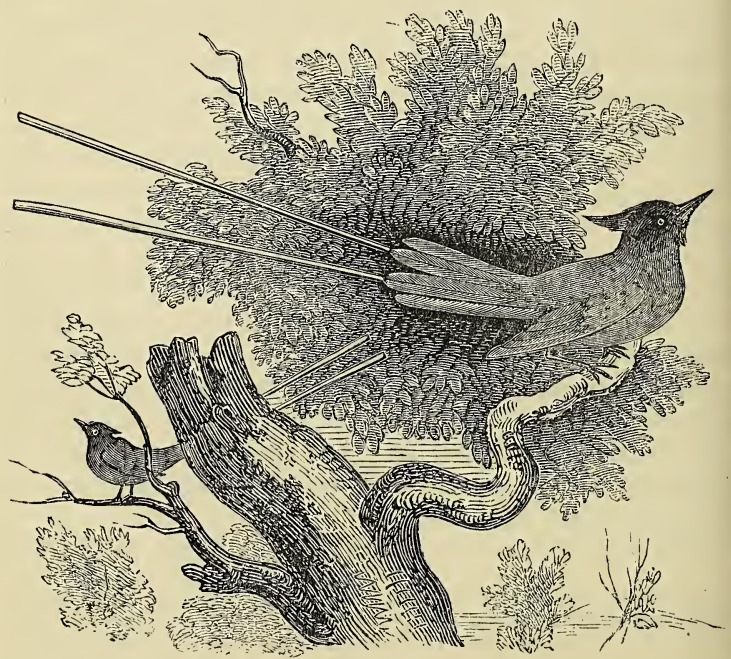

The Paradise Fly Catcher. 
perched. The clearness of sight in birds is indeed prodigious, and has been calculated by an eminent naturalist, (Lacépède,) to be nine times more extensive than that of the farthestsighted man.

The foreign varieties of this kind are, many of them, of exquisite beauty in plumage, and elegance in form; we may mention, for example, the Paradise Fly-Catcher.

Of the fourth genus, (the Cotingas,) we have but one species in England, and that but rarely seen, the Silk-tail, or Waxen Chatterer, from the secondary quills of the wings being ornamented with a flat horny substance, of a bright vermilion colour, looking like red sealing-wax. In foreign countries, however, there are many varieties, amongst others, the singular Bell-Bird, of which we have spoken. It is about the size of a Jay, of a pure white, with nothing remarkable in its appearance, except that from the junction of the forehead and base of the beak, a long fleshy sort of slender wattle hangs down; the bird has, however, the power, either by filling it with air, or exciting the muscles, of rendering it quite stiff, when it sticks up like a horn of about two inches in length. We have alluded to the probability of this odd appendage, in some way or other, being the cause of the deep bell-toned sound of its note, the air it contains probably contributing to its utterance.

Of the Tanagras (Table VII., p. 12,) we have not one in Europe; which is much to be lamented, for although they would not enliven our groves with their song, the brilliancy of their plumage would make ample amends. In the different species, every colour, in its brightest hue, may be found, sometimes mingled together, as in the Painted Tanager (Tanagra picta), where the brightest shades of green, blue, orange, and black, are so intermingled as to render it, when exposed to the full rays of the sun, almost dazzling to look upon. In another, the Scarlet Tanager, there are only two colours ; but so contrasted, as to produce the strongest effect; the wings and tail appearing like the deepest shade of jetblack velvet; while the rest of the bird is of the deep crimson blood-red colour of the fleshy part of a ripe cherry. Its note 
is very simple, but has one peculiarity : viz., that although the bird may be close at hand, the sound appears to come from a distance; and as it lives generally in the most secluded shades of the forest, it is not improbable that this deception in its note may often be the means of preserving its life, the hunter being thus led away from an object so easily discovered; but which, owing to the apparently distant sound, he little suspects to be within his reach.

\section{TABLE VIII. (See page 12.)}

Order 2. Passerine. Tribe 2. Serratirostral (serrated bills), so called from the jagged or tooth-like edges of the bill.

THIS tribe consists of but three genera: 1 . the Plant1 cutter; 2. the Momots; 3. the Hornbill; all foreign birds, and their habits but little known. Of the last, namely, the Hornbills (Buceros), living specimens are occasionally taken; and in the spring of 1833 , one was procured for the Zoological Gardens, in the Regent's Park, London, but notwithstanding every attention, it did not live long. Of the seemingly deformed and monstrous bills of these birds, we have already spoken.

Of their use, we are still much in the dark, but if, as may be presumed, the horny substance is furnished with highly sensible nerves, for the purpose of smelling or feeling, we can more easily account for their instinctive discovery of snakes,

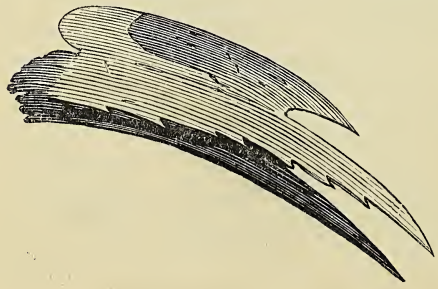
on the eggs of which, as well as insects and fish, they feed. On passing over a spot where the snake has concealed itself, though many feet underground, the Hornbill immediately begins digging till it 
has uncovered it. They are found in Africa, but even there seem to be scarce, and are highly prized; their flesh being used as a remedy in many disorders, being placed hot to the part affected.

\section{TABLE IX. (See page 13.)}

Order 2. Passerine. Tribe 3. Plenirostres ( full and strong beaked).

THIS tribe comprises a number of full and strongbeaked 1 birds, some of which, as the Pies and Crows, are familiar to us, others again, such as the Grackles and Paradise-birds, are foreigners. The Grackles, indeed, are widely spread, some species inhabiting the hottest, and others the coldest climates, from the torrid zones of India to the remoter parts of North America : and they might probably be naturalized in this and other countries, where hitherto they have been strangers.

Like our Jackdaws, with which, indeed, they are very closely allied, being the connecting link between the Crow and Thrush tribe, they are a pert, familiar, lively race, soon tamed; and when so, making themselves so perfectly at home, as to be often a great inconvenience. In North America, they contrive to gain the good will of even a greater enemy than man, no less a one than the Osprey, or Sea Eagle, which actually permits them to build their nest amongst the interstices of the sticks of which its own nest is framed,* where they hatch their young, and live together in harmony, like the small bird in the nest of the African Eagle, mentioned in p. 109.

They herd together in immense flocks, rising from the ground in such prodigious numbers, that their wings make a noise resembling thunder; and when they settle, whole trees are covered from the top to the lowest branches, looking as black as if hung in mourning. In India, they assemble in much the same way, though not quite in such abundance,

\section{* Richardson's Fauna Americana.}


and like our Rooks and Crows, are suspected of doing mischief, by picking out the new-sown grain; but as we shall soon see when we come to treat of our crows, the charge is a good deal exaggerated.

It happened some years ago, that one of the French islands, in the East Indies, was overrun with locusts, to such a degree, that there was every appearance of the crops suffering severely. The governor, a sensible and observing

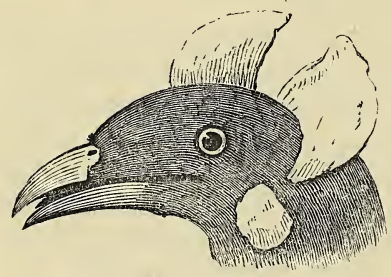

Head of Gracula Reliǵiosa. man, and well acquainted with the habits of the Grackles, imported a number of them from the Continent, as they never bred upon, or visited the island. The consequence was, that the locusts rapidly diminished in number; but the people, seeing the birds busied in thrusting their bills into the new-sown fields, fancied they could be only occupied in picking out the grain, and accordingly they made war upon the poor Grackles, and destroyed them all, and forthwith the locusts reappeared in full force. The fact is, the Grackles, like our Rooks and Crows, are great destroyers of grubs and insects, though at the same time it cannot be denied, that they may occasionally commit partial depredations on the farmer's property.

Some birds of the Grackle genus have a singular appendage to the head, composed of a naked skin or wattle, which gives them a very odd appearance, as shown in the above figure.

Of the Paradise-birds we know but little, for they are almost entirely confined to New Guinea, and a few neighbouring islands in the Indian seas, inhabited by wild tribes, with whom travellers have but little communication. These people catch the Paradise-birds and dry their skins, which they barter with ships passing along the coast. It was for a long time believed, by ignorant persons, that they had 
no legs, for they were never seen alive, excepting when flying across from one island to another, the natives always bringing dead specimens for sale, without the legs, possibly because they thought they looked better without them, in many species the leg being coarse, and unbecoming a bird in every other respect so exquisitely beautiful. It is quite impossible to describe their beauty, or give even a faint idea of it without coloured representations; and few of the most favoured of the feathered race can rival them in the gorgeous variety and singularity of their splendid dress. Some are ornamented with light projecting tufts, of a fine downy substance, while others have plumes and tendrils flying out in every direction, like pennants and streamers, while their bodies glisten with the most dazzling and resplendent hues, changing from crimson and gold to the most delicate green or purple, according as the sun's rays fall upon the feathers. It is said that they frequent the most retired spots of the thick woods of their native country. If so, it is difficult to conceive how they can move amongst close and entangled boughs, without injuring their loose and delicate robe of plumage; or, for what purpose Providence has so fancifully and profusely decorated them with ornaments apparently so inconvenient.

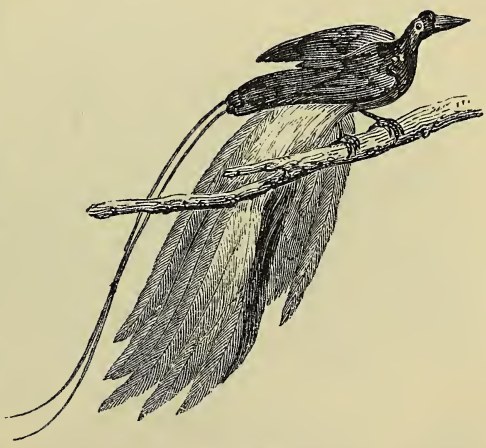

Great Bird of Paradise.

None have ever reached this country in a living state, and but one species, that we are aware of, has ever been kept in confinement. This was the great Paradise-bird, the flowing yellow plumage of whose tail is so much prized as an orna- 
ment for ladies' head-dresses. It was in the possession of a gentleman who had a valuable aviary of the rarest foreign birds, at Macao, in China. He kept it in a large cage, where it had abundance of room for the display of its gaudy dress, of which it seemed very proud; dancing about when visitors approached, as if delighted at being made an object of admiration. It washed itself twice every day, and then threw up its delicate feathers nearly over its head. Nothing appeared to disturb it so much as any sort of dust attaching itself to its plumage. For at its toilet it pecked and cleaned all within reach, and throwing out the elegant and delicate tuft of feathers underneath the wings, cleaned each in succession, by passing it through its bill. Having completed its toilet, it would utter its usual cawing notes, and then look archly at the spectators, as if ready to receive their admiration.*

* See Bennetr's Wanderings in New South Wales, vol. ii.

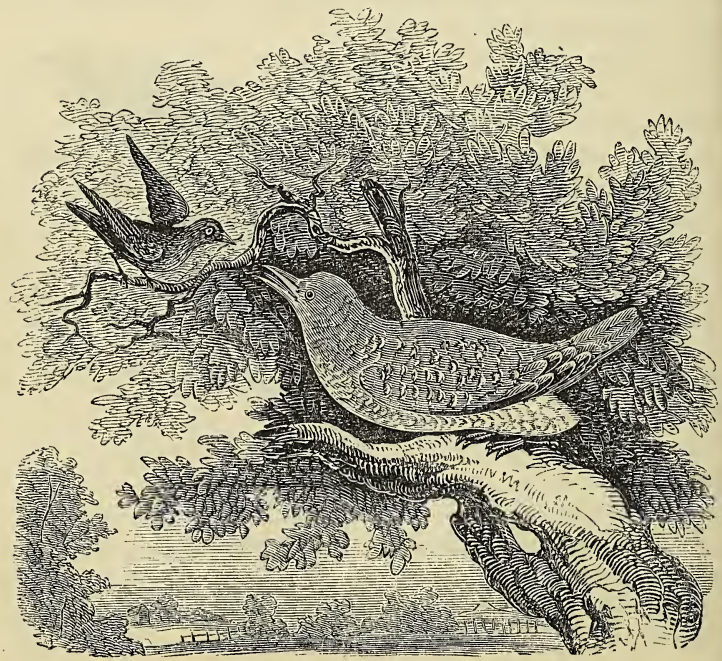

Young Cuckoo fed by a small Birã 


\section{CHAP'TER IX.}

Ravens-occasionally desert their Young.-Predacious Habits. Sagacity.-Various Anecdotes.-Crows and Rooks.-Characters of each.-Tame Crow.-Meetings, or Councils, of Crows, Herons, Magpies, etc. - Whether Rooks are beneficial or injurious to the Farmer.-Hard Winters favourable to Insects. -Rookeries.-Red-legged Crow.-Jackdaws. - Jays and Magpies.

TO a superficial observer of nature, there may appear a 1 much greater resemblance and connexion between the Raven, the Crow, the Rook, and Jackdaw, than we find from experience to be the case. At the same time, so different in outward appearance are the Jay and Magpie, that it may appear contrary to all rule to class them together under one head-but while there is a decided mark of separation between each and all of them in many respects, they nevertheless are by naturalists included in the first section of what is called the genus or family of Crows. The Raven, however, from his size and character, naturally takes the lead. Go where we will over the face of the wide world, and the wellknown hoarse croak of the Raven is still to be heard. $\mathrm{He}$ was seen perched on the bare rocks, looking over the dreary snows of the highest points visited in the Arctic Expeditions. Under the burning sun of the Equator he enjoys his feast of carrion. He was discovered in the islands of the Pacific Ocean by Captain Cook; and in the lowest southern or antarctic regions, other travellers have found him pursuing his cautious predatory life, just as in England.

With us he may be called the herald of the year; for, as early as the latter end of January, if the weather be mild, or at all events in the beginning of February, some faithful pair (for the union of the male and female is for life) may be seen looking into the state of their nursery-tenement, usually con. structed on the upper and most inaccessible branching fork of some high tree, where they have been known to build 
beyond the memory of the most ancient chronicler of the parish. Probably most of our readers have, if not within their own precincts, at least within their knowledge, a venerable establishment of this description. Ours is a noble beech, about ninety feet in height, in the centre of a beautiful wood, -from time immemorial called the Raven tree. At one extremity of this wood, a noisy troop of Jackdaws have long been accustomed to rear their progeny unmolested, provided they venture not too near the sacred tree of the Ravens,in which case, one or other of the old birds dashes upon the intruder, and the wood is in an uproar, till the incautious bird is driven off. Few have dared to scale the height of this famed tree; but the names of one or two individuals are on record, who have accomplished the perilous undertaking, and carried off the contents of the nest.

Some years ago the wife of a neighbouring farmer made such loud complaints, on the diminution of a fine brood of young Turkeys, which occasionally wandered from her farmyard into some fields adjacent to the wood, that one of the old ones was shot: it proved to be the female, whose young ones had unfortunately been hatched, and were then nearly fledged. For a time, the surviving parent hovered about the nest, uttering loud and menacing croakings whenever anybody approached. At length, however, he disappeared, and absented himself for two or three days, and then returned with another mate; when a strange scene occurred. The poor half-starved nestlings were attacked without mercy by the stepmother; who, after severely wounding, precipitated them from the nest; two, however, were found at the foot of the tree with signs of life, and with great care and attention reared at the Rectory, about half a mile distant, and after being slightly pinioned, were allowed their liberty; but they seldom quitted the lawn or offices, roosting in a tree in the shrubbery. Here, however; they were soon discovered by their unnatural parents, who, for a long time, used to come at early dawn and pounce upon them with fierce cries. This antipathy to their young (which by several authors has been considered as peculiar to Ravens) has been remarked by 
many, who have not only known them to show great indifference to any young ones accidentally thrown out of the nest, but have further ascertained that the parents actually devour them.

It would appear from some passages in the Sacred Scriptures, that the desertion of their young had not escaped the observation of the inspired writers. It was certainly a current belief, in the olden times, that when the Raven saw its young ones newly hatched, and covered with down, it conceived such an aversion, that it forsook them, and did not return to the nest, till a darker plumage had shown itself. And to this belief commentators suppose the Psalmist alludes, when he says, He giveth to the beast his food, and to the young ravens which cry. (Psalm cxlvii. 9.) And again, in Job, Who provideth for the raven his food? When his young ones cry unto God, they wander for lack of meat. (Job xxxviii. 41.)

But we do not believe this want of feeling to be peculiar to Ravens; on the contrary, in an aviary where several Canaries build annually, instances repeatedly occur of young birds falling out of the nest, when, if they are of very tender age, the old ones seem to show no uneasiness whatever; hopping or flying over them with the greatest unconcern, though the poor naked birds may be struggling for life.

We have yet, indeed, much to learn respecting the real extent and quality of the affection of animals for their young; for in the case of Canaries we have known, if wet or cold weather chanced to continue for a day or two, not only nests containing eggs, but others, with nearly full-fledged nestlings, requiring all a mother's care, to be at once abandoned, and left to perish by cold or hunger.

On the 2nd of June, 1833, a Canary bird in an aviary was unexpectedly drenched, having built her nest, during dry weather, in a spot exposed to rain, which fell in a heavy shower on that day. On the following day, she accordingly quitted her nest, and appeared so unwell, that it was deemed expedient to remove her into a small cage, and place her in a warmer situation. But to our great surprise a Goldfinch, 
which had been in confinement with the Canary birds for three or four years, without paying any attention to the nests, immediately took her place, and continued to sit very closely, though uselessly, over the chilled and lifeless eggs, which were completely addled.

At all events, while sitting or rearing its progeny, the Raven deserves the highest credit for persevering attachment, and has been known (though one of the shyest and most suspicious of birds) to die rather than desert its post. Mr. White, the naturalist, of Selborne, speaks of an old oak as his Raven-tree, which bulged out into a large excrescence in the middle of the stem, defying the attempts of all who aspired to get at the nest. Many had tried in vain; all were ambitious of surmounting the arduous task, but when they arrived at the swelling, it jutted out so in their way, and was so far beyond their grasp, that the most daring and expert climbers were awed, and were obliged to give up the undertaking as too hazardous. So the Raven built on, nest after nest, in perfect security, till a fatal day arrived when the wood was to be levelled. It was in the month of February, and the old one was on her nest. The saw and the hatchet were both at work, the wedges were inserted into the opening, the woods echoed to the heavy blows of the beetle or mallet, the tree nodded to its fall; but still the dam sat on. At last when it gave way the bird was flung from her nest, and though her constancy deserved a better fate, was whipped down by twigs, which brought her dead to the ground.

But constant or affectionate as they may be to their brood, it lasts but for a time; and as is the case with Eagles, and indeed almost all birds, when the young ones are sufficiently matured to take care of themselves, the old ones invariably drive them away and live independently. We have noticed their hostility to the Jackdaws and other birds daring to intrude on their favourite haunts; they are themselves, however, occasionally very outrageous marauders on the property of others. Between Rooks and Ravens, if a rookery perchance is within visiting distance of a Raven's abode, there 
is eternal warfare ; and no wonder, for they will venture to attack the very nests, and carry off the unfledged Rooks as food for their own young: and those who are partial to rookeries have found it necessary to shoot the Ravens and destroy their nests, as the only effectual means of keeping peace amongst the Rooks. But notwithstanding the Raven's superior courage, he does not always succeed; for not only Rooks, but Carrion Crows will sometimes put them to flight. A person once heard an uncommon chattering and clamour proceeding from a tree, and going near to learn the cause, observed no less than three Ravens successively issue from the tree, followed by a single crow, which pursued and drove them fairly off.

Generally speaking, they are solitary birds, the same pair only remaining together; but occasionally this is not the case, particularly in the northern parts of Europe, where they are more abundant, and are often seen in greater numbers. Thus, in the month of June, 1832, a party leaving the Bay of Kirkwall, in the Orkney Islands, north of Scotland, counted twenty-four of these birds passing over their heads flying towards the north ; they were very near to each other, and followed in the same way as Rooks usually do in returning to their rookery; and about a week afterwards twenty-six were observed by the same party flying to the southward. There is reason, however, to believe, that these assemblages of Ravens ought not to be admitted as proofs of their being, under any circumstances or seasons of the year, really gregarious ; that is, naturally disposed to associate in flocks, but is rather to be attributed to the attraction of distant food, which, if beyond the reach of vision, they can by some unknown faculty discover at great distances. It can scarcely be by scent, for in those northern regions, when all is calm and quiet, and the severity of frost rapidly destroys all the effluvia of dead matter, still troops of Ravens, within an incredibly short time after the slaughter of an animal, will be seen advancing from all points to this common centre of attraction, like the Vultures of which we have before spoken, though at the time not a single bird was to be seen 
on the wing. This sagacity in discovering their prey is indeed too well known in some less-favoured spots, where food is scarce for man, as well as beast or bird, and the Raven's presence is looked upon as a perfect nuisance. Thus in the Hebrides, Shetland, Feroe Islands, and Iceland, they are sadly destructive. Nothing escapes them; they watch the Wild Duck to her nest, and drive her from her eggs; they pounce upon fish like Fishing Hawks; they attack the ewe as well as the lamb, and fixing on a galled horse, feed on his flesh even while living. It is not therefore surprising, that laws are made for their extirpation. Accordingly, in the Feroe Islands every man who is in a condition to catch fish, must deliver annually the bill of one Raven, or those of two Crows, or in failure thereof, must pay a certain sum to the provincial judge, that these destructive birds may be exterminated. Besides its human enemies, it has, in those islands, other very forminable ones of its own order, in the shape of certain sea-birds, called the Oyster-catcher (Hamatopus ostralegus), or Sea-pie, and the Puffins, or Sea-parrots. The former follows it in its rapid flight, and darting its long sharp bill into its back, makes it scream out, and then by a shrill cry, collects several more of its own species, which unite in pursuing the persecuted Raven, and oblige it to seek shelter in holes amongst the rocks, where its back can be protected.

The Puffin acts rather in self-defence, for the Raven is the aggressor, attacking the Puffins for the purpose of eating their eggs, of which the Ravens are remarkably fond; in this case a desperate fight ensues; for the Raven usually takes an opportunity of committing the theft when the Puffins are at sea in search of food, and he can without opposition enter the holes or burrows in which the Puffins breed; but should the latter catch the robber in the hole on returning, it darts its claws into its breast, seizes him by the neck with its strong, razor-formed bill, and as soon as they issue from the hole, struggling with each other, the Raven endeavours to ascend to the land, while the Puffin, on the contrary, does its best to descend to the water; and if it succeeds, it becomes for the most part the conqueror, for when the Raven's 
feathers get soaked, he can no longer defend himself, and perishes.

Young Ravens, it is well known, may be easily tamed; but they are so cunning and mischievous, that it is necessary for those who harbour them to keep a constant watch on their motions, for they will catch up anything that is glittering, and carry it off to some secret hiding-place. Stories without end might be told of their thieving propensities. Let one suffice : a gentleman's butler having missed a great many silver spoons and other articles, without a suspicion as to who might be the thief, at last observed a tame Raven with one in his mouth, and watching him to his hidingplace, discovered more than a dozen. But pilferers as they are, and inclined to mischief, they have redeeming good qualities, which often make them deservedly great favourites, and they may be sometimes trained for useful purposes.

Thus the landlord of an inn, in Cambridgeshire, was in possession of a Raven which frequently went hunting with a dog that had been bred up with him. On their arrival at a cover, the dog entered, and drove the hares and rabbits from the thicket, whilst the Raven, posted on the outside of the cover, seized every one that came in his way; when the dog immediately hastened to his assistance, and by their joint efforts nothing escaped. On various occasions the Raven has proved of more use than a ferret, and has been known to enter a barn with several dogs, and enjoy the sport of rat-hunting. The sagacity of these birds is certainly quite extraordinary, and might almost lead us to suppose that they were gifted with reasoning powers.

It would be needless to enumerate the many instances which might be mentioned. We must quote a few, commencing with one communicated by a friend. All birds, we know, have an instinctive faculty of finding their way, when on the wing, to certain spots they have been accustomed to frequent, in which it might be supposed that eye-sight, from high elevation, might materially assist them; but in the following case it will be seen, that the inhabitants of the air are not in all cases indebted to this sense for discovering their 
former abodes, but can, like dogs and various other quadrupeds, and even turtles, as we have before remarked, find their way by some unknown faculty to places from which they have been removed. A few years ago a gentleman, near Chapel-le-Frith, in Derbyshire, took a young Raven from its nest, and kept it in an out-building for some months; its wings were then clipped, and it was allowed to go at large. It soon became well known for a mile round, regularly visiting every farm-house within that distance whenever a pig was killed, when it was always rewarded with some titbits. Soon after the death of its owner, about three years ago, the Raven was given to a surgeon, resident in Stockport, Cheshire, who kept it chained by the leg for about twelve months ; he then gave it its liberty, and as before, it wandered about near home, but not with the same success, for its thigh was one day broken by some idle, thoughtless boys, who threw stones at it. The fracture was reduced, the Raven recovered, and then again took to rambling about for a few weeks, when it disappeared altogether, and was supposed to have met with an untimely end;-when, about a fortnight after it had been missed, the news arrived of its safe return to its old residence at Chapel-le-Frith, distant fourteen miles, where it was allowed to remain, and where it still lives.

A writer in the Naturalist's Magazine says that he remembers, about fourteen years ago, seeing on a post near the Elephant and Castle inn, at which such a multitude of coaches stop, an inscription on "Ralph," a Raven of great celebrity, who had been in his days a distinguished member of the Elephant and Castle establishment. Those who recollected him gave several instances of his sagacity, amongst others, that of his knowledge of, and intimacy with, several of the coachmen; with his particular favourites and friends he would frequently take short jaunts out on the coach top, until he met some other coach, whose driver he also knew, passing in a homeward direction, when he would immediately change coaches and return.

A still more curious anecdote of attachment and observa- 
tion in Ravens, is given in the weekly periodical, the Saturday Magazine, which, from its application to the subject before us, we here repeat. It occurred many years ago, at the Red Lion Inn, Hungerford. A gentleman who lodged there, thus tells the story :- " Coming into the innyard," says he, "my chaise ran over and bruised the leg of a favourite Newfoundland dog, and while we were examining the injury, Ralph, the Raven, looked on also, and was evidently making his remarks on what was doing; for the minute my dog was tied up under the manger with my horse, Ralph not only visited him, but brought him bones, and attended him with particular marks of kindness. I observed it to the ostler, who told me that the bird had been brought up with a dog, and that the affection between them was mutual, and all the neighbourhood had been witnesses of the many acts of kindness performed by the one to the other. Ralph's friend, the dog, in course of time, had the misfortune to break his leg, and during the long period of his confinement, the Raven waited on him constantly, carried him his provisions, and scarcely ever left him alone. One night, by accident, the stable door had been shut, and Ralph had been deprived of his friend's company all night; but the ostler found, in the morning, the door so pecked away, that had it not been opened, in another hour Ralph would have made his own entrance. The landlord not only confirmed the ostler's account, but mentioned many other acts of kindness, shown by this bird to all dogs in general, but more particularly to maimed or wounded ones."

But, however attentive they may be to dogs, as in this case, or to men, as in the preceding one, the following instance of shrewd cunning shows that they are ready enough, when it suits their interest, to trick each other. At the Zoological Gardens, in the Regent's Park, London, two Ravens were kept in one large cage or pen; a visitor passing by, threw them two pieces of bun, when one of them immediately jumped from his perch, and before his comrade could reach either of them, he had both secure in his beak, and had regained his former position on the perch, holding them until 
he saw his comrade at the further end of the cage; he then flew down, buried one of the pieces, which he carefully covered with gravel, and jumping back to his perch with the other piece, devoured it. He then hopped down for the other piece, and regaining his perch a second time, consumed that, much to the annoyance of his companion, whom he thus artfully and cleverly contrived to outwit.

No wonder that so knowing a bird, gifted, at the same time, with a voice so deep and solemn as to command attention whenever it is heard, should, in all ages, have impressed superstitious people with a notion that it had something unearthly in its nature; and in heathen countries especially, should have been respected by the ignorant as interpreters of the will of their idol gods. Thus, in the remotest periods of antiquity, the Raven was consecrated to Apollo, one of their chief deities, and by the priests and people was therefore considered as a foreteller of good or evil. Through a long course of centuries it has borne the same character, and even to this day there are not a few who believe that

\section{_ "Ravens give the note of death,}

As through mid-air they wing their way."

It is most probable that their supposed prophetic powers, respecting battles and bloodshed, originated in their very frequent presence on these occasions, drawn to the field of slaughter by an attractive banquet of unburied bodies of the slain. Hence, poets have described it as possessing a mysterious knowledge of these things.

“ Ill-omen'd bird ! as legends say,

Thou hast the wondrous power to know,

While health fills high the throbbing veins,

The fated hour when blood must flow."

The Icelanders, notwithstanding their endeavours to destroy as as many as they can, yet give them credit for the gift of prophecy, and have a high opinion of them as soothsayers. And the priests of the North American Indians 
wear, as a distinguishing mark of their sacred profession, two or three Raven-skins, fixed to the girdle behind their back, in such a manner that the tails stick out horizontally from the body. They have also a split Raven-skin on the head, so fastened as to let the beak project from the forehead.

That birds, if entirely unmolested, will become tame and fearless, has been frequently noticed. During Captain Back's Arctic expedition, two Ravens appeared as his earliest visitors, announcing the approach of Spring; he would not suffer them to be disturbed, and in a few days they consequently became so familiar as scarcely to move ten paces when any one passed them : they were the only living things, he adds, that held communion with the party, and it was a pleasure to see them gambol in their glossy plumage on the white snow.

\section{CROWS AND ROOKS.}

People who live in towns, or pay little attention to these matters, would no doubt consider the above-mentioned birds as one and the same, alike as they are in size and colour, and seen, as they usually are, spread over our fields, or uttering their well-known cawings on the top of some hedge. They are, however, as distinct in their characters and habits as a hare and a rabbit. The real Crow, commonly called the Carrion Crow (Corvus corone), is the next link in the chain after the Raven, which it resembles far more nearly than it does the Rook. The male and his mate, for example, seldom associate with the rest of their species, except, as we shall show by-and-by, for particular purposes, but generally remain in pairs. Their favourite food, too, like the Raven, is carrion, and they will watch their opportunity, and pounce down on young lambs, or even sheep, when they find them what is called cast,- that is, thrown upon their backs in a furrow, and unable to rise. In these cases, the eye is the point which they first attack; but smaller living prey they will also attempt to carry off, to be devoured at leisure. A 
person walking near a plantation heard a shrill cry, and running in to find out the cause, discovered a Crow fastening itself on a young rabbit, weighing from half to three-quarters of a pound, which was making great efforts to release itself, but in vain, for the Crow actually caught it up and bore it away across two or three fields. Such is their favourite food; but, when pressed by hunger, they will also feed on potatoes, barley, or, in short, whatever comes within their reach.

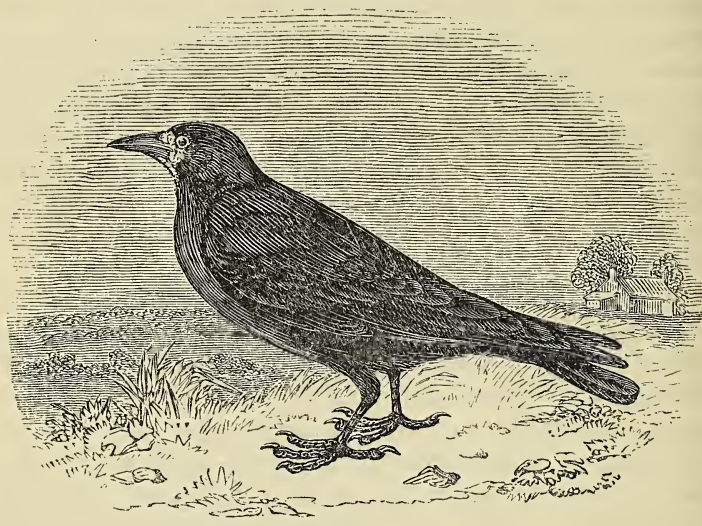

Rook.

The Rook, on the other hand, is a social bird, passing its days with those relations and friends amongst whom it was born and bred; and for its food, preferring a vegetable diet, or such insects as it can collect under the sod of the meadow, or pick up in its progress over a fallow or freshploughed field. There is one intermediate link seen, in parts of England, between the Carrion Crow and the Rook, namely, the Hooded-gray or Royston Crow. They are clever birds, and when frequenting the sea-shore, in search of shell-fish, may be frequently seen, after vain attempts to 
break through the hard shell of a cockle or mussel, to seize it in their bill, mount with it to a great height, and then let it fall on a hard rock, by which it is broken, and the bird has nothing more to do than to reap the fruits of its forethought.

It is said that this species of Crow will pair with the common Crow, a proof how nearly allied the two species are; as it seems almost an established law of nature, one at least rarely infringed, that neither animals nor birds essentially differing, however near may be their apparent resemblance, will ever breed together. One great difference, besides the colour, which in the Hooded Crow is, as we have remarked, partly gray, is, that the latter is a regular migrating bird,- - that is, going and coming at certain times of the year, to certain districts. But even in this respect the Carrion Crow has been known to resemble it in a slight degree; it having been remarked by a naturalist, that in the parish in which he resided no Crows were seen for several months, and what became of them, or whither they went, he could never learn.

The Crow, like the Raven, may be easily tamed, and converted into a very entertaining member of a family; though, like the rest of the tribe, he is sure to carry off, to some secret store, whatever he can conveniently dispose of. He soon becomes quite familiar, and distinguishes, at a glance, a stranger from one of his friends ; and, even after a long absence, will recollect those from whom he has received kindness. A gentleman had reared one, and kept it for a long time, but at length it disappeared, and was supposed to have been killed; when, to his great surprise, about a year afterwards, as he was walking out, a Crow, flying over his head, in company with others, left them, and, flying towards him, perched on his shoulder. He soon recognised the bird to be his lost favourite; but, though the Crow appeared very glad to see its old master, it seemed to have learned the value of liberty, and would not allow itself to be caught; and at last, looking up after its companions, again took wing, and was never seen or heard of more. 
It has been observed, that they are usually of solitary habits, seldom associating in greater numbers than pairs; but this rule has also its exceptions, and the following instances of the mysterious assemblages of birds may be justly classed amongst their most extraordinary instinctive habits.

In the northern parts of Scotland, and in the Feroe Islands, extraordinary meetings of Crows are occasionally known to occur. They collect in great numbers, as if they had been all summoned for the occasion; a few of the flock sit with drooping heads, and others seem as grave as judges, while others again are exceedingly active and noisy: in the course of about an hour they disperse, and it is not uncommon, after they have flown away, to find one or two left dead on the spot. Another writer* says, that these meetings will sometimes continue for a day or two, before the object, whatever it may be, is completed. Crows continue to arrive from all quarters during the session. As soon as they have all arrived, a very general noise ensues, and, shortly after, the whole fall upon one or two individuals, and put them to death: when this execution has been performed, they quietly disperse.

Another and nearly similar meeting was witnessed near Oggersheim, a small village on the banks of the Rhine; where, in a large meadow, every autumn, the Storks assemble, to hold (as the country people call it) a council, just before their annual migration. On one of these occasions about fifty were observed, formed in a ring round one individual, whose appearance bespoke great alarm. One of the party then seemed to address the conclave, by clapping its wings for about five minutes. It was followed by a second, a third, and a fourth, in regular succession, each, like the first, clapping its wings in the same odd and significant manner. At last they all joined in chorus, and then with one accord fell upon the poor culprit in the middle, and despatehed him in a few seconds; after which they rose up

* Dr. Edmonston's Shetland Isles. 
in a body, and one, according to their custom, taking the lead, flew off to the southward. This curious story is in some degree corroborated by the opinion of old writers, one of whom, in describing the migration of these birds in the eastern countries, says, that when they go away, the Stork that comes last to the place of rendezvous is killed on the spot by the others.*

At Dunham, near Altrincham, in Cheshire, the seat of the Earl of Stamford, there is a heronry, which has existed for many years. It happened, about the latter end of March, or beginning of April, a few years ago, that a gentleman, riding along the turnpike-road, saw, in a small field, about a mile from the trees where the birds breed, about thirty-five or forty standing on the ground, and occasionally moving slowly in various directions. At first he was uncertain what birds they were, as their heads were thrown back, and they appeared little raised from the ground; but, on approaching the spot, he was soon satisfied that they were Herons. His presence, however, had no other effect (though in general they are remarkably shy and cautious) than inducing those nearest the hedge, where he had stationed himself to watch their motions, to walk leisurely to a more distant part of the field. He remained for some time a spectator of their singular assemblage, which impressed him with the opinion that it was a deliberate council; and we agree with him that in this case, at least, though not in the preceding, which occurred in the Autumn, their object was connected with the usual pairing, which takes place about that time. We are the more strengthened in the opinion, from having witnessed meetings in some degree similar amongst Magpies, and some other birds.

In the month of February, we recollect once seeing a prodigious number of Magpies in a field; some hopping about near the edge, others secreted in the hedges, and no less than twenty-seven perched on a small ash-tree. At first, the presence of a fox was suspected, knowing it to be a constant

* Bellonius. 


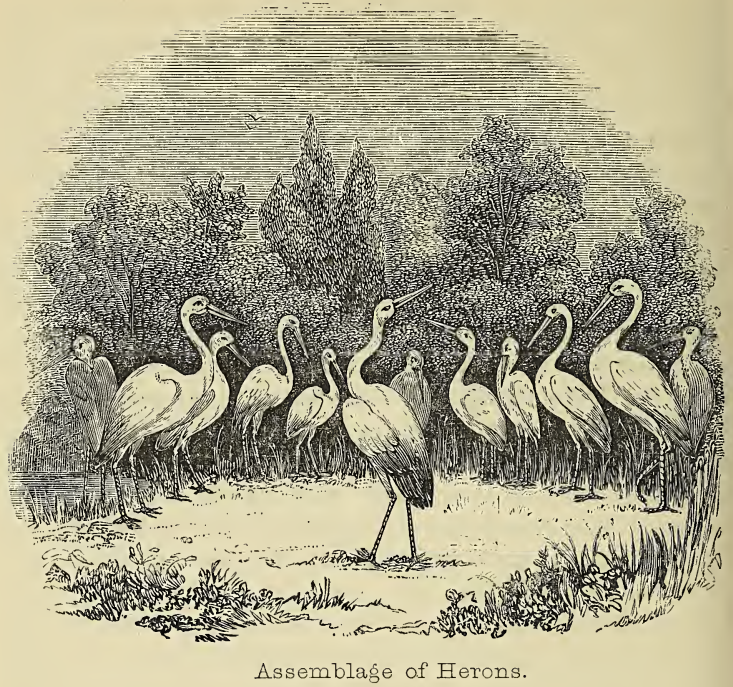

practice with these birds to collect, if Reynard shows himself; but as they did not appear to be hovering over any particular spot, as if a concealed enemy was lurking near, we inclined to the opinion, that some private concerns of their own had brought them together. The chattering was incessant, and when disturbed, and under the necessity of beating a retreat, they flew nearly in the same direction, as if disposed to adjourn their meeting to a more retired spot, than with a view to break it up.

A singular habit, somewhat similar, little known or noticed, though uncommon, prevails also among Starlings. If carefully watched, they may be seen occasionally to alight in a regular circular form. A numerous flock was once seen to divide itself into two companies, each forming a distinct circle. If undisturbed, they will remain a considerable 
time in the same place, uttering the same twittering note upon the ground, as when perched on trees or reeds. This habit is usually observable in pastures; sometimes, though rarely, in stubble-fields; but never upon fallow or newploughed land.

We have pointed out some of the broad marks of distinction between the Crow and the Rook, as far as relates to their food and habits : a slight reference to the personal difference between them will be sufficient. The beak of the Crow is more bent and rather stronger, and is never without the bristly feathers that cover the base and the nostrils, as is the case with the Rook, whose beak, when of full growth, is easily distinguished by the naked and scurfy white skin at its base and on the skin, produced, as some naturalists assert, by the bristles being rubbed off, owing to its constantly thrusting its bill deep into the soil, in search of worms and insects. We feel, however, much inclined to doubt this, and would rather attribute this nakedness in the base of the bill to an original and natural peculiarity. It has been well argued, in favour of the former opinion, that a specimen was killed whose beak was much longer than usual, and the extremities of which were not only much curved, but actually crossed, like a Crossbill's, and that the base of the beak of this bird, from an impossibility of its being thrust into the ground, was clothed with a full plumage of bristles, and not bare like those of other Rooks. On the other hand, it has been urged, that if these bristles were worn down by being thrust into the ground, they would be renewed, like other feathers, at the regular moulting-time; and, further, as all new feathers are full of blood at the roots, any application tending to grind them down would be so painful to the Rook, that it would be very unwilling, if indeed able, to thrust its beak into the ground; and again,-which we consider as a still stronger argument,-it may be asked, if the Rook's bristles are destroyed by this process, how comes it that the Jackdaw, Jay, and Magpie, and some other birds, retain them, though as constantly thrusting their beaks into the ground, in search of worms, as the Rooks? 
When viewed together, a further distinction will be seen between the Rook and the common Crow, in the glossy colours of their plumage; that of the Rook being more inclined to a rich purple, whereas that of the Crow is of a greenish blue. There is one other supposed distinctive mark, which we shall mention, merely because we believe it does not exist, namely, that the Rook has a pouch under its chin, in which it can carry a full supply of food for its young.

It is perfectly true that Rooks appear to have such an appendage, which, in the Spring-time, is particularly conspicuous, when they may be seen flying with a swelling under the throat, of the size of a Pigeon's egg; but closer observers have discovered that in the Crow, Jackdaw, \&c., there is the same elasticity and pliability of the skin, and that they not only can, but do often take in a provision of food, which swells the upper part of the throat out to a considerable size; though, owing to the grey colour of the Rook's chin, this swelling is more apparent.

We now come to a more important question respecting Rooks, in the settlement of which the world is much divided. Are they beneficial or injurious to man? Is the farmer a gainer or a loser, by being subjected to the daily visits of two or three hundreds of these birds from a rookery?

In former days, there can be no question of public opinion being entirely against them, and that the destruction of Rooks was regular and systematic,-an inference which may be fairly drawn from the following entry amongst certain presentments concerning the parish of Alderley, in Cheshire, in 1598, being the fortieth year of Queen Elizabeth's reign: "We find that there is no Crownett in the parish, a payne that one be bought by the charge of the parish."

As in most cases, so in this, we are inclined to think that a great deal may be said on both sides; for, as the Rook cannot be altogether acquitted of the charge of doing some harm, so neither is he to be found guilty of doing nothing but mischief. We will examine, first, the unfavourable side. 
A Rook, which we kept for some time, was, after a night's fast, fed entirely upon oats, of which it ate, in twenty-four hours, two ounces, of sixteen ounces to the pound; while another, under similar circumstances, consumed two ounces and a half of bread.

This certainly would bear strongly against them; was there nothing to be said in mitigation; but it should be remembered, that the above consumption is founded upon the supposition that Rooks live entirely upon grain, which, so far from being the case, is very much the reverse; for they prefer an insect diet, if not altogether, at least to a great extent. And even with respect to grain, they will not willingly eat it, except in a particular state, preferring it when somewhat softened, and more particularly during the time of its undergoing the natural malting process, when it not only swells, but becomes soft, with an addition of about two-thirds of gum and sugar to the small quantity it before contained. During this critical time, the fresh-sown crop is undoubtediy in some peril, as well as a short time before harvest, when the soft and sweet ears of green grain offer irresistible temptation to a robbery, of which it is to be feared they must be found guilty; and no money can be more profitably laid out, at such critical moments, than the daily wages of a few boys, for the sole purpose of frightening them away.

Fresh-planted potatoes are also, for a time, in jeopardy; but when they have fairly sprouted, the Rook's depredations are suspended till the season of digging them up, when a trifling loss may be sustained by their carrying off a few of such smaller ones as they can conveniently grasp in their bills.

Such are the depredations which may be fairly laid to their account; but, nevertheless, we feel quite certain, that on striking a fair balance, the advantage will be in favour of preserving the Rooks, and that if every nest were pulled to pieces, the farmers would soon do all in their power to induce the old birds to rebuild them; finding out, when too late, that their crops might suffer the fate which befel an entire district in Germany, and which was once nearly deprived of its corn- 
harvest, by an order to kill the Rooks having been generally obeyed, the immediate consequence being an increase of grubs and their depredations. For, allowing that the Rook may do an occasional injury to the husbandman, it confers benefits in a far greater proportion, and to an extent of which few are aware. Some of our readers, who live in the southern counties, know full well how the air, on a summer's evening, swarms with cockchafers and other insects of the beetle tribe; but, unless they are naturalists, they do not know that each of those cockchafers or beetles has been living under-ground for no less than from three to four years, in the form of a large whitish grub, devouring incessantly the tender roots of grasses, and every description of grain; and that it is in search of them the Rooks flock round the ploughshare, and, thrusting their bills into the loosened earth, devour these ruinous root-eaters by thousands and tens of thousands. So injurious are they, indeed, in favourable seasons, that the sum of twenty-five pounds was once allowed to a poor farmer in Norfolk as a compensation for his losses; and the man and his servant declared that they had actually gathered eighty bushels of cockchafers.

In France, again, many provinces. were so ravaged by grubs, that a premium was offered by government for the best mode of ensuring their destruction; and yet, singularly enough, so little were the people acquainted with the real and best mode of stopping the mischief, that when their dreadful Revolution broke out, accompanied with murder and bloodshed which can never be forgotten, the country people, amongst other causes of dissatisfaction with their superiors, alleged their being fond of having rookeries near their houses; and, in one instance, a mob of these misguided and ignorant people proceeded to the residence of the principal gentleman in the neighbourhood, from whence they dragged him, and hung his body upon a gibbet, after which they attacked the rookery, and continued to shoot the Rooks amidst loud acclamations.

It is scarcely necessary to name the wire-worm as one of the greatest scourges to which the farmers are exposed; and 
yet it is to the Rooks chiefly, if not entirely, that they can look for a remedy. Cased in its hard shelly coat, it eats its way into the heart of the roots of corn, and is beyond the reach of weather, or the attacks of other insects or small birds, whose short and softer bills cannot penetrate the recesses of its secure retreat, buried some inches below the soil. The Rook alone can do so; if watched, when seen feeding in a field of sprouting wheat, the heedless observer will abuse him, when he sees him jerking up root after root of the rising crop; but the careful observer will, if he examines minutely, detect, in many of these roots, the cell of a wire-worm, in its silent and under-ground progress, inflicting death on stems of many future grains. Their sagacity, too, in discovering that a field of wheat, or a meadow, is suffering from the superabundance of some devouring insect, is deserving of notice. Whether they find it out by sight, smell, or some additional unknown sense, is a mystery; but that they do so is a fact beyond all contradiction.

We remember, a few years ago, seeing, for several days, a flight of Rooks regularly resorting to a field close to the house; and, on walking over it, observed that the whole surface was covered with uprooted stems of one particular plant, and on looking more narrowly it was ascertained that many of those still untouched were of an unhealthy yellow appearance, and that to these alone the Rooks seemed to direct their attention; and, on still closer examination, the roots of each of these unhealthy plants were found to have been attacked by a small grub, which at once accounted for the daily presence of these sable visitants.

A similar testimony in favour of a bird of this species, the Purple Grakle, or New England Jackdaw, occurs in King's Narrative (vol. ii., page 217). He says, that " a reward of threepence a dozen was once awarded in that country for the extirpation of the Grakles; and the object was almost effected, to the cost of the inhabitants, who at length discovered that Providence had not formed these supposed destructive birds in vain: for, notwithstanding they caused great havoc among the grain, they made ample recompence, by 
clearing the soil of the noxious worms, particularly of one called the pease-beetle (Bruchus pisi). For no sooner were the birds destroyed, than the insects multiplied to such a degree, as to cause the total loss of the grass in 1749 , when the colonists had to get their hay from Pennsylvania, and even from Great Britain."

We often hear persons congratulating themselves on a deep snow, a hard frost, or dry weather, as the surest means of destroying insects; whereas it is just the reverse. A hard frost, or a deep snow, or a dry summer, are the very best protection they can have, and for this reason: the Rooks and other birds cannot reach that innumerable host which pass the greatest part of their existence under-ground. In vain the hungry Rook, in a hard frost, looks over a fine fallow, or a field of new-sown wheat. $\mathrm{He}$ may be seen sitting on a bare bough, like Tantalus, in the midst of plenty beyond his reach, with his feathers ruffled up, casting every now and then an anxious glance over the frozen suriace, beyond the power of even his strong beak to penetrate. His situation is much the same in dry Springs or Summers, when he may be seen walking up and down by the sides of highways, picking up what he can get. In the hot Summer of 1825 , many of the young broods of the season are reported to have been starved: the mornings were without dew, and consequently few or no earth-worms were to be obtained, and they were found dead under the trees,* having expired on their roostings. It was quite distressing, says an eye-witness, to hear the constant clamour of the young for food. The old birds seemed to suffer without complaint; but the wants of their famishing offspring were expressed by unceasing cries. Yet, amidst all this distress, it was pleasing to observe the perseverance of the old ones in the endeavour to relieve their perishing: families; for many of them remained out, searching for food, long after their accustomed roosting-time; and then, adds this interesting writer, "the Rook became a plunderer," and dreadful havoc took place in the potato-fields, where whole

* Journal of a Naturalist. 
lines were afterwards seen broken up, in consequence of the visits of the suffering Rooks.

We have before noticed the instinctive sagacity shown by Rooks, Jays, \&c., in avoiding the approach of sportsmen, or other suspicious characters; and it would appear that they can, with equal discrimination, discover and attach themselves to friends. A clergyman, who had a small rookery near his house, assured us, that when he walked near or under the trees, they exhibited no signs of alarm; but when a stranger approached, they were evidently uneasy, and manifested, by their loud cawings and movements, their wish for his departure. The following anecdote is a still more convincing proof of this instinctive faculty.

A farmer rented a farm in the county of Essex some years ago, where he had not resided long, before a number of Rooks came and built their nests upon the trees immediately surrounding the premises, and multiplied so much in the course of three or four years, as to form a considerable rookery, which he much prized. About this time, however, he was induced to take a larger farm, which obliged him to change his residence and forsake his Rooks ; but, to his great surprise and pleasure, the whole rookery manifested such an attachment towards him, as led them to desert their former habitation, and accompany him to his new abode, which was about three-quarters of a mile off, and there they have continued to flourish ever since. It should be added, that this person was strongly attached to all animals whatsoever, and that he always experiences a striking return of affection even from the least docile of them.

Could we dive into all the mysteries of a rookery, a page in the book of nature would be opened, filled with much that " man's philosophy hath never dreamed of." Without any assignable cause, a party will secede from an old-established rookery and form a new one. A case of this sort occurred about ten years ago, in the parish of Alderley, in Cheshire. Seven pair of Rooks, supposed to have come from an old rookery about two miles distant, where an extent of wood admitted of unlimited accommodation, took up their residence 
in a clump of trees, and proceeded to build; there they have continued ever since, the number of nests increasing as follows. In 1828, there were seven nests ; in 1829, nine ; in 1830 , thirteen ; in 1831, twenty-four ; in 1832, thirty-three; in 1833, upwards of fifty; and in this latter year, there was a proportionate increase, with colonies settling in adjacent trees. Another instance of unaccountable removal from an accustomed place of resort, occurred within the last few years, in a comparatively small rookery in the Palace Garden, in the city of Norwich. For several years the birds had confined their nests to a few trees immediately in front of the house, when one season, without any assignable cause, they took up a new position on some trees, also in the garden, but about two hundred yards distant, where they remained till the Spring of 1847, when, before their nests were completed, or young hatched, they disappeared altogether, and the heretofore frequented trees are only now and then resorted to by a few stray casual visitors.

It has been said, that Rooks usually prefer elm-trees for building, and it was observed, that in a mingled grove of horse-chesnuts and elms, at Hawley, in Kent, not a single nest was ever built in the horse-chesnut-trees, though the elms were full of them. In the above instance, however, they certainly gave the oak a preference, leaving an elmtree close at hand untenanted. These birds, like the rest of their species, return at a particular time in Autumn; and for a few days seem to be very busy about their nests, as if preparing them for immediate use; and then desert them for the Winter: no reason has been discovered for this singular habit, peculiar, it is believed, to Rooks. May it not probably arise from an instinctive feeling, that as the nests will be wanted early in the Spring, a few repairs may be requisite to strengthen and prevent their being shattered or blown to pieces by the storms of Winter; and that, according to the homely proverb of " the stitch in time saving nine," they may thus be saving themselves a greater degree of labour than they could easily bestow, when the trees are again to be occupied? Most other birds are under no ne- 
cessity of looking after these autumnal repairs, as they do not use the same old nests, but build entirely new ones.

Rooks, we have seen, will occasionally remove, and colonize other situations at a distance from their late frequented abodes; and, as some persons may wish to establish a rookery in their own immediate neighbourhood, it has been said, that by looking out for a Magpie's nest near the wished-for spot, and exchanging her eggs for those of a Rook, the desirable point may be accomplished; the young Rooks having no other associations than those of the tree in which they were bred, and being sure of a harsh reception, if not of being picked to death, if venturing to join any neighbouring rookery in which they have no family connexions. In the Spring of 1847, a rather singular strife took place between the Rooks which for many years occupied a large tree in the garden of Westhill Terrace, Sheffield, and a pair of stranger Rooks which had established themselves on a neighbouring tree, illustrative of the jealousy entertained by these birds, of interlopers not immediately belonging to their own clan. The stranger birds had almost completed their nest, when their neighbours, disapproving of a new or rival colony, watched their opportunity, and descending in a body, wreaked their vengeance on the nest, which they soon destroyed. Several times was this scene repeated; at length, however, profiting by experience, it. was deemed advisable for one of the birds to remain constantly at the nest, to repel any attempts that might be made upon it by their enemies. So rigorously, indeed, was this caution observed, that the one remaining at home was supplied with food by the other. Many attempts were, notwithstanding, made upon it, but the united energies of these two persevering birds enabled them to rear their nestlings in spite of the determined opposition of the original possessors of the adjacent rookery.

The habits of a Jackdaw are known to everybody ; whereever found, he is the same active, bustling, cheerful, noisy fellow. Whether in the depth of a shady wood, " remote from cities and from towns," or whether established in the nooks and niches of some Gothic cathedral-tower, in the 
very midst of the world, it matters not to him. He seems to know neither care nor sorrow,-ever satisfied-always happy! Who ever saw or heard of a moping, melancholy Jackdaw?

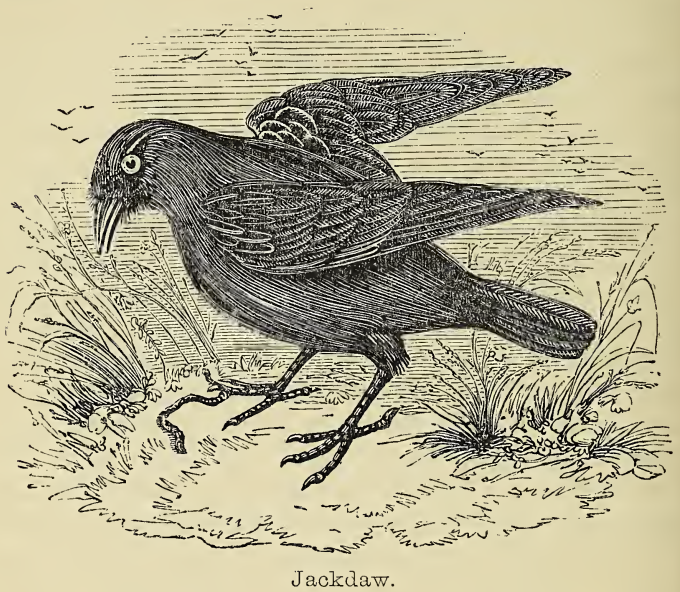

We have in England another bird much resembling him in manners and colour, though from certain distinguishing features, such as a bent, orange-coloured beak and legs, \&c., it has been placed in another division of birds. It is the Red-legged Crow or Chough, never seen in most parts of our island, though in its favourite haunts, in front of high precipices and steep rocks by the sea, often very abundant. Like Jackdaws, the Choughs are easily tamed, and are as entertaining, and at the same time as troublesome when tamed. On a lawn, where five were kept, one particular part of it was found to turn brown, and exhibit all the appearance of a field suffering under severe drought, covered as it was with dead and withering tufts of grass, of which it was soon ascertained the Choughs were incessantly employed in tearing up 
the roots, for the purpose of getting at the grubs, already alluded to in our description of Rooks. The way they set about it was this:--they would walk quietly over the surface, every now and then turning their head, with the ear towards the ground, listening attentively in the most significant manner. Sometimes they appeared to listen in vain, and then walked on, till at length, instead of moving from the spot, they fell to picking a hole, as fast as their heads could nod, just like the Thrushes before mentioned; and in the end, almost always succeeded in extracting a few large grubs, with which, as soon as the fortunate finder had secured one, he hopped off to enjoy his delicate morsel, followed and jostled by the rest, who had been less successful in their search; adding another proof of the utility of birds in ridding us from injurious insects,- and all in favour of the Rook family. An accident which befel one of these birds, afforded an interesting instance of the efforts of nature to repair injury and mutilation. It was standing on a window-sill, and had the greater part of its beak crushed off, by the sudden shutting of the window. The person who fed them nursed it with the greatest care, and kept it alive; when the wound began to heal, it was turned out amongst its companions, by whom it was as regularly fed, as if they had been made to understand that it could not feed itself; but what was still more extraordinary, soon afterwards, flights of wild ones, which usually remained in their lonely haunts, upon a neighbouring rocky mountain, came down to the garden, and were constantly hovering over their disabled and mutilated companion, as if to marvel at its strange appearance. As the wound healed, the upper part of the bill, two-thirds of which, at least, had been severed, began to grow, and in a few months had made considerable progress, with every prospect of its finally assuming its original formation. In every part of the world, the character of the Jackdaw tribe seems to be the same.

Thus, in the island of Ceylon in India, these birds are extremelyimpudent and troublesome; and it is found very difficult to exclude them from the houses, which, on account of the heat, 
are built open, and much exposed to intruders. In the town of Colombo, where they are in the habit of picking up bones and other things from the streets and yards, and carrying them to the tops of the houses, a battle usually takes place for the plunder, to the great annoyance of the people below, on whose heads they shower down the loosened tiles, leaving the roofs exposed to the weather. They frequently snatch bread and meat from the dining-table, even when it is surrounded with guests, always seeming to prefer the company of man, as they are continually seen hopping about near houses, and rarely to be met with in woods or retired places. They are, however, important benefactors to the Indians, making ample compensation for their intrusion and knavery; for they are all voracious devourers of carrion, and instantly consume all sorts of dirt, offal, or dead vermin; they, in fact, carry off those substances which, if allowed to remain, would, in that hot climate, produce the most noxious smells, and probably give rise to putrid disorders. On this account they are much esteemed by the natives; their mischievous tricks and impudence are put up with, and they are never suffered to be shot or otherwise molested.

In North America there is a small species, called the Cinereous Crow, which also much resembles the Jackdaw, and is near akin to him. It is described* as very familiar, and fond of frequenting habitations, both houses and tents; and so much given to pilfering, that no provisions it can come at, either fresh or salt, are safe from its depredations. It is so bold as to come into tents, and sit on the edge of the kettle when hanging over the fire, and steal victuals out of the dishes. It is very troublesome to the hunters, both English and Indian, frequently following them a whole day. It will perch on a tree, while the hunter is baiting his martin-traps, and, as soon as his back is turned, alight on the ground, and eat the baits.

Thus, all over the world, the Jackdaw tribe is notoriously given to pilfering. Whatever it sees it considers a prize, and 
carries off to its hoard. In the ruins of Holyrood Chapel, in Edinburgh, a Jackdaw was one day seen flying away with a large piece of lace towards its nest; a soldier undertook to climb up and recover it. He did so, but was surprised to find, not only the stolen lace, but the following strange assortment of articles :-part of a worsted stocking, a silk handkerchief, a frill, a child's cap, besides several other things, but so ragged and worn out, that it was impossible to make out what they were.

\section{JAYS AND MAGPIES.}

IT is remarkable how exactly similar are the habits and propensities of birds of the same tribe or family, though of a different species. Thus the Jays of North America are of various sorts, entirely differing from our English Jays in parts, or the whole of their plumage; and yet in their manners scarcely a difference is observable. We have before remarked, that these and some other birds will just keep out of the range of gun-shot, as if they had learned, either from experience, or by some unknown mode of communication from their older companions, that provided they never allowed a shooter to come within a given distance, they were quite safe. But the American Jays we are speaking of have no such knowledge founded upon experience, as is fully proved by the account of an English officer, * who was travelling in a very wild, unfrequented part of North America, where no gunners had ever gone before him, and no Jay could therefore have ever learned the proper distance to keep, in order to ensure its safety. Yet there they were, exactly like our common English Jays, shy and cautious, as if they had been hunted by sportsmen every day of their lives, keeping at a certain distance, with that occasional clatter and chattering so well known to those who have patiently and perseveringly pursued from copse to copse, or tree to tree, a disturbed party of these cunning birds.

At the same time, certain birds of similar habits will

* Captain Sir Francis Head. 
naturally, under peculiar circumstances, act very differently ; we have an instance of this, in the singular departure of the Magpie from its usual custom of building its nest. Everybody knows that where trees abound, that which is loftiest, or most difficult of access, is chosen; but in parts where there are no trees, instead of retiring to high rocks, and choosing places not easily approached, they will take possession of bushes close to the very doors of houses, particularly in those countries where, instead of being persecuted, they are preserved, from an opinion that it is unlucky to kill them. Accordingly, in Sweden and Norway, travellers are struck by their surprising numbers and tameness, their nests being built in some low bushy tree close to the cottage-doors, where they are never disturbed.

The following instance, which fell under the observation of a gentleman when making an excursion in a remote and barren part of the north of Scotland, not only corroborates the statement from Norway and Sweden, but is attended with many other interesting particulars of the sagacity shown by a pair of Magpies. Observing them hopping round a gooseberry-bush, and flying in and out in an extraordinary manner, he noticed the circumstance to the owners of the house in which he was, who informed him that as there were no trees in the neighbourhood, they had for several years built their nest, and brought up their young in that bush. And that foxes, cats, hawks, \&c., might not interrupt them, they had barricadoed not only the nest, but the bush itself all round, with briers and thorns, in a formidable manner. The materials in the inside of the nest were soft, warm, and comfortable to the touch, but all round, on the outside, so rough, strong, and firmly entwined with the bush, that, without a hedge-knife or something of the kind, even a man could not, without much pain and trouble, get at their young; the barrier from the outer to the inner edge being above a foot in breadth. Frogs, mice, worms, or anything living, were plentifully brought to their young. One day, one of the parent-birds attacked a rat, and not being able to kill it, one of the young ones came out of the nest and assisted in its 
destruction, which was not finally accomplished till the other old one, arriving with a dead mouse, also lent its aid. The female was observed to be the most active and thievish, and withal very ungrateful; for although the children about the house had often frightened cats and hawks from the spot, yet she one day seized a chicken, and carried it to the top of the house to eat it, where the hen immediately followed, and having rescued the chicken, brought it safely down in her beak; and it was remarked that the poor little bird, though it made a great noise while the Magpie was carrying it up, was quite quiet, and seemed to feel no pain, while its mother was carrying it down. These Magpies were supposed to have been the very same pair which had built there for several years, never suffering either the young, when grown up, or anything else, to take possession of their bush. The nest they carefully fortified afresh every spring, with rough, strong, prickly sticks, which they sometimes drew in with their united forces, if unable to effect the object alone. To this tameness and familiarity the Magpie will sometimes add a considerable degree of courage, and not satisfied with driving away intruders from its premises, has been known to attack animals much its superior in size. One of them was seen pursuing a full-grown hare, making frequent and furious pounces upon it, from which the animal at last escaped only by making for a thick hedge, at the other side of which it ran off to some distance from the place where it had entered, without being observed by its pursuer. No cause could be assigned for this assault.

A favourable trait in their character occurred in Essex, where some boys, having taken four young ones from a Raven's nest, placed them in a wagon in a cart-shed. About the same time, they happened to destroy the young of a Magpie, which had built its nest near the cart-shed; when the old Magpie, hearing the young Ravens cry for food, brought some, and constantly fed them till they were given away by the boys.

Generally speaking, these birds prefer our northern climates, though they are very plentifully spread over the 
world. In some spots they are, however, very scarce, without any apparent reason. Thus, a traveller, who had been 'through Turkey, remarked that he never saw a single bird of this species, and had seen very few indeed in the adjoining: countries.

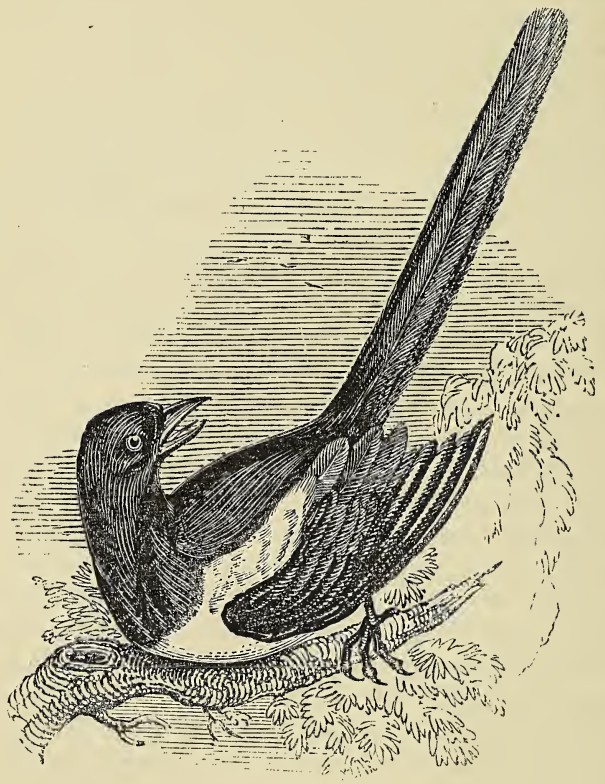

Maśpie. 


\section{CHAPTER X.}

Passerine Order continued. - Conirostres. - Conical Beaks. Orioles.-Starlings.-Habits of.-Finch Tribe.-Goldfinch.Anecdotes of.-Nests rapidly completed.-Curious Nests in Africa.-Age of small Birds. - Canary Birds. - Trade in.Bullfinches, Piping.-How trained.-Boldness of.-Affectionate and social Habits of. - Also of Linnets. - Use of small Birds in destroying Insects.

\section{Table X. Order 2. Passerine.}

THERE are seven genera of this tribe, of which four are 1 foreign; it is the most numerous, perhaps, of all the divisions, including, as it does, that host of hard-billed birds, of infinite variety, from the Starling down to the Sparrow, which is scattered so widely over the face of the globe. To pretend to enumerate them in a work of this kind would be impossible, and we shall therefore confine ourselves to a few anecdotes, illustrating the habits of some of those species which are most familiarly known. We have placed the Starling at the head of them, as being one of the connecting links between the Grackles and Thrush genera of the preceding table, and those of the present. There is one other bird, the Golden Oriole, indeed, which is a more closely connecting link, and might, without impropriety, be placed among the conirostral birds, inasmuch as the point of its upper mandible is slightly notched: but we mention the Starling as the best known, the Oriole, or Golden Thrush, being a bird of great rarity in this country, though, when once seen, it cannot fail of being recognised and remembered, the whole plumage, with the exception of the wings and tail, being of a bright orange or golden colour.

The Starling, although closely resembling the Thrush and Blackbird in some respects, differs from them essentially in others; and as its beak, on examination, will be found to be 
without a notch at its extremity, it may be decidedly placed amongst the conirostral tribe.

Of some birds it is difficult, from their retired habits, to give any clear and accurate account. Not so of our friend the Starling. When it suits his purpose, he comes fearlessly under our observation, and invites us to learn his history. For many and many a year have we watched him from month to month, with the exception of a certain season, when, for reasons best known to himself, he altogether disappears, and leaves us to wonder what is become of him.

Close before the window of our scene of observation, a well-mown short-grassed lawn is spread before him-it is his dining-room; there in the Spring he is allowed to revel, but seldom molested, on the plentiful supply of worms, which he collects pretty much in the same manner as the Thrush, already described. Close at hand, within half a stone's throw, stands an ivy-mantled parish church, with its massy grey tower, from the turreted pinnacle of which rises a tall flag-staff, crowned by its weather-cock; under the eaves, and within the hollows and chinks of the masonry of this tower are his nursery establishments. On the battlements and projecting grotesque tracery of its Gothic ornaments he retires to enjoy himself, looking down on the rural world below ; while, at other times, a still more elevated party will crowd together on the letters of the weathercock, or, accustomed to its motion, sociably twitter away their chattering song, as the vane creaks slowly round with every change of wind.

We will give a journal of our Starling's lives. At the close of January, one or two unconnected birds now and then make their appearance on this weathercock; at first but for a few minutes, as if without an assignable reason they had merely touched upon it as an inviting resting-place, in their unsettled course. In February, if the weather happens to be mild, the number of idlers may possibly now and then in crease; but still the visit seems to be but the mere passing call of a few strangers, without a leading object. In March, however, about the first or second week, according to the state of the weather, things begin to assume a more bustling and 
serious appearance. Hitherto but one or two, or at most three or four, may have dropt in, as if to say, Here we are, the Winter is past and gone, a happier season is at hand. But now the flights increase, the three and the four are multiplied to fourteen or sixteen, and the song becomes a little chorus, more loud and more joyous than before; and occasionally, though at first with some circumspection and hesitation, one or two of the boldest will let themselves gently fall from their airy height, and glide down upon the lawn, as if to inquire into the state of their future larder; for they scarcely take time to taste the hidden treasures below the sod, but looking suspiciously about, are on the wing in a moment, if an inmate approaches the window, or a door is heard to shut or open.

About the latter end of the second week, affairs begin to be placed upon a more regular footing; the parties on or about the battlements and weather-cock seem as if they had determined upon a permanent establishment. From early

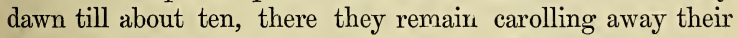
communications ; at that hour, however, off they go, and till four or five o'clock are seen no more throughout the greater part of the day; being absent in the fields, where they may be seen chattering in company with the inhabitants of a neighbouring rookery, or a noisy set of Jackdaws, who have, for time out of mind, been the undisputed tenants of a certain portion of an ancient beech-wood, at no great distance.

About the third week, the plot begins to thicken still more. The field, the lawn, and the weather-cock, are no longer the only objects of interest. Detachments may be now seen prowling busily over the roof, cautiously creeping in and out, from under the projecting eaves, and by the end of the month, the regular establishment, amounting to about thirty, has assembled, and the grand work of the year fairly commences. From this time, all is bustle; straws and nestfurniture are seen flying through the air in beaks, contriving, nevertheless, to announce their comings and goings by particular harsh or low muttering cries, according as they think 
they are watched or not. They are cunning birds, and discover in an instant, whether a passer-by has an eye to their movements, and perfectly aware whether he is following his own business or theirs. If he steps onwards, without troubling himself about them, they go in and out with perfect unconcern; but if a glance of curiosity or observation is directed to their motions, they are all upon the alert; the bearer of a tuft to the nest, wheels to the right about, and perching on the naked upper twig of a small beech-tree, or the projecting point of a gable end, sits there, uttering a particular note, which seems to give, as well as words could do, intimation to a mate to be on its guard, as a spy is at hand. If the weather is tolerably favourable, everything goes on smoothly and regularly; but (and we have, in the journal of our Starlings' proceedings, many instances on record) should a severe and sudden change occur, a violent storm of snow, or continuance of chilling winds, all operations are suspended; not only the eaves and half-built nests, but even the tower itself, battlements, weathercock, and all, are deserted, till a return of fine weather, when the Starlings too return, and the work again proceeds. At length the nests are built, the eggs laid, and the young ones hatched. Then a new scene of noise, and activity, and bustle commences, increasing of course as the nestlings become older and more voracious. Then it is that the lawn becomes a favourite resort; hitherto a few idlers may have hopped and pecked up a stray worm or two, but now the search is a matter of serious occupation.

Down they come, the sober-coloured hen, and the cock with the sun glittering on its spangled feathers, with claws and beaks as busily employed as if their very existence depended upon it. All however in good social harmony, never quarreling with the shy and less intrusive Thrush or Blackbird; or with the lively Wagtails, contenting themselves with the lighter fare of the myriads of minute flies and beetles hovering over the fresh mown turf.

The noise and bustle go on incessantly, till the young ones are fledged, when for a day or two they may be seen fluttering about the building, or taking short flights. At length, their 
strength being matured, old and young collect on the tower, and then wheel away over the neighbouring fields, as if practising for future and more important evolutions. But still the evening finds them roosting near the place of their birth. At last, however, a day comes when all is hushed. No hungry guests are feasting on the lawn, no clamorous throats are calling aloud for food, no twitterings are heard from bough or battlement, not even a straggler is to be seen on the pinnacle of the weather-cock.

The joyous assembly is broken up. The Starlings are gone,* and till the Autumn, with scarcely an exception, we shall see them no more. Then, about the third week in September, again on their favourite perch, the weather-cock, one, or two, or three, may chance to appear towards evening, not with the merry note of Spring, but uttering that monotonous, plaintive, long-drawn, whistling cry, as cheerless as the cheerless season for which they seem to bid us prepare. That these, and the few other stragglers occasionally occupying the same post, are our Spring friends is most probable; for a lame Starling was observed for eight years to return to the same nest, and every observation we have made tends to prove that this is a general instinctive custom of, we believe, every bird whatever.

Having thus given some report of our Starlings for the greater part of the year, we will endeavour to follow the main body for the remaining months, as yet unaccounted for. To do this effectually would be no easy matter, as we believe that they are partially migratory, i.e., quitting one part of the kingdom for another more fitted for their usual mode of life; nevertheless, enough remain within the sphere of our observation, and are to be met with in little flocks during the Summer in favourite meadows, where food is plentiful, associating with their old friends, the Crows, ${ }_{4}^{\circ}$ Rooks, and Jackdaws.

* The abandonment of their breeding-place depends, of course, upon the season. In 1833 , the month of May having been remarkably warm, it occurred on the sixth of June; but we have known it to be delayed till the second week in July; the whole of June having been very unseasonable and stormy. 
As winter approaches, however, they follow the example of some other birds, such as Larks, Buntings, \&c., and congregate in larger quantities. Not far from the church we have mentioned, there is a considerable sheet of water, occupying nearly thirty acres ; flanked and feathered on the eastern side by the oll beech-wood, already spoken of as the abiding place of the Jackdaws. Its western margin is bounded by an artificial dam, which, as the water is upon a much higher level, commands an extensive view over a flat, rich country, the horizon terminated by the faint outline of the first range of Welsh mountains. This dam, on the finer evenings of November, was once the favourite resort of many persons, who found an additional attraction in watching the gradual assemblage of the Starlings. About an hour before sunset, little flocks, by twenties or fifties, kept gradually dropping in, their numbers increasing as daylight waned, till one vast flight was formed, amounting to thousands, and at times we might almost say to millions. Nothing could be more interesting or beautiful than to witness their graceful evolutions.

At first they might be seen advancing high in the air, like a dark cloud, which in an instant, as if by magic, became almost invisible, the whole body, by some mysterious watchword or signal, changing their course, and presenting their wings to view edgeways, instead of exposing, as before, their full expanded spread. Again, in another moment, the cloud might be seen descending in a graceful sweep, so as almost to brush the earth as they glanced along. Then once more they were seen spiring in wide circles on high; till at length, with one simultaneous rush, down they glide, with a roaring noise of wing, till the vast mass buried itself unseen, but not unheard, amidst a bed of reeds, projecting from the bank adjacent to the wood. For no sooner were they perched than every throat seemed to open itself, forming one incessant confusion of tongues.

If nothing disturbed them, there they would most likely remain : but if a stone was thrown, a shout raised, or more especially, if a gun was fired, up again would rise the mass with one unbroken, rushing sound, as if the whole body were 
possessed but of one wing to bear them in their upward flight. In the fens of Cambridgeshire and Lincolnshire, where reeds are of cousiderable value for various purposes, the mischief they occasion is often very considerable, by beating down and breaking them, as many as can find a grasping hold clinging: to the same slender stem, which, of course, bends and plunges them in the water, from whence they rise to join some other neighbours, whose reed is still able to bear their weight. This perpetual jostling and breaking down is the probable cause of the incessant clatter, which continues for a considerable time; indeed, till all have procured dry beds and a firm footing.

It has been remarked, that the flights of these birds have of late years much diminished, a fact to which we can speak from our own experience, for the assemblages which we have just described as forming so interesting a feature in autumnal evening walks have long ago ceased; and it is now a rare thing to see a passing flock of even fifty, where, in years gone by, they mustered in myriads.

Their favourite dormitory of reeds, indeed, has dwindled gradually away, since the dam was raised, and the depth of water increased, which may partly account for the diminution; but still reeds are left in sufficient abundance for the accommodation of ten times the number that are ever assembled in the neighbourhood of which we speak.

Under the head of Fringilla, or Finch, (which is our translation of the Latin word,) are included, amongst Sparrows, Goldfinches, and Canaries, tribes of small birds, each exhibiting in its own domestic habiis and arrangements, as much sound philosophy and wisdom in the management of their concerns, as the wisest of human kind.

Some of these little birds, moreover, seem occasionally to have something like a reasoning, as well as an instinctive faculty. A gentleman had a Goldfinch which was chained to a perch, instead of being kept in a cage. Its food was put into a box, resembling a water fountain used for cages, and the little opening at which the bird was fed had a cover loaded with lead, to make it fall down. The bird raised this by pushing down a lever or handle with its bill, which raised 
the lid of the box, after which, by putting its foot on the lever, it could feed at leisure. He had also a Redpole, chained on a nearly similar perch; this bird fed from an open box without the trouble of having recourse to the lifting power, like his neighbour, the Goldfinch. But though the Redpole could have known nothing of the use of the handle from his own experience, as his food was to be got at without such trouble, yet it seems he must have taken notice of it, and seen that by touching this handle he could get at the Goldfinch's food, were he within reach; and this he kept in mind for the day of need; for one morning when loose, and his own seed-box empty, he flew at once to the perch of his friend, raised the lid of the seed-box with his bill, and then laying hold of it with one foot, kept it open till he had made a good breakfast. This apparently trifling circumstance clearly shows that birds can and do take notice of some things, and collect information which may be useful when needed. In this case it required some time and attention to teach the Goldfinch the use of the handle for holding up the lid of the box; but the Redpole had watched the operation, and learned by observation how to do it as well as his friend.*

The following is another instance of sagacity in a pair of Goldfinches. These little birds had built their nest on a small branch of an olive-tree; after hatching their brood, the

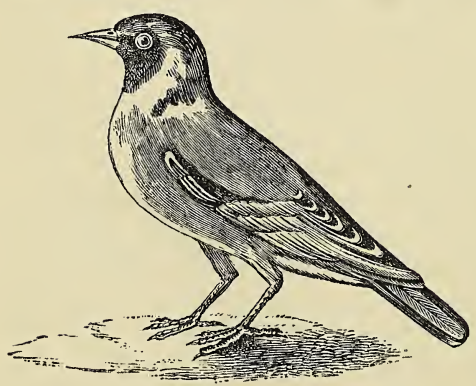

Goldfinch. parents perceived that the weight of the growing family would soon be too great for the strength of the branch which supported the nest; in fact, it was beginning to give way. Something was to be done, or the nest would fall, - this was evident

* Phren. Journal, No. 34, p. 72. 
to beholders, and equally so to the Goldfinches; accordingly, they were observed to fasten by a small string they had picked up, the bending twig to a stronger and higher branch of the tree, and thus their nest was saved.

Another pair happened to build in the garden of a naturalist, who was fond of observing the manners and habits of birds. They had formed the ground-work with moss and dried grass as usual, but on his scattering small pieces of wool, they in a great measure left off the use of the first materials, and employed the wool. He next provided them with cotton, which they immediately collected; the third day he supplied them with down, on which they forsook both the others, and finished their work with it.

It is surprising, too, with what rapidity, in cases of emergency, these small birds can build a nest. A Canary was observed to commence her labours about five o'clock in the morning, from which time till near seven she worked so hard, that it was completely finished; she had been often disturbed before, in consequence of building in inconvenient places, which probably induced her to use more than ordinary despatch in this nest, availing herself of early hours, before people were likely to see and interfere.

An African traveller speaks of some singular nests built by birds, which he describes as resembling our Goldfinch; but he probably mistook them for a family of birds nearly allied to them, and known to inhabit the Cape of Good Hope. For although Bishop Heber found Goldfinches* at the foot of the Snowy Mountains in India, and in some other parts where they are caught and sold for about two shillings each, we are not aware that they are known in Africa. The account of the nest, however, is very curious, and, at all events, illustrates the social manners of a set of little birds, like " brethren dwelling together in unity." A tree at a little distance from our wagon, says the traveller who noticed the fact, $\uparrow$ had two remarkable nests in it. The one was about four yards

* The Goldfinch of the East Indies is the Carduelis carriceps, a bird much resembling, but not exactly the same as our British species.

$\dagger$ CAMpbell's Travels in Africa. 
in circumference, and the other three, and about a yard in depth. They were built of coarse grass. One of these nests had seventeen holes in the bottom, by which the birds enter; the other had seven. At one time, I saw about a hundred birds come out of them. Instead of being the nest of a single pair of birds, they seemed to be towns of birds, or the property of a single pair, in which they accommodate all their descendants. A Horned $\mathrm{Owl}$ had taken possession of the outside of the roof of the largest for a nest. She was sitting on it, and it appeared, from the bones and hair strewed under, that she lived upon the field-mouse. The whole was neatly thatched, and had a hollow in the middle to contain the Owl, but no passage leading to the inside.

Our Goldfinches partake a good deal of this sociable character, for they are usually seen in little flights calling each other together, and betraying uneasiness if separated from their friends. They are also docile, easily tamed, and have occasionally been known to show a certain degree of confidence in man, when they found no danger to be apprehended, as the following will prove. In the spring of 1827, a Goldfinch had been lost from a cage which was left hanging up, and the door open, in the passage-entrance to a back court of a house in a country town in the West of England; when a Goldfinch was one morning found feeding in it, and the door was closed upon the prisoner; but, as it appeared to be a female, it was shortly after let out again. In the course, however, of about two hours it returned, and re-entered the cage, when it was again shut in, and once more, after a short time, released; and these visits were repeated daily, for a considerable time. She was then missing for a few days, but then returned, accompanied by a male bird; when she entered the cage and fed as usual, leaving her companion, who appeared rather more shy, sitting on the outside wires of the cage, from whence he shortly flew to a neighbouring tree, until she joined him. They then went away, and were absent so long that nobody thought anything more about them; when, at the end of seven or eight weeks, she again made her appearance, accompanied not only by her 
former companion, but by four full-grown young ones, when she entered the cage and fed as usual. But as she could not persuade her brood to follow her example, she finally went off, and from that time was never seen again.

Small birds seldom live above eight or ten years, but Goldfinches have been known to live sixteen or eighteen years. We have the authority of a very eminent naturalist, for one having attained to the age of twenty-three years ;* at last it grew so infirm, that the people to whom it belonged were obliged to scrape its beak and claws, that it might eat, drink, and sit upon its perch. It had subsisted on poppyseeds chiefly, and had lost its power of flying, and all its feathers had become white, which is contrary to what has been usually observed in aged small birds, whose plumage at times assumes a darker shade, particularly if fed much upon hemp-seed. Thus there are instances of Goldfinches, Bullfinches, and Larks becoming almost entirely black.

So nearly allied are Canaries to Goldfinches, that they will breed together, and the produce is a very pretty bird (called a Mule), with a strong clear voice, which, in addition to its scarcity, causes it to be much valued, and commands a high price. And yet, nearly connected as they are, the Canary is entirely of foreign origin, being a native of the Canaries (from whence they took their name), a cluster of islands in the Atlantic Ocean, near the coast of Africa. They are very indifferent flyers, which may account for their never having migrated like other birds, and being thus occasionally found in their wild state in other countries. They accordingly for a long time remained unknown in Europe; indeed it was not till the enterprising reign of Queen Elizabeth, about three hundred years ago, when so many of our now common fruits and vegetables, such as nectarines, potatos, \&c., and even poultry, such as Turkeys, \&c., first found their way into England, that Canaries were introduced; and they were then for a time so prized and scarce, that none but the most wealthy could purchase them. But the desire of having them seems rapidly to have spread, for not long after, the 
Spaniards found them so profitable a trade, that an order was issued for either destroying all the hens that were taken, or setting them at liberty, that the breed night be confined to the islands. The trade in Canary birds is now much greater than it was then, though entirely removed from the original spot. They are reared in Germany and other parts of Europe, by people who bring them over to this country in great numbers every Spring.

About thirty years ago a very industrious people, the Tyrolese, were the chief providers. They brought over every year nearly two thousand, which they carried all the way in cages on their backs, and made a good livelihood by selling the best at five shillings a-piece. Since then the trade has, we have reason to believe, still further increased.

Though not very hardy, Canaries might possibly be naturalized in our country, by putting their eggs in the nests of Sparrows, Chaffinches, or other similar birds. The experiment has been partially tried in Berkshire, where a person for years kept them in an exposed aviary out of doors, where they seemed to suffer no inconvenience from the severest weather.

But this singing-bird trade is not confined altogether to Canary birds ; Piping Bullfinches, so called from being taught to pipe different tunes, forming a considerable branch of it.

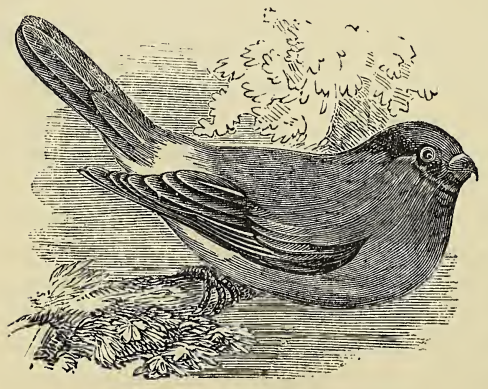

Bullench In the month of June the young ones, which are sought for in the nests of wild birds, are taken when about ten days old, and brought up by a person who, by care and attention, so completely tames them that they become perfectly docile and obedient. At the 
expiration of about a couple of months they first begin to whistle, from which time their education begins; and no school can be more diligently superintended by its master, and no scholars more effectually trained to their own calling, than a seminary of Bullfinches. They are formed first into classes of about six in each-and after having been kept a longer time than usual without food, and confined in a dark room, the tune they are to learn is played over and over again on a little instrument called a bird-organ, the notes of which resemble as nearly as possible those of the Bullfinch. For a time, perhaps, the moping birds will sit in silence, not knowing what to make of these proceedings, but after a while they will one by one begin to imitate the notes they hear. As soon as they do this, light is admitted into the room, and they are allowed a small supply of food. By degrees, the sound of the organ, and the circumstance of being fed, become so associated that the hungry bird is sure to imitate the notes as soon as it hears them. They are then turned over to the care of boys, whose sole business it is to go on with their education, each boy having a separate bird placed under his charge, who plays away from morning to night, or at least for as many hours as the birds can pay attention, during which time their first teacher or feeder goes his regular rounds, scolding or rewarding his feathered scholars, by signs and modes which he has taught them to understand, till they become so perfect, and the tune, whatever it may be, so imprinted on their memory, that they will pipe it for the remainder of their lives. But though the greater number may be taught their tune, few only, not above five in a hundred, possibly, can be so correctly taught as to pipe in perfect harmony; and these, of course, fetch a much higher price than the rest.

Whether from the early habit of associating the utterance of their notes with the agreeable addition of a meal, or from some particular pleasure they feel in singing, we know not, but it so happens that singing and satisfaction generally go together in Bullfinches; for a bird attached to any particular individuals in a family, will always express delight when they approach, and greet them with his well-known air, hopping 
towards them on his perch, and practising all his little coaxing ways. An interesting story was once told by Sir William Parsons, who was himself a great musician, and who, when a young man, possessed a Piping Bullfinch, which he had taught to sing "God save the King." On his once going abroad, he gave his favourite in charge to a sister, with a strict injunction to take the greatest care of it. On his return, one of his first visits was to her, when she told him that the poor little bird had been long in declining health, and was at that moment very ill. Sir William, full of sorrow, went into the room where the cage was, and, opening the door, put in his hand, and spoke to the bird. The bird remembered his voice, opened its eyes, shook its feathers, staggered on to his finger, piped "God save the King," and fell dead!

It is often remarked, what impudent birds are London Sparrows! and not without reason. Born and bred in the bustle of the town, they must either live and jostle with the crowd, or look down from the house-tops and die of hunger. Naturally enough, they prefer the former; and every one of our London readers will, we are sure, testify to the cool intrepidity with which this familiar bird will pounce upon a bit of bread or some other tempting morsel, which happens to catch its eye upon the pavement, and with what triumph and exultation it bears it off to its mate, seated on some windowsill or coping-stone above, or followed, perhaps, by three or four disappointed companions, who were a moment too late in seizing the spoil. Then for his nest:- -while other birds must select their own accustomed spots, the similar tree or bush, the same materials, \&c., the Sparrow, like a bird who knows the world, is everywhere at home, and ready to establish himself wherever chance may happen to place him. If he lives remote from towns and cities, and the habitations of men, a tree answers his purpose, and a comfortable nest he will there build, with the rare addition of an arched top into the bargain, which possibly he may have learned from that knowing bird, the Magpie. In default of a tree or a house, a chink in a rock or a hole in a wall suits him; but, after all, the nooks and eaves of buildings are his favourite re- 
sorts : accordingly, in London, where he has his choice, he will often select droll places. Amidst the carved foliage of the capital of some Corinthian column, a projection of straws, with now and then a feather, announce a nest in preparation.

But some London Sparrows aspire still higher, one pair having actually built in the Lion's mouth, over Northumberland House at Charing Cross. A still more extraordinary place was pitched upon by a north-country couple. A coal-vessel from Newcastle, put into Nairn, in Scotland, and while there, two Sparrows were frequently observed to alight on the top of the vessel's mast, while the vessel remained in port. This occasioned no great surprise to the crew ; but, after putting to sea, the two Sparrows were seen following the sloop, and, having come up with her, resumed their posts at the top of the mast. Crumbs of bread were scattered upon the deck, with a view of enticing them down, of which they soon availed themselves; and, after eating heartily, again returned to the mast-head. By the time the vessel had been two days at sea, they became much more familiar, and descended boldly for the purpose of feeding. The voyage was a long one, lasting for some days; when, on reaching the river Tyne, to which they were bound, the nest with four young ones, was carefully taken down, and being put, in the presence of the old birds, into the crevice of a ruined house, on the banks of the river, they continued to rear their brood.

When thus upon the subject of young Sparrows, we may direct attention to the very rapid growth of their feathers in hot weather. On the ninth of August, a young one was taken from a nest, with neither down nor feathers upon it, the rudiments only of plumage being visible under the skin, on the back of the head, and along the back; on the side of the wings, the shafts of the quills had just pierced the skin. Eight days after, another young one was taken from the same nest, covered with feathers, and able to make some use of its wings. Another circumstance is worthy of notice. The old ones had adapted the food to their powers of digestion. The stomach of the first was weak, and filled almost entirely with 
insects, only one grain of wheat, and a few of sand found. In the second, the gizzard was become vastly more muscular, and contained nine grains of wheat whole, besides some smaller pieces, the remains of several beetles, and some larger gravelstones.

A Sparrow is not only bold with regard to men, but still more so, on particular occasions, towards other birds. On the edge of a certain lawn grew a close thick bush. On this lawn, amongst others, the Blackbird used to come and forage for worms. One day a person happened to be looking at a Blackbird in the act of making off with a prize, when a Sparrow, darting from the thick bush, instantly assailed the Blackbird, and compelled him to drop the worm, of which he took immediate possession. So singular a circumstance induced the observer to look out now and then, when Blackbirds came, and he frequently saw the same piratical practice adopted by the Sparrow, who thus, by keeping watch in his bush, was enabled to enrich himself on the labours of the larger bird. But, notwithstanding this unfavourable feature in his character, he has been known to act with great consideration and kindness to birds requiring his good offices.

In the Naturalists' Magazine we find the following story in point:- " A lady, living in Chelsea, was extremely fond of birds, of which she kept a considerable number in cages. Amongst others she had a Canary, which was a particular favourite, but the loudness of his note often obliged her to put him outside of her window, in some trees which were trained up in front of her house. One morning, during breakfast, when the cage was there placed, a Sparrow was observed to fly round about it, then perch upon the top, and twitter to the bird within, between whom and itself a sort of conversation seemed to ensue. After a few moments he flew away, but returned in a short time, bearing a worm or small grub in his bill, which he dropped into the cage, and immediately flew away. Similar presents were received day after day, at the same time, by the Canary, from his friend the Sparrow, with whom, at length, he became so intimate, that he very often received the food, thus brought, into his 
own bill, from that of the Sparrow. The circumstance attracted the notice of the lady's neighbours, who often watched these daily visits; and some of them, to try the extent of the Sparrow's kindness, also hung their birds out at the window, when they found them also fed; but the first and longest visit was always paid by the Sparrow to his original friend the Canary.

"Though thus intimate and social with his own kind, it was observed that this Sparrow was exceedingly shy and timid with respect to human beings; for, though many were witnesses to the above, they were obliged to keep at a distance, and use great caution, otherwise he immediately flew away. This attention was carried on throughout the Summer, and extended to the beginning of Autumn, when the visits entirely ceased, whether intentionally on the part of the Sparrow, or that he met with some accident, could not be ascertained."

That they will attend to their young far beyond the usual period, in case of necessity, the following anecdote will prove, though we believe many, if not most birds, will do the same, under similar circumstances; the experiment may be easily tried, by slightly tying the wings of young birds, when nearly fledged, or confining them by a thread to the bottom of the nest, taking care not to injure them. A pair of Sparrows, which had built in the thatched roof of a house, were observed to continue their regular visits to the nest long after the time when the young birds ought naturally to have taken flight. This unusual circumstance continued throughout the year; and, in the Winter, a gentleman, who had all along observed them, determined on finding out the cause. He therefore placed a ladder, and, on mounting, found one of the young ones detained a prisoner, by means of a string, or scrap of worsted, which formed part of the nest, having become accidentally twisted round its leg. Being thus disabled from procuring its own living, it had been fed by the continued exertions of the parents.

An unfortunate Sparrow, who had also been made prisoner in his own nest, met with a very different fate, being 
actually killed, instead of preserved, by the over-zealous kind attentions of his mate. The case occurred in the Spring of 1818, in Surrey. The pair were in search of a place for building their nest; and the male bird, finding a tempting hole among the tiles of the roof, got into it; unfortunately, he became entangled in the broken mortar, and could not force his way back. The female saw his situation, and after flying backwards several times, twittering, and apparently in great distress, attempted to pull him out. Several birds were attracted by the accident, and came fluttering round, but were beaten off by the hen Sparrow. She then redoubled her own efforts to get him out, and seizing his beak above the nostrils, with her own beak, pulled it so hard that she killed him. She did not appear, however, aware of the mischief she had done, but continued pulling at the dead body of the unfortunate bird, with as much perseverance as if it had been alive. She was, at length, driven away by a person who saw the whole transaction, and with some difficulty extricated the dead bird. Its head was dreadfully mangled, and the beak of the hen had evidently penetrated the brain. About an hour afterwards, a Sparrow, supposed to be this hen, was observed sitting on the very spot where the accident had happened, crouched together, with her feathers all standing up, so as to give her the appearance of a ball, conveying a perfect idea of disconsolate suffering.

Timid as birds are, attachment to their young will frequently change their very nature, and inspire a boldness and confidence in these little creatures, which calls for respect and admiration. What can be more interesting than the affection of the two Linnets we are about to mention? A nest, containing four young ones, scarcely fledged, was found by some children, who resolved to carry them home for the purpose of rearing and taming the young birds. The old ones, attracted by their chirping, continued fluttering round the children, till they reached the house, when the nest was carried upstairs to the nursery, and placed outside the window. The old birds soon afterwards made their appear- 
ance, approached the nest, and fed the family, with. out showing alarm. This being noticed, the nest was soon afterwards placed on a table, in the middle of the apartment, and the window left open. The parent birds came boldly in, and fed

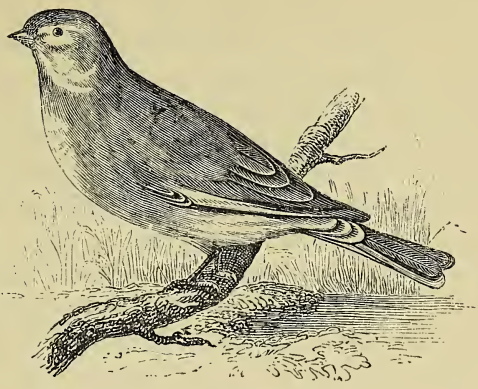

Linnet.

their offspring as before. Still further to put their attachment to the test, the nest and young ones were placed within a bird-cage; still the old ones returned, entered boldly within the cage, and supplied the wants of their brood as before, and, towards evening, actually perched on the cage, regardless of the noise made around them by several children. This continued for several days, when an unlucky accident put an end to it. The cage had been again set on the outside of the window, and was unfortunately left exposed to a sudden and heavy fall of rain: the consequence was, that the whole of the young were drowned in the nest. The poor parents, who had so boldly and indefatigably performed their duty, continued hovering round the house, and looking wistfully in at the window, for several days, and then disappeared.*

Before we take leave of this tribe of small birds, we would say a word or two respecting the benefit or injuries imputed to them. That they are occasionally mischievous, cannot be denied; though it is but fair to add, that they also, like the Rooks before mentioned, repay us by a considerable balance of good. That the Bullfinch feeds on the buds and seeds of trees there can be no doubt; and that the Chaffinch, though, by many considered as a pure feeder on insects, does the 
same, particularly in early Spring, when he inflicts ruinous injury on the sprouting crops of several plants, is equally true. Sparrows, too, burrow in our stacks, and consume a certain quantity of corn,-not, indeed, in the same serious quantities that another bird does, called the Snow-Bunting: these birds, in hard Winters, come from the north in prodigious flocks, and, where they take up their quarters, become quite a nuisance,-not so much by what they consume, as by what they destroy; which they do thus: in search of grain, they frequent the stack, and then seizing the end of a straw, deliberately draw it out. To such a degree has this been done by them, that the base of a rick has been found entirely surrounded by the straw, one end resting on the ground, the other against the stack, as it slid down from the top, and as regularly placed as if by hand: and so completely was the thatching pulled off, that it was found necessary to remove the corn.

That some guess may be formed of the possible extent of good or evil occasioned by small birds, we annex the result of our own observations on the precise quantity of food consumed by certain birds, either for their own support, or that of their young; remarking, at the same time, that the difference observed in the instances may be partly accounted for by the different quantity of food required by young birds, at different periods of their growth.

Sparrows feed their young 36 times in an hour, which, calculating at the rate of 14 hours a day, in the long days of Spring and Summer, gives 3,500 times per week; a number corroborated on the authority of another writer, who calculated the number of caterpillars destroyed in a week to be about 3,400 .

Redstarts were observed to feed their young with little green grubs from gooseberry-trees, 23 times in an hour, which, at the same calculation, amounts to 2,254 times in a week; but more grubs than one were usually imparted each time.

Chaffinches, at the rate of about 35 times an hour, for five or six times together, when they would pause, and not return 
for intervals of eight or ten minutes: the food was green caterpillars.

The Titmouse, 16 times in an hour.

The comparative weight consumed was as follows:-A Greenfinch, provided with 80 grains, by weight, of wheat, in 24 hours, consumed 79 ; but of thick paste, made of flour, egg, \&c., it consumed upwards of 100 grains.

A Goldfinch consumed about 90 grains of Canary-seed in 24 hours.

Sixteen Canaries consumed at the average rate of 100 grains each, in 24 hours.

The consumption of food by these birds, compared with the weights of their bodies, was about one-sixth; which, supposing a man to consume food in the same proportion to his weight, would amount to about 25 pounds for every 24 hours! 


\section{CHAPTER XI.}

Subulirostres ; awl-shaped Bills.-Manakins ; curious Nests of.Tomtits. - Wagtails.-Redstarts.-Robins, \&c.-Migration of this Tribe. - Nightingales. - Whether they return to same Nests._Ear for Music._Night Singing-birds.-Planirostres ; flatbilled.-Swallow Tribe.-Whether occasionally Dormant; instances of.-Migration of.-Insects, number devoured by Swallows.-Spiders, high flights of.-Curious Nests of Swallows.-Courage of.

\section{Table XI. Order 2.-Passerine.}

$\mathrm{O}^{\mathrm{F}}$ the four genera included in this tribe, three are common in England, but the fourth, that of the Pipras or Manakins, is entirely foreign, comprising a number of little birds of beautiful plumage. Some of these species are exceptions to the general rule of classification, as the upper mandible, on examination, will be found, as in the Manakins, notched; in other respects, the beak has a tolerably marked character, being short and usually feeble and flexible; and, as the word subulirostrum implies, awl-shaped, from a Latin word, subula, signifying an awl, and rostrum, a beak.

Under the second genus, Parus, are comprehended the various species of Titmouse. Under the third, Motacilla, the Wagtails, Wrens, Robins, and a large family of singingbirds, usually separated from the rest, under the term Sylvias or Warblers; at the head of which stands the Nightingale. Under the fourth, the Alauda, or Larks. The Tomtits are familiar to everybody ; they might be called our minor Jackdaws, so pert and bustling,--never at rest,-always prying about, peering into every little chink and cranny,-and, even in the breeding season, when most birds retire to more unfrequented haunts, still lurking about our homesteads, and placing their nests in the oddest and sometimes most conspicuous situations. Thus, a pair of Titmice (Parus caruleus), built their nest in the upper part of an old pump, 
fixing it on the pin in which the handle worked. It happened, that during the time of building and laying the eggs, the pump had not been in use; when again set going, the female was sitting, and it was naturally supposed that the motion of the pump-handle would drive her away. The young brood, however, were hatched safely, without any other misfortune than the loss of a part of the tail of the sitting bird, which was rubbed off by the friction of the pump-handle. opening for the pumphandle seems, indeed, to be a favourite spot, notwithstanding its danger, as we knew of another pair of Titmice, who, for several days, persevered in inserting,

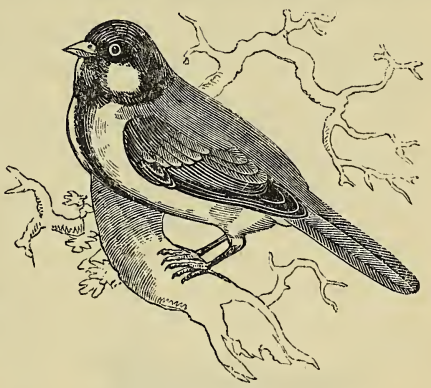

Greater Titmouse, close upon the point of the handle, the materials for a nest, though, every time the handle was raised, they were either crushed or forced out, till the patience of the persevering little builders was fairly exhausted.

Another pair of the same species established themselves in a still more singular, though certainly less frequented spot, neither more nor less than in the mouth of the skeleton of a man who had been hung in chains for murder. Another pair of a different species (Parus major), had wisely fortified themselves in the centre of an old Magpie's nest, where, surrounded by a. prickly defence of thorns, \&c., they had built their little warm nest without fear of molestation.

The interior of a skull, as well as the interior of a Magpie's nest, were (however singular) at least better suited to the sedentary life of a bird when sitting on her eggs, than the noisy workshop of a brass-founder's factory ; yet in such an unlooked-for place did a female Water-Wagtail once build her nest, within a foot of the wheel of a lathe, in the midst 
of the din of hammers and braziers. There, unmolested and unconcerned, she hatched four young ones. The cock, not reconciled to such a scene, instead of taking his part in feeding the nestlings, carried the food he collected to a spot on the roof, where he left it till the hen fetched it when wanted. She became quite familiar with the men who were constantly employed in the shop, and flew in and out without showing signs of fear; but if a stranger approached she immediately flew off her nest, or, if absent, would not return until he had departed.

We once found a Wagtail's nest under the half-deck of a pleasure-boat, which was anchored on a sheet of water. Several times, from the discovery of the nest to the final departure of the young ones, we embarked and sailed about, the old

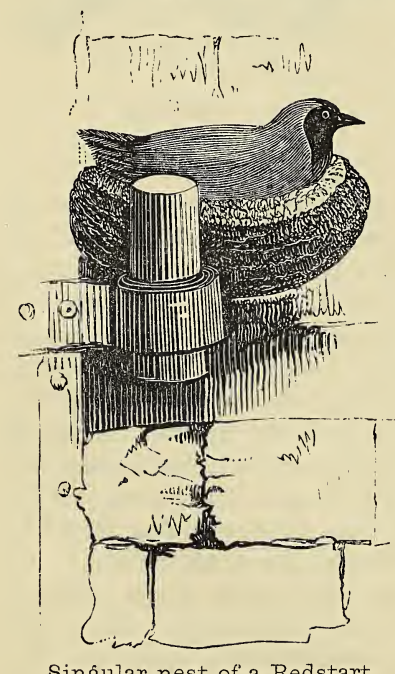

Singular nest of a Redstart. birds keeping a look-out upon our motions, and frequently alighting on the gunwale, and finally rearing and flying off with their brood.

The Redstart, one of our prettiest summer birds of passage, though in its general habits very shy, is frequently in the choice of position for its nest, the very reverse. We remember one which built on the narrow space between the gudgeons or upright iron on which a garden door was hung; the bottom of the nest, of course, resting on the iron hinge, which must have shaken it every time the door was opened. Nevertheless, there she sat, in spite of all this inconvenience and publicity, exposed as she was to all who were constantly passing to and fro. 
Amongst Robin Redbreasts, many instances of strange selection have come to our knowledge, quite as singular as those hitherto mentioned. Thus, we know of one which attempted to build in the library of a gentleman's house, at least, so it was suspected, from a few suspicious materials, such as dried leaves, \&c., having been occasionally found amongst the shelves, without any person being able to ascertain from whence they came. Probably disappointed by perceiving that they were swept away as soon as deposited, the domestic bird resolved to try another equally sheltered situation, and, accordingly, selected the dining-room, which, as the family never entered it till luncheon-time, she had all to herself from the moment the housemaid had done her duty in the morning and retired, leaving, as she was accustomed to do, the window open. How long the bird had carried on her operations unnoticed, we know not; but a servant accidentally moving the drapery of one of the windowcurtains, discovered in the folds of a festoon the Robin's nest.

In this instance the bird availed itself of a situation in which, during the greater portion of the day, she was in solitude and silence; but solitude and silence do not seem essential to all Robin Redbreasts, for we lately heard of a pair which took possession of a pigeon-hole book-shelf in a school, which was constantly frequented by seventy children. The hole selected was at the farthest extremity of the room, immediately above the heads of a junior class of little girls from four to five years of age, who, much to their credit, never disturbed the bird. There she laid and hatched five eggs. One of the young ones died in a few days, and the body was carried off by the parent-birds. The remaining four were regularly fed in the presence of the children, and in due time reared. Soon after their departure the old bird repaired the nest, and laid three more eggs, which she attended to with the same perseverance and success. We have often alluded to the frequent return of birds to the same nests, and perhaps the most singular feature in this anecdote is, that about twelve years ago a Robin built in 
that identical pigeon-hole. Why the visits were not renewed every year it is impossible to conjecture, but that the pair of the present year were either the same old birds, or young ones of the brood then reared in it, is more than probable, from the circumstance of this pigeon-hole being again selected; when others, forming the school-library within the same framework, would have equally suited the purpose.

Another nest was constructed, and for two successive years, in a still more extraordinary situation, which we give, not on our own authority,* but fully believing it, corroborated, as it may in a manner be said to be, by the proofs of confidence already given. A few years ago, a pair of Robins took up their abode in the parish church of Hampton, in Warwickshire, and affixed their nest to the church Bible, as it lay on the reading-desk. The vicar would not allow the birds to be disturbed, and therefore supplied himself with another Bible, from which he read the lessons of the service. A similar instance occurred at Collingbourne Kingston church, in Wiltshire, on the 13th of April, 1834: the clerk, on looking out for the lessons of the day, perceived something under the Bible in the reading-desk, and in a hollow place, occasioned by the Bible's resting on a raised ledge, found a Robin's nest containing two eggrs. The bird not having been disturbed, laid four more, which were hatched on the 4th of May. The still more extraordinary part of the story is, that the cock-bird actually brought food in its bill, and fed the young brood during divine service, which is performed twice every Sunday; and it is further highly creditable to the parishioners, particularly the junior portion of them, that the birds were never molested, and not an attempt ever suspected to be made on the nest and eggs deposited in so hallowed a spot.

We can remember, indeed, a 'Robin hopping more than once familiarly, as if aware how safe from peril it was at such a moment, upon our own Bible, as it lay open before us, reading the lessons on a Christmas-day.

* Nat. Hist. Mag., No. 31. 
We shall close our anecdotes of singular situations chosen for building nests, with an instance of a Sparrow, who, like the preceding Robin, attached herself to a church; but instead of the parish Bible, selected the middle of a carved thistle, which decorated the top of the pulpit in a chapel at Kennaway in scotland. It found free ingress and egress by means of the windows, which were left open for the purpose of airing the chapel in the week-days. This bird might literally be said to have verified the words of the Psalmist, "The Sparrow hath found an house, where she may lay her young, even thine altars, O Lord."

Most of the birds of this tribe are migratory, either partially, or altogether so: we mean, that while the Nightingales, Willow-wrens, and others disappear entirely from our shores, and retire to distant and more congenial climates, others, such as the Wag-tails, only move from one part of England to another. The exact times of their appearance and departure it would be desirable to ascertain, with reference to state of weather, direction of the wind, and prevalence of particular insects, \&c. In short, the same principle holds good in natural history as in other science: namely, the importance of noting down observations, however trivial they may appear at the time, as the most minute circumstance may possibly, when connected with other inquiries, lead to unexpected additions to our knowledge of the operations of nature, just as a unit or cipher in arithmetic becomes important, simply by taking its proper place.

It might, indeed, in connexion with this view of the subject, afford an interesting object of research, were the daily, or almost hourly migrations, if we may so speak, more closely observed; my own belief being, that several species of birds are in the habit not only of, generally speaking, confining themselves to certain localities, but at certain hours of the day frequenting particular spots, an instance in proof may be given of a Robin, which during a considerable portion of the winter took shelter in Norwich Cathedral, perching during the Morning Service, and almost always within a minute or two of the same time, on a particular 
part of the Cathedral, when, after warbling a few notes for a short time, it flew to another particular spot, and from thence to a third, generally terminating its course by alighting on the pavement in search of small particles of food. Hopes were entertained that it might repeat its visits in the following winter, but its return was looked for in vain, having most likely met with its death in the course of the summer.

The migration of Nightingales is attended with some peculiarities deserving attention. In some parts of England they are to be heard in every hedge-row, filling the air, particularly at night, when most of our other warblers are silent, with their rich melody; while in other parts, to all appearance as well suited to their habits, not one was ever known to be heard; this comparative rarity or abundance not unfrequently occurring in spots only a few miles apart. It might be supposed that the warmest parts of the kingdom were best adapted to their habits; if so, why are they not to be found in the southern parts of Devonshire and Cornwall, where, we believe, they are never heard? As a general rule, it has been said, that they are not to be met with north of the Trent; but this is not strictly correct; as in the northern parts of Yorkshire, as far as Wetherby, they are at least occasional visitors.

If they are limited to certain districts by the nature of their favourite food, it might be interesting to discover what this precise food is, so capriciously and unaccountably confined to certain spots. We have alluded more than once to the regular return of birds to the same nests and places of their birth; and it might be supposed that this would solve the mystery, the Nightingales naturally returning only to those spots where, for time out of mind, a train of ancestors might have built before them; but this is not borne out by facts : for a gentleman who was very desirous of introducing these birds on his estate in a northern part of the kingdom, commissioned a person in London to purchase as many Nightingales' eggs as he could procure at a shilling each. This was done accordingly; they were carefully packed 
in wool, and forwarded by the mail. In the meantime men had been employed to find and take care of several Robin Redbreasts' nests, in places where they might hatch securely. The eggs were then placed under the Robins, by whom the young Nightingales were successfully reared, and remained in the neighbourhood till the usual time for migration; when it is supposed they went away, as they were not seen again after that period, and not one was known to return to the place of its birth. It has been suggested by others, that being a delicate bird, and little calculated to endure the fatigue of long flights, they migrated from the Continent only to the eastern coast of England, and then gradually journeyed inland; and consequently that this would account for their not being seen in Cornwall, and some of the other western parts of England. But in reply to this, it should be remembered, that the eastern flight across the Channel, unless they all embarked at Calais for the coasts of Essex and Kent, is as wide as that between the western coasts of France, where they are plentiful, and the corresponding coasts of England, which they do not visit.*

The Nightingale stands unrivalled at the head of our singing birds, and may be called, as old Izaak Walton, the angler, terms them, " chiefest of the little nimble musicians of the air, that warble forth their curious ditties with which nature has furnished them to the shame of art;" but proud as they may be of their own skill, they are not insensible to the harmony of musical instruments. The German hymn played upon a flute very softly near a bush, in which there was a nest, soon attracted the attention of the birds. Scarcely was the air finished, than the cock was heard to chirp; and when played a second time it was seen to hop through the bushes with great quickness towards the place where the player stood, at the same time making a sort of sub-warbling, which it soon changed into its usual beautiful and lengthened song.

The Nightingale is usually supposed to withhold his notes till the sun has set, and then to be the only songster left. 
This is, however, not quite true, for he sings in the day, often as sweetly and as powerfully as at night; but amidst the general chorus of other singing birds, his efforts are less noticed. Neither is he by any means the only feathered musician of the night. The Wood-lark will, to a very late hour, pour forth its rich notes, flying in circles round the female, when sitting on her nest. The Sky-lark, too, may frequently be heard till near midnight high in the air, soaring as if in the brightness of a summer's morning. Again, we have listened with pleasure long after dark to the warblings of a Thrush, and been awakened at two in the morning, by its sweet serenade. The Sedge-bird and Grasshopper-lark may also be heard long after sun-set.

Light, however, seems to be, in most cases, a regulator of their song ; for in the case of the Sky-lark and Thrush, as it occurred in the middle of June, there was a strong twilight, and we have listened in vain for the Sky-lark's note beyond the hour above mentioned; though in the Northern part of Scotland, and the Shetland Islands, still further northward, where in summer it is scarcely ever dark, they are heard throughout the night singing; and again, to use old Izaak Walton's words, " ascending higher into the air, and then for a time ending their heavenly employment, becoming mute and sad to tinink they must descend to the dull earth, which they would not touch but from necessity." 


\section{TABLE XII. (See page 14.)}

\section{Order 2. Passerine.-Tribe 6. Planirostres.}

THis tribe contains but three genera, two of which, namely, the Swift and the Swallow, are by common observers considered as the same, though there is a remarkable difference in the position of their claws : the third is that of the Goatsuckers, whose enormously wide, gaping mouths, and short, flat, softish beaks, at once distinguish them from other species.

As we are not writing a regular book upon the natural history of birds, but confining ourselves chiefly to anecdotes

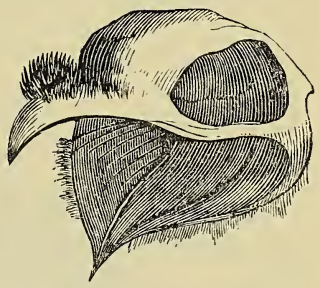

Skull of a Goat-Sucker. connected with their habits, we shall not pretend to enter into the many details which it might be otherwise necessary to mention, and shall therefore merely remind our readers that Swallows are the most conspicuous of our summer birds, that with their first appearance we are accustomed to associate the departure of Winter, and the forthcoming of Summer.

We have four sorts, a little brownish bird, called the SandMartin (Hirundo riparia), which leads the way, and if looked for about the first week in April, may be seen hurrying over the surface of large sheets of water or rivers, near to which are banks of sandy soil, in which they burrow and build their nests ; the Chimney-Swallow (Hirundo rustica), with his red patch upon his throat, and the Martin (Hirundo urbica) follow nearly together; the large screaming Swallow or Swift (Hirundo apus) being the last to come and the first to go.

We have already spoken of migration (p. 78), and the 
little difficulty in accounting for it, rapid as these birds are in motion, and fitted by their length of wing for long-continued flight. Notwithstanding which, many naturalists formerly, and some few still, maintain that they do not desert us entirely, but become dormant during the cold weather, or, what is still more extraordinary, plunge into water, and remain buried in the mud at the bottom, till the warmth of Spring revives them, when they awaken from their slumbers and again become tenants of the air.

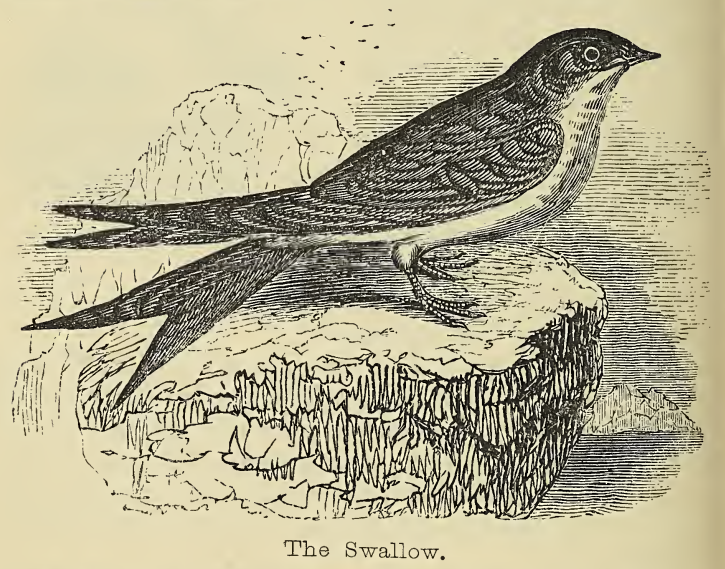

We will not positively assert that Swallows can, under any circumstances, continue through the Winter in a dormant state, and still less, that they can exist at the bottom of water; but as instances well attested, without assignable reasons for deceiving, are abundant, coming too from different and distant quarters, they at all events merit some notice; and that future observers may, by being made acquainted with a few of the instances given, be enabled to clear up all doubts, or explain what may still remain to some a mystery, we will give those cases which have come to our knowledge, on the most respectable authority. 
On the 16th of November, 1826, a gentleman residing near Loch Awe, in Scotland, having occasion to examine an outhouse, used as a cart-shed, saw an unusual appearance upon one of the rafters, which crossed and supported the thatched roof. Upon mounting a ladder, he found to his astonishment, that this was a group of Chimney-Swallows (Hirundo rustica), which had taken up their Winter quarters in this exposed situation. The group consisted of five, completely torpid, and none of the tribe to which they belonged had been seen for five or six weeks previously: he took them in his hand as they lay closely and coldly huddled together, and conveyed them to his house, in order to exhibit them as objects of curiosity to the other members of his family. For some time they remained to all appearance lifeless; but the temperature of the apartment into which they were carried being considerably raised, by a good turf fire, they gradually evinced symptoms of reanimation; and in less than a quarter of an hour, finding that they were rather rudely handled, all of them recovered, so as to fly impatiently round the room in search of some opening, by which they might escape. The window was thrown up, and they soon found their way into the fields, and were never seen again.

A similar circumstance, though, from the place of its discovery, it must refer probably to Sand Martins, was related by a gentleman, who found two Swallows in a sandbank at Newton, near Stirling, quite dormant.

Again at Belleville, in North America, a gentleman observed one evening, a little after sun-set, late in the Autumn, a vast number of Swallows collected together, high in the air, and hovering over a particular spot. Having been informed by one of his school-fellows, when a boy, that Swallows had been seen to dive into a mill-pond and disappear, he determined to watch these, and in about ten or fifteen minutes, as darkness came on, they lowered their flight, and gathered themselves into a smaller circle, and at length poured down into a very large hollow sycamore-tree. It was observed that they came out for several successive days, and returned in the evening in the same manner. In 
the following year the tree was cut down, the hollow was then found to be about six feet in diameter, and filled, six inches deep, with bones, feathers, and other remains of dead birds, such, probably, as were too old or too feeble to fly out in the Spring. They apparently must have occupied the tree for several years. Two other trees were subsequently seen, fallen, with similar appearances.*

Again, about half a dozen Swallows were found a few years ago, in a torpid state, in the trunk of a hollow tree, by a countryman, who brought them to a respectable person, by whom they were deposited in a desk, where they remained forgotten till the following Spring, when, one morning, on hearing a noise, he opened the desk, and found one of them fluttering about: the others also began to show signs of life, and, upon being placed out of doors in the sun, speedily arranged their plumage, took wing, and disappeared.

On the 2nd of November, 1829, at Loch Ransa, in the Island of Arran, a man, while digging in a place where a pond had been lately drained off, discovered two Swallows in a state of torpor: on placing them near the fire, they recovered. One unfortunately escaped, but the other was kept by the man for the purpose of showing it to some scientific persons.

In addition to these cases relating to Swallows, we have two instances of dormant Corncrakes, which are also migratory Summer birds. A farmer at Aikerness, in Orkney, about mid-winter, in demolishing a mud wall, there called a hill-dike, found a Corncrake in the midst of it,-a bird which is plentiful in summer, but departs, like Swallows, at the close of that season. It was apparently lifeless; but, being fresh to the feel and smell, it was placed in a warm situation. In a short time it began to move, and in a few hours was able to walk about, and lived for two days in the kitchen; but, refusing all food, it died.

The other occurred at Monaghan, in Ireland, where a gentleman, having directed his labourers, in Winter, to 
remove a large heap of manure, that had remained undisturbed for a great length of time, perceived a hole, which was supposed to have been made by rats; it penetrated to a great depth, but at its termination, instead of rats, three Corncrakes were discovered, as if placed there with the greatest care, not a feather being out of its place, and apparently lifeless. The birds, on examination, were, however, considered to be in a torpid state, and were placed near a fire in a warm room. In the course of a short time a tremulous motion was observed in one of their legs, and soon after a similar motion was noticed in the legs and wings of the whole, which at length extended itself to their whole bodies, and, finally, the birds were enabled to run and fly about the room.*

Humming-birds also, we are assured, are sometimes overtaken by cold, and have been known to fall into a torpid state. $\dagger$

It has been argued, that as some animals, such as the bear, dormouse, \&c., are subject to long seasons of torpidity, during which time they require no food, Swallows may, in like manner, continue in a torpid slumbering state throughout the Winter. A few experiments, carefully attended to, might throw additional light upon the subject. If Swallows, for instance, were exposed to cold, at or near the freezingpoint, sleep might overcome them, just as it does travellers who have been accidentally exposed to the inclemency of the weather : on becoming benumbed, we know that drowsiness commences, which, if not shaken off by active exertion, inevitably ends in death. If man is subject to this effect, as well as some animals, why may not Swallows? Two of these birds were, a Summer or two ago, caught, and placed for twenty-four hours in a cage suspended in an ice-house; at the expiration of this time, one was found dead, but the other was alive, and when released, flew away in perfect vigour. In this case, therefore, nothing was learned from the experiment. But the constitution of the bird may be different 
towards the close of the season, and better prepared for a Winter's sleep: and that this, to a certain degree, is the case, may be collected from the following statement:- " On the 22nd of September, at about seven o'clock in the morning, with a drizzling cold rain, and wind easterly, a vast number of Chimney-Swallows were observed hovering over or resting on a house, in the south of England; in the course of the morning, large flocks continued to join this main body. The appearance of the whole was, however, very lethargic and moping; and so tame were many, that they were taken by hand from the window-sills on which they had perched. For experiment's sake, our informant put his arm out of an attic-story window, and in a short time one of them settled on his hand; he withdrew it, expecting the bird would fly off, but there it remained, giving him ample time to examine it more narrowly. Its eyes appeared nearly shut, its wings and tail drooping, and its whole frame in a torpid state. Finding some force necessary to take it from his hand, he had the curiosity to whirl it round several times, but to no purpose, the only exertion of the bird used being a languid expansion of the wings for preserving its seat, which it did by grasping its claws so firmly as to draw blood from the hand. In the course of the day he collected twenty, confining them at large in a room.

"On their first introduction they perched themselves on various parts, and appeared as languid as their neighbours out of doors. In a short time, one, which had placed itself on the mantel-piece, near a small fire, was observed to become more lively, moving its head with a good deal of animation, and seeming to enjoy the warmth. On this the fire was increased, and the air in the room considerably warmed; on which the little prisoners soon became more sprightly, and flew about the room as rapidly as on a Summer's day in the open air. Between eight and nine o'clock the main body went off, with the exception of five or six, and were absent for about two hours, when they returned in seemingly greater numbers than before, and remained till the following morning, when, between nine and ten o'clock, there appeared a great 
commotion amongst them, and within a few minutes they all took their departure, in a south-east direction, appearing to have entirely cast aside their torpidity, and to be as full of animation as ever. Their flight was at a great height, further than the eye could reach, to which they rose by several circumvolutions ; that is, flying round in large circles, just as Kites and Ravens do when they soar. About half an hour after they had flown off, two of those confined in the room were released. For about half a minute they flew exactly in the contrary direction from their companions, and seemed bewildered; they then, however, turned about, and darted away with the greatest velocity, in the same direction as the others. The remainder were let out in the course of the day, at intervals, between the hours of eleven and four o'clock, all of which took the same direction as their predecessors."

This is one of the most minute and satisfactory accounts of migration we ever met with; and although these birds were not, in this case, compelled by immediate hunger (for the stomachs of several found dead were full of the remains of their common food, consisting of small insects, spiders, \&c.), there nevertheless can be no doubt that one of their chief reasons for quitting us is want of food; for in Ceylon, where the species are said to be similar to our own,* and where the climate is such as to allow of a perpetual supply of food, they never quit the island. Why, indeed, they ever should quit those favoured spots, where they can exist in the midst of plenty, without wandering to distant regions, is the most surprising part of their history; and it is difficult to account for a flight of Swallows departing from the warm climate of the tropics, to pass their short Summers in such remote and uncongenial quarters of the globe as Iceland, in the north, and Port Famine, near Cape Horn, in the south, in both of which inhospitable regions they are found, as well as near the still more cheerless shores of Hudson's Bay, where the supply of food is more particularly precarious, owing to 
the large masses of ice which hang upon the northern sides of the bay until the beginning of August, every breeze from which sweeps over the land, chilling the insects, and driving them to shelter; and, when this happens, the Swallows suffer severely, and many of their yonug perish. Whereas, in the interior of the same country, beyond the reach of these iceblasts, they run no risks, and rear their broods without difficulty.

The quantity of insects devoured by Swallows is far greater than most people imagine. On picking up a Swift that had been shot, a number of minute flies or beetles, some mutilated, and others scarcely injured, were observed crawling out of the bird's mouth: the throat and pouch seemed absolutely stuffed with them, and as many were collected as, when pressed close, could conveniently be contained in the bowl of an ordinary table-spoon. If nearly examined, a great proportion of these minute insects will be found of one particular sort; and it is a curious fact, that by far the greater part, indeed we may say, from repeated examinations, all of those which suddenly fly into our eyes, when walking or riding, are of the same genus (Staphylinus), if not the same species (Staphylinus brachypterus), devoured by Swallows. Most persons may have noticed, in the Summer season, a disagreeable-looking insect, running rather briskly across a sand or gravel walk, which, if touched or disturbed, immediately throws up its tail, from whence project two formidable-looking spines; it appears to have no wings, but it is provided, nevertheless, with a pair, most beautifully folded up beneath two little short wing-cases; still, however, these wings are disproportioned to the size of the insect, and we mav, therefore, reasonably conclude, that it is by no means so active on the wing as others with a larger expansion, and consequently unable so adroitly to guide itself, and avoid danger; which may account, at the same time, for its being more readily seized by the Swallows, and also for its being carried headlong into the eye, if the eye happens to be in the line of its accidental course. Those who have experienced the annoyance of these minute intruders, will well remember the 
extreme pain felt, as soon as the eye closes upon its prisoner: this is occasioned, as the annexed figure will show, by the irritation produced when the insect, as in the case of its larger representative on the gravel walk, on being caught, instantly darts upitstail, covered with similar sharp and fork-like appendages.

Ourreaders, on perusing the above narrative of the torpid state of

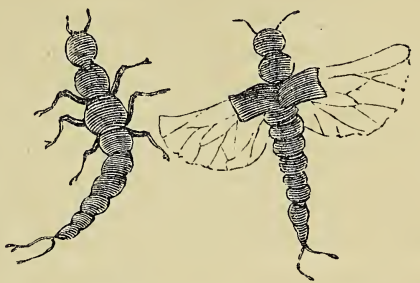

Staphylinus Brachypterus

(Magnified). the migratory Swallows, may have been surprised that spiders should be found in the mouth of a bird collecting its food on the wing; but they will be still more so, in hearing that spiders form a very considerable part of the food of the Swift, which flies higher in search of insects than any other insect-feeding bird. The fact is, the air is abundantly tenanted with small spiders, and to a height almost incredible. Of the quantity, we may form some idea, by the perfect carpeting of webs which are occasionally seen in an autumnal morning, glistening with moisture. These are the webs of the gossamer-spider, which, rendered heavier by the dew collecting on their slender threads, fall to the ground, and cover whole acres.

Of the height to which these spiders rise, we have the evidence of a person, who, from the summit of York Minster, nearly two hundred feet above the ground, found himself surrounded by immense flights of little spiders, floating upwards on their airy webs, and could perceive them, in equal numbers, higher in the air, as far as the eye, aided by a good telescope, could reach.

It is a common weather rule, that when Swallows fly low, there will be rain; but when high, it will be fair. The reason may be readily guessed. They feed entirely, as we have said, upon insects; and the flight of insects depends, in 
a great degree, on the state of the air ; if it is clear and dry, they rise; if moist, or likely to be so, they keep nearer the ground: and thus the Swallow, like the hand of the clock, moved by invisible wheels and springs, tells us when we may expect the weather to be moist or dry.

We have noticed some odd places chosen by birds for their nests, but none, perhaps, more curious than those selected by Swallows, at the same time affording another proof of the constant return of birds to the same places. That they do return, is, indeed, a fact established beyond a doubt, it having been ascertained, by the experiment of fastening a small piece of silk round one of the legs of a female, when sitting upon eggs, and finding her again similarly occupied on the following Spring. At a nobleman's house, in Scotland, the kitchen was in a building separated from the main part of the house by an open court, but connected with it by a covered passage, supported by posts, and open to the south. In the corner of the passage, close to the kitchen-door, a bracket was placed for holding a lamp, which was taken down to be trimmed every day, and lighted every evening. On that bracket, a Swallow, and it is believed the same Swallow, built her nest for three or four years, quite regardless of the removal or light of the lamp, and the constant passing and repassing of the servants. On the opposite side of the same open court,

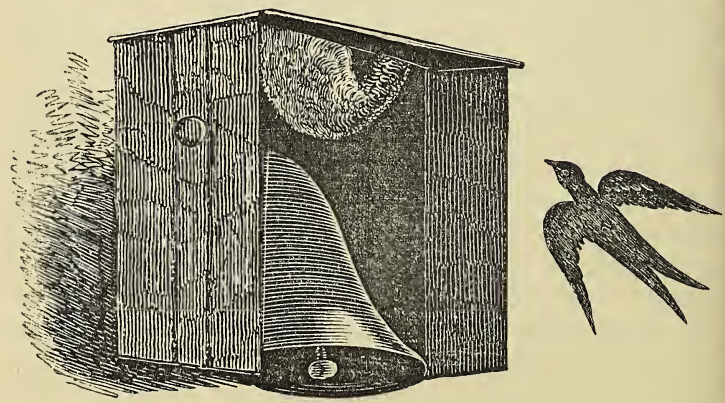

Curious Nest of a Swallow. 
the great house-bell was hung, under a wooden cover, fastened to the north wall of the house : it was a large bell, and was rung several times a day, to call the servants to their meals. Under the wooden cover of this bell, the same Swallow, it is believed, which had formerly built on the bracket for the lamp, built a nest for several years, and never was in the least disturbed by the ringing of the bell, or the rattling of the rope.

One of the chimneys in a house at Blois, in France, was surmounted by an old moving iron chimney-pot, placed there to prevent it from smoking; the fire-place with which it communicated having been bricked up, it became a safe place for building in. Accordingly, as such, it was pitched upon by a couple of Swallows, and in it, moved as it was by every wind, and making at every motion a dismal creaking noise, for two successive years did they build their nest; and often were they seen, for minutes together, when the wind was high, trying in vain to get into it, its constant motion rendering entrance an affair of some difficulty.

Timid as they appear to be, when occasion calls for exertion and courage they can not only fight a good battle, but manifest a good deal of generalship. A pair of Martins, having built in a corner of a window, one of which, from a remarkable white feather in one of its wings, was known to be the same bird which had built there the year before, had no sooner finished their nest, than a strange Swallow conceived the plan of taking possession of the property, and once or twice actually succeeded in driving the owners out. For a week there was constant battling. At length, the two rightful owners were observed to be very busily engaged in lessening the entrance into the nest, which in a short time was so reduced that it was with difficulty they could force themselves into it singly. When they had accomplished their object, one or other of them always remained within, with its bill sticking out, ready to receive any sudden attack. The enemy persevered for a week, but àt length, finding its prospects hopeless, left the pair to enjoy the fruits of their forethought. 
The latter of the two preceding anecdotes tends to corroborate a more bold and sagacious measure, adopted by a pair of Swallows, no doubt those of the preceding year; which, on arriving, found their old nest already occupied by a Sparrow, who kept the poor birds at a distance, by pecking at them with its strong beak, whenever they attempted to dislodge it. Wearied, and hopeless of regaining possession of their own property, they, at last, hit upon a plan which effectually prevented the intruder from reaping the reward of his roguery. One morning they appeared with a few more Swallows,--their mouths distended with a supply of tempered clay,-and, by joint labour, in a short time, actually plastered up the entrance-hole, thus punishing the Sparrow with imprisonment, and death by starvation. This instance of apparent reasoning occurred at a rectory-house in Lancashire; but a similar story is on record, near London, of a pair of Swallows calling in the assistance of their neighbours for the very same purpose.

Swallows, too, like the Raven, (mentioned p. 180,) and probably many other birds, will, when deprived of their mates, provide themselves with others, a fact of which the following account, from an eye-witness, is a proof:-A couple of Swallows built their nest in a stable; the female laid her eggs, and was observed to continue motionless beyond the time of hatching, while the male fluttered about, or occasionally settled on a projecting nail, uttering plaintive notes, which induced some persons at length to examine the nest, when the female was found to be dead; she was accordingly thrown away. The male then went to sit upon the eggs, but after remaining about two hours, flew off, and in a short time returned with another female, which sat upon the eggs, and afterwards hatched and fed the young ones, till they were able to provide for themselves.*

* Forster's Travels in North America. 


\section{CHAPTER XII.}

Swallows' Nests continued.-Edible Nests, East Indies.-GoấSuckers.-Mode of seizing Moths.-Cavern with their Nests described.-Tenuirostres ; Narrow-billed.-Nuthatch.-Treecreeper. - Bee-eater. - Hoopoe. - Kingfisher. - Humming Birds. - Climbing Birds. - Cuneirostres ; Wedge-billed. Jacama.-Anis.-Cuckoo-Anecdotes and Habits of.

SWALLOWS' nests, as we know, are in this country in$N$ variably made of mud externally; but in America, an intelligent traveller, Sir Francis Head, informs us, that he met with those of the common species, building in hollow trees; the place he observed them in being beyond the dwellings of man, and the accommodation of houses and walls; and that they formed their nests of the minute fibres of roots, strongly cemented together, so as to make a compact vessel, as tight as a China cup.

But the nest most worthy of notice is that of a small Swallow, met with in the East Indies (Hirundo esculenta). The species, by whose labours these nests are formed, is about the size of the common Martin. Its chief peculiarity consists in having the width of its bill increased by a naked piece of skin, something like parchment, which, when the bill is shut, lies folded together, but which, when open, is considerably extended, enabling the bird to catch with greater ease, while on the wing, the insects that serve it for food. They are exceedingly light and tender; ten of them together weighing little more than two ounces and a half. There are two places in particular, near Batavia, where they are found in great numbers; both in a range of high land, extending towards the sea. There are, indeed, other places in the same district, or at a greater distance from the coast, which either produce a few, or are carefully concealed by the Javanese, who are unwilling that others should interfere 
with the profit they make by selling them to the Chinese, who are the chief purchasers.

The two bird-mountains above alluded to, are insulated rocks, hollow within, and pierced with a great number of openings. Many of these openings are so wide, that a person can enter them with ease; others are attended with more difficulty, and some are too small to admit of intrusion; in these, therefore, the poor little birds are alone safe from robbery. To the walls of these caverns the birds affix their small nests in regular rows, and so close that for the most part they adhere together. They construct them at different heights, from fifty to sixty feet, sometimes higher, sometimes lower, according as they find room; and no hole or convenient place, if dry and clean, is left unoccupied; but if the walls be in the least wet or moist, they immediately desert them. At daybreak, these birds fly abroad from their holes, with a loud fluttering noise, and in the dry season rise so high into the atmosphere in a moment, as they have to seek their food in distant parts, that they are soon out of sight. In the rainy season, on the other hand, they never remove to a great distance from their breedingplaces.

About four in the afternoon they again return, and confine themselves so closely to their holes, that none of them are seen any more flying, either out or in, but those which are hatching. They feed upon all sorts of insects which hover over stagnant waters, and these they easily catch, as they can extend their bills to a great width. They prepare their nests from the strongest remains of the food which they use, and not of the scum of the sea, or of seaplants, as some persons have supposed. They employ two months in preparing their nests; they then lay their eggs, on which they sit for fifteen or sixteen days. As soon as the young are fledged, people begin to collect their nests, which is done regularly every four months; and this forms the harvest of the proprietors of these rocks.

The business of taking them down from the rocky ledges on which they are placed, is performed by men who have 
been accustomed from their youth to climb amongst these dangerous places. They construct ladders of reeds and bamboos, by which they are enabled to ascend to the holes; but if the caverns are too deep, they employ ship-ropes. When they have got to the bottom of a cavern, they place bamboos, with notches in them, against the wall, if these be sufficiently long to reach the nests, but if not they stand on the ladders, and pull the nests down with poles of bamboo made for that purpose. This employment, which is very dangerous, sacrifices the lives of a great many men, and particularly of thieves, while attempting to rob the caverns at improper seasons. For this reason, small watchhouses are everywhere built in the neighbourhood.

The mountaineers, who are the persons chiefly accustomed to this employment, never undertake their labour till they have slaughtered a buffalo, as a propitiatory sacrifice, which is the usual preparation made by the Javanese for all their undertakings. On such occasions they mutter over a few prayers, anoint themselves with aromatic oils, and fumigate the holes with sweet-smelling substances, which they conceive to be charms against accident.

At the chief of these caverns, in the island of Java, a protecting female deity is worshipped, under the name of Princess of the Southern Sea. A small hut, with a covered sleeping-place, is there appropriated for her, together with various elegant articles of dress, which none under the rank of a princess can wear; and every Friday when the nests are taken down incense is continually burnt, and the body and clothes of every one who intends to ascend the rocks must be exposed to it. To afford them light in the cavern, they use torches made of the resinous gum of a large tree.

The collecting of these nests continues no longer than a month, and, as already mentioned, may be repeated three times in the year. Some believe that it may be done a fourth time; but this is not probable, as all experienced people brought up to this employment confidently assert, that a nest, as long as it remains entire, is continually enlarged by the 
bird, or made thicker, until it is entirely deserted by her, when it becomes dry or hairy in the inside. When the nests have been collected, no further trouble is necessary than to dry and clean them; after which they are put in baskets, and sold to the Chinese. The price of them depends on their whiteness and fineness. Those of the best sort are exceedingly scarce. They are sold at the rate of from eight to fourteen hundred rix-dollars per one hundred and twenty-five pounds, which amounts in our money to the sum of from thirty to forty-two shillings per pound. This high price and the great avarice of the Chinese, give rise to much dishonesty and thieving. The two places above-mentioned, were, about fifty years ago, sold by auction by the Dutch East India Company, to the highest bidder, who received for them above twentythousand pounds more than they expected, which proves the value and quantity of these singular productions. About two thousand five hundred pounds' weight of these nests are collected every year in the island of Java, which, at an average of the above prices, amounts to about five thousand pounds a-year.

Some of these bird-caverns are dreadfully exposed, particularly a few situated on the coast; these are washed by the sea, which forces its way so deep into the latter, that fish may be caught in it; but on account of the steepness of the rocks, the nests can only be collected at the most imminent risk. The young birds are eaten, both by the Javanese and the Europeans in India; but they are considered to be very heating, and are, moreover, difficult to procure. The nests, on the other hand, when they have been boiled to a kind of slimy sort of soup, exposed in the night-time to the dew, and mixed with sugar, are exceedingly cooling, and they are therefore much used in violent fevers; they are also prescribed, and with great success, in cases of hoarseness and sore throats. They are, however, not supposed to be possessed of any very superior medical qualities, and are chiefly sold as articles of luxury, and ornaments for the tables of the rich Chinese. Their mode of using them is to put them, after being well soaked and cleaned, along with a fat capon or 
duck, into an earthen pot closely covered, and suffered to boil over a slow fire for twenty-four hours.

Swallows are generally hailed as welcome guests, and allowed to fix their plastered dwellings without molestation under the eaves or corners of window-sills; but when very numerous they are apt to occasion a good deal of dirt, and when once established it is by no means easy to drive them away. This, however, may be effected by rubbing the corners of the windows with soft soap early in the spring. This was practised with success in a house, the windows of which used to be quite darkened by the dirt \&c. occasioned by a colony of nests. The Swallows on their arrival began to build as usual: but as fast as they attempted to attach their materials to the stone, they slipped off. For some days they renewed their attempts, but then gave the matter up; and what was very remarkable, although the soaping was never renewed, not a single Swallow ever afterwards attempted to build on the windows, not even on those which had not been soaped, though several built in the adjacent out-houses and immediate neighbourhood.

But we fear we are suggesting a needless remedy for an inconvenience not likely to occur; for within the last few years, particularly since 1809, these pretty social Summer visitors, like our Starlings, have been decreasing in numbers in the most unaccountable manner, not only in England, but in almost every part of the Continent.

The same church-steeple which has enabled us year after year to watch the Starlings,* was formerly a source of equal interest respecting Swallows; nests were snugly concealed in sheltered nooks, the belfry itself being a favourite resort, notwithstanding the frequent peals which might have shaken the nerves of less determined birds; and a few days before their final departure, it was pleasant to watch them marshalling their newly-fledged broods along the projecting dripstones and mouldings on the eastern side of the old grey tower, enjoying the morning sun. As the numbers collected seemed 
far to exceed those which were reared there, it appeared as if the united broods of the neighbourhood had, by common consent, fixed upon it as a favoured central rendezvous. All was exhilaration,-a perpetual twittering was kept up; a few of the old ones would, after flying in circles round the battlements, pass screaming by the reposing ranks of young ones, and then, as if by word of command, the whole body would sweep from their resting-places, and in loud chorus take a wider circuit, as if to try their powers; and then in an instant crowd again together, and rest as before. But those days are gone by; year after year the numbers have fallen off, and at present we are not aware of even a single nest.

There may be, however, some solitary exceptions to their diminution; one, indeed, fell under our observation, on the 17th of June, 1833, when we were delighted with a little colony of upwards of fifty nests, attached in closest order beneath the eaves of a lone public-house, called "Cates' Cabin," between Stamford and Huntingdon, in the parish of Chesterton.*

The Goat-suckers, or Fern-Owls, so called from being fre-

* There are some interesting circumstances connected with this publichouse which may be worth recording. The name of Cates' Cabin, being derived from Catius, the officer who commanded the station at the great Roman Camp, mentioned by Camden and Stukeley. The sign of this inn has also its peculiar interest, being the head of Dryden, painted by Sir William Beechey in his early days, under the following circumstances:-About 400 yards from Cates' Cabin stood a fine old manor house, built in the reign of James $\mathrm{I}$., the seat of the Drydens, collaterals of the poet. This estate descended to a Mr. Pigott (through his mother, a Dryden) of the family of Pigott of Chetwynd, in Salop, who was in his day famous on the turf; having become embarrassed, he sold his patrimony at Chesterton to a Mr. Walker, and purchased a few acres in Anwalton parish, only a few miles from Cates' Cabin, and built a house, which was called "Pigott's Folly." Retaining a taste for the pursuits and luxuries of his prosperous days, he resolved to adorn "Pigott's Folly" with paintings of the heathen gods and goddesses, and finding in London a sprightly youth, an artist, he brought him down to paint his house; this was young Beechey, who was lodged during his employment at Cates' Cabin, and, in his leisure hours, painted for his landlady its sign, the Dryden Head (this was about the year 1770), copied from an engraving of the poet in the frontispiece of his Miscellanies, borrowed by the landlady from a neighbouring clergyman. 
quently met with on heather, or wild places abounding with fern, ought more truly to be called Moth-Hawks, from their feeding almost entirely upon these soft-winged insects, which they catch up in their flight, however dark it may be. To human beings, who at dusk can scarcely trace a swift-flying moth as it glances by, it is inconceivable how this bird can contrive to make its constant meals on such precarious prey. Nature, however, has amply provided it with never-failing means of feasting to its satisfaction. In the first place, the eye is large, full, and clear, like the Owl's, and so thin and transparent is the membrane separating it from the base of the upper mandible, that as it flies, when in search of food, with its mouth open, it has been surmised by some naturalists that the bird is enabled thereby to keep a look-out forward, as well as on either side, through the thin bony membrane. At all events, without this odd addition to great powers of vision, a skull more than half filled up with eyesight must enable the possessor to see more clearly in the dark than we can conceive possible. But in the next place, look at the mouth (see annexed figure and p. 241), such a prodigious opening as it is, with a fringe of strong bristles on either side of the nostrils, the use of which is this:- that as it flies along, if a moth crosses the pathway of these widelyopened jaws, the bristles fetter the insect's wing, and help to imprison it beyond the power of escape.

This bird has, moreover, another peculiarity, adapted for the capture of moths, namely, a kind of glutinous liquid which exudes from the upper part of the bill, and is so adhesive, that small insects are retained by it, and it is thus enabled to imprison and swallow a number of them together; and what is still more singular, that, although swallowed, they still continue to exist; a fact only lately, we believe, known, and discovered accidentally by a person who, having one evening shot a Goat-sucker, was surprised to see a moth come out of its mouth and fly away; and on opening the crop the next morning, it was found to contain several other moths, which had lived all night in this strange prison, and when released ran about the table fluttering their wings. 


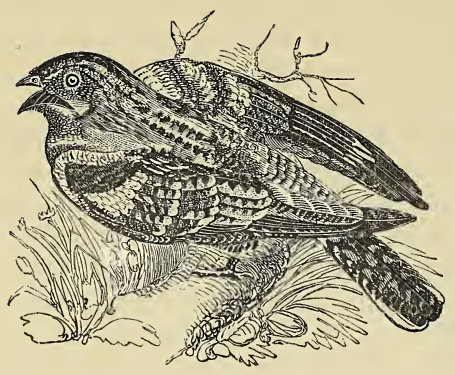

The Fern Owl, or Goat-Sucker

In the last place, its foot is doubly fitted for grappling its volatile game. We give it in the annexed figure of its natural size, not much larger, it will be seen, than that of a Sparrow, though the bird in size is little less than a Pigeon. The hind claw is remarkably small, but it is what is termed reversible, that is, it can turn forwards, and act in concert with the other three, which must be very convenient in catching such nimble things as moths; but it has another peculiarity, - the middle claw serrated or toothed very much like the Heron's, and for the same purpose, that of preventing the escape of quick and active prey. That this peculiarity is intended for the purpose stated, may be inferred from some of the largest species, in size almost equal to a Raven, being without a serrated claw, and whose food has been ascertained to consist of the fruit of the palm. Another use has been also assigned to these toothed-claws, - that of enabling them to carry off their eggs, if disturbed: some naturalists asserting that they have such a power, and have been actually seen in the act of flight with eggs in their claws; but the fact has been denied by others. That it is not impossible, however, even for birds, without such claws, to remove their eggs, we can vouch from good authority : for a Pheasant having laid her

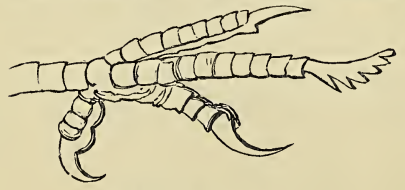

Goat-Sucker's Foot. eggs in a fallow-field, became dissatisfied with her situation, and re. moved them to a less frequented spot in the same field, where she deposited them in another nest, which she had previously scraped together. 
With all these united powers, swift and silent too in flight as it is, no wonder that this bird makes such havoc amongst the, to us nearly invisible, multitudes that people the silent air on a summer's night. At twilight, it may sometimes be seen at work, flitting about, hovering now over one spot, then over another, occasionally dropping or tumbling over, as if shot; this is the moment, when having seized a moth, the bird reaches it to its mouth, and loses its balance, when again rising, it glides away like a ghost, till lost in shade. We have but one species visiting England, but in foreign countries there are many. In South America, particularly, they abound: the curious retreats of one species of these birds are thus described by the celebrated traveller, M. de Humboldt, who visited a dark chasm in the rocks called the cavern of Guacharo, frequented by a species (Caprimulgus steatornis) whose young were caught to furnish oil :-

"A frightful noise, made by these birds, issued from the dark recesses of the cavern; their shrill and piercing tones reverberated from the arched roofs, and re-echoed from the depths of the cave. The Indians, by fixing torches to the end of a long pole, pointed out their nests, arranged in funnel-shaped holes, with which the whole roof of the grotto was riddled. As the travellers advanced, the noise increased, the flare of the torches alarming the birds still more. When it ceased for a few minutes, distinct moans were heard from other remote branches of the cavern, the alternate responses of other flocks of these birds. The Indians, every year about Midsummer, descend into the cave, furnished with poles, for the purpose of destroying the nests. At this time many thousands of birds are killed, and the old ones, as if to protect their broods, hover over the heads of the Indians, uttering the most dreadful shrieks. The young that fall to the ground are immediately ripped open, to procure a sort of unctuous or fatty substance with which they are then loaded. At this period, which is commonly termed the oilharvest, the Indians construct little habitations of palmleaves, close to the opening, and even in the mouth of the cavern. - Here the grease of the young birds just killed is melted over a fire of dry sticks, and run into pots of white clay. This grease, known by the name of Guacharo butter 
or oil, is semi-liquid, transparent, and without smell, and so pure that it may be kept a twelvemonth without becoming rancid. At a neighbouring convent, visited by these travellers, no oil but that of the cavern was used in the monks' kitchen, and it was never found to give to any dish a disagreeable taste or smell.

\section{TABLe XIII. (See p. 15.)}

\section{Order 2. Passerine.-Tribe 7. Tenuirostres.}

THE birds of this tribe, comprehending the rest of this division, are classed together, not so much with reference to the actual strength or weakness of the bill, as on account of its form, and comparative narrowness and length, which is seldom less than twice that of the head, sometimes straight, at other times more or less bent. In other respects, they differ very materially; in fact, they have no connexion whatever with each other. Amongst them we find, of foreigners, the Humming-birds, and the genus Todus, much resembling Kingfishers, but feeding on insects, instead of fish. Some species of the rest are British, such as the Hoopoe and Beeeaters, both of which are, however, very scarce.

Of the habits of one of the above genus, the Todus viridis, which, though of a beautiful green on the back, has a crimson throat, whence it is called the Robin Redbreast of Jamaica, an interesting account is given by a close observer of nature in that island. One which was caught in a net, and turned into a room, began immediately to catch flies and other minute insects that flitted about. At this employment it continued incessantly, and most successfully, all that evening and all the next day, from earliest dawn till dusk. It would sit on the edge of the tables, on shelves, or on the floor, ever glancing about, now and then flitting up into the air, when the snap of its beak announced a capture, and it returned to some station to eat it. It would peep into the lowest and darkest corners and under the tables, for the round long-legged spiders, which it would drag from their webs, and swallow. 
It sought them also about the ceiling and walls, and found many. It continued all day, without intermission, at this employment, and on an average caught something every minute. "We may," says the writer, "thus form some idea of the immense number of insects destroyed by this and similar birds, bearing especially in mind, that this was in a room where the human eye could scarcely recognise a dozen insects altogether, and that in the open air, insects would, doubtless, be much more numerous. Though so actively engaged in its own occupation, it seemed to care little for the presence of a spectator; for it sometimes alighted on either my head, my shoulders, or fingers ; and when settling, would permit me at any time to put my hand upon it and take it up, though when in my hand it would struggle to get away. It seemed likely to live and thrive, when unfortunately, on settling in front of a dove-cage in the room, one of the doves thrust its head through the wires, and struck it forcibly with its beak. At first the poor little bird did not appear to suffer from the blow, but it never flew again; and about an hour afterwards, on my taking it up in my hand and throwing it up, it could only flutter to the ground; and on my laying it on the table, it stretched out its little feet, shivered, and died."

In walking through woods, a rapping sort of noise may be frequently heard high up in the trees; and though the hearer feels pretty confident that he is within a few yards of the spot from whence this rap, rap, rap, proceeds, he may fail in finding out the cause; but if he has a keen eye, he may at last perceive a small greyish blue-backed bird with a yellowish breast, busily employed, knocking away with the full force of its head, beak, and body, as if the whole were one solid mass, moving on the hinges of its thigh-bones. After a while, the bird will be seen to glide, rather than climb, up or round the stem, and disappear, till it is again detected by a repetition of the rap, rap, rap. It is the Nuthatch, in the act of examining trees for insects, or engaged in hammering nuts to pieces, which it first adroitly fixes in a crevice of the bark, and when the shell is broken, eats the kernel. Should the nut acci- 
dentally fall, it will dart down, and in most cases, catch it with its claws before it reaches the ground, and replacing it in its chink, resume its work. One slightly wounded, and caught, was put in a cage, when, without loss of time, it began battering the wood-work, just as it would have done a nutshell, and persevered till it died, more from fatigue than hunger, for they are bold birds, and feed readily. In America, it is said that they can be tamed, and will creep up and down their owner's body, poking their bills into seams and button-holes, just as they do on trees in their wild state.

The Certhia, or Tree-Creeper, like the Nuthatch, glides up and down the stems of trees; but so far from having a bill strong enough to crack a nut, it is so feeble that the shell of a beetle's wing would resist its powers; but it is admirably adapted for its mode of life. The little Tree-Creeper looks more like a mouse than a bird, as it runs in silence up and down a bough in search of minute insects; and so beneficial has it been found in ridding trees of noxious insects, that in America, where it seems to be more abundant than with us, a box is placed at the top of a long pole, to entice it to build in gardens, where it makes itself a very welcome guest.

The Bee-Eaters are so rarely seen in England, as scarcely to be considered British birds; but when once seen, can never be mistaken or forgotten, brilliant as they are with blue and green of various shades, tinged by beautifully reflected lights. As its name implies, it lives chiefly upon bees, which it catches on the wing.

The Hoopoe is another elegant bird, very scarce, but not quite so rare as the Bee-Eater. One was not long ago caught on Salisbury Plain, in a weak and exhausted state; it must have come from a distance, as its beak was filled with red clay, of a quality not found in that neighbourhood. If fatigued from the journey it had performed, the distance must have been very great; for one approached a vessel in the middle of the Atlantic, and kept company with it a good way, but did not settle on board, which it probably would have done had it been tired.

It is common in some parts of the Continent, and by no 


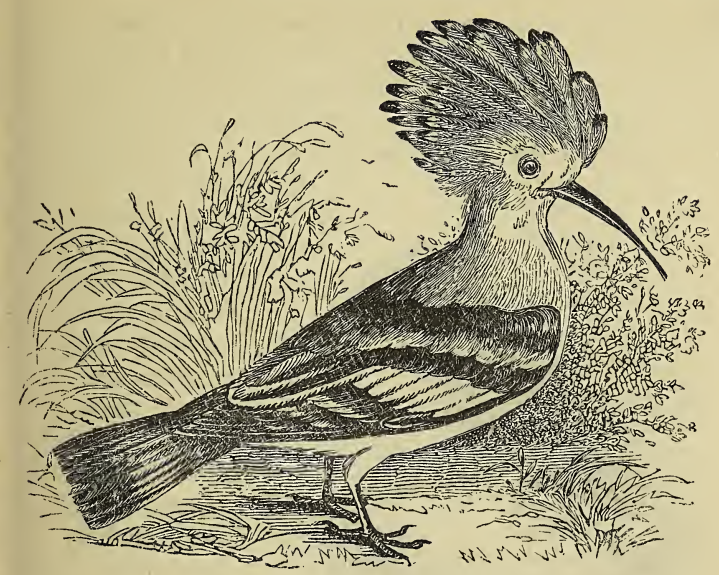

Hoopoe.

means wild, for we have seen it on the ground, and on the trees in a public walk at Seville, but is most abundant in Egypt and Arabia, where they are called the children of Solomon, from a tradition that they formed part of the cargo of the "navy of Tarshish," bringing to him, from Ophir, "gold and silver, ivory, and apes, and peacocks." (1 Kings x. 22.) It is currently believed by the people of the country, that its crest was then a crown of gold; but that the avidity of mankind for this precious metal occasioning the birds to be often killed for their crowns, they assembled together, and represented their case to Solomon himself. This monarch, in his great wisdom, understood the languages of all animals, as well as of all people on the face of the earth; and hearing and pitying their case, he prayed to their Creator to ameliorate their destiny, when the crown of gold was instantly changed to a cresc of feathers, of equal, if not still greater beauty.

The Kingfisher, rivalling, if not exceeding the Bee-Eater, 
in the blues and greens of its beautiful plumage, is also much more common. Most of our readers may probably have seen it darting in the direction of a brook-course, like a flying emerald. We were once fortunate enough to watch one, within a few yards, for some time. It was on a calm

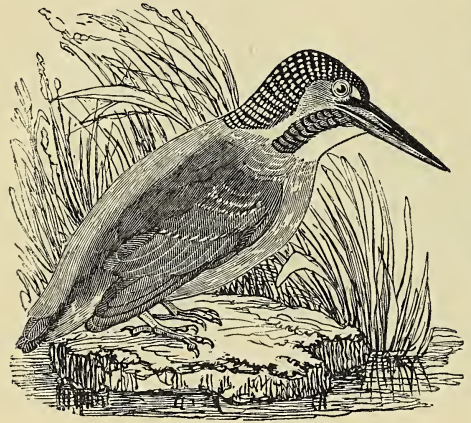

The Kingfisher. sunny day; the bird was observed to settle on the post of a rail, projecting into a piece of water: a boat was gently impelled towards it, in perfect silence; it seemed to take no notice, sitting motionless, as if it had been stuffed and placed there for ornament. In an instant it darted off, with so rapid a motion, that a green bright line from the post to a splash of water where it had plunged, alone marked its course. In another instant it rose, and with as rapid a flight resumed its position on the post, having swallowed the little fish whose bright scales we could just see glistening in the sun, as the bird emerged from the water. There it rested motionless as before, till another plunge denoted the capture of another fish; and so on, till, after having captured four or five, it darted away, and was seen no more. Its nest is in great part composed of fish-bones, which it throws up in pellets, similar to those cast up by Owls, of which we have already spoken.

The Humming-birds are the last of this tribe we shall notice, lamenting that none but those who cross the seas, and can visit them in their native haunts, will ever be fortunate enough to behold the glorious robes with which nature can invest even the smallest of her works. Truly may it be said of these lovely birds, as of the lilies of the 
field, "that Solomon in all his glory was not arrayed like one of these."

"Never was I more excited to wonder than by one of these little creatures," says a traveller,* "so much more resembling a splendid shining insect than a bird. It was on a fine day, at the commencement of an American summer, on the banks of Lake Huron, that I first beheld them. Beautiful birds were drinking and splashing themselves in the water; and gaudy butterflies, of a very large size, were fanning the air with their yellow and black wings. At this moment a little blazing meteor shot, like a glowing coal of fire, across the glen; and I saw for the first time, with admiration and astonishment, what in a moment I recognised, that resplendent living gem, the Humming-bird! buzzing like a humble-bee, which it exactly resembled in its flight and sound: like it, it sprang through the air by a series of simultaneous impulses, tracing angle after angle with the velocity of lightning; till, poised above its favourite flower, all motion seemed lost in its very intensity, and the humming sound alone certified to the ear the rapid vibration of its wing, by which it supported its little airy form."

They vary from the size of a humble-bee to that of a Willow-Wren; the nests of the smaller sort appearing more like mossy knots on a branch, than the manufacture of a bird, not exceeding an inch in diameter, and formed of the most delicate materials. They will build fearlessly within sight of a window, where they may be leisurely observed. They frequently assemble in great numbers round some sorts of flowers, yielding those sweet juices which, together with insects, compose their food. The aloe is one of them. A gentleman in Jamaica thus describes them hovering round a plot of these plants covering nearly twenty square yards, of which about a dozen were in full bloom. "The spikes, bearing bunches of flowers, were from twelve to fifteen feet high; on each spike were many hundred blossoms, of a bright yellow colour, each of a tubular shape, and containing its drop of honey. These alone afforded," as he says, " a

\section{* Captain Head's Forest Scenes.}


splendid scene; but the interest was doubled by the addition of vast numbers of Humming-birds, fluttering round the openings of the flowers, and dipping their bills first into one floret and then into another, the sun shining bright upon their beautiful plumage, giving them the appearance of, now a ruby, then a topaz, then an emerald, and then all burnished gold."

Delicate and tender as these little creatures are, seeming as if they could not exist for a moment beyond the confines of a sunbeam, they are nevertheless scattered very extensively over the whole continent of America: they were found in the desolate regions of the south, near Cape Horn, hovering over the fuchsia blossoms at Port Famine, and even flying about in snow-storms. In the north they have been seen in the still more dreary regions of Prince William's Sound, on the same parallel of latitude as the Shetland Islands, to the north of Scotland; and, what is even more extraordinary, they were discovered on the snowy heights of the Orizaba mountains, three times the height of Snowdon above the level of the sea. In all these desolate situations they seemed as lively as when under the influence of burning sunbeams near the equator. It was in one of these latter situations that Mr. Bullock, who visited Mexico with a view to the natural history of a country then scarcely known, saw how ingeniously these little birds contrived to rob the webs of the spiders of that country, of the flies that were entangled in them. They would advance beneath the web, and enter the various labyrinths and cells, taking care to make good their retreat, if the spider sallied forth to repel them. In ascending some of the spider's fly-traps great skill and care were required; sometimes the bird had scarcely room for his little wings to spread, and the least mismanagement would have insnared him in the meshes of the web, and insured his destruction. It was only the outworks of the comparatively small spiders, of about his own size, that the Humming-bird durst attack, as the larger sort rushed out in defence of their property, when the robber would shoot off like a sunbeam, and could be only traced, like an electric spark, by the luminous glow of its refulgent colours. 


\section{TABLE XIV. (See page 15.)}

Contains the third order, consisting of birds with two toes before and two behind, for the purpose of climbing. This order is subdivided into two tribes, distinguished by the form and character of their beaks : the cuneiform, or wedgeshaped, being small, and not toothed or indented; and the levirostral, or light beaks, which are indented more or less, and though in general large, are of a lighter and thinner substance.

\section{TABLE XV. (See page 16.)}

\section{Order 2. Tribe 1. Cuneirostral, (Wedge-billed.)}

OF the five genera included in this tribe, the Cuckoos, Woodpeckers, and Wrynecks, are found in England. The remaining two, viz., Jacamars and Anis, are American. The Jacamars are nearly allied to the Kingfishers, living, however, on insects instead of fish, and building on low branches in the depth of dark and damp forests, instead of in holes by the water-side. The Anis, like the Jacamars, frequent the woods, but seem to be of a much more social nature. If taken young, they may be easily tamed, and even taught to speak some words. Amongst themselves, too, they are the most friendly birds imaginable, for they not only fly in flocks, but lay and sit, many pairs together, in one large nest, built by joint consent for the whole party. Future travellers, we doubt not, will be able to relate many interesting anecdotes of these sociable, happy birds, but at present little more is known about them than what we have related.

Not so, however, of our British cuneiform birds, our Cuckoos, Woodpeckers, and Wrynecks. Everybody's attention is drawn to the first, whether he will or no. For as soon as the Winter is well over, and "April showers prepare the way for May flowers," we hear the Cuckoo's note. It 
would be difficult to say, whether we should call them solitary birds or not. Usually indeed one only is seen; but not unfrequently three, four, or even more, will assemble upon a tree, and make the air resound with their well-known notes, uttered sometimes as they remain perched, at others as they quiver through the air with an odd sort of wild fluttering flight. It appears, however, from good evidence, that they either quit their Winter quarters together, or falling in with each other on the journey, land in little flocks. Some years ago, at dawn of day, early in the Spring, a gentleman living on the Cheshire side of the river Mersey, opposite Liverpool, was awakened by a kind of chattering noise, interrupted by the cry of-" Cuckoo, cuckoo," in a low plantation near his house, situated amongst the sand hills bordering the shores of the estuary, and on looking out observed a pretty large flock, which at sunrise, or soon after, all took to flight.

Here, then, we have an instance of their being sociably inclined on their arrival; and it would seem that they are equally so when about to leave us: for in a garden in the county of Down, in Ireland, from the 18th to the 22nd of July, not less than forty Cuckoos were observed for the most part amongst the gooseberry-bushes, probably collecting the grubs which often infest those plants, and not to eat gooseberries, as the gardener supposed; and it was remarked that they were almost all so sleepy and dozing, as to permit a very near approach, though not quite so near as to admit of being caught by the hand. There happened to be a late brood of Blackbirds, not quite fledged, in a nest. They were discovered by the Cuckoos, who destroyed all but two; they were seen to tear them in pieces, the gardener actually rescuing one from their grasp, which had its leg and wing severed. Not above three or four were heard to cry, "Cuckoo," and then in a sort of hoarse unnatural tone.The greatest number collected towards sunset, though many remained throughout the day. After the 22nd of July, only one or two remained, which were evidently smaller than the rest, probably the youngest.

Singular as is its cry, so equally singular, and equally 
known to all, is that strange unnatural propensity peculiar to this bird, of leaving to others the care of its young. Why does the Cuckoo do this? Is it because it has no knowledge of building a nest for itself? Is it because, alone of all the feathered race, it is without those affections and sympathies which are discoverable and innate in every other species? Is it because it is unfitted, from its structure or mode of life, for those sedentary habits essential to incubation?

To this, and a thousand other such marvellous instincts and habits, we have no answer to give. The why and the wherefore are yet to be learned. But that $\mathrm{He}$ who gave the bird such an apparently unnatural habit had his reasons for so doing, there can be no doubt, and it is one of the pleasing occupations and pursuits of a naturalist to use all diligence, diving as far as possible into these mysteries, and finding out, as far as he can, why what is apparently wrong may nevertheless be really right, a working together for a good end, and a fulfilment of one great uniform design of Perfection and Wisdom.

In p. 170, a curious case was mentioned of a Cuckoo having been fed by a Thrush of its own age. The bird was successfully reared, and continued in good health till about the period at which other birds of its kind were in the habit of leaving the country, when it began to mope, particularly during the day; towards night, however, it became more restless and fidgety, fluttering about and flying up and down the cage. After this, not being able to escape, it recovered its spirits, and was alive and in good health in October, 1832, when the narrative reached us, though it probably died in the course of the Winter, the usual fate of numbers which have been kept in a state of confinement. We do not, indeed, recollect a single well-authenticated instance of one of these birds living for a year, when kept in confinement, which is the more surprising, as their usual insect food might be generally procured.

To naturalists various other peculiarities in the Cuckoo are well known, but in closing our account, we would refer to two more particularly worthy of notice, as instances of 
the wonderful manner in which its wants are assisted by nature. The Cuckoo, as we have said, lays its egg in the nest of a small bird; of course, if this egg were large in proportion to the size of the parent bird, it would be far too large for the little nest in which it was placed, and its unnatural size would, moreover, in all probability, frighten the lesser foster-mother, and induce her to desert her own nest; but a Cuckoo's egg is remarkably small, and therefore can be laid, without exciting suspicion, in the midst of others, of a naturally small size. In the next place, it is known that the young Cuckoo always contrives to make room for its increasing size, by throwing the other nestlings out of the nest; but were it of the usual form with other birds, it would find great difficulty in accomplishing this. Nature, however, lends a helping hand, and has given it a remarkable depression or hollow between its shoulders, into which, by an odd sort of jerk, it contrives to lift the young birds, and then shuffling backwards to the edge of the nest, throws them over. This hollow, however, only remains for a certain time, and then fills up; and it is an extraordinary fact, that if the young birds are designedly kept in the nest till the hollow is filled up, the young Cuckoo, as if aware that it has no longer the power to get rid of them, allows them to remain unmolested. 


\section{CHAPTER XIII.}

Cuneirostral, continued.-Woodpecker-Tame one.-Wryneck -Tongue of. -Levirostral-Light-billed.-Parrots.-Toucan. - Gallinaceous - Poultry Tribe. - Pigeons, American-Prodigious numbers of-Rapid flight-Employed as MessengersMiode of catching-Attachments of.-Cocks.-Pheasants Courage of.-On breeding Pheasants-Box for Feeding.Prized by Ancients.-Turkeys, Wild-Social Habits of.Partridges, tamed-Nests of-Various sorts of.-Quails-Immense Flights of.-Bustards.-Ostrich-Nests of-AffectionHunting-Strength of.-Cassowary and Emu.

THE Woodpecker is, by sound at least, almost as well 1 known as the Cuckoo. Its noisy, merry, laughing cry may often be heard in the neighbourhood of woods, or issuing from some large tree, to the stem of which, if carefully looked for, the bird may be seen clinging, the head thrown a little back, the weight of the body resting almost entirely upon the tail, the feathers of which are hard and wiry, more like bristles indeed than feathers; and if examined, these will generally be found much worn at the edges, by being constantly rubbed against the rough bark of trees. It is a shy and solitary bird, but nevertheless some species at least can be tamed.

A clergyman, travelling in Turkey, was performing quarantine in a Turkish village, having passed through a district in which the plague was raging. He was confined in a wretched apartment, and had nothing to interest or amuse him during a tedious imprisonment, everybody keeping at a distance for fear of infection, when one morning, while at breakfast, a bird of the Woodpecker species flew in at the window with, to use his own words, " all the familiarity of an old friend," hopping on the table and picking up the crumbs and flies. It had belonged to a young girl just buried, and by a singular instinct left the house of the dead, 
and flew into his room. Its habits were curious, and so familiar, that they were quite attractive; it climbed up the wall by any stick or cord near it, devouring flies. It sometimes began at his foot, and at one race would run up his leg or arm, or round his neck, and down his other arm, and so to the table. It would there tap with its bill with a noise as loud as a hammer, and this was its general habit, on the wood-work in every part of the room; when it did so, it would look intently at the place, and dart at any fly or insect it saw running-in all probability adopting this noisy mode of disturbing such insects as might be concealed within, that it might seize them the moment they appeared.*

The Wryneck is a small bird about the size of a Thrush, which comes and goes nearly at the same time as the Cuckoo,

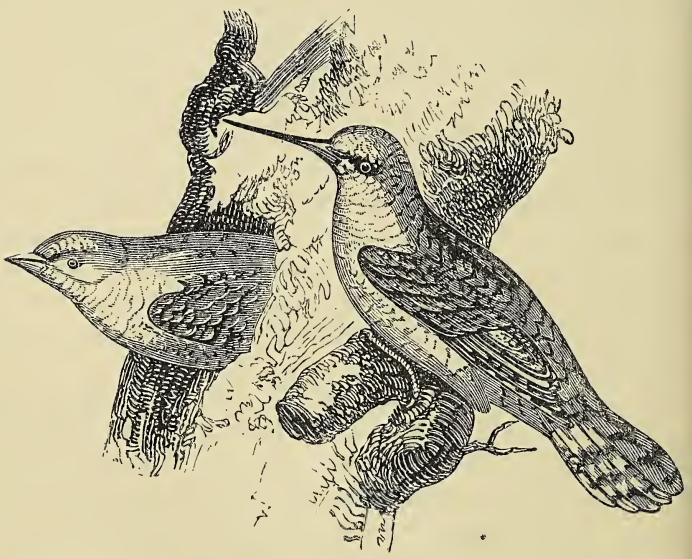

The Wryneck.

whence it is in some places called the Cuckoo's Mate. Its habits and formation in many respects resemble those of the

* Walsh's Constantinople, page 310. 
Woodpecker, particularly its tongue, which well deserves examination. On opening the mouth of either of these birds, the tongue appears neither larger nor longer than the usual size, but if taken hold of by the tip, which in these birds is almost as hard and sharp as a thorn, and drawn out, it will be found to extend to the length of several inches. The use of this remarkable instrument is, that by being darted suddenly out, it may transfix, or pin through, any distant insect, which is immediately swallowed, by the bird's having the power of as rapidly drawing it back. The Wryneck, though a migratory bird, may, however, be kept alive for a longer time than the Cuckoo: we knew an instance of one which lived a year and a half in a cage, and never appeared to show impatience during its confinement; it was observed always to take its food by throwing out its long tongue.

\section{TABLE XVI. (See page 16.)}

\section{Order 3. Tribe 2. Levirostral, (Light-beaked.)}

Here we have no less than eight genera of birds, not one of which inhabits our country-and, with the exception of the Parrot and Parroquet tribe, (and we may add the Toucan,) are comparatively very little known. We have already noticed the Toucan and its enormous, though light, beak; indeed, were it heavy in proportion to its size, the poor bird would find it a sad inconvenience, not only preventing its flight, but actually weighing its head down to the ground. As for parrots, we, who are accustomed to prize them as valuable and scarce birds, are little aware of the actual plague they are in their own country. Nothing can be more beautiful, certainly, in description or appearance, than a flight of these brightly-feathered birds; but the husbandman, who sees them hastening through the air, with loud and impatient screams, towards his crops, looks upon them with dismay and detestation, knowing that the produce of his labour and 
industry is in jeopardy, when visited by such a voracious multitude of pilferers, who, like the locusts of Egypt, desolate whole tracts of country by their unsparing ravages.

\section{TABLE XVII. (See page 17.)}

\section{Order 4. Galdinaceous, (or Poultry tribe.)}

WE now come to one of the most useful divisions of birds, forming in their domesticated state no inconsiderable source of profit to those who rear them for the purpose of sale. In the tables of classification, the Order comprises three tribes: -1st, Pigeons; 2nd, Fowls, or common Poultry; and 3rd, the short-winged families of Ostriches, Cassowaries, \&c., which by others have been classed amongst the Waders, in consequence of their length of legs.

In this country, where Pigeons are, generally speaking, a domestic bird, few persons have an idea of their countless increase and abundance, when left to themselves, roaming over wide tracts, and following, almost without interruption, their natural habits. Even in our dovecots, however, their increase is often prodigious ; it having been found, that in the course of four years, nearly 15,000 have been produced from a single pair. Bearing this in mind, the reader will be better prepared to credit the startling accounts of the myriads of these birds, so often witnessed in North America, consisting of a particular species called the Passenger, or Migratory Pigeon, from their regular visits to certain districts, either for the purpose of feeding, or rearing their young. And though tens of thousands are destroyed, chiefly at their roosting-places, the numbers seem rather to increase than diminish. Such multitudes had never before been witnessed as in 1829. Flocks extending miles in length, were, for days together, seen passing over the hills during the Spring, from the southward; the mighty mass collecting 
in an encampment in a forest, upwards of nine miles in length, and four in breadth, in which there was scarcely a tree, large or small, which was not loaded with their nests. In those parts of England frequented by our common Wood-Pigeons, the well-known rustling and rattling of a host of wings, as a cloud of them rise from some favourite haunt in the wood, will not easily be forgotten; but this clattering of flapping pinions is nothing when compared to the uprising of these American flights, which is described as an absolute and constant roaring, so loud and overpowering, that persons on approaching the wood can with difficulty hear each other speak. Amidst these scenes of apparent bustle and confusion, there reigns, notwithstanding, the most perfect regularity and order. The old ones take their turns regularly in feeding their young; and when any of them are killed upon their nests, others immediately supply their places.

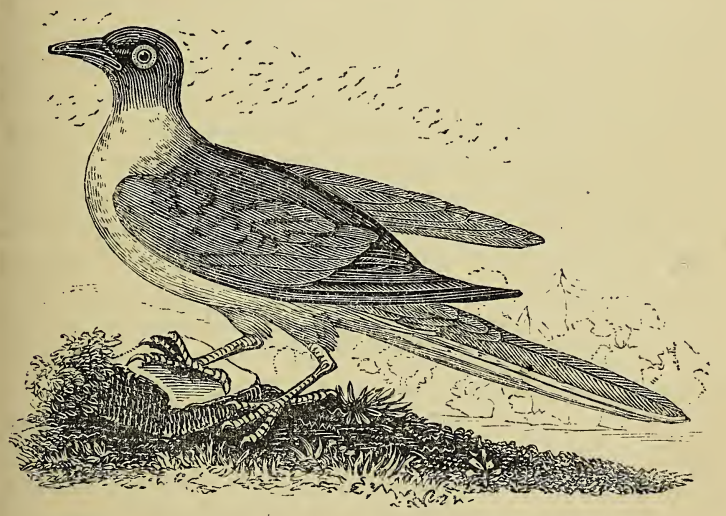

The Passenger, or IVigratory Pigeon.

It has been said, that they only lay one egrg at a time, but this is not strictly true, many of them laying two. But 
even at this rate, it would be difficult to account for their vast numbers, without the further knowledge of their prolific nature, and the rapid growth of the young birds. Their sittings are renewed, or rather continued; one pair having been thus known to produce seven, and another, eight times in one year. In twenty-three days from the laying of the egg, the young ones could fly, being completely feathered on the eighth day. When the broods are matured, with the exception of, probably, some tons of the young, which are killed and carried off by actual waggon-loads, being more esteemed for food than the old ones, they continue their course towards the north; from whence, in December, they return in the same dense mass, and are usually found to be remarkably fat; proving that in the northern regions they find an ample supply of food; and vast indeed must be the stock, to furnish and fatten such a swarm of hungry mouths. In the crop of one of our common English Wood-Pigeons, just killed, we found upwards of an ounce of the freshbudding leaves of clover, and in another, mentioned by Mr. White, of Selborne, was found an equal quantity of tender turnip-tops, so nice and inviting, that the wife of the person who shot it, boiled and ate them, as a delicate dish of greens, for supper. The consumption of grains of wheat by a common House-Pigeon, we found to amount to two ounces in twenty-four hours, and in the following twenty-four hours, when fed with peas, it consumed about the same weight. Hence we may easily form some idea of the enormous consumption of a large flight. Supposing one Pigeon to feed regularly at the above rate, its annual average supply would amount to about fifty pounds in weight,- - a serious consumption of grain when large numbers are concerned. The following calculation, made by a very accurate observer, places the subject, as far as relates to the American Wood-Pigeons, in a still more striking point of view. He saw a column of Pigeons, one mile in breadth, moving at the rate of one mile a minute, which, as it was four hours in passing, made its whole length 240 miles. He then calculated that each square yard of this moving body contained three Pigeons, which 
thus gave two thousand two hundred and thirty millions, two hurdred and seventy-two thousand Pigeons! and yet this he considered to be less than the real number. Computing each of these to consume half a pint of seed daily, the whole quantity would equal seventeen millions, four hundred and twenty-four thousand bushels per day. Heaven, he adds, has wisely and graciously given to these birds rapidity of flight, and a disposition to range over vast uncultivated tracts of the earth, otherwise they must have perished in the districts where they resided, or devoured the whole productions of agriculture, as well as those of the forests.

When noticing the flight of birds, the rapidity of these, and of our trained Carrier Pigeons, was alluded to.* The Passenger Pigeon is particularly adapted for speed, having a light active body, furnished with long wings, in which the first quill feather is equal in length to the rest, a sure indication of that rapid and long-continued flight which they are known to possess. This faculty, in addition to the possibility of training that particular species, the Carriers, to return without deviation or delay to places from whence they had been removed, was, from very early days, turned to good account. We learn from an ancient historian, Diodorus Siculus, that, above two thousand years ago, they were used as conveyers of intelligence, and about five hundred years ago, relays of Carrier Pigeons formed part of a telegraphic system, adopted by the Turks. Regular chains of posts were established, consisting of high towers between thirty and forty miles asunder, provided with Pigeons, and sentinels stood there, constantly on the watch, to secure the intelligence communicated by the birds as they arrived, and to pass it on by means of others. The note was written on a thin slip of paper, enclosed in a very small gold box, almost as thin as the paper itself, suspended to the neck of the bird; the hour of arrival and departure were marked at each successive tower, and for greater security, a duplicate was always despatched two hours after the first. The despatches were, 
however, not always enclosed in gold, but merely in paper; in which case, to prevent the letters being defaced by damp, the legs of the Pigeons were first bathed in vinegar, with a view to keep them cool, so that they might not settle to drink, or wash themselves on the way, which in that hot climate they were often doing.

Of late years, the number of Wild Pigeons in England is, like the Swallows and Starlings, evidently diminishing, and it is rare to see a flock of any magnitude; but formerly they were very abundant, as we may learn, not only from incidental remarks in ancient writers, but from allusions to the particular manner of catching them. Thus we find the prophet Isaiah speaking of them, "flying as a cloud :" and constant allusions are made to their prodigious numbers. Indeed, had they not been far more numerous than they are at present, it would not have been worth while to have adopted the expensive mode of catching them, which we believe is at present entirely given up, though till within a few years it was practised near Cava, on the Gulf of Sorento, in Italy, where, upon the tops of some bushy hills, were erected small circular towers : on each of these, towards the latter end of September, a man posted himself, and as soon as a flight of Pigeons passed on their way through the valley, he flung a flat stone over them, which by its form or manner of throwing, made a sort of whistling noise, which frightened the birds, and hastened their flight towards a place of refuge. Another was thrown from each tower as they passed, until the affrighted flock was thus driven to the last turret in the valley, where a large net was spread in the hollows amongst the bushes, in which the birds were taken. Great art was requisite in throwing the stone, as upon this the success of the diversion depended.

At a small village called Gerde, about a league from Bagnère de Bigorres, in the Pyrenees, a mode somewhat similar is adopted from the middle of September to the middle of November, which attracts the notice, and is resorted to as a favourite amusement, by those who visit that beautiful country. Large nets are stretched across the end of a narrow 
valley, and made fast to trees. Three tall spars, nearly fifty feet in height, are reared in a triangular form, meeting in a point at the summit, where a sort of nest of bushes is made, in which a person conceals himself, ascending the high poles by small pegs, which, as they shake under his weight, are as slender as possible, consistently with strength, appears to lookers-on to be a service of no small risk. Two men are also concealed in bushes near the nets, which, by means of lines, they are enabled to throw over the Pigeons as they advance; while others, assembled on the heights immediately above, frighten the birds and force them to fly downwards as they pass through the channel of the valley. When all have taken their positions, they wait patiently and silently the arrival of a flock of Pigeons. Their approach is announced by a rushing sound, on hearing which the people on the heights pour upon them a volley of short sticks, which compel them to lower their flight towards the ground, when, if they attempt to rise, the man in the nest immediately begins shaking his airy perch as much as possible; and throwing upon the affrighted birds sticks tied together in the form of a cross, which make a whizzing sound as they fall. Impelled by this united attack, the Pigeons rush forward to the head of the gorge, and there meet their fate in the nets which stop their progress. By this means sometimes as many as two hundred are caught at once.

The American Wild Pigeons, as well as our common Wood Pigeons (Columba cenas and palumba), the Stock Dove and Ring Dove, usually build in trees; but not always, for in many situations they prefer holes in rocks and precipices, and even in some cases old rabbit-burrows : when found in these, the warreners fix sticks at the mouth of the hole, in such a manner as to prevent the escape of the young birds, but wide enough apart to allow the old ones to feed them. In the eastern countries and the Holy Land the Wild Pigeons almost invariably prefer such situations to trees; thus confirming the words of the prophet, who speaks of the Dove that maketh her nest in the sides of the hole's mouth. (Jeremiah xlviii. 28.) 
It is remarkable that, although our common Wood Pigeon is supposed to be the origin of all our common House Pigeons, every attempt at taming the young of these birds has failed. No sooner are they released from confinement, notwithstanding every attention and care, than they fly off at once to their native woods, and return no more. But the Indians of North America seem to have found out some method of changing their nature, as a traveller found wild Pigeons amongst a tribe of Indians, which where so tame as to fly and return again.

That birds of this species can form odd attachments, we may learn from the following strange association between a House Pigeon and a cat. The Pigeon had made her nest in a loft much infested with rats, which had more than once destroyed her eggs, or devoured her young ones. Her repeated losses at length induced her to rebuild her nest in another part of the loft, where a cat was rearing three kittens, with whom she contrived to form a strong friendship. They fed from the same dish, and when the cat went out into the field, the Pigeon was often observed to be fluttering near her. The Pigeon, aware of the advantage of her protection, had placed her nest close to the straw bed of the cat, and there, in safety, reared two broods of young ones; and, in return for the protection she experienced from the cat, she became a defender of the young kittens, and would often attack with beak and wings any person approaching too near.

Considering their insignificant means of defence, consisting, in great measure, of the spur on the ley of the male, few birds exhibit a more bold and resolute spirit than the Poultry tribe, in which we may include Pheasants, so nearly are they allied to our common barn-door fowls, in their habits and mode of life. We knew an instance where a barndoor Cock became the terror of his little domain. Accustomed to be fed by his owner, a clergyman, he shortly began to express his disappointment by very determined attacks, if his master 'happened to pass him without the accustomed offering. On one occasion he actually struck a piece out of 


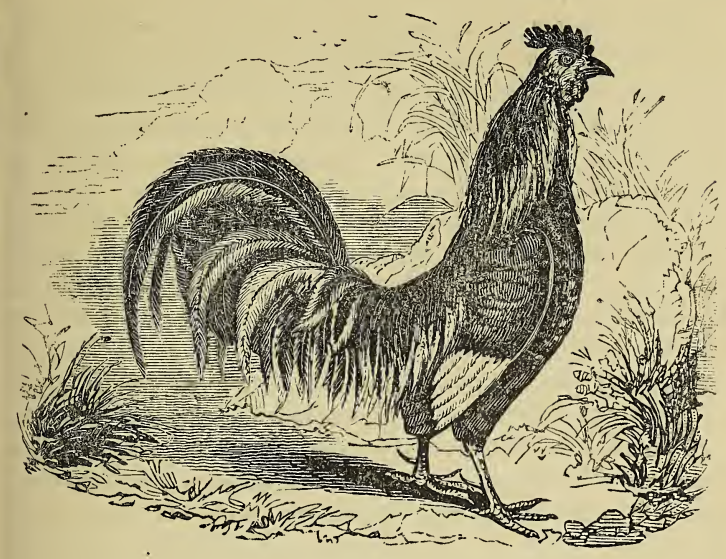

Cock

a strong kerseymere gaiter, and repeated the attack, in spite of some severe kicks which it was found necessary to inflict in self-defence. Nothing daunted, though occasionally fairly kicked several yards, like a foot-ball, he would still come on as fiercely as ever, for three or four times.

During one of these assaults he received an injury which lamed him for a week; but no sooner had he recovered than he became as pugnacious as ever. His reasoning, too, appeared to be on a par with his courage, for he soon discovered that women were protected by the lower part of their dress; and accordingly, instead of flying at their legs and feet, he invariably flew at their heads, fixing himself on their shoulders. To such a degree did he carry on this warfare, that the female who had charge of feeding the fowls, and had been accustomed to poultry all her life, never ventured into the yard without some weapon of defence. His offensive operations were carried on with such persevering spirit, that for fear of his doing some serious injury, particularly to children, it was at last found necessary to destroy him. 
This boldness is not always confined to the domestic tenants of the farm-yard. The following instances prove that even the wild Pheasant of the woods, and the still more shy and solitary Bustard of the plains, can occasionally lay aside their fear of the human race, and fight as fierce a battle as this Game Cock.

A young lady walking alone, a few miles from Stirling, observed a beautiful cock Pheasant perched on a stone by the road-side. Instead of showing timidity at her approach, he flew down upon her, and with spurs and beak began a furious assault. Being closely pursued, and seeing no way of escape from the enraged bird, she adopted the only alternative that was left-namely, of seizing her adversary, whom she carried home, but soon afterwards released. On the door being opened, however, he went out without any sign of fear, and, with a deliberate step, paced backwards and forwards in front of the house, and manifested an inclination to join the fowls in the poultry-yard. It should be remarked, that the young lady, when attacked, wore a scarlet mantle, which probably excited the irritability of the Pheasant, as it is well known to do that of the Turkey-cock and some other animals.

The case of the Bustard occurred some years ago on Tilshead downs, in Wiltshire, in the month of June, to a man who was going along the road on horseback, about four o'clock in the morning. His attention was first turned to a large bird flying above his head, which proved to be a Bustard, though till then he had scarcely ever heard of such a bird. He had not proceeded far before it had alighted on the ground, immediately in front of the horse, which it soon showed signs of attacking, and in a few seconds began the onset. The rider dismounted with all speed, and, getting hold of the Bustard, endeavoured to secure it, in which, after a long and severe struggle, he succeeded, and carried it to the house of the person to whom he was going, where it was confined. During the first week it was not known to eat anything; but, finally, it became very tame, and would take food from the hands of those accustomed to feed it, though 
it still continued shy in the presence of strangers. From the time of its capture in June, till August, when it was sold to a nobleman for thirty-one guineas, it was never seen to drink; indeed, after the first three weeks, water was never given to it. A second instance of one of these birds attacking a human being occurred about a fortnight afterwards, near the same spot, and under circumstances very similar. The horse, however, took fright, became unmanageable at so unexpected an attack, and ran away with his rider.

In the above cases, we find only an increase of that spirit with which Nature has endowed them. But the clergyman who possessed the pugnacious Cock just mentioned, had a Hen, which so far overcame its natural fear of water, as to be in the constant habit of making a short cut from the churchyard (into which she, with the rest of the poultry, occasionally wandered) to the barn-yard, by regularly swimming across a pool, which was situated between it and the churchyard. The distance was about thirty yards, and the part of the pool where she crossed was so near the end of it, that the other fowls which came round arrived before her. This Hen had another uncommon propensity, that of catching mice, a practice she pursued with the greatest eagerness, and when caught she was seen to run off with them; whether she ate them or not was never known with certainty; at all events, she did not do so invariably, as they were sometimes found dead up and down the yard.

It has been often doubted whether the Pheasant will breed with the common Hen; but the following account from a highly respectable authority,* seems to set the question at rest, and deserves the attention of those who are interested in the improvement of their race of poultry.

In the Autumn of 1826, a wandering Pheasant made its appearance in a small valley of the Grampians, the first of the species ever noticed so far north in that part of the country. For some time it was only occasionally observed, and its presence actually doubted. Winter wants, however,

* Quarterly Journal of Agriculture, No. V. 
brought it more frequently into notice; and in due season more unequivocal proofs became apparent: for when the chicken broods of common poultry came forth, and approached to maturity, no small admiration was excited by certain stately, long-tailed, game-looking birds standing forth amongst them, and continuing to grow in size and beauty, until all doubts of direct relationship with the Pheasant effectually vanished. These hybrids partook largely of the character of the parent stranger; and as they were found to grow to a good size, and possess hardy constitutions, a useful and agreeable variety for the poultryyards was secured, in a thus simple and unlooked-for manner.

Pheasants are not what is termed indigenous in this country,- that is, originally produced or bred here; but were imported from the eastern countries, to which they are chiefly confined. Their short wings and heavy bodies are little calculated for long flights, which may, in a great measure, account for their remaining so long in one particular part of the world, and explain the cause why none have yet been found in America. But as they are very plentiful layers,-a pair belonging to a gentleman near Dover having been known, in one season, to lay the extraordinary number of one hundred and eighty-three eggs,- -and may, with proper attention, be easily reared, we see no reason why they may not be successfully introduced, and abundantly supply any country in the world.

The following directions for rearing them under hens have been, we know, adopted with success. A sufficient number of eggs being provided, put them under a hen that has kept her nest for three or four days; and, if two or three hens happen to sit on the same day, an opportunity will be afforded of shifting the good eggs. At the end of ten or twelve days, examine, and throw away those that are bad, and set the same hen or hens again, if sitting hens should be numerous. The hens having sat their full time, such of the young Pheasants as are already hatched must be put into a basket, with a piece of flannel, till the hen has done hatching. Then 
place the whole brood under a frame, with a net over it, and a covered place for the hen, so as to confine her, but leave the young Pheasants at liberty to leave or return to her at pleasure. Their food must consist of boiled eggs cut small, boiled milk and bread, alum curd, and ants' eggs, - a little of each, and often. Rice may also be given, softened by boiling; and instead of ants' eggs, which in some places are not easily procured, or in addition to them, maggots from decayed flesh may be used. Artificial ants' eggs may be easily made, composed of flour, beaten up with an egg and shell together, and the pellets rubbed between the fingers to a proper size.

After two or three days, they will be acquainted with the call of their foster-mother, and they may then be allowed to run upon a grass-plot, or elsewhere; the edge of a corn-field is very desirable, as they like the tall stems, and soon learn to pick up the green grains,- - taking care to shift them with the sun, and guard them from cold winds. They ought not to be released in the morning before the sun is up, and they must be shut in with the hen in good time in the evening. When they are old enough, those that are to be turned out wild ought to be taught to perch. This is done by tying a string to the hen's leg, and obliging her to sit in a tree all night. She should be placed there before sunset, and, if she falls down, she must be perseveringly replaced, till she become contented with her situation; then the young birds will follow the hen, and perch with her, and in a few days will shift for themselves. If regularly fed, they will remain near any particular spot, and frequent a lawn or pleasure-ground as familiarly, and almost as fearlessly, as common poultry. An ingenious feeding-machine has been made, by which the grain may not only be kept dry, but reserved for the sole use of the Pheasants, or, at least, the larger sort of fowls ; as the lid, covering a trough containing the seed, opens and shuts by the weight of the Pheasant hopping on or off a perch connected with a crank.

Pheasants have been considered, and with some reason, foolish birds, easily taken by every variety of snare; but, 
together with the Peacocks, they were, nevertheless, probably on account of their beauty, not only highly esteemed in ancient times, but viewed with a sort of superstitious respect; so much so, that, by the heathen Romans, those who first served them up at entertainments were deemed guilty of a sort of impiety to their idol-gods; and even when they were afterwards introduced as food, they were never used, even by the emperors, except on the most solemn occasions. In after-times, the Christians, who too often adopted the customs of their heathenish predecessors, paid an almost equal respect to these birds. Thus we find so serious a writer as St. Jerome, giving directions for boiling a Pheasant, so that the form of the bird might be completely preserved. From the table, Pheasants and Peacocks became most fashionable and honoured additions to the toilet; historians telling us, that the most splendid present one of the Popes sent to Pepin, one of the earliest kings of France, was a mantle, embroidered with the feathers of the latter; and the richest furniture in the apartments of the nobles in the middle ages, was painted or inlaid in such a manner as to represent a Peacock's tail, spread out and studded with eyes.

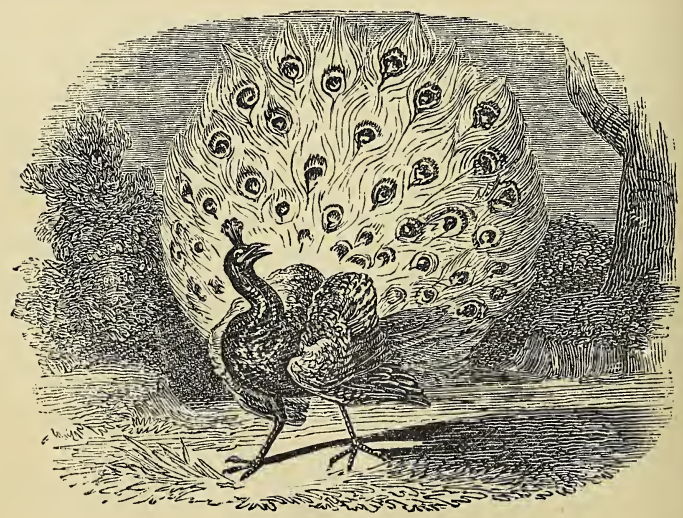

Peacock. 
At table, they were never introduced, except on the most important and magnificent occasions; and he who carved them was considered as honoured in the highest degree. The feathers from the tail of the Peacock were formed by the ladies of quality into a crown, for the purpose of decorating their favourite troubadours or minstrels. The eyes were considered to represent the attention of the whole world as fixed upon them. And in those days of chivalry, so constantly was the Peacock the object of the solemn vows of the knights, that its image was hung up in the place where they exercised themselves in the management of their horses and weapons; and before it, when roasted and dressed in its plumage, and placed, with great pomp and ceremony, as the top dish, at the most splendid feasts, all the guests, male and female, took a solemn vow: the knights vowing bravery, - the ladies engaging to be loving and faithful. It was, no doubt, in consequence of this veneration, that Queen Elizabeth chose to have her picture taken in a gorgeous robe, covered with Peacock's eyes.

If we are indebted to India for the Peacock (where, in their wild state, they fly in coveys, glittering in the sun, or may be seen roosting in trees, in such numbers that an author describes them as almost hiding the foliage with their plumage), and to the Eastern countries for our pheasants, we have to thank the New World for that more homely, but more useful bird, the Turkey, which, there is reason to believe, was never known in Europe till about three hundred years ago, when it was imported from America; but which has now been so widely spread, that in some places, as, for instance, in the neighbourhood of the Black Sea, * they have nearly returned to their originally wild state;

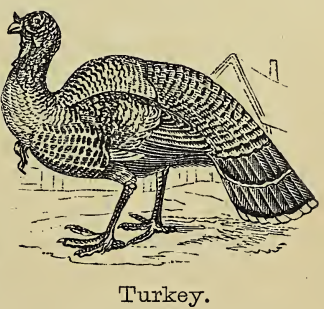

* See Clarke's Travels, vol. ii. 
and near Smyrna, such immense flocks of Turkeys approach in the depth of winter, that a traveller speaks of purchasing four of the largest size for about five shillings.

From the journals of travellers in the interior of New Holland, we learn that a species of wild Turkey is, in some places, very abundant; the bird has been described as resembling our Bustard, and is remarkably shy. We have heard, from a highly respectable naturalist, of a singular instinct in their mode of building their nests and hatching their young. It is said, they collect a mass of fallen leaves together, forming a considerable pile, in the middle of which the eggs are deposited; from the particular character of the trees usually found in that country, the leaves are full of moisture, consequently, when collected, they soon heat, and the sagacious bird ascertains, by some instinctive signs, the period when the heat of the mass of leaves has continued long enough to hatch the eggs, when the old one pulls the heap to pieces, and, releasing the brood, leads them off to the woods or plains.

In their native wilds of North America, they herd together in considerable flocks, but like the original inhabitants of the country, the poor Indians, they are every year becoming more scarce; driven from their accustomed haunts by those who have taken possession of their land. Partial as these birds are to Indian corn and buck-wheat, they are very destructive visitors, and the farmers, with reason, dread their approach, as fearful devourers of their crops.

Though on the whole friendly and sociable birds, and fond of travelling together in flocks, a good deal of severe discipline is exercised by the old birds, particularly the males, who seem to rule over the juniors with a very strong hand. The young males, called Gobblers, are compelled to live by themselves; for if they venture to approach their seniors, they are sure of being severely punished; and many are killed on the spot by repeated blows on the skull. They frequently meet with great difficulties in their journeyings, in consequence of rivers stopping their progress. In this case they seem to hold a council; the old males strut about, and gobble loudly, 
while the hens and young males spread out their tails, and make the most of their figures. At last, as if by common consent, they mount the highest trees, from whence, at a particular signal from a leader, away they launch themselves. If, as is often the case, the river is wide, these short-winged, heavy-bodied travellers perish in great numbers. The strong, old, and healthy, generally accomplish their object, while the weak and tender, falling short, are hurried down the stream; but they. do not, in this perilous predicament, lose their presence of mind,-for, spreading out their tails as a sail, they close their wings, stretch out their necks, and strike out boldly for the shore.

There can be no doubt that our European stocks of tame Turkeys are descendants of these wild Americans; and yet it is remarkable that, train and keep them as long as you please, the wild Turkey will still retain its original habits; and it is not improbable that, if left to themselves, the descendants of our tame ones would in time resume the wild habits of their forefathers, like those which we have above mentioned, abounding near the Black Sea.

We are not, indeed, without instances of wild Turkeys, at this day, in our own country, and a curious anecdote has reached us of a friendship taking place between a flock of these birds and a Partridge. It occurred at Tyninghame, in Scotland, where there is a breed of Turkeys which never enter into the poultry-house or yard, but roost in the trees, and live chiefly on beech-mast, and anything else they can pick up, though they are tame enough to come about the house to be fed in the time of frost and snow. About eight or ten years ago, a cock Partridge, full grown, suddenly joined himself to the flock of these Turkeys, and remained with them constantly during the whole Summer, Autumn, and Winter; at night he slept under the trees in which they roosted; in the day he fed with them, and was not the least frightened or disturbed by people walking among them. He took great liberties with the old Turkey-cock; when he saw him going to pick up a worm or any seed, he used to run under him between his legs, and snatch it out of his mouth, 
the Turkey-cock never resenting the indignity. Early in the Spring he left them, as it was supposed, to find himself a mate for the pairing-season. But, in the beginning of Autumn, he rejoined his old friends, and continued with them as formerly, until the next pairing-time, when he again disappeared, but returned no more, having probably been killed.*

Male birds of the gallinaceous or poultry tribe, which associate with a plurality of females, are in general less attached to the young birds of their species than others which pair, and confine themselves to one mate. The following is, however, a curious instance that this insensibility is not invariably the case.

In May, a Turkey-hen was sitting upon eggs, and as the cock in his solitude began to be uneasy and appear dejected, he was allowed to remain in the same space along with her. He immediately, on being admitted, sat down by the hen, and it was at first supposed that this was a mere mark of affection, but it was soon found that he had taken some of the eggs from under her, which he carefully covered with his own body. The maid who looked after the poultry thought this mode of hatching would be attended with little advantage, and therefore put the eggs back again under the hen; but the cock was no sooner at liberty than he again carried some of them away as before. The owner, when he observed this, resolved, for the sake of experiment, to let the cock have his own way, and caused a nest to be prepared with as many eggs as its large body was able to cover. The cock seemed to be highly pleased with this mark of confidence, sat with great patience on the eggs, and was so attentive to the care of hatching them, that he scarcely took time to go in search of food. At the expiration of the usual time, twenty-eight young ones were produced; and the cock, who was now in some measure the parent of this numerous offspring, appeared a good deal perplexed when he saw so many little animals pecking around him, and requiring his constant vigilance;

* Edin. Phil. Jour., No. viii. 
they were therefore removed, from a fear that he might tread upon or neglect them.

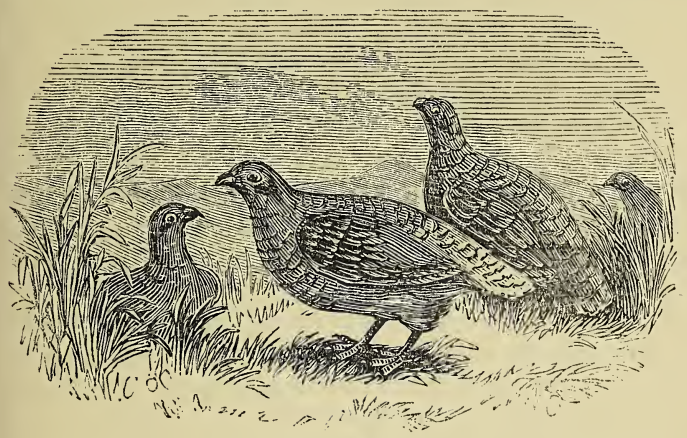

Partridges

Generally speaking, the Partridge is a much shier bird than the Pheasant, and though we have found it, in the above case, quitting its own species to live with another, it can seldom be induced to lay aside its natural habits and become quite tame. Occasionally, however, by great care, they have been known to attach themselves to man.

In a clergyman's family, one was reared, which became so familiar that it would attend the parlour at breakfast, and other times, and would afterwards stretch itself before the fire,seeming to enjoy the warmth, as if it were its natural bask on a sunny bank. The dogs of the house never molested it, but unfortunately it one day fell under the paws of a strange cat, and was killed.

The Partridge, as is well known, usually builds in corn-fields, where, undisturbed amidst a forest of tall wheat-stems, it rears its brood. Like other birds, it sometimes, however, chooses a very different sort of nursery, as, for instance, a hay-stack, on the top of which a nest was once formed, a covey hatched, and safely carried off.

In England we have but one sort, but in France, and other 
parts of Europe, they have beautiful varieties,-the red-legged, Barbary Partridges, \&c.; and in America, there are again other sorts, peculiar to the New World. We shall give Captain Head's lively description of two varieties, the larch and spruce Partridges, which he met with in his expedition into the interior, near Lake Huron.

"Early in the Spring," he says, " they make their appearance in the pine woods, welcomed by the solitary back-settlers, not only as harbingers of returning warmth, but as an agreeable addition to their stock of provisions, and a source of amusement. At first when the snow still covers the ground, they are easily tracked, though by no means easily discovered in the trees, on which these two species invariably perch. They run for a considerable distance from their pursuers, before they rise, turning backwards and forwards, and round and round, twisting about the trees in such a manner as to make it difficult to follow up the footmarks, and but for the assistance of dogs familiar with the sport, the keenest eye is often foiled." Captain Head thus describes his first meeting with one of these birds :-

"The snow in the woods was crisp from the night's frost, and the sun was just rising in a clear sky, when the marks of game attracted my notice, and my spaniel at the same time evinced the most eager interest and curiosity in the pursuit, quartering the ground from right to left. After walking about half an hour, he suddenly quested, and on going up to him I found him at the edge of a swamp, among a clump of white cedar-trees, to one of which he had evidently tracked some description of bird; for he was looking steadfastly up into the tree, and barking with the utmost eagerness. I looked attentively, but nothing whatever could I discover. I walked round the tree, and round again ; then observed the dog, whose eyes were evidently directly fixed upon the object itself; and still was I disappointed in perceiving nothing. In the mean time, the dog, working himself up to a pitch of impatience and violence, tore with his paws the trunk of the tree, and bit the rotten sticks and bark, jumping and springing up at intervals towards the game: and five minutes had at least 
elapsed in this manner, when all at once I saw the eye of the bird. There it sat, or rather stood, just where Rover pointed, in an attitude so perfectly still and fixed with an outstretched neck, and a body drawn out to such an unnatural length, that twenty times must I have overlooked it, mistaking it for a dead branch, which it most closely resembled. It was about twenty feet from the ground, on a bough, and sat eight or ten feet from the body of the tree. I shot it, and in the course of the morning killed four more, which I came upon much in the same way as I did upon the first. At one of these my gun flashed three times, without its attempting to move; after which I drew the charge, loaded again, and killed it. The dog all the time was barking and baying with the greatest perseverance. There is, in fact, no limit to the stupidity of these creatures; and it is by no means unusual, on finding a whole covey on a tree in the Autumn, to begin by shooting the bird which happens to sit lowest, and then to drop the one above him, and so on till all are killed."**

Very different, indeed, from our straggling coveys, are the assemblages of these birds in America. Near Fort Churchill, on the shores of Hudson's Bay, in the Winter season, they may be seen by thousands feeding on the willow-tops peeping above the surface of the snow. The crew of a vessel wintering there, killed one thousand eight hundred dozen in the course of the season. They are provided with a plumage well calculated for the severe weather to which they are exposed, each feather being in a manner doubled, so as to give additional warmth. Our British Partridges huddle together in the stubbles, but these birds shelter and roost by burrowing under the snow : in the snow, too, they practise a common mode of escaping observation and pursuit, as they will dive under it as a Duck does in water, and rise at a considerable distance. The Indians, as well as European settlers, catch them in great abundance in traps, and live upon them throughout their long Winter. 
From the earliest ages, Partridges seem, indeed, to have been a favourite food, and the pursuit of them as favourite an amusement. In the Scriptures, "to hunt the Partridge on the mountains," is alluded to as a well-known sport; and to this day, though not exactly with the same weapon, it is practised by the Arabs of Mount Lebanon. They make a slight square frame of wood, of about five feet in height, over which they stretch an ox-hide, perforated in three or four places. The ox-hide is moved quietly, in an upright position, along the ground, and the Arab, concealing himself behind it, is hidden from the view of the game, which unsuspectingly allow the sportsman to come within shot of them. The Arab, seeing through one of the apertures, quietly protrudes the muzzle of his long musket through another hole, and firing upon the birds, as they feed in coveys upon the ground, kills a great many of them.*

Our limits will not allow us to dwell much longer on this family of birds, which includes Quails; but we cannot

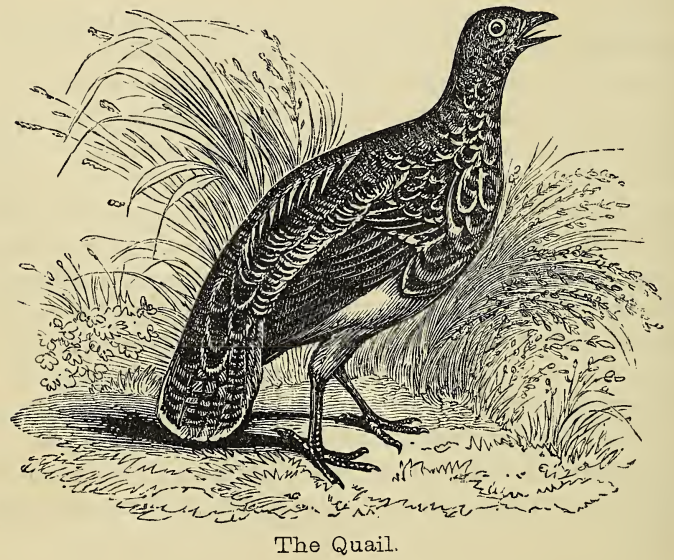

* FrankLrin's CJnstantinople, vol. ii. 
leave them without showing how strongly modern travellers corroborate the account given in the Scriptures of the prodigious numbers of Quails, and the mode of drying them for food.

" And there went forth a wind from the Lord, and brought Quails from the sea, and let them fall by the camp, as it were a day's journey on this side, and as it were a day's journey on the other side, round about the camp, and as it were two cubits high upon the face of the earth. And the people stood up all that day, and all that night, and all the next day, and they gathered the Quails : he that gathered least gathered ten homers; and they spread them all abroad for themselves round about the camp," (Numbers xi. $31,32$.

Their coming with the wind, their immense quantities, covering a circle of thirty or forty miles, and being spread in the sun for drying, appeared so impossible to one of our most learned commentators on the Bible, * that he was persuaded our translation was incorrect, and that instead of Quails, locusts were meant. Here, however, we have the evidence of eye-witnesses. "Near Constantinople, in the Autumn, the sun is often nearly obscured by the prodigious flights of Quails, which alight on the coasts of the Black Sea, near the Bosphorus, and are caught by means of nets spread on high poles, planted along the cliff, some yards from its edge, against which the birds, exhausted by their passage over the sea, strike themselves and fall. In October, 1829, the sultan sent orders to one of his admirals to catch four hundred dozen. In three days they were collected, and brought to him alive in small cages." $\dagger$ Another traveller tells us that they visit Egypt in immense flights about harvest-time, where the Arabs take them by thousands, in nets. They fly, he adds, in a direct line from north to south, and very rarely from east to west. With respect to their being dried in the sun for food, we have equally good evidence from a third

* Bishop Patrick.

† SLADE's Travels in Turkey, vol. i. $\ddagger$ Madden, vol. ii. 
traveller,* a foreigner, whose words we will, therefore, translate. There is, says he, a small island off the coast of Egypt, where these birds usually alight in the Autumn, on which they are taken in such quantities, that after having been stripped of their feathers, and dried in the burning sands for about a quarter of an hour, they are worth but one penny a pound. The crews of those vessels which in that season lie in the adjacent harbour, have no other food allowed them. The object of the Israelites, therefore, in spreading them round the camp, was to dry them,-a mode of preparing fish and camels' flesh, still practised by the Arabs, in the very same country.

The only difficulty seems to be in their being so thickly strewed as to form a solid mass of "two cubits from the face of the earth." But Josephus, who must be allowed to be a better judge of the meaning of words in the Scripture than we can be, and more conversant with the subject on which he writes, explains the passage, by saying that it merely meant, that the Quails flew within reach of the Israelites, about two cubits above the ground; which they, in fact, often do when exhausted, and are knocked down by the Arabs with sticks.

The Quail is the smallest of the poultry tribe: but there is one more to be mentioned, forming the connecting link between this and the last of the gallinaceous order, by far the largest of the family. We mean the Bustard, of whose courage in attacking a man and horse we have already spoken. $\uparrow$ The Bustard can fly, but its usual motion is on foot, running with such speed as of en to rival a greyhound. Formerly they were common on our plains, and in the open country of England; but, as enclosures have taken place, they have gradually disappeared, and are now supposed to be, in this country, an extinct species.

In Norfolk it is said that there are a few still remaining: the last authentic instance is that of a gamekeeper at Cresswall, near Mildenhall, Norfolk, who took a hen Bustard in a 
rabbit-trap, in the month of May, 1829, and the male was seen about the same time in the neighbourhood.

One great peculiarity deserves mentioning, namely, a singular pouch which they have, large enough to hold upwards of a quart of water. Its use has not been ascertained; by many it was supposed to be a provision of nature for supplying them with water, living as they did in vast plains, where water was not common; but as it is confined to the male, this supposition seems to be erroneous, unless, when the female is confined to her nest, her mate provides her with water from this reservoir.

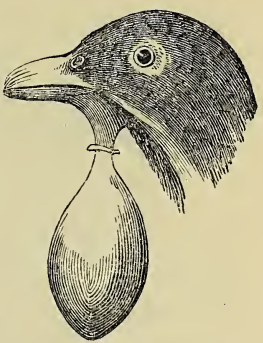

Pouch of Bustard

We come now to the last tribe in the gallinaceous order, consisting of birds altogether foreign, of very peculiar habits : these, as far as wings and flight are concerned, having scarcely a right to be classed amongst birds, as they never quit the ground, and know nothing of the power possessed by others of the feathered race, of soaring aloft, and fleeing away like the Dove, should they wish to seek for food, or repose, in a distant country. These birds are the Ostrich, the Emu or the Cassowary, and one or two others little known.

Of these the Ostrich is the most common; its beautiful light plumes have long been used as ornaments in ladies' head-dresses; and to this, probably, as it was diligently sought after as a valuable prize to the captor, we are indebted for all we know of its natural history, though still much remains unknown, for no bird has been more misrepresented; first, as a parent, who, after laying her eggs in the desert, left them to be hatched by the sun, and cherished no affection for her young. This, indeed, is the character she bore in the ancient days of the prophet Jeremiah, who compares the Ostrich to the unnatural mothers of Zion : Even the sea monsters draw out the breast, they give suck to their 


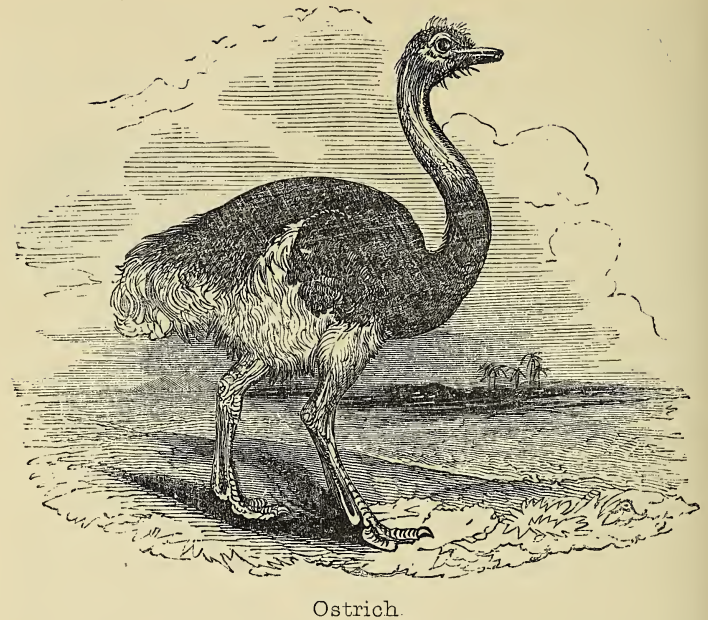

young ones; the daughter of my people is become cruel, like the Ostriches in the wilderness. (Lam. iv. iii.) It is certainly true, that she does lay her eggs in the desert, leaving them by day to the warmth of a burning sun; but no sooner does the evening set in, than swiftly she hastens across the wild tracts of sand, over which she has, throughout the day, been wandering in search of a scanty supply of food, and all night long she covers them with the tenderest care.

The American Ostriches (Struthio Rhea) are not only most affectionate, but sociable, laying together in the same nest, or rather the same hole, showing equal attention to their joint broods; and that they are not deficient in attachment towards each other, the following affecting story fully proves.

A pair of Ostriches had long been kept in the Zoological Gardens, at Paris. The skylight over their heads having been broken, the glaziers proceeded to repair it, and, in the 
course of their work, let fall a triangular piece of glass. Not long after this, the female Ostrich was taken ill, and died in an hour or two, in great agony. The body was opened, and the throat and stomach were found to have been dreadfully lacerated by the sharp corners of the glass, which she had swallowed. From the moment his companion was taken from him, the male had no rest: he appeared to be incessantly searching for something, and gradually wasted away. He was moved from the spot, in the hope that he would forget his grief; he was even allowed more liberty; but nought availed, and he literally pined away till he died.

Their swiftness is proverbial ; to run like an Ostrich is, in its own country, the same as to say in ours, to run like a greyhound. When roused from the desert, with their long legs and huge strides, they scour away beyond a horseman's speed, with their short wings expanded to balance them. Vain would be the hope to catch them at first setting off, for, in a few minutes, they are out of sight. The persevering hunter, however, keeps on a steady course, sparing his horse, till he can again see his game at a distance, when off it runs once more, and thus, at length, by over-exertion, wears itself out, its joints becoming stiffer after every run, till finally the horseman approaches near enough to shoot it.

In Morocco, the Arabs adopt another method. Mounted on swift desert horses, called heiries, they set off in parties of about twenty, riding against the wind, till they meet with the track of an Ostrich, separated themselves at distances of about half a mile apart; when, as soon as they obtain a view of their game, they spur onwards at full speed. For a time, the bird runs from them against the wind, till, finding its wings an impediment, it turns round and foolishly runs towards them, when every huntsman fires, as opportunity occurs, until they bring it down.

At Bornou, in the interior of Africa, ther adopt a very different method, for which patience instead of speed is required : on finding a nest, a hole is dug, in which the finder buries himself, leaving only his head and arms free, and 


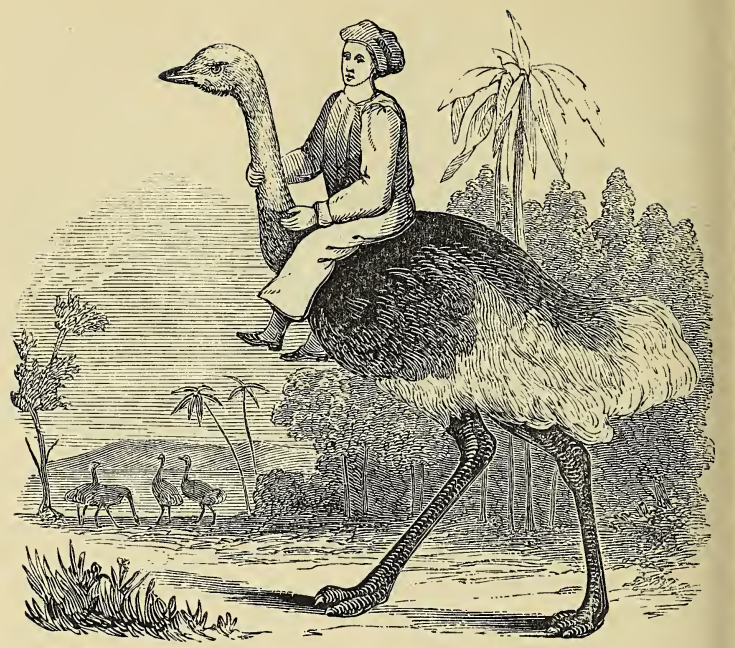

then quietly waits the return of the bird; and when s he is steadily seated on her nest, an arrow is shot through her head.

So great is their muscular strength, that tame ones will run along with a person on their back; and it is on record, that F. Firmius, who reigned in Egypt in the third century, was drawn in a chariot by Ostriches. Their strength of leg renders them sometimes very mischievous; and at a farm in the Cape of Good Hope, the owner was obliged to kill a favourite tame one, which was not satisfied with swallowing chickens whole, and trampling hens to death, in order to tear them in pieces, but at last took to trampling even sheep to death.

The Cassowary and Emu in many respects resemble the Ostrich, differing from him chiefly in the plumage, which in the former partakes more of the nature of hair or bristles, 
than of feathers.They are lively birds, and frisk and dance away when roused, when they look very like a woolly cushion on the top of two poles. Like the Ostrich, they are stupid, and like it, also run with amazing swiftness; so much so, that it is very difficult to run them down, unless by the

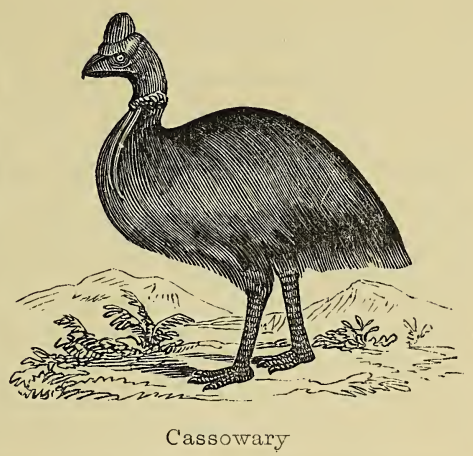
swiftest dogs, and by them only in an open country. They defend themselves by kicking with their powerful legs, and the blow is quite sufficient to stun a dog, or even at times to fracture a man's leg; accordingly, dogs trained for hunting them, always approach the running bird, not immediately in its rear, but a little on one side, so as to turn and seize it by the body.

In the Emu of New Holland, there is also a very curious internal bag, or pouch, connected with the windpipe, but having no communication with the other air-cells; its use is not exactly known, but it has been ingeniously conjectured, that in a country like New Holland, parts of which are particularly exposed to sudden floods, the sandy plains in the interior are inundated, and the Emus in seeking their food amongst, or attempting to escape from these marshes, must be often obliged to have recourse to swimming; which, considering their weight, would be difficult, were it not for the power of filling this pouch with air, and thus keeping their heads and necks above water. That this is correct we have good reason for believing : for Captain Short, in the account of his recent expedition into the interior of Australia, mentions the fact of two Emus swimming across the Morumbidgee, in a part of considerable width and rapidity, which 
they would never have ventured to attempt, so peculiarly are they in body and limb unfitted for swimming, without some internal capacity similar to the above.*

Of the last bird in this list, the Dodo, no particulars are known. The following account of one exhibited in London is the only instance, we believe, on record of its appearance as a living species in modern times; we give it on the authority of Sir Hamon L'Estrange, quoted in Sir Thomas Browne's works, vol. ii., p. 174. “About 1638, as I walked London streets, I sawe the picture of a strange fowle hang out, and myselfe, with one or two more then in company, went in to see it. It was kept in a chamber, and was a great fowle, somewhat bigger than the largest Turkey-cock, and so legged and footed, but shorter and thicker, and of a more erect shape, couloured before like the breast of a young cock Fesan, and on the back of dunn or deare coulour. The keeper called it a Dodo, and in the ende of a chimney in the chamber there lay an heap of large pebble stones, whereof he gave it many in our sight, some as bigge as nutmegs, and the keeper told us shee eate them, conducing unto digestion; and though I remember not how far the keeper was questioned herein, yet I am confident that afterwards shee cast them all agayne."

Whether this bird was, however, after all, a real Dodo is very questionable; for although there is no doubt of its having been in former times abundant in some of the islands of the Indian Ocean, it is supposed to have long ago ceased to exist, and is therefore generally considered by naturalists as extinct a species as those animals whose bones are occasionally found in a fossil state, in rocks and caves.

* See note on the pouch of the Hurgila, p. 325 . 


\section{CHAPTER XIV.}

Water Birds.—Waders. - Pressirostral; Narrow-beaked.—Waterhens; Anecdotes of ; Nests of.-Coots ; Nests of.-Jacanas ; Singular Foot of. - Horned Screamers. - Rails. - Oyster Catchers ; Tamed. - Cultrirostra ; Cutting-billed. - Herons ; Toothed-claw of ; Voracity of.-Storks and Cranes ; Migrations of; Respect paid to.-Gigantic Crane ; Particulars respecting.-Jabiru.-Anastomus; Open-beaked.-Tantalus.

\section{TABLe XXII. (See page 19.)}

\section{Order 5. Waders.-Tribe 1. Pressirostres,} (Narrow-beaked.)

WE now come to a different class of birds from those of which we have been hitherto treating, though still with a connecting link between them, so fine as scarcely to mark the point where the one begins, or the other ends; a numerous and widely-extended race, living and seeking their food more or less amongst the waters. Some are fitted for swimming,-others are not: to make up for this deficiency, the latter are furnished with long legs for wading, or long bills for penetrating the mud,-usually, though not always, with both.

The first of these to which we would allude is the WaterHen (Gallinula chloropus). That pretty, smart, active bird, which we may almost at any time see, if we peep cautiously and silently through the bushes of an old marshpit in a meadow, or a pond half choked up with rushes, or well paved, if we may so express ourselves, with the broad floating leaves of the water-lily, or persicaria (Polygonum amphibium). In the middle of any such little open space she may be usually detected swimming about with a joyous sort of jerking motion, but on the least rustle exciting a 
suspicion that an enemy is near, gliding silently through the narrow channels, or running with a light tread over the floating leaves, to seek invisible shelter under the roots or hollows of the bank. Not that she always prefers the water, -for often in the evening she may be seen wandering in the new-shorn grass of a hay-field, easily distinguishable by the white feathers on her wing and vent, and a peculiar jerk or flirting of the tail. But with all her shyness, she is, nevertheless, a tame and sociable bird, and if treated with kindness, will show a marked confidence. We have seen WaterHens visiting the lawn of an inclosed garden, and remaining there, notwithstanding the constant intrusion and barking of parlour-dogs, Peacocks, and tame Pheasants : and, again, not unfrequent intruders in a barn-yard, mixing in a party of poultry. But at the residence of a clergyman near Cheadle, in Staffordshire, a much more striking instance of familiarity has for some years occurred. Adjacent to the lawn there is a moat, on which a pair of Water-Hens were observed for several seasons, always however leaving it in the Spring. By being constantly fed, they in time became quite tame, and at length were induced to breed there, from the circumstance of a thorn-bush covered with ivy having fallen into the water, in which they afterwards continued to build their nest. When the young are a few days old, the old ones bring them up close to the drawing-room window, where they are regularly fed with wheat: and, as the lady of the house pays them the greatest attention, they have learned to look up to her as their natural protectress and friend; so much so, that one bird in particular, which was much persecuted by the rest, would, when attacked, fly to her for refuge; and whenever she calls, the whole flock, as tame as barn-door fowls, quit the water, and assemble around her, to the number of seventeen (November, 1833). They have also made other friends in the dogs belonging to the family,-approaching them without fear, though hurrying off with great alarm on the appearance of a strange dog. The position of the water, together with the familiarity of these birds, has afforded many interesting particulars respecting their habits. They have 
three broods in a season-the first early in April; and they begin to lay again when the first hatch is about a fortnight old. They lay eight or nine eggs, and sit about three weeks, - the cock alternately with the hen. The nest in the thornbush is placed usually so high above the surface of the water, that when the young are first hatched and have quitted it, they cannot climb into it again; but, as a substitute, within an hour after they leave the nest, the cock bird builds a larger and more roomy nest for them, with sedges, at the water's edge, which they can enter or retire from at pleasure. For about a month they are fed by the old birds, but soon become very active in taking flies and water-insects. Immediately on the second hatch coming out the young ones of the first hatch assist the old ones in feeding and hovering over them, leading them out in detached parties, and making additional nests for them, similar to their own, on the brink of the moat.

On the appearance of the third brood, the old ones invariably drive the first away to a neighbouring pond, where they remain till September, when the last hatch is about halfgrown. About this time a fresh party of birds makes its appearance, which from their tameness is, no doubt, composed of broods formerly bred there; and in the moat the united families remain till the following Spring, when the original pair drive all the rest away, but not without many severe and curious contests frequently in the water, when they throw themselves on their rumps, and strike at each other with their feet. When either of the combatants begins to find himself worsted, he dives, and does not reappear,-thus eluding his adversary, by hiding his whole body under water, and merely exposing his beak for respiration.

During the breeding season, they are constantly adding materials to their nest, making sad havoc in the flowergarden; for, though straw and leaves are their chief ingredients, they seem to have an eye for beauty, and the old hen has been seen surrounded with a brilliant wreath of scarlet anemones. As in this case, so do they usually build their nests on stumps of trees, or convenient bushes, by the side of 
the water; and artlessly formed as it is of a few rushes, one might suppose that it would be easily discovered, which would be the case, but for the caution adopted by the bird, who, before she quits her eggs, covers them carefully up, for the joint purpose of concealment and warmth. A person fishing on the banks of the Thames, when passing a willow-bed, heard a slight rustling motion: suspecting it to proceed from some water-bird, he kneeled down and remained perfectly quiet, when the noise ceased. On rising and looking about, he saw a Water-Hen busily employed in collecting dry rushes and flags, and laying them one by one over her eggs deposited in one of these bare nests close beside her. It was not long before she had completely hidden them; and then, looking round with a cautious glance, not aware that her motions were observed, softly and silently glided away amongst the reeds and disappeared. On a nearer approach, strange to say, the nest was with difficulty found, and no one who had not previously ascertained its existence was thereabouts, could possibly have discovered it.

We have said that they usually build either upon a level with, or very little raised above the water, but not invariably so,-for although almost entirely confined to the water, as their abiding as well as feeding-place, they will not only perch on trees when roosting, but even build their nests at a considerable elevation above the ground. An instance of this occurred in Surrey, where the attention of a person who had landed upon an island in the middle of a large pond, was drawn to a mass of dry rushes, flags, and reeds, strangely heaped together, about twenty feet above the ground, in a spruce fir-tree. Curiosity induced him to climb up,-when, to his surprise, out crept a Water-Hen, which dropped into the pond and made off towards the shore.

But it is not only in their instinctive attachments and habits that they merit notice; the following anecdote proves that they are gifted with a sense of observation approaching to something very like reasoning faculties. At a gentleman's nouse, in Staffordshire, the Pheasants are fed out of one of those boxes described in page 287 , the lid of which rises with 
the pressure of the Pheasant standing on the rail in front of the box. A Water-Hen, observing this, went and stood upon the rail as soon as the Pheasant had quitted it; but the weight of the bird being insufficient to raise the lid of the box, so as to enable it to get at the corn, the Water-Hen kept jumping on the rail, to give additional impetus to its weight; this partially succeeded, but not to the satisfaction of the sagacious bird. Accordingly it went off, and soon returning with another bird of its own species, the united weight of the two had the desired effect, and the successful pair enjoyed the benefit of their ingenuity. We can vouch for the truth of this singular instance of penetration, on the authority of the owner of the place where it occurred, and who witnessed the fact.

Nearly allied to the Water-Hen is the well-known family of Coots ; they, too, build a simple rushy nest, but with this difference,- - that instead of seeking to raise it above the water, they seem to prefer its floating upon the very surface; where, of course, it is exposed to the double danger of being carried hither and thither, according as the wind blows; or, if interwoven with reeds or bushes close to the water, of being covered, should the waters be raised by floods. But the Coot is apparently well aware of these possibilities, and accordingly guards against them: preventing the nests being carried away by ingeniously fastening the materials of which they are made to the rushes or osiers near them; but at the same time, these fastenings are of such a nature as to allow of the nests rising with the water, so that no ordinary flood would expose them to the danger of immersion. The Coot, like the Water-Hen, covers her nest, and if not so effectually, yet with a most extraordinary rapidity. We have repeatedly watched a Coot quietly sitting on her nest; if the boat approaches, she rises, and immediately begins pecking away, right and left, which she continues to do till the enemy is so near, that she is compelled to decamp for her own preservation. In this short time, however, she almost always contrives to cover her eggs; and though the nest itself remains a very conspicuous object, a careless observer might pass it as deserted and empty. 
When the young are hatched, they look more like little puff-balls than the bodies of birds, with their bright red heads sticking out like handles. For some days they lead a weary life, exposed as they are to the attacks of pike, and we believe of rats, which devour numbers of them, in spite of the flouncings and flappings of the poor mother, who in vain tries. to drive away the intruder. It is surprising, indeed, how any of them escape; for though they are tolerably active, no efforts of theirs are sufficient to elude the swift, unerring, open-mouthed dart of a voracious pike. Against other enemies they can make a better defence; and we have frequently witnessed the beautiful instinct with which they manage to elude pursuit. On seeing a fleet of these little red-headed floaters, paddling away in the rear of their two velvet-coated parents, we have often given chase. It is not till the danger of capture becomes imminent, that the old ones desert their charge, first giving the convoy a signal to disperse by a few short but most expressive clucks. When hard pressed, the young bird dives, and, if the water is clear, may be traced, working away with all its energies ; but, after remaining about a minute below, during which time it will dive some fifteen or twenty yards, it is forced to rise, and the chase is renewed. After a few divings, it becomes exhausted, and is easily taken. The downy covering, too, seems to partake of the weakened force of the body; for the harder the little bird is pressed, the more susceptible is it of moisture; and, instead of rising above the water glossy and dry, like a powder-puff, it becomes wet and spongy. Should it, however, contrive to gain a patch of weeds before it is quite exhausted, it seems to disappear by magic; in vain is its rising looked for,-not a ripple betrays its progress; and, had we not been fortunate enough, in several instances, to detect it, cowering about an inch below the surface, its body under the shelter of a floating leaf, and its beak projecting just to admit an occasional supply of air, we might have concluded that the poor little bird had either fallen in with a Pike, or fairly foundered. As if conscious of their safety, we have watched them, remaining motionless for several minutes 
together, and then taken them up before they had time to struggle.

Foxes are said to be fond of Coots, and when the waters they frequent are frozen up, it is not improbable that many fall victims. This may probably account for their returning in diminished numbers after long frosts. On a mere, where, from constant observation, we knew the precise number, they would remain as long as a few square yards of water were unfrozen, sitting on the ice, or swimming with a sort of despairing restlessness, round their rapidly contracting space, as if unwilling, while hope of thaw was left, to seek shelter elsewhere. Even when this, their last opening, is sealed up, they will, for a day or two, linger amongst the rushes on the borders; but at length they disappear altogether, and may in vain be sought for in the ditches and open streams adjacent. As they do not return till many days after the frost has broken up, and Ducks and other birds common to the mere have reappeared, it is probable they migrate to some distance, most likely to the sea-coast, where frost has little power, and where we know, during very severe weather, they have been observed to congregate in flocks far beyond the average numbers frequenting the neighbouring meres or marshes.

The third genus in this table comprises the Jacanas, a tribe of Waders, or rather we should say, walkers on the water; for, by means of their very long toes, they are enabled to walk with ease over the large water-plants, whose leaves form a floor, as it were, over the surface. They are inhabitants of the marshes of warm climates, and so shy, that those who hunt for them can only approach by covering themselves with leaves.

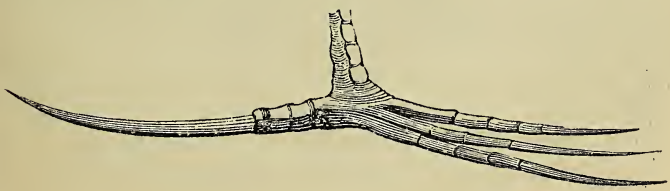


The means of defence in some of the Jacana species are very singular. Thus, the Horned Screamer (Palamadea cornuta), of which we annex a plate, so called from its peculiar shrill and piercing cry, and the long horn upon its head, is abundantly supplied with spurs; having, in addition to this upon its head, two very sharp ones upon each wing, and, by means of these spines, they fight dreadfully during the breeding season,-the conqueror remaining with a selected female, to whom he remains constant. So attached indeed are they to each other, that if one dies, the survivor usually pines away and dies too.

But, with all this warlike appearance, its character is rather mild: one species is often tamed, and from its being a resolute enemy to certain birds of prey, which make sad havoc in the poultry-yards, the inhabitants of the countries where it is found, rear it as a protector for their fowls,

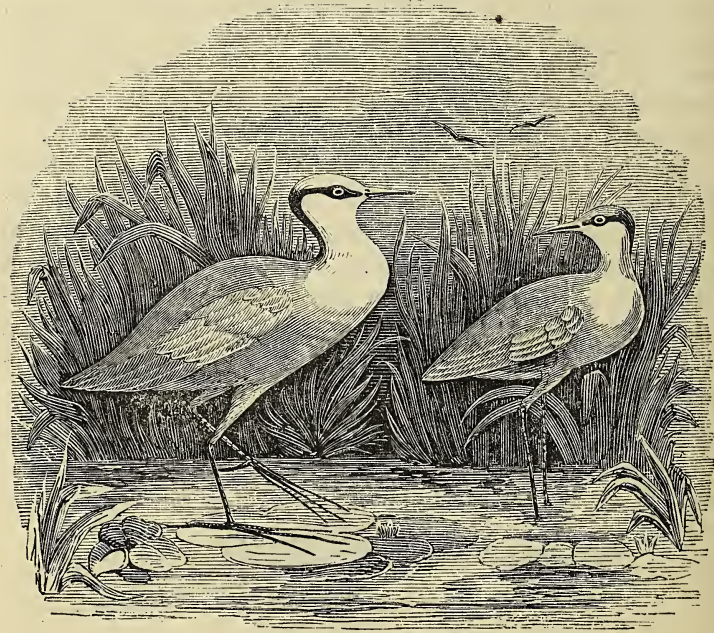

Jacana walking on Water-Hlants 
as it not only feeds with them, but accompanies them into the fields, and brings them back in the evening. It has in consequence been named the faithful Jacana (Parra chavaria).

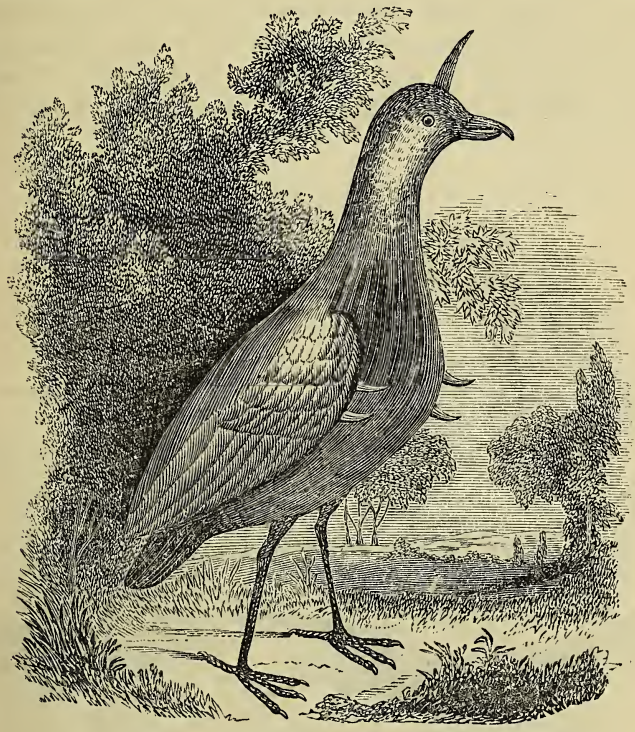

The Horned Screamer.

The fourth genus consists of the Rails, including our Corncrake and Water-rail, which may be called English Jacanas, as, in manners and habits, there is a considerable resemblance; they differ from the Coots chiefly in having no plate or horny-shield covering the forehead, and from the Jacanas, in not having their wings armed with spines. They are rarely seen, as they feed, morning and evening, amongst reeds and marsh-growing plants, and conceal themselves during the day in long grass, or ditches, from whence 
it is difficult to rouse them, as they run very swiftly, and will not rise, if they can avoid it.

The fifth and last genus consists of Oyster-Catchers, or Sea-Pies, from the black and white plumage of our British species bearing some resemblance to that of the Magpie. They live by the sea-side, feeding on marine insects, for which they may be seen actively searching at low water. Their name of Oyster-Catcher is also derived from their

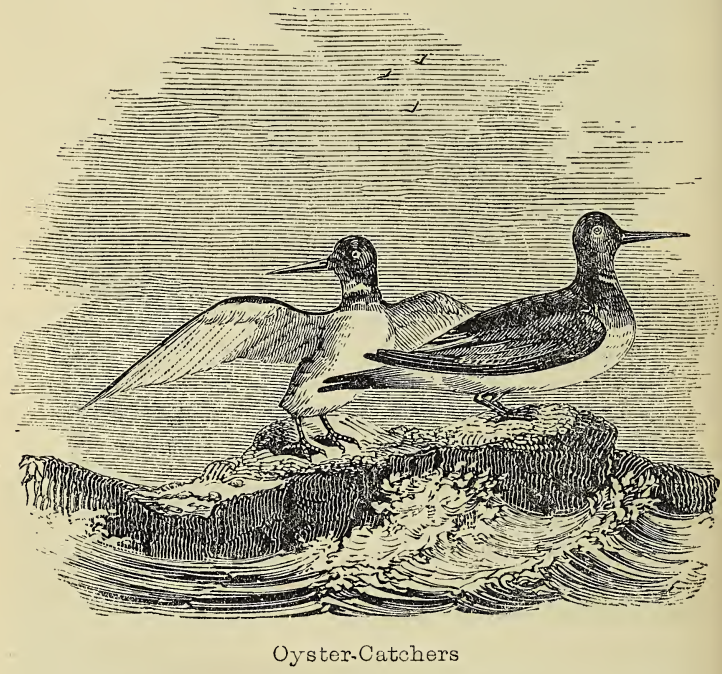

expertness in extracting the oyster, which, however, can be done only when the shell is open, and not even then without great caution; for instances have been known of the unfortunate bird being made prisoner by the oyster closing upon its beak.

Its eggs are laid on the bare ground, for the nest, if it deserves to be so called, consists only of small shingle and 
shells thrown up by the sea, so little above high-water mark, that in high spring-tides they are frequently swept away. When taken young, they may be easily tamed, and we have been surprised that they are not more frequently introduced into our pleasure-grounds. We remember seeing very considerable numbers of them, some years ago, on the lawn of the Pavilion at Brighton, collected by order of his. late Majesty George the Fourth, where they were running about with the tameness and familiarity of poultry. Nothing could be more ornamental than their smart pieballed glossy coats, in contrast with their long, bright, orange beaks and legs, and crimson irides.

\section{TABLE XXIII. (See page 20.)}

Order 5. Waders. Tribe 2. Cultirostres, (Cutting Beaks,) so called from the Latin words, culter, a knife, and rostrum, a beak.

ThIs tribe contains the Herons, Cranes, \&c., known by their thick, long, and strong cutting bills. The first genus consists of the Heron, properly so called, which differs from the others chiefly in the middle toe being toothed or pectinated, and in having their beaks cleft under the eyes. In other respects, they in so many points resemble the second and third genus-namely, Storks and Cranes, that they may be all looked upon as forming one family. With the Heron, however, we are most familiar, as he alone stays with us all

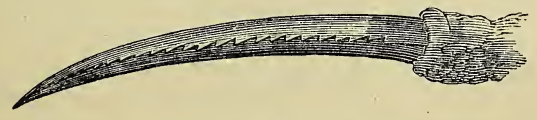

Serrated Claw of the Heron.

the year round; and he may be often seen standing like a grey statue, motionless on one leg, up to his knees in water, in some retired spot, watching for fish, the very picture of 
patience. Impatient would he nevertheless be, if long unsuccessful, for he has a most prodigious appetite, destroying an inconceivable number of fish, which are digested almost as soon as swallowed. The powers of its stomach are indeed very great, surpassing those of most other birds; Owls, Crows, and Kingfishers, we know are unable to digest the harder portions of their food, such as bones, \&c., which are thrown up in pellets; but in the Heron's stomach they are easily dissolved. So rapid, indeed, is their digestion, that ignorant people have exaggerated facts, and given marvellous accounts of the feeding habits of this bird. For instance, the people of the Ferroe Islands have a notion of the internal economy of the Heron's stomach, which truth will not quite warrant, though the principle on which it is founded is correct. They imagine that it has only one large gut, white as silver, which proceeds through its whole body, and that as soon as it catches and swallows a fish, "it is under the necessity of placing its rump against a hillock or stone, to prevent the fish from getting out again; and that it stands in that position until it has been digested."* They have also such a respect for its fishing powers, that they believe a Heron's foot, carried in the pocket, will ensure success.

But this opinion is not confined to the ignorant people of the Ferroe Islands: the idea was once, and very possibly still may be, current in some parts of England, that the feet and legs of a Heron had something in them very attractive to fish, and particularly to eels, which enabled the bird, when standing in water, to bring his prey about him, and thus take it with greater facility. Accordingly, Herons were in great request with fishermen, on account of their feet and legs, which were supposed to contain an oil, which, if rubbed over a worm, rendered it a sure bait for eels. Possibly, however, and indeed probably, Herons may really be gifted with some peculiar power of attracting fish.

'There is a very extraordinary light, said to be visible on 
the breast of a species of the American Bittern; and most, if not all the birds of the Heron genus, especially our common Heron, have on their breasts a considerable space void of feathers, filled up by tufts of down, to which adheres a sort of clammy oily substance. It is not therefore unlikely that this oily matter may, either by smoothing the water or in some other way, enable the bird to attract, or when attracted, to strike its prey with greater certainty. This idea is strengthened by a generally prevailing opinion respecting the Fish Hawk of North America, which, when hovering

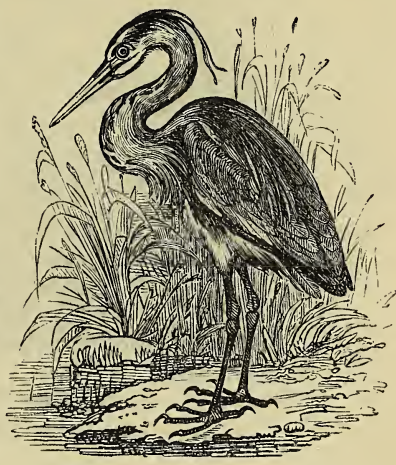

Heron. over the water, is supposed to have some attractive power over its prey, upon which, when collected within reach, it pounces. The charm is believed to be an oil contained in a small bag in the body, as baits touched with a drop of it are considered to be an irresistible lure for all sorts of fish.

The Heron's feathers are also occasionally found loaded with a blue powder, which may possibly serve its purpose in some way not hitherto diseovered. Their appetite is in proportion to their powers of digestion. A Heron was once seen to dart upon a large eel, and after killing it by repeatedly dashing it against the ground, gulp it all down. We have known another to consume no less than five moderate-sized eels at a single meal, which the glutton seemed quite ready to repeat within a very short time after; and one was found dead not long ago on the banks of Pulganny, otherwise called the Water of Badenoch, near Drumlanford House, in Scotland, the stomach of which actually contained the extraordinary number of thirty-nine fine trouts. 


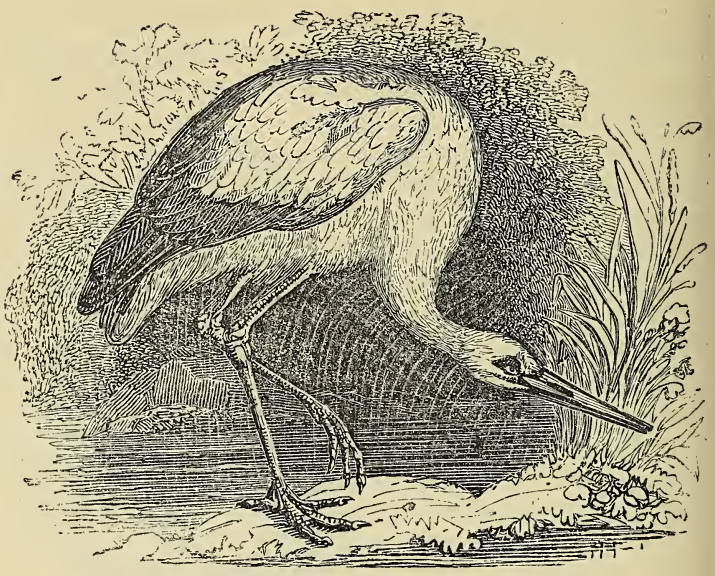

The Stork.

Storks and Cranes are not, like the Heron, stationary, but even in the countries to which they are most attached, are regular birds of passage ; but so punctual in their comings and goings, that from the most remote times, they have been considered as gifted with reasoning powers. The prophet Jeremiah, speaking of their knowledge, contrasts their instinctive obedience to their Creator's laws, with the culpable departure therefrom by those on whom God has bestowed the higher gifts of reason and understanding. "Yea, the Stork in the heaven knoweth her appointed times; and the Turtle, and the Crane, and the Swallow, observe the time of their coming; but my people know not the judgment of the Lord."-(Jeremiah, viii. 7.)

So punctual is the arrival and departure of the various migratory birds, that to this day, the Persians, as well as ancient Arabs, often form their almanacks on their movements. Thus, the beginning of the singing of the Nightingales was the commencement of a festival, welcoming the return of warm weather; while the coming of the Storks was the period 
of another, announcing their joy at the departure of Winter. The expression, " the Stork in the Heaven," is more applicable than at first appears, for even when out of sight, its pathway may be traced by the loud and piercing cries, peculiar to those of the New as well as of the Old world.* In America, $\uparrow$ too, its migrations are equally regular, passing its immense periodical journeys at such a prodigious height as to be seldom observed. It is satisfactory thus to strengthen the authority of a Scriptural passage from so distant a source, though amply borne out by witnesses in the very country in which the prophet dwelt.

"In the middle of April," says a traveller ${ }_{\ddagger}^{+}$in the Holy Land, "while our ship was riding at anchor under Mount Carmel, we saw three flights of these birds, each of which took up more than three hours in passing us, extending itself, at the same time, more than half a mile in breadth." They were then leaving Egypt, and steering towards the north-east of Palestine, where it seems, from the account of another eyewitness, they abound in the month of May. "Returning from Cana to Nazareth," he observes, "I saw the fields so filled with flocks of Storks, that they appeared quite white with them; and when they rose and hovered in the air, they seemed like clouds. The respect paid in former times to these birds is still shown; for the Turks, notwithstanding their recklessness in shedding human blood, have a more than ordinary regard for Storks, looking upon them with an almost reverential affection."

In the neighbourhood of Smyrna, and indeed throughout the whole of the Ottoman dominions, wherever the bird abides during his Summer visits, it is welcomed. They call him their friend and their brother, the friend and brother exclusively of the Moslem race, entertaining a belief that wherever the influence of their religion prevailed, he would still bear them company, and it might seem that these sagacious birds are well aware of this predilection; for singularly enough, a recent traveller, $\S$

* See p. 61 .

$\ddagger$ Chardin. 
who met with them in incredible numbers in Asia Minor, observed that although they built on the mosques, minarets, and Turkish houses, their nests were never erected on a Christian roof. In the Turkish quarters they were met in all directions, strutting about most familiarly, mixing with the people in the streets, but rarely entering the parts of the town inhabited by the Greeks or Armenians, by whom possibly they may be occasionally disturbed. Nothing can be more interesting than the view of an assemblage of their nests. Divided as they always are, into pairs, sometimes only the long elastic neck of one of them is to be seen peering from its cradle of nestlings, the mate standing by on one of his long slim legs, and watching with every sign of the closest affection. While other couples on the adjacent walls are fondly entwining their pliant necks, and mixing their long bills, the one sometimes bending her neck over her back, and burying her bill in the soft plumage, while her companion, clacking his long beak with a peculiar sharp and monotonous sound, raises her head and embraces it with a quivering delight; while from the holes and crannies of the walls, below the Stork's nest, thousands of little blue Turtle Doves flit in all directions, keeping up an incessant cooing by day and night.

At another Mohammedan town, Fez, on the coast of Barbary, there is a rich hospital expressly built, and supported by large funds, for the sole purpose of assisting and nursing sick Cranes and Storks, and of burying them when dead! This respect arises from a strange belief, handed down from time immemorial, that the Storks are human beings in that form, men from some distant islands, who, at certain seasons of the year, assume the shape of these birds, that they may visit Barbary, and return at a fixed time to their own country, where they resume the human form. It has been conjectured that this tradition came originally from Egypt, where the Storks are held in equal respect, as we shall see, when we speak of their sacred bird, the Ibis. By the Jews, the former was also respected though for a different reason; they called it Chaseda,-which in Hebrew signifies piety, or mercy,from the tenuerness shown by the young to the older birds, 
who, when the latter were feeble or sick, would bring them food.

This affection, however, appears to be mutual, for the parent birds have a more than ordinary degree of affection for their young, and have been known to perish rather than desert them. An attachment of this sort once occasioned the death of an old Stork, at the burning of the city of Delft, in Holland. When the flames approached her nest, situated on a house-top, she exerted herself to the utmost to save her young, but finding every effort useless, she remained and perished with them. Besides the Jews, other ancient nations held these birds in veneration. A law among the Greeks, obliging children to support their parents, even received its name from a reference to these birds.* By the Romans it was called the pious bird, and was also an emblem on the medals of such Roman princes as merited the title of Pius. Of their attachment towards each other, we can give another instance, which occurred in this country.

A gentleman had for some years been possessed of two brown Cranes (Ardea pavonia): one of them at length died, and the survivor became disconsolate. He was apparently following his companion, when his master introduced a large looking-glass into the aviary. The bird no sooner beheld his reflected image, than he fancied she for whom he mourned had returned to him; he placed himself close to the mirror, plumed his feathers, and showed every sign of happiness. The scheme answered completely: the Crane recovered his health and spirits, passed almost all his time before the looking-glass, and lived many years after, dying at length of an accidental injury.

In return for this attachment, the male expects the strictest fidelity from his partner; and it would seem, from the following anecdote, that severe punishment awaits the mother suspected of inconstancy. We do not recollect where the first occurred, but the latter, which was seen by numbers of the most respectable persons, and communicated from the best

* ПI $\lambda \alpha \rho \gamma t \kappa o s ~ \nu o \mu \circ$ s. 
authority, lately took place near Smyrna. Some hen's eggs were placed in a Stork's nest, and the others removed. The female Stork, not aware of the change, sat patiently the appointed number of days, till the shells were broken, and the young chickens made their appearance. No sooner were they seen by the old birds, than they testified their surprise by harsh notes and fierce looks, and after a short panse, they jointly fell on the unfortunate chickens, and pecked them to pieces, as if conscious of the disgrace which might be disposed to attach to a dishonoured nest. Whether the female suffered afterwards, we do not know. We shall see, however, by the following, that the expected consequences of such a discovery might well account for the horror and indignation manifested by the wondering parents.

A French surgeon, at Smyrna, wishing to procure a Stork, and finding great difficulty, on account of the extreme veneration in which they are held by the Turks, stole all the eggs out of a nest, and replaced them with those of a hen: in process of time the young chickens came forth, much to the astonishment of Mr. and Mrs. Stork. In a short time Mr. S. went off, and was not seen for two or three days, when he returned with an immense crowd of his companions, who all assembled in the place, and formed a circle, taking no notice of the numerous spectators, which so unusual an occurrence had collected. Mrs. Stork was brought forward into the midst of the circle, and after some consultation, the whole flock fell upon her, and tore her to pieces ; after which they immediately dispersed, and the nest was entirely abandoned.

The following, in many respects, similar case, occurred on the estate of a gentleman of large landed property near Berlin, and is a valuable corroboration of what might, to many, appear as unworthy of credit. A pair of Storks built a nest on one of the chimneys of his mansion; having a curiosity to inspect it, the owner climbed up, and found in it one egg, which being about the size of a goose egg, was replaced by one belonging to that bird. The Storks seemed not to notice the exchange, but no sooner was the egg 
hatched, than the male bird, apparently perceiving the difference, rose from the nest, and flying round it several times with loud screams, disappeared, and was not seen again for three days, during which time the female continued to tend her adopted offspring as usual. Early on the fourth morning, however, the inmates of the house were disturbed by hearing loud and discordant cries in the field fronting the house, where they perceived about five hundred Storks assembled in a dense body, and one standing about twenty yards before the rest, apparently haranguing its companions, who stood listening, to all appearance, with great emotionwhen this bird had concluded, it retired, and another took its place, and seemed to address them in a similar manner. This proceeding and noise was repeated by several successive birds, until about 11 o'clock in the forenoon, when the whole flock simultaneously arose in the air, uttering dismal cries. The female was all this time observed to remain on her nest watching their motions with apparent trepidation. In a short time the body of Storks made towards her, headed by one bird supposed to be the mate, who struck her vehemently three or four times, and knocked her out of the nest, the whole mass then followed up the attack, until they had not only destroyed the female Stork (who made no attempt either to escape or defend herself), but the young Gosling, and utterly removed every vestige of the nest itself. Since that time, about five years ago, no Stork has been known to build, or even been seen in that neighbourhood. The person who stated this singular anecdote was a gentleman of undoubted veracity, who had been visiting at the house, and seen the preserved remains of the dead Stork and Gosling. It may be added, that in the part of Germany where this occurrence took place, there is a superstition prevalent, that a Stork never builds on a bad man's house, and to such an extent is this notion carried, that if a man were suspected, even of murder, the people could scarcely be induced to bring him before the magistrates, if a Stork was known to build on his house. This is mentioned as one amongst other reasons 
why the gentleman permitted such, in some respects, troublesome birds to build on his chimney-top unmolested.

We suspect that constancy and fidelity amongst birds exist to a greater degree than we are aware of;-whatever testimony can be collected on the subject certainly tends to prove it Thus, a pair of Magpies had built their nest in a tree, where they were constantly under the observation of a person whose house was near at hand. One morning early, during the absence of the male, the female flew from her tree to a field hard by, where she was soon joined by a male, who paid her great attention. During this interview the mate returned to the nest, and on seeing his partner hopping about familiarly with another, he immediately darted upon the guilty parties, and attacking them with the greatest anger and fierceness, put them to flight, and followed them: whether he killed his faithless partner or not was unknown, but she never returned; and the deserted widower, after occasionally visiting his nest for a day or two, finally quitted, and disappeared altogether. It is not improbable, indeed, that similar suspicions or prejudices may have been the cause of some of the mysterious meetings already mentioned, in which individuals were put to death.

Of this tribe, there is one which, from its extraordinary size, shape, and appearance, deserves to be particularly noticed. It is called the Gigantic Crane (Ardea argila), a native of the East Indies, and was the first of birds to meet the eye of Bishop Heber, on his landing in India. "In the morning, as the day broke," says he, "we were much struck by the singular spectacle before us. Besides the usual apparatus of a place of arms, the walks, roofs, and ramparts of the fort swarmed with gigantic birds, the Hurgila, larger than the largest Turkey, and twice as tall as the Heron, which, in some respects, they much resemble, except that they have a large blue and red pouch under the lower bill, in which, we were told, they keep such food as they cannot eat at the moment. These birds share with the jackalls, who enter the fort through the drains, the post of scavenger; but unlike them, instead of shunning mankind day and 
night, they lounge about with perfect fearlessness all day long, and almost jostled us from our paths." The bishop's information, however, respecting this pouch, is not correct; it having been ascertained, that this bag is not at all connected with the gullet, and has therefore no reference to food, but is merely an air-vessel on a very large scale, employed as occasion requires, either in sustaining the bird in its lofty soaring flights, or assisting it in searching for food in its original dwelling-places amongst marshes and lakes. Its natural food in these situations consisting of reptiles and amphibia, it must often find it necessary to go beyond the depth of even its long legs, while from the structure of its limbs it cannot swim, and it is evident that its ponderous awkward beak would prove an additional incumbrance. To overcome these difficulties the bag, when filled with air, may be of great service, by counteracting the weight of this enormous bill, and thus enabling it to procure food in deep water. And this view of the subject seems to be confirmed by the testimony of an experienced witness, by whom a Hurgila was seen, wading in a large piece of water, and proceeding to a distance from the shore, which was afterwards found to be beyond its depth. The conclusion therefore was, that by filling this pouch with air it was enabled to support itself* That its further use may be to supply it with air in its soaring flights, there are also good grounds for supposing. When the dense vapours of the rainy months are dispersed, and the sun has again burst forth with undiminished fervour on the Indian plains, the Hurgilas are observed to avoid the sultry heat of the lower regions, by taking refuge in the higher, rising gradually till they appear mere specks in the firmament, or entirely lost to the sight. In the hot months, when not a cloud obscures the vault of the heavens, hundreds of these gigantic birds may be seen performing their graceful evolutions, and wheeling majestically at a vast height, enabled to remain in so thin

* It appears to be analogous to the pouch of the Emu, and applicable in part to similar purposes. See p. 303. 


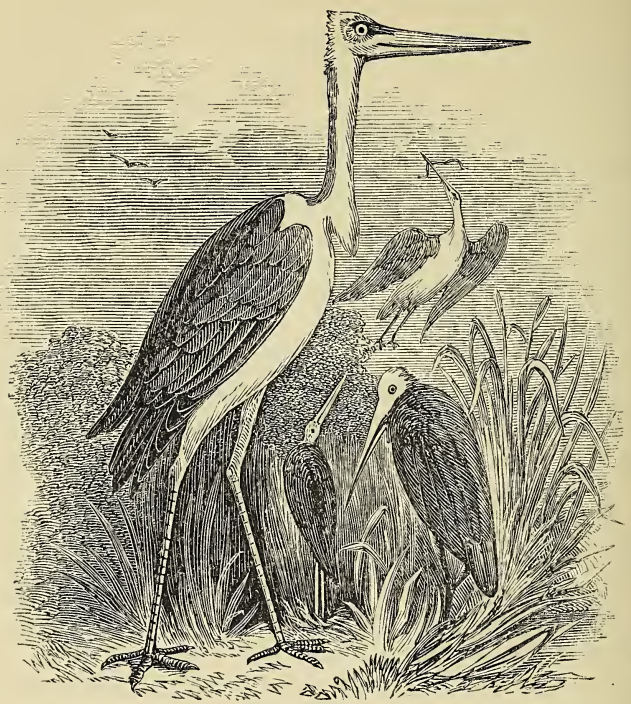

Gigantic Crane.

an atmosphere, most probably, by the supply of air collected in this bag.

In its appetite the Hurgila is as great a glutton as our Heron. Nothing comes amiss to its all-digesting stomach. A leg of mutton, and a litter of live kittens swallowed whole, proved equally acceptable with the additional sauce of earth, bones, and hair, picked up between times.

The fourth genus, Jabiru, very much resembles the Storks, and appears to have similar habits, the chief distinction consisting in the form of the bill, which is rather fuller, and slightly curved upwards at the end. The skin of the neck is wrinkled, and so flaccid that it hangs down like the dewlap of a cow, and probably may be of the same use as the pouch of the Hurgila above mentioned. It is, indeed, from con- 
sidering this dewlap as an air-vessel, that it derives its name Jabiru, which, in the language of the Guarani Indians, in South America, signifies anything inflated by wind; and they, like the Hurgilas, not only frequent marshes, but rise slowly to immense heights, where they will remain for a considerable time.

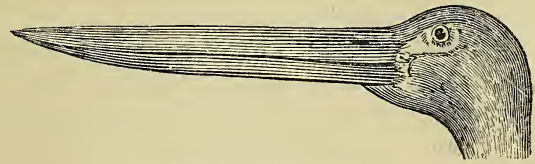

Beak of the Jabiru.

We cannot take leave of the Heron family without putting our readers on their guard against a very dangerous instinctive faculty they seem to possess of depriving their assailants of eye-sight: If wounded, they will allow a dog to approach, and then, though apparently insensible, will in an instant, with unerring aim, dart at its. eye with a force, rapidity, and certainty, which it is almost impossible to guard against. We remember a gentlemen who narrowly escaped; he had, as he conceived, killed a Bittern, and deposited it in a large pocket of his shooting-jacket; when, fortunately, as he was walking on, happening to feel something insinuating itself between his arm and side, he, just in time to save his eye, caught sight of the beak of the Bittern, which had been only wounded, and was in the act of lancing itself, with the full elastic jerk of its long neck, towards his face. This faculty, however, is not entirely confined to either the Heron or Bittern, it extends itself to other species, as appears from the similar escape of a naval officer on the coast of Africa. "I winged," says he, "a beautiful white Aigrette that was passing over head, and brought it to the ground; when, as I was in the act of picking it up, it struck at my eye with its beak, and had it not been for my glasses, must inevitably have reduced it to perpetual darkness." "I have since," he adds, " heard of a gentleman who, under similar circumstances, was not so fortunate; he still lives, and I shall feel pleasure if, by stating 
this incident, it should be the means of saving others from so distressing a circumstance."**

Of the fifth genus, Anastomus, or Open-Beaks, little is known, except that their habits and food are similar to those of the preceding genera. The beak is the prominent distinguishing feature; the edges of which, instead of closing throughout, meet only at the extremities.

The sixth and last genus is that of the Tantalus, all foreigners inhabiting Asia, Africa, America, and Australia. They have feet, nostrils, and beaks, like those of Storks, but differ from them in the form of the bill, the back of which is rounded, and its point curved towards the bottom. They frequent marshy spots, living on reptiles and fish. When their appetite is satisfied, they retire to high trees, where they remain in an erect attitude, the bill resting on the breast. They are simple birds, and may be easily shot.

* Captain Owen's Voyages. 


\section{CHAPTER XV.}

Latirostral - Flat-beaked. - Boat-bill._Spoonbill._FlamingoMode of Feeding - Nests of-Watchful Habits.-Tenuirostral, or Longirostral.-Long, Slender-billed Birds.-Avoset.Sand-Pipers.-Dotterel-Preservation of its Young.-Dunlin's Nest and Eggs-Plover-Mode of Catching.-Ibis-Mummies of - Why held Sacred.

\section{Table XXIV. (See page 20.) .}

\section{Order 5. Waders.-Tribe 3. Latirostres}

\section{(Flat-beaked).}

THE three genera of this Table have been included by I some naturalists amongst the cultirostral, or cuttingbeaked birds; but the general form of their beaks renders them easily distinguishable under the term latirostral, or flatbeaked. The Spoon-bills, indeed, alone really deserve that title to the fullest extent; for the beaks of the Boat-bills and Flamingoes, though to a certain degree wide and flattened, have also a considerable degree of depth.

The Cancroma, or Boat-bill, so called from the boatformed shape of its beak, resembles the Heron in almost every other particular, and, like that bird, will dart with fury at the object of its anger. It is found in the hot and damp parts of South America, frequenting the banks of fresh-water streams.

The Spoon-bill cannot be

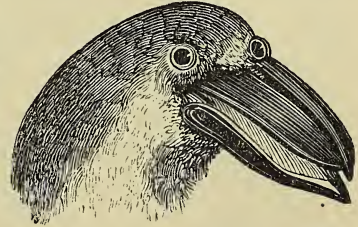

Head of the Boat-bill. mistaken, the round and flattened termination of its beak at once pointing out the name. Sometimes, but rarely, they 
are found in England. Near Holyhead, in the island of Anglesey, a very fine specimen was shot and preserved, in 1832. It was first seen early in May, feeding at low water, in company with some Herons, on the marine productions left by the tide, but was so shy that some weeks had elapsed before it was killed, at three o'clock in the morning, by a man who had marked its roosting-place on a small rocky island, accessible only on foot at low water. Another was also killed about this time, at no great distance from the same place. When rising from the grơnd, it always made several wide circles before getting into full flight. It was very shy, and never could be approached nearer than one hundred yards.

The Flamingo is by far the most striking of these three genera; its scientific name is Phonicopterus, from two Greek words, signifying "wings of flame," their beautiful carnation colour contrasting with the plumes of the neck and body, which in one species are of delicate white. It is a most extraordinary bird. Its legs are of an excessive length, and so slender, that at a little distance, standing, as they usually do, on one alone, it is not easily seen, and the bird appears as if stationary in the air. But the chief singularity is in the bill, which the an-

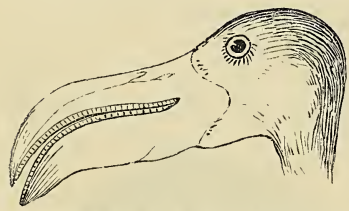

Beak of the Flamingo. nexed figure will explain better than any verbal description. With this misshapen instrument, it would appear, that the act of collecting food must be an affair of some difficulty -an opinion rather confirmed by the still more extraordinary manner in which it feeds. On looking at the plate, it will be seen that, owing to the sudden curvature, or almost broken and deformed appearance of the beak, food, collected in the usual way, must naturally drop from the mouth; and so it would, if the bird fed as other birds do; but it adopts its own method, by turning its head and scooping up the soft substances on which it preys, using the upper mandible as a 
sort of spoon. This would certainly be inconvenient, if not impossible, to other birds; but not to the Flamingo, owing to its remarkably long, slender, and flexible neck. A still greater inconvenience would ensue, if it were under the necessity of sitting on its nest, like other birds ; for it would then be utterly impossible to dispose of its long,

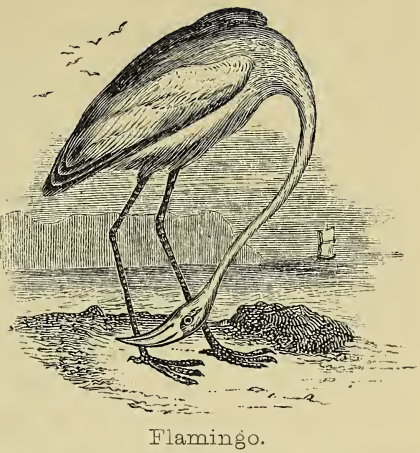
stilted, disproportioned legs. Nature has, however, met the difficulty, and taught it how to make a nest exactly suited to its form and length of leg. It is made of mud, in the shape

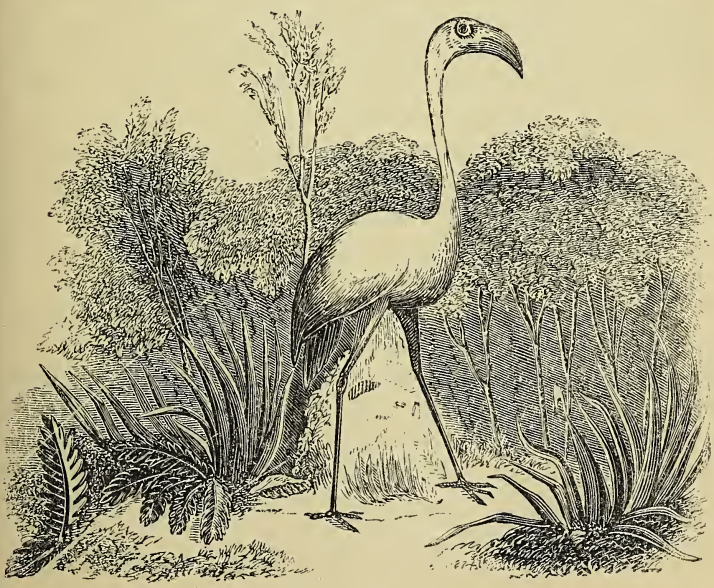

Nest of the Flamingo. 
of a hillock, with a cavity on the top where the eggs are laid; and the height of the hillock is such, that she can sit as comfortably on her nest as a horseman does on his saddle, leaving her legs to hang dangling down at full length on either side.

The bill, misshapen as it is, can also, in case of necessity, be used for a very different purpose from that of feeding; for one of these birds in confinement having been accidentally deprived of a leg, soon found a remedy by walking with the other, and using its bill as a crutch, and probably finding it as serviceable as a wooden leg, which, strange to say, has been supplied in a similar case. The circumstance is mentioned by an eye-witness.* "A Crane, having," as he says, " had one of his legs broken, and cut off above the knee, had a wooden leg and thigh, with a joint so accurately made, that the creature could walk and use it as well as if it had been natural."

We have alluded to the bright pink and scarlet colours of the Flamingoes, which give them a soldier-like appearance, in addition to further military habits they seem very generally to adopt. Not only do they always assemble in flocks, but they form in long lines of regular rank and file, as well for the purpose of fishing, as when they repose on the strand. Still further : after the manner of experienced soldiers, they post sentinels, who keep a good look-out; and, if anything suspicious attracts their notice, immediately send forth a cry like the sound of a trumpet, when the whole corps moves off in regular marching order.

In the river Inhambau, on the eastern coast of Africa, the officers of Captain Owen's surveying-ships found them so numerous, that every shoal was covered with them, "looking," to use their words, " at a distance, like large variegated plains, and, upon a nearer approach, resembling files of soldiers. When the sun was shining upon them, nothing could surpass the beauty of their brilliant and dazzling appearance."

* Evelyn's Diary, vol. ii. 


\section{TABLE XXV. (See p. 21.)}

\section{Order 5. Waders.-Tribe 4. Tenuirostres,* or Slender-billed.}

By some naturalists, the birds of this Table have been classed amongst the long-billed birds (Longirostres, CuVIER); but there can be no impropriety in adhering to the arrangement here adopted, as their bills are, without exception, more or less slender and flexible, - a character, indeed, more generally applicable than length, as some of them are by no means long-billed.

There are five genera :-
1. Avosets,
2. Sandpipers,
3. Phalaropes,
4. Curlews,
5. Woodcocks.

Of the first of these birds, the Avosets, there is little to be said, one species only being known in England, and this confines itself almost entirely to the fen-countries, or southern coasts. Its beak is so soft and flexible, that it might be mistaken for two thin pieces of whalebone, turned upwards

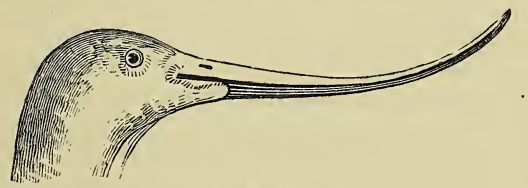

Beak of A $\mathrm{A}$ oset.

considerably for about half its length. It is web-footed, but, as it never swims, the use of the web is supposed to be to support it, as it runs lightly over morasses, or soft muddy spots.

* As there is a division of Tenuirostral birds in the Passerine Order, this tribe, to avoid confusion, is often designated as Longirostral; most of the birds composing it having long bills. We have adhered, however, to Dumeril's title. 
The four last genera of this Table form nearly the most. obscure and difficult division in the whole arrangement of birds : running one into another, by shades so slight and variable, that it is almost impossible to trace any positive line of distinction. They comprise, under the scientific names of Tringa, Charadrius, Numenius, and Scolopax, the tribes of birds known under the more familiar appellations of Sandpipers, Purres, Plovers, Phalaropes, Curlews, Woodcocks, \&c.

Amongst the Sandpipers and Purres, we find those busy, active flocks of little birds, which so often enliven a sauntering walk along the rocks and shores of the ever-ebbing and flowing sea. There they may be seen, now running incessantly with a light tripping motion, up and down, and here and there, in search of shrimps, sea-worms, or small shellfish; and then, particularly if approached too near, taking flight at the same instant, with a whirring, whizzing sound, and a loudish whistling cry, reminding us, by their sudden changes in flight, and shades of colour, of our friends the Starlings ; at one moment appearing as a little dark cloud, if their backs are presented, and then in an instant almost dazzling the eye with the bright white of their under delicate plumage, occasioned by an instantaneous turn of their bodies ; and then again seeming almost to disappear, as they dart along with their wings edgeways towards the eye. It is impossible to watch the flight of these merry, sociable little birds, without pronouncing them to be a happy race, with all the enjoyments and few of the cares of life. The skulking, solitary gunner, who prowls about the shore, appears to be their only enemy; and, conscious of their power of keeping aloof, they seem to treat him with indifference.

Some species of these birds, such as the Ring-Dotterel, or Sea-Lark, have advantages over other birds, with respect to their young, on the appearance of danger being enabled to carry them out of harm's way. There can be no doubt of this curious fact. One of these birds was seen on a rocky shore in Anglesey, running over a sandy patch a few yards off, accompanied by two young ones. On finding herself 
surprised, she immediately rose with one of the young ones, either caught up, or clinging to her by its own instinctive efforts. Whether from a wish to remain as near as possible while the other was in danger, or from the additional weight, could not be ascertained; but her flight was short, and she alighted on a rock at no great distance. The remaining little one was with difficulty overtaken, as it ran with great activity and swiftness, although very young, being covered with down, and evidently not long hatched. Most of the little birds of this tribe make no regular nests, but deposit their eggs, four in number, either on the bare sand, just beyond the high-water mark, or like the Dunlin, or Sea-Snipe, on the ground, among long grass and heather: exposed, as the eggs then are, both to weather and observation, the bird contrives to place them so as to take up the smallest possible space; and this

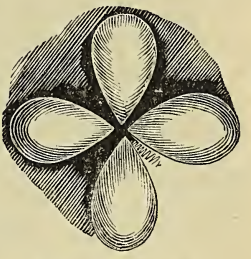

Egsss of Dunlin she effects by making them all meet at their smaller ends, which also taper more than most other eggs.

The four little eggs, for they are much smaller than a Snipe's, huddled in so narrow a compass, require a keen and accustomed eye to see them, and at the same time are easily covered by the parent-bird. Her affection for her young is not confined to them when unable to take care of themselves after hatching, but is manifested when they are still in the egg; for, should a stranger disturb her, she will, instead of running or flying away in her usual manner, immediately affect lameness, or decoy him away from the nest by tumbling over and over, as if in the last stage of weakness or decrepitude; or, if actually found upon her nest, she will sometimes nobly persevere in sacrificing herself, rather than desert it. In two instances, amongst many, they were found to sit so close, that they allowed themselves to be lifted off their nests, rather than fly away. It is remarkable how much the same instinctive habits prevail in similar families of birds. Those who may not have had oppor- 
tunities of witnessing these manœuvres by the Sandpipers, have probably often' watched the similar proceedings of our common Lapwing or Pewit, which decoys a dog or a stranger away, either by screaming close to his ear, as she flits by in a sort of tumbling flight, or by scrambling along the ground as if wounded, when the young brood are in

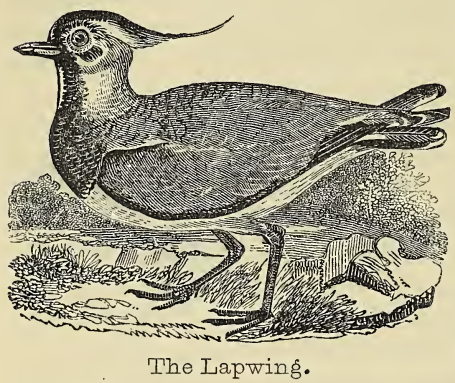
danger. Indeed, these latter birds, above any others, have need of all the art and cunning they can muster to save their eggs, which are eagerly sought after in the places where they are known to breed, for the purpose of selling them at a high price, as a luxurious article of food.

In the Orkney Islands, to the north of Scotland, they were, and possibly still are, allowed to breed unmolested; and their increase is consequently very great. Probably they were once equally unmolested in every other part of North Britain, which may account for a curious Act of Parliament, said to have been passed many years ago in Scotland, for encouragement to destroy them as " ungrateful" birds ; " for that they come to Scotland to breed, and then returned to England with their young to feed the enemy."* Their food consists chiefly of grubs and insects, easily procured in the low mossy grounds, which they prefer. Earth-worms, too, form a large portion of their diet; but, as their bills are neither so long nor so strong as to pierce deep enough into the soil to get at them, they adopt the following clever mode of inducing them to show themselves above ground, when they are instantly seized by the watchful Lapwing. A friend of ours, one day finding a young Plover, carried it home, and kept it in a

* Letters from the North of Scotland, vol.i. 
confined place. In addition to its common food, a few square pieces of turf, six or seven inches in thickness, were introduced; upon these were thrown a number of garden-worms, which buried themselves in the sods as fast as they could. Care was taken to keep them moist by frequent waterings. The Lapwing, when disposed to make her meal, mounted one of these sods, and, standing on one leg, kept regularly beating the turf with the other. Worms, as we have already shown, in speaking of the manner in which Starlings and Thrushes feed upon them, are very sensitive of danger; and their great enemy being the mole, no sooner do they perceive a vibration or shaking motion in the earth, than they make the best of their way to the surface, and thus fall into a greater and more certain peril; for, as in the case of the Starling or Thrush, so in the present instance, no' sooner did it make its appearance, than the Lapwing drew it out, and having disposed of it, renewed his operations till he had fully satisfied himself.

But we have another story to tell of a certain species of Plover's meals, far more extraordinary, and which we should feel great hesitation in relating, had not the original observer of former days been supported by eye-witnesses of later times. Herodotus, an old Grecian historian, asserted, that there was a certain small bird which, as often as the crocodiles came on shore from the river Nile, flew fearlessly within their jaws, and relieved them of a peculiar kind of leeches which infested their throats. This ancient historian added, that, although other birds invariably avoided the erocodile, it never did this bird any injury. So extraordinary a story was treated as fabulous by all naturalists. It is, notwithstanding, strictly true; M. Geoffroy Saint Hilaire, an eminent and accurate French naturalist, confirms the fact beyond a doubt. The bird alluded to is the Egyptian Plover (Charadrius AEgyptiacus), which sometimes enters the mouth of the crocodile, attracted thither, not, according to his account, by leeches, but by a small insect like a gnat, which frequents the banks of the Nile in great quantities. When the crocodile comes on shore to repose, he is assailed by swarms of these gnats, which get into his mouth in such numbers, that 
his palate, naturally of a bright yellow colour, appears covered with a blackish-brown crust. Then it is that this little Plover, which lives on these insects, comes to the aid of the half-choked crocodile, and relieves him of his tormentors; and this without any risk, as the crocodile, before shutting his mouth, takes care, by a preparatory movement, to warn the bird to be off. This singular process is, moreover, not confined to the crocodiles of Egypt: it has been noticed in those of the West Indies, where, when attacked in a similar manner by small flies, called Maringouins, a little bird (Todus viridis), which lives chiefly on flies and insects, performs the same kind office.

In the above cases, the food of the bird is said to be flies, but there is good reason for believing that perfect reliance may be placed on the account of Herodotus, and that leeches and insects are the objects sought for; as a letter from a gentleman in Calcutta was read at a late meeting of the Linnæan Society, in London, describing certain leeches which had been taken from the throat of a large alligator (which are also found to infest the throat of the Gigantic Crane, or Hurgila, already mentioned): these leeches were of various sizes, some exceedingly minute, of a florid red when alive, semi-transparent, and thus showing the blood they had swallowed.

In some parts of France, where Plovers fly in large flocks, they are decoyed into nets spread on the ground by the playing of a looking-glass, which attracts their notice,-with the addition of some stuffed birds, and here and there a live one intermixed. In another part they are hunted at night with torches, the light of which attracts them.

Woodcocks and Snipes are too well known to require description, as far as their outward appearance is concerned. But in their habits, and more particularly in the migrations of the former, there is much to excite our curiosity. With few exceptions, other birds manifest a fondness for each other's society, and even if they do not fly in flocks, may be found associating together, as if they disliked a lonely, solitary life. Not so the Woodcock and the Snipe; 
for they, except at the breeding-season, seem to shun not only other birds, but even their own species. It may be said that this is incorrect, because often in the same woods, or favourite marshy haunts, they may be occasionally put up in considerable numbers; but in these cases it should be remembered, that if many are found, the number depends not upon any social feeling, but the attraction of their common food; a large proportion of their lives being passed alone in the solitude of a marsh, or the shaded retirement of a wood. If undisturbed, and in some cases even although disturbed, there will the Woodcock or the Snipe remain, till called away by that instinctive faculty which compels them to visit regions far distant, and still' more solitary; where, without fear of intrusion, they may rear their young broods. Every sportsman is well aware of the attachment evinced by these birds for some favoured spot. Upon the same patch of rushy, marshy ground, the same Jack-Snipe may be found, day after day, in spite of the annoyance to which it is often exposed from an indifferent marksman : up rises the little bird from its rushy covert, turning and winding swiftly through the air, and thus escaping charge after charge of shot, which only seems to add vigour to its wings; and after a wide whirl or two, down

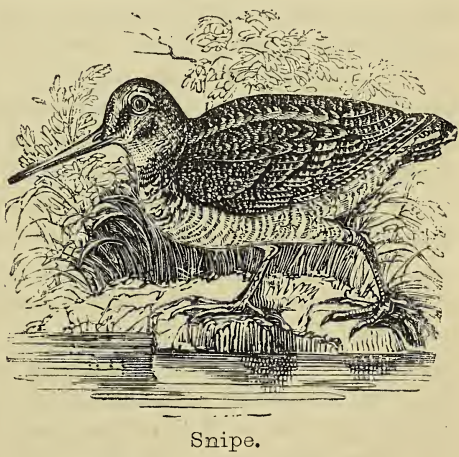
it starts again, often within a few yards of the seat of danger.

The difficulty of hitting this active little bird is indeed so proverbial, that we can readily betieve a story told of a gentleman,-a very bad shot,-who having at length suc- 
ceeded in killing a Jack-Snipe, deeply lamented the loss of a bird which, as he was always sure of finding it in the same place, had afforded him constant amusement during a whole Winter. Of this attachment to a particular spot and regular return to it, there can be no doubt; we have already alluded to it in the case of other birds, and Woodcocks and Snipes seem to form no exceptions to the practice. One instance amongst many will be sufficient to prove the fact. A Woodcock was accidentally found by a keeper, entangled in a rabbit-net and preserved alive; a brass ring was put on its left leg, and it was turned loose. This occurred in February. On finding itself at liberty, it rose to a very great height in the air, and directed its flight towards the sea, from whence it was distant about twenty miles. In December, this same bird was shot in the same wood where it had been captured in the preceding February.

That Woodcocks, however, can and do breed in this country is beyond a doubt; instances without end have occurred; one of which alone we shall notice, on account of a very curious circumstance connected with it.

The communication first appeared in a Scotch newspaper, the Elgin Courier. In the month of April, near Dornaway Castle, the seat of the Earl of Moray, a Woodcock was flushed, which flew as if wounded. On a person, who was present, remarking this to the gamekeeper, the latter observed, that the bird was not wounded, but was carrying off a young one in her talons, and that no doubt the nest was close at hand: this was found to be the case, and two other young ones were discovered in it, which, on being disturbed, ran off, uttering a piping note. The keeper spoke very positively of its being customary with the old birds to fly off every morning and evening with the young ones to the nearest springs, and when they were fed, they were conveyed back to the nest in a similar manner.

In the first edition of this work we expressed a doubt as to the correctness of the keeper's account, admitting only the possibility that it might be true, from a knowledge that some other birds were in the habit of transporting either their 
eggs or their young, or both, when disturbed, to a place of greater security; thus, at page 334 , we have instanced the case of the Ring-Dotterel, and we know, on good authority, that the Pheasant will, in like manner, when alarmed, carry ofi her eggs, and form a new nest, but with respect to the Woodcock also, the fact may be considered to be established on the authority of other competent witnesses, who had had repeated opportunities of ascertaining the point, in other parts of Scotland, where Woodcocks frequently breed. It is probably, indeed, more commonly adopted by birds than we suspect; it has been noticed in the case of the Ring-tailed Glede (Falco cyaneus); and the following account from eye-witnesses bears similar testimony to the power of the Owl.

A friend of ours had taken a brood of young Owls, and placed them in a recess on a barn-floor, from whence, to his surprise, they soon disappeared, and were again discovered in their original breeding-place. Determined to solve the mystery of this unaccountable removal, he placed them on the barnfloor, and concealing himself, watched their proceedings, when to his surprise he soon perceived the parent bircs gliding down, and entwining their feet in the feet of their young ones, flew off with them to their nest. To confirm the fact beyond a doubt, the experiment was often repeated, in the presence of other witnesses. We have also on record a remarkable instance of Nightingales removing their eggs under peculiar circumstances, communicated by Mr. Merveaux, of the French Academy of Sciences. A pair of these birds had built their nest in his garden in the lower part of a hedge, containing four eggs, when some water in the neighbourhood rose with such impetuosity as to inundate the garden. Mr. Merveaux watched the Nightingales with some anxiety, and one day when the water had reached to within six paces of the nest, he only perceived two eggs. He at first thought that the nest had been abandoned, but coming to it very soon after, he only saw one, and this time he waited to see the result, and was much astonished to see the last egg disappear with the birds, which, flying cautiously but rapidly, carried it to 
a new nest, at the highest part of the hedge, where he saw all the four eggs deposited in safety, and where they were afterwards hatched. He could not, however, ascertain how the parent birds carried these eggs.

It remains to make a few remarks on the migration of Woodcocks, which is attended with more mystery than that of most other birds. We shall endeavour briefly to state the chief points for consideration. First, we have every reason to believe that the greater proportion, on leaving this country in March, retire to the wild solitudes of Norway or Sweden. Secondly, that on re-appearing in England, in October, they are, for the most part, poor and weak. Thirdly, that instead of being first seen on the eastern coasts, they are, for the most part, known to land on the western shores of Ireland, and, almost in flocks, on the Scilly Islands, twenty miles to the westward of the Land's-End, Cornwall, quite exhausted.

Now, on the supposition that the major part are bred in Norway and Sweden, if we examine a map, it will be evident that they ought naturally to alight on the eastern shores, as the nearest points. Their weak, lean, and exhausted state, however, supposing it to arise from fatigue, implies a far longer and more continued flight than that from Norway, which, even supposing that they prefer, for some unknown cause, the western to the eastern shores of our island for their first appearance, is quite a trifling affair for most birds ; the distance, in a straight line, from the nearest point of Norway to the Land's-End being not more than seven or eight hours' journey for a bird whose rapidity of flight, when once fairly on the wing, is exceeded by few, if any, of the feathered race. It is obvious that so short a space of time is by no means sufficient to occasion fatigue, and still less, to lower the bodily condition, so as to affect the health of the bird.

But some may be ready to say, How know we that their flight is short? If they land on the west coast, may they not have crossed the wide Atlantic, and taken their departure from America? The answer is decisive of the contrary, the American Woodcock being entirely different from the British 
species. Having said thus much, we think some light may be thrown upon this obscure subject, by examining the above facts, and comparing them with some others, which are equally well known about Woodcocks.

In the first place, their lean, poor, and often scurfy condition, is not owing to exhaustion from length of flight; because, not only those which are found on the eastern coast, are usually very weak and reduced, but even those which are killed in Norway, before the migration has taken place, are found to be already in an emaciated state, and infested with vermin. In a short time, however, after frequenting their favourite haunts in our country, they become fat and plump, and then, as the season advances, they usually fall off, and the flesh of those that have been accidentally met with in the Summer is found to be hard and dry. That their fatigue may be the consequence of this previous debility is therefore not improbable: but it is not the cause. We will next touch upon their first appearance on our western instead of our eastern shores. It is a generally prevailing opinion that the state of the moon has much to do with the arrival and departure of Woodcocks; but more experienced naturalists have remarked that the wind, and not the moon, determines the time of their arrival, which is usually in misty weather, during the northerly or easterly winds. Supposing then that, about dusk, - and we know that the migrations of Woodcocks usually, if not invariably, take place at night-a flight of them starts from Norway, with a sharp northerly or easterly wind helping them, in adding to the natural velocity of their own most rapid flight, which has been estimated at one hundred and fifty miles per hour,--high up in the air, as we moreover know they fly,- the land below them, when they had crossed the Channel, would be invisible, and, borne upon the breeze, by the time they had continued their flight till early dawn, where would they be? Look to the map, and we shall find them, after their flight, at the rate of one hundred and twenty, or one hundred and fifty miles per hour, far away to the westward of Ireland, hovering over the Atlantic, steering for America; and that they are found at sea, we learn from the 
most respectable authority. A Cornish gentleman, sailing at a distance from land unusual for birds to be seen, discerned a bird high in the air, which, gradually descending, alighted on the deck, and proved to be a Woodcock. During a heavy gale, two others sought shelter on board a line-of-battle ship cruising in the Channel; and a naval officer informed us, that after a stormy night, several leagues to the westward of the Land's-End, when shaking the reefs out of the topsails, early in the morning, several Woodcocks were discovered in the rigging. With these premises before us, we think the mystery is, if.not entirely removed, at least much lessened, and a first landing on the western shores of Ireland, and the Scilly Islands, fairly and easily accounted for; the birds, naturally, as day approached, sinking downward to the nearest land.

That their flight, too, is rapid to the last, is farther proved by many instances having occurred of their killing themselves by flying against the glass of the Eddystone Light-house. Of their speed, indeed, some estimation may be formed, by one which struck against the plate-glass of a light-house, on the coast of Ireland, and broke a pane cast for the place, of unusual strength, viz., from $\mathrm{A}$ to $\mathrm{B}\left(\begin{array}{ll}\mathrm{A} & \mathrm{B}\end{array}\right)$, being more than three-eighths of an inch thick; the blow was so violent, that in addition to the glass being broken, the bird was found dead, with its breast-bone, and both wings also, smashed. Again, no less than five Woodcocks have killed themselves, in a similar manner, against the plate-glasses of the South-Stack Light-house, in Anglesey.

There was a time when Woodcocks might be almost said to be as plentiful as Wood-Pigeons are now; at least, they abounded to such a degree, that catching them was a regular trade: and so late as fifty years ago, they were sold at the moderate rate of from six to seven-pence a couple; but, like Starlings, Wood-Pigeons, and several other birds, they have of late years diminished in numbers.

As far as concerns Woodcocks, this, indeed, may easily be accounted for. In the first place, the demand, not for the full-grown birds merely, but for the eggrs, has greatly increased in Sweden, where they are as highly esteemed, and therefore 
as diligently sought for, as Plovers' eggrs with us. Thus, not a twentieth part of the former abundant numbers may now be reared, and of course, our annual Winter supply must proportionably decrease. But other causes have operated, in this country, still further to diminish the number of those which, under former circumstances, might be inclined to come over -namely, the great decrease of our woodlands ; the improvements in agriculture, by which their haunts have been drained or broken up; and, lastly, the increase of population, which, more than we are aware of, deters shy and solitary birds from remaining in neighbourhoods to which they formerly resorted. It was a favourite amusement, in former days, to catch Woodcocks, by dozens, of a night, in places where now not a dozen could be taken in a whole season. Large openings were left, or rather made, in woods, which at night were filled up with wide-spreading nets, fastened by pulleys to tall branches; a man stood concealed on one side, with a rope running through the pulleys, who, the instant he felt a cock touch the net, let it go, and the net falling over the bird, secured the prize. In the fine old beech wood, which we have already more than once alluded to, numbers were formerly taken, in a wide space, still known by the name of the Woodcock-glade, where many a Winter's night might now be spent unprofitably and possibly without meeting with a single bird. Another mode of catching them was by springes - a sort of trap, formed of an elastic stick, to which was fastened a horse-hair noose, put through a hole in a peg, fastened into the ground, to which a trigger was annexed; and in order to induce the Woodcock to walk towards the noose, a little fence was extended on each side by small sticks, set up close enough to prevent the bird passing between: these all met at the trap; so that, by this funnel-shaped fence, the Woodcock in feeding is compelled to pass through the narrow passage, with every chance of being caught by the legs. The elastic stick, in flying up, of course draws the noose quite tight, and effectually secures the Woodcock; but common horse-hair nooses will often answer the purpose, particularly if the little avenue fence is placed to lead the 
birds to the snare. We remember seeing in the South of France a tolerably large fallow-field actually sown with horsehair nooses, placed in straight lines, for catching Larks and other small birds; so closely were they set, that it was almost impossible for any small bird to alight in the field, and run a few feet, without being caught. The guiding avenue consisted merely of two small twigs, curved outwardly on each side : this external curve acting as a sufficient check to the bird's free passage, excepting along the line of snares. The labour of the person who had given himself the trouble of setting them, was, we understood, amply repaid by the numbers taken by this simple process.

We shall conclude what we have to say on the Woodcock, or, as it is scientifically termed, the Scolopax genus, by a few remarks upon one species, which was formerly an object of adoration amongst the ancient Egyptians, during life; and, after death, was honoured with funeral rites equal to those bestowed upon their kings and princes, being entrmbed in sacred monuments, and still found, as mummies, embalmed with precious ointments, and divers kinds of spices. It was to this bird that St. Paul chiefly alludes, in Romans i. 23, when he accuses the Gentiles of changing the glory of the incorruptible God into an image made like to corruptible man and to birds; and it was this bird, again, which formed part of the idol abominations alluded to in the vision of Ezekiel. It is called the Ibis religiosa, or Sacred Ibis, and is peculiar to Egypt, and the countries bordering on the river Nile,-coming down from Ethiopia on the increase of the river; and from this circumstance is named by the Arabs, Abou-mengel, (Father of the Sickle,) in allusion to the fruits of harvest, which are derived from the inundations of the Nile. It feeds on the smaller reptiles, and, as the Arabs still say, on serpents, which has by many been supposed the sole cause of its being worshipped by the Egyptians; but this appears doubtful, and we are inclined, with some other high authorities, to attribute their respect for it to another cause-namely, a fancied resemblance to the moon, whether from the curved and crescent shape of its 


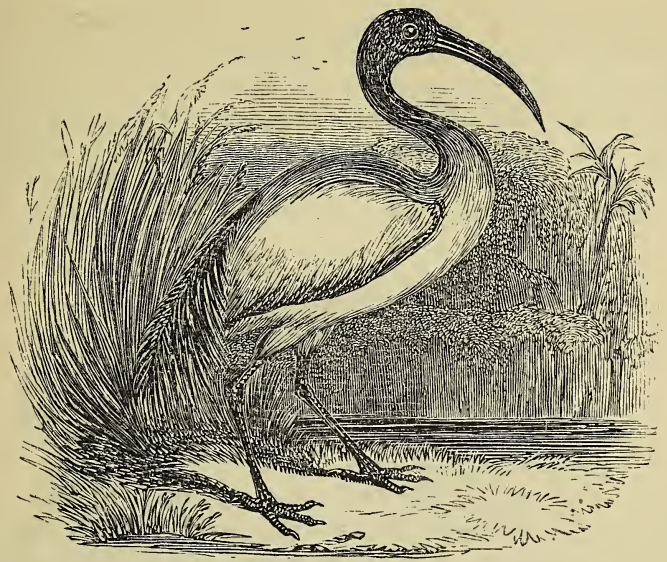

The sacred Ibis.

beak, or from the contrasted colours of black and white, which, in the opinion of an ancient writer* on the subject, made it appear as if marked with a crescent. Now the moon, as well as the sun, was a known object of worship amongst many of the heathen nations, and more especially the Egyptians. Thus Job alludes to it, when he says, If $I$ beheld the sun when it shined, or the moon walking in brightness, and my heart hath been secretly enticed, or my mouth hath kissed my hand; this also were an iniquity to be punished.-Job xxxi. 26, \&c. The reason why the Egyptians more particularly venerated the moon, was, because they considered it, in its crescent form, as bearing some resemblance to the boat, or ark, in which Noah was preserved in the Flood, and in their language, accordingly, they used the same terms for the moon and the ark.

Looking upon the Ibis, therefore, as a type or emblem of the moon, and again associating its appearance on the

* Plutarch, de Iside et Osiride. 
banks of the river Nile, at a season reminding them of the approach of those abundant crops produced by the inundations of their sacred river, we can easily see the reason why the priests of the country held it up to the ignorant people as a bird sent from Heaven, and therefore to be worshipped in life and honoured in death.

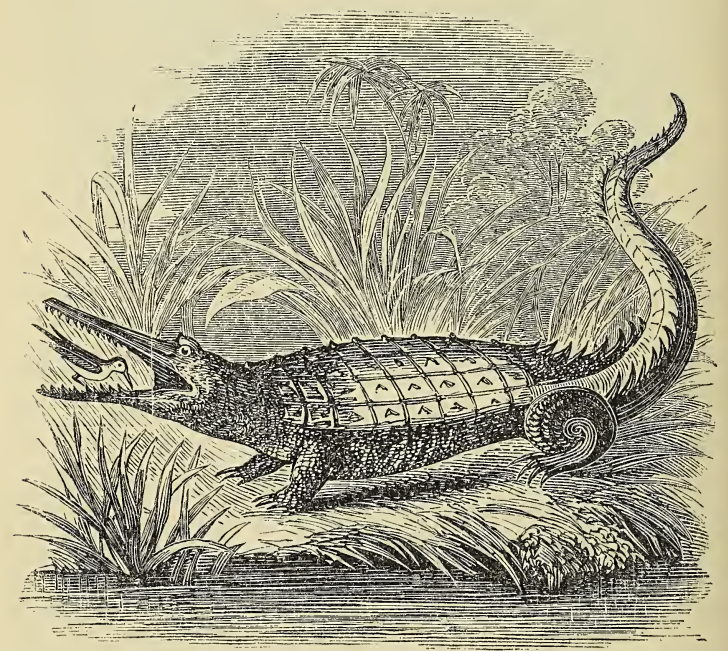

Egyptian Flover and Crocodie. 


\section{CHAPTER XVI.}

Palmipedes ; Web-footed. — Serrated or Tooth-billed. — Geese ; Flocks of-How managed-Plucking - Singular attachment - Sagacity - Courage of. — Tree-geese. — Swans ; Muscular strength-Courage.-Black Swans. - Trade in Swan-quills.

\section{Table XXVI. (See p. 21.)}

Order 6. Palmipedes (Web-footed.) Tribe 1. Serrirostreses, (or Tooth-billed.) TABLE XXVII.

WE now come to the last order, consisting of those birds which are evidently calculated for swimming; having their toes connected with a web, extending nearly to the nails. There are, however, some few not classed here, although they are undoubtedly web-footed,-for instance, the Avosets and Flamingoes; but these, as has been already noticed, are not swimmers, their webs being of use only in supporting them as they tread lightly over marshy grounds. The first genus is that of the Anas, comprising Geese and Ducks, whose beaks all, more or less, partake of the toothed or serrated character, represented in the plate of the ShovellerDuck's bill (page 30), for the obvious purpose of feeding in the manner there mentioned.

Notwithstanding certain points of resemblance, connecting Swans, Geese, and Ducks under one head, there are, nevertheless, some peculiarities in each, fully justifying the various subdivisions adopted by modern naturalists; by whom they have been, accordingly, separated into four sections,-Geese, Swans, and Ducks of two sorts, - one of which has the hindtoe furnished with a loose membrane; these latter chiefly frequent sea-shores or salt-marshes.

At the head of this list stands the Goose, and with reason, considering how valuable a bird it is, and how many benefits we derive from it in divers ways. Those who live in the fen countries of Lincolnshire look to the produce of 
their flocks, in the shape of quills and feathers, exclusive of the body considered as an article of food, as a source of profit to them almost as great as the shepherd derives from his flocks and herds. These Geese are reared and protected with a care and attention of which those who have not witnessed it can form no conception.

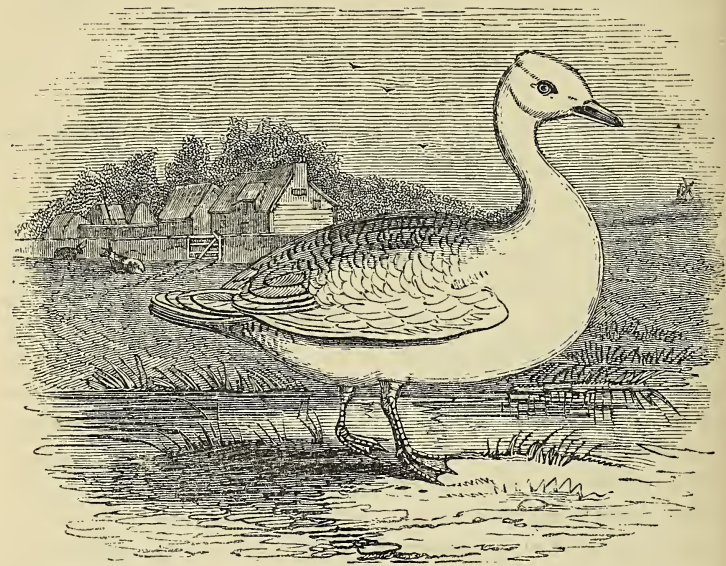

Goose.

It may, indeed, be doubted whether, under certain circumstances, Geese, in a profitable point of view, may not be considered as nearly equal to sheep. The latter, it is true, furnish a lucrative trade to weavers and manufacturers, as well as the farmer who feeds them; but the Goose affords no small item in the ledger of the upholsterer and the stationer, as well as the poulterer, in addition to thousands of acres of marsh land, which, but for this nseful bird, would remain for ever worthless, or at best, supply a scanty and precarious pittance. A slight sketch of the mode of managing a flock in Lincolnshire may not be uninteresting. A single person will keep a thousand old Geese, each of 
which will rear seven; so that, at the end of the year, if fortunate in rearing, he will be possessed of seven thousand. During the breeding season, these birds are lodged in the same houses with their owners, and even in their bedchambers; three rows of wicker pens are placed one above another in every department; each Goose having its separate lodge divided from the others, of which it keeps possession during the time of sitting. A person called a gozzard attends the flock, and twice a day drives the whole to water, then brings them back to their habitations, helping those that live in the upper stories to their nests, without ever misplacing a single bird. They are, as we have observed in treating of Feathers (p. 67), plucked frequently, we believe not less than five times a year; the first plucking being on Lady-day, for feathers and quills; the remaining pluckings, between that time and Michaelmas, being for feathers only. The old Geese submit with tolerable patience to this barbarous operation, but the young ones are noisy and unruly. Even goslings of six weeks old are not spared; their tails being plucked, as it is said, to habituate them to future plucking.

When ready for the London market, flocks, from two to nine thousand in number, are sent off, travelling slowly from three in the morning until nine at night, during which time they will accomplish, on an average, about eight or ten miles.

Those who live near commons can turn the rearing of a few Geese to good account, and might reap still greater advantages if they paid due attention. If well kept, a Goose will lay not far short of one hundred eggs a year. The French, who understand the management of poultry much better than we do, put their Goose-eggs under large hens of common fowls, in the proportion of from four to five eggs to each; and under Turkeys, to which they give nine or ten. When the Goslings are hatched, they are kept in a warm place for about four or five days, and fed on barley-meal, mixed, if possible, with milk, and then they will begin to graze. 
Thus much for the attention due to the Goose for its pecuniary worth ; but beyond this, it has qualities, we might almost say, of the mind, of a very singular character : we mean, the unaccountable constancy and affection which it has been known to show not only to its own species, and to other birds and animals, but more particularly to man. And it is not improbable, that these qualities, which, as we shall soon show, were known to the ancients, might have rendered it an object of high esteem, and even in some cases sacred, as, for instance, it was to Juno, the queen of their idol gods. In addition to which it has other qualifications, proving the fallacy of the proverbial libel, " as silly as a Goose." Thus, its watchfulness at night-time has always been noted, and it certainly is endowed with a strong organ of self-preservation, for, as it has been well observed, you may drive over cat, dog, hen, pig, or even pigeon, but few, if any, can record an instance of driving over a tame Goose; and as for Wild Geese, there are no animals, biped or quadruped, so difficult to deceive or approach, their sense of hearing, seeing, and smelling being so extremely acute; independently of which, they appear to act in so organized and cautious a manner, when feeding or roosting, as to defy all danger. Sportsmen could give iṇstances without number of their utmost skill being of no avail in attempting to approach these birds; either a careless step on a piece of gravel, or an eddy of wind, however light, or letting them perceive the smallest portion of their persons, has rendered useless whole hours of manœuvring.

We shall briefly illustrate this part of our history, alluding to their instinct and affection, by examples drawn from various sources, ancient as well as modern, corroborating them with a case which occurred in our own neighbourhood.

We have just mentioned that this bird was held sacred to Juno, and we have good reason for supposing, that by the Gauls, an ancient and barbarous people, inhabiting the northern and western parts of Europe, it was held in almost equal estimation. How long this continued we do not 
know; but, at the time of the Crusades, that famous expedition undertaken by our ancestors in the reign of Henry the Second, about six hundred and fifty years ago, a Goose was carried as a standard at the head of one of those irregular bands proceeding from Europe to Asia, with the design of rescuing the city of Jerusalem from the hands of the Saracens. Of its attachment to the human race, Pliny, an ancient Roman writer, gives several instances ; one only we select, as closely resembling that with which we shall conclude. A person named Lacydes, a philosopher, had a Goose which took so strong a fancy to him, that it would never willingly leave him by night or day,-wherever he went, the Goose was his companion; if he went abroad and walked in the public streets, the bird followed him, and, in his own house, always forced itself into his presence. The philosopher, struck with this constant and strange attachment, seems to have considered it as in some way or other connected with religious feelings, and accordingly, when at last he died, he was at the expense of bestowing upon it a magnificent funeral.

Our next instance occurred in Scotland; a Goose, a year old, formed a similar attachment to a person in Elgin, and would follow him any distance, even through the crowd and bustle of the main street. One day, when going down this street, its master went into a hair-dresser's shop to be shaved, whereupon the bird waited patiently till the operation was finished, and then accompanied him to the house of a friend; after which it proceeded home with him. Change of dress seemed to make no difference in the bird's powers of distinguishing its master, for in whatever dress he appeared, the Goose recognised him, and whenever he spoke, it responded by a cry expressive of satisfaction.

Another similar case is on record in Germany : an aged blind woman, who probably might have been in the habit of feeding it, used to be led every Sunday to church by a Gander, taking hold of her gown with its bill; when she had seated herself, it retired to graze in the churchyard till she came out again, when it led her home. One day, the clergyman called at her house, and, expressing his surprise 
to her daughter, that her mother should venture abroad, she replied-" OOh, sir! we are not afraid of trusting her out of sight, for the Gander is with her." We frankly own, that so strange and improbable do the above stories appear, that we should neither have inserted, nor paid them the slightest attention, had we not the following testimony to their credibility, for the accuracy of which we can vouch ; and deeply do we regret, that a better fate did not await so extraordinary a bird, which, under more intelligent observers, might have afforded opportunities of ascertaining the extent of so unusual a development of affection.

A farmer in Cheshire possessed a flock of Geese, one of which, at the end of about three years, without any apparent cause, began to show a peculiar partiality for its master. It first appeared on the bird's quitting its companions in the barn-yard or pond, and stalking after him. These symptoms became daily stronger, and in a short time, wherever the farmer went, whether to the mill or the blacksmith's shop, or through the bustling streets of a neighbouring manufacturing town, the Goose was at his heels. So perseveringly did it follow his steps, that if he wished to go out alone, he was under the necessity of fastening up the bird.

The farmer was in the habit of holding his own plough, and, on these occasions, the Goose as regularly passed the day in the ploughing field, walking sedately, not with the usual waddling pace of its fellow Geese, but with a firm step, head elevated, and neck erect, a short way before him, in the line of the furrows, frequently turning round and fixing its eyes intently upon him. When the length of one furrow was accomplished and the plough turned, the Goose, without losing its step, adroitly wheeled about, and thus continued its attendance till the evening, and then followed its master home; and if permitted, would mount upon his lap as he sat by the fire after dark, showing the strongest signs of affection, and nestling his head in his bosom, or preening the hair of his head with its beak as it was wont to do its own feathers. Sometimes the farmer would go out shooting, and no sooner had he shouldered his gun, than his companion was at its post, following him as before, in spite 
of every obstacle;- “"getting over," to use the man's own words, "the fences as well as I could myself." All this, it should be observed, continued, not only without any encouragement on the part of the farmer, but even in spite of every discouragement on his part. How long it would have continued, or to what extent, we lament to add, he effectually precluded the world from knowing; for, with an unpardonable inattention to so truly a wonderful case, in addition to equally unpardonable superstitious fear, he took it into his head, that this mysterious affection of the poor Goose foreboded some evil; and in a moment of alarm, he killed the faithful bird.

Thus much for the attachment of the Goose to man; and many equally striking instances might be adduced, of a similar attachment to animals. The two following anecdotes show the mutual affection which may exist between this bird and the dog.

A species of the armed, or Cambrian Goose, a native of Africa, belonging to a person in Scotland, was observed for some time to pay particular attention to a dog which was chained up; and what was singular, this dog had invariably manifested a great dislike to poultry, never allowing them to come within reach of his chain. But, in this case, he laid aside all his former animosity, and received his new acquaintance with every mark of affection. The Goose, finding she had nothing to fear from her canine friend, would enter his kennel,--in the centre of which, among the straw, she made her nest, and deposited her eggs, which was not known till one of the family mentioned that the Goose slept in the dog's bosom. The singularity of the circumstance led to an examination of the box (but not without the greatest reluctance on the part of the dog, who appeared determined to protect what was left to his care). On removing the straw, five eggrs were discovered in a fine bed of down and feathers. The dog was in the habit of going into his box with the greatest care, for fear of injuring the eggs.*

Phil. Mag., vol. LVI. 
A Canada Goose was also observed to associate itself, in a similar manner, with a house-dog; and would never quit the kennel, except for the purpose of feeding, when it would return again immediately. It always sat with the dog, but never presumed to go into the kennel, except in rainy weather. Whenever the dog barked, the Goose would cackle, and run to the person at whom she supposed the dog was barking, trying to bite him by the heels. Sometimes she would attempt to feed with the dog; but this was not allowed by the dog, who treated his faithful friend with as much indifference as the farmer above mentioned. The Goose would never go to roost at night with her natural companions, unless driven by main force; and when in the morning she was turned into the field, she would never stir from the gate, but sit there the whole day in sight of her favourite. At last, orders were given that she should be no longer molested, but suffered to accompany the dog as she liked; being thus left to herself, she ran about the yard with him all the night; and whenever the dog went out of the yard, and ran into the village, the Goose as constantly accompanied him, contriving to keep up with the assistance of her wings; and thus, running and flying, would follow him to any distance. This extraordinary affection of the Goose towards the dog, which continued till his death, two years after it was first observed, is supposed to have originated from his having once accidentally saved her from a fox. While the dog was ill, the mourning bird never quitted him day or night, not even to feed; and it was apprehended she would have been starved to death, had not a pan of corn been placed every day close to the kennel. At this time she generally sat close by him, and would not suffer any one to approach, except the person who brought the dog's or her own food. The end of the poor bird was very tragical; for when the dog died, she still kept possession of the kennel ; and a new house-dog having been introduced, which in size and colour resembled that lately lost, the poor Goose was unhappily deceived; and going, as usual, within his reach, the new dog seized her by the throat, and killed her on the spot. 
We knew a similar instance of a strong attachment formed between a Raven and a large otter-dog. The Raven had been taken when young, and reared in a stable-yard, where the dog was kept chained up. A friendship soon commenced, which, increasing from little to more, in time ripened into a most extraordinary degree of intimacy. At first, the bird was satisfied with hopping about in the vicinity of the kennel, and occasionally pecking a hasty morsel from the dog's feeding-pan, when the latter had finished his meal; finding, however, no interruption on the part of his firiend, the Raven soon became a constant attendant at meal times, and taking up his position on the edge of the dish, acted the part of a regular guest, and partaker of the dog's dinner, which consisted usually of meal and milk, with occasional scraps of offal meat, a piece of which the bird would often snatch up, almost from the very mouth of the dog, and hasten beyond the reach of his chain, as if to tantalize his four-footed friend, and then hopping towards him, would play about and hang it close to his nose, and then as speedily, at the moment the dog was preparing to snap it up, would dart off beyond the reach of the chain. At other times he would hide the piece of meat under a stone, and then coming back, with a cunning look, would perch upon the dog's head. It was observed, however, that he always ended his pranks, by either sharing, or giving up the whole piece to his friend, the dog.

The intimacy continued for a length of time, and terminated only with the death of the poor Raven, who was killed by a boy throwing a stone at it; for which he was very properly dismissed from the service of his master. The author would here suggest the propriety of parents and teachers losing no opportunity of instilling into the minds of children a feeling of kindness and benevolence to the brute creation. He has again and again witnessed with pain the utter absence of these feelings in children, whose daily lessons at school from the Bible ought to have been attended with different effects,- one instance amongst the thousands that might be adduced, of the facility with which religious truths can be taught by a routine and common-place process, and by 
which, though the memory is impressed, the heart may remain altogether untouched and uninfluenced.

Very different from the character and disposition of the idle and heedless boy, who killed this poor bird, was the conduct of a dog, (we do not now recollect whether it was the Raven's chief friend, the otter-dog, or another,) by whom its life had been a short time before preserved. By some accident the Raven had fallen into a tub of water, and either weakened by struggling, or unable to get out, owing to its feathers being soaked with water, it was nearly drowned. The dog, chained at a short distance, saw the poor bird's danger, and dragging his heavy kennel towards it, reached his head over the side of the tub, and taking the drowning Raven up in his mouth, laid him gently on the ground, where he soon recovered, to die by the hand of the boy, who, though he might have known by heart, had never learned to feel in his heart the golden precept, of "doing to others as he would be done by."

Another instance of attachment, though originating in a quadruped, yet so closely connects itself with the subjectmatter before us, that its insertion needs no apology. A cat having kittened between the tiles and roof of an out-house at Earley Court, in August, 1836, was a short time afterwards accidentally killed, and two out of three of her kittens were caught in a trap placed there for that purpose; the third, however, remained in its hiding-place, eluding all attempts to catch it, when, to prevent its being starved, (as it was too young to feed itself,) a sort of platform was fixed against the tiles, and food and milk placed within its reach. It so happened that a brood of chickens was in the habit of attending the spot near the kitten's quarters, who by degrees approached them, at first with great timidity, but at last, bolder grown, it ventured to lie down amongst them, while they were seeking their food, and following wherever they went. It was very amusing and curious to see the kitten soon, instead of following, leading its forces, consisting of (at least) twenty hens, chickens, \&c., about the grounds, sometimes catching at their feet, as if going to bite them, and they pecking at the kitten 
in return; sometimes hiding behind a bush, or concealing itself in the shrubs, and springing unexpectedly in the midst of them, and then purr and rub itself against their sides. One pullet, in particular, was an especial favourite ; it accompanied her every day to her nest, which was under the boards of an out-house, and would then lie down at a short distance. The person who first noticed this circumstance, was in the habit of feeding the kitten, and it was therefore less shy with him than any one else; he had observed it in the position described without perceiving the pullet, but when he did, he was induced to watch whether it remained there, after she had left her nest. He at length observed her fly off and join the other fowls, when the kitten immediately left its place and followed the pullet, setting up its tail and purring as if much pleased. It however did not confine itself to one set of chickens only, but every fresh brood excited its interest, and was more or less taken under its protection, the parent hen not appearing the least alarmed.

The Canada Geese appear to be peculiarly susceptible birds, and will sometimes make up by imagination or fancy what is deficient in reality. Thus, a Canada Gander in a nobleman's park, near Windsor, having no mate, for two Springs regularly mounted guard opposite a drawbridge, in front of a thicket, where, it was clear, he imagined there was a nest, and defended the approaches very courageously, continuing this ideal defence till the first brood of ducklings appeared from some other quarter, which he immediately took under his protection; and in the second year he thus actually chaperoned twenty-five. It should be added, that there was no nest of any kind whatever within the precincts which he so strenuously guarded.

But if, in this case, we may smile at the old Gander's fancy and credulity, in believing eggs to be hatching where none were laid, we can quote another, showing that a Goose is occasionally possessed of a keen sense, enabling her to detect imposition, and distinguish her own eggs from others closely resembling them. A Goose, belonging to a clergyman in Cheshire, was set (as it is termed) on six or eight 
eggs. The dairy-maid, thinking these too few for so large a bird to cover, added an equal number of Duck eggs. The next morning she went as usual to see if all was right, when, to her great surprise, she found the Goose quiet on her nest, but every one of the Duck eggs picked out, and lying on the ground. Her mistress directed her to replace them, which was accordingly done; but the next morning, on going again to examine the nest, she found all the Duck eggs, as before, moved off, and lying round about the nest; the Goose eggs remaining under the sitting bird in perfect order. How long she would have persevered in removing them is not known, as, for fear of driving the Goose from her nest, the experiment was not repeated.

When once attached to each other, they appear to be very constant; in proof of which, a person having marked five separate Ganders, and five separate Geese, with which they had paired, found that, for three successive years, when he attended to them, each regularly selected his companion of the former year, and continued faithful to her. Why the Goose has been so generally pointed out, proverbially, as the most foolish of birds, it is difficult to say; for the above, as well as the following instances, would lead us to believe that they are endowed with a larger, rather than a less, portion of sense than other birds.

An old Goose, which had been for a fortnight hatching in a farmer's kitchen, was perceived on a sudden to be taken violently ill. She soon after left the nest, and repaired to an out-house, where there was a young Goose of the first year, which she brought with her into the kitchen. The young one immediately scrambled into the old one's nest, sat, hatched, and afterwards brought up the brood. The old Goose, as soon as the young one had taken her place, sat down by the side of the nest, and shortly after died. As the young Goose had never been in the habit of entering the kitchen before, the fact can only be accounted for by supposing that the old one had some way of communicating her thoughts and anxieties, which the young one was perfectly able to understand. We give this anecdote on the authority 
of a Mr. Brew, who states it to have occurred at Ennis, in July, 1828.

So strong are the affections of these loving birds, that some who have exposed themselves to their vengeance have occasionally found themselves fearfully worsted. A Game Cock, near Ashford, in Kent, priding himself, no doubt, on his prowess, happened, a short time ago, to take offence at a Goose during the time of incubation; and, attacking her with great fury, pecked out one of her eyes, and destroyed several of her eggs. An old Gander, seeing the danger to which his mate was exposed, flew to her assistance, and many desperate battles took place. One day, in his absence, the Cock renewed his attack upon the Goose; when the Gander, hearing the bustle, hurried up, and seizing the Cock, dragged him into the pond, where he ducked him repeatedly, and finally drowned him.

Another somewhat similar instance occurred at Astbury, near Congleton, in Cheshire. Several Geese were feeding near a barn, where some men were threshing, and a Sparrow near them, when a Hawk suddenly pounced upon the latter, and would have inevitably have carried it off, had not the Gander flown to its rescue, and with its beak struck the Hawk so violent a blow, that it was stunned, and taken up by one of the threshers. The Goose is, in truth, by no means a cowardly bird, and will often, when excited, defend himself very courageously,-a quality of which the Russians seem well aware, as it is not an uncommon thing in that country, instead of training up Game Cocks for fighting, to have what are termed Goose-pits, where they are regularly trained for the sport. The birds are taught to peck at each other's shoulders, so as to draw blood; and well-trained Ganders have been known to sell as high as twenty pounds, and betting upon them runs very high. This cruel sport takes place in March.*

Our domestic Geese are descended from the marsh or fen Goose (Anser palustris), which, though originally a wild 
species, is more easily tamed than some others, particularly if taken young. Not but that some of this race may be domesticated. In America, where vast flights pass to the northward to breed, the people shoot them in great numbers; and as many, owing to their wide spread of wing, are often merely pinioned, they are kept alive, and in process of time have been made so tame, that having been let out in the morning, they returned in the evening. Several have been thus kept for many years; but, although they constantly associated with the farm-yard Geese, they were never known to breed with them. Under particular circumstances, a wild Goose has, indeed, been known to throw itself under the protection of man. Thus an officer settled on a farm near the Missouri, in North America, one day, when walking near the banks of the river, observed a large Eagle frequently darting towards the water, and then rising again. On a near approach, he perceived that its object was to take a wild Goose, which had alighted on the water, and which was diving to avoid so powerful an enemy. Its efforts, however, appeared to be in vain, and after diving again and again, and as often rising to get breath, it became nearly exhausted; when suddenly turning, it made for the shore with all speed towards the officer's house, where two men were at work; and, as soon as it had landed, walked leisurely up to them, permitting itself to be taken without attempting to escape. It was completely exhausted, but soon recovered, and within three days seemed quite contented, and confident of protection.

Amongst other species of wild Geese, there is one called the Bernacle, or Tree-Groose (Anas erythropus), which we shall mention on account of the extraordinary origin imputed to it, not only by ignorant, but even by some better informed people, in former days; and which may be adduced as one, amongst very many instances, of the advantages of knowledge in separating truth from error.

It will scarcely be now-a-days believed, that this Bernacle, or Tree-Goose, actually derived its name from a very general belief, that, instead of being hatched, like other 
birds, from an egg, it was produced from a shell which grew on trees and rotten wood; and the shell was, therefore, called the Goose-bearing shell (Lepas anatifera). For this foolish idea there was no other foundation than pieces of wood and decayed trees being often found in parts of the sea frequented by these Geese, all covered over with these shells, which seem to grow upon little stalks; and as the feelers of the fish within it are feathered, or fringed, they were supposed to be the downy covering of the young Goslings.

As a curious specimen of ignorant reasoning and credulity, we shall extract an account, written by the sage Gerard, as he was called, author of a well-known book, called GERARD's Herbal, or History of Plants. This author was born at Nantwich, in Cheshire, and lived in the time of Queen Elizabeth. " There is," says he, "a small island in Lancashire called the Pile of Foulders (on the west side of the entrance into Morecambe-bay, about fifteen miles south of Ulverston), wherein are found the broken pieces of old and bruised ships, and also the trunks and bodies, with the branches of old and rotten trees, cast up there likewise; whereon is found a certain spume, or froth, that in time breedeth unto certain shells, in shape like those of the muskle, but sharper pointed, and of a whitish colour, wherein is contained a thing in form like a lace of silke, finely woven as it were together; one end whereof is fastened unto the inside of the shell, even as the fish of oisters and muskles are; the other end is made fast unto the belly of a rude masse or lump, which in time cometh to the shape and form of a bird: when it

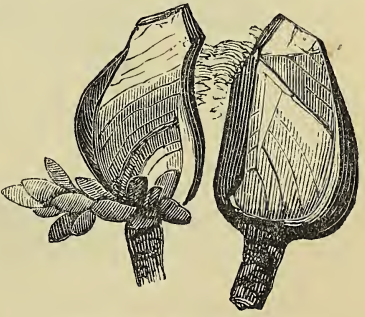

Bernacle Goose-shell.

(Lepas anatifera.) is perfectly formed, the shell gapeth open, and the first thing that appeareth is the aforesaid lace or string; next 
come the legs of the bird hanging out, and as it groweth greater, it openeth the shell by degrees, till at length it is all come forth, and hangeth only by the bill; in short space after, it cometh to full maturitie, and falleth into the sea, where it gathereth feathers, and groweth to a fowl bigger than a Mallard, and lesser than a Goose, which the people in Lancashire call by no other name than a Tree-Groose; which place aforesaid, and all those parts adjoining, do so much abound therewith, that one of the best is bought for threepence."* So fully convinced was the sage Gerard of the "truth hereof," that he closes his account with an invitation to all who doubted the fact to apply to him. "If any doubt, may it please them to repair unto me, and I shall satisfie them by the testimonie of good witnesses." These shells are represented in the preceding figure.

Of Swans, we have three sorts: one, our well-known tame

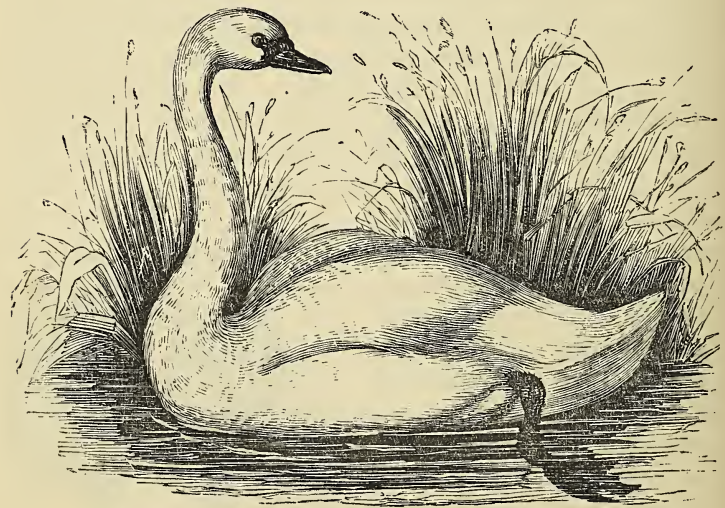

The Swan

species : the two others wild, called Hooper, Whooper, or Whistling Swans, from their loud, hoarse, and shrill cry, 
which has been expressed by whoogh, whoogh; but, harsh as this cry is, it is far from disagreeable when heard at a distance, and moderated in the breeze. The Icelanders, whose year may be said to consist but of one long day of Summer months, when they enjoy the light of the sun, and long night of Winter, when he never cheers them with his rays, compare this cry of the wild Swan to the sound of a violin; and when heard at the end of their long and dreary Winter, announcing the approach of genial weather, it is associated and coupled in their minds with all that is cheerful and delightful. Any person who has seen a common Swan lash the water with its wings, as it flaps along the surface, or has witnessed the force with which it strikes a boat, when the rowers approach the female with her young cygnets, needs not to be reminded of the strength of its enormous pinions, and their consequent effect upon the air, enabling the bird to fly, according to the report of those who have watched the immense flocks passing to and from the lakes and rivers of the British settlements in Canada, at a rate of not less than one hundred miles an hour,-a prodigious velocity, when we consider the size and weight of these noble birds. It is a prevailing opinion, amounting almost to a proverb, that a stroke of a Swan's wing will break a man's leg. How far this may be strictly true we cannot say; but having once seen the pinion of an old Swan laid entirely bare to the very bone, and feathers and skin stripped off, by an angry stroke on the gunwale of a boat, which it fiercely endeavoured to board, we think it not impossible. At all events, a blow of its wing can be inflicted to good and fatal effect, in case of necessity, as a crafty fox, wishing for a feast of Swan's eggrs, found to his cost. The female was sitting on her nest at one side of a river, when she observed a fox swimming from the opposite shore: rightly judging that she could encounter the enemy with much better chance of success on water than on land, instead of retreating, she boldly advanced to meet him, and, dashing forwards, so battered him with her wings, that he was soon killed, in the sight of several persons who saw the combat. 
Besides the Swans above mentioned, there is another peculiar to Australia or New Holland, entirely black; but, as they are tolerably hardy, it is not improbable that they may, in the course of a few years, be naturalized in England, and form an additional ornament to the rivers and lakes of our parks and pleasure-grounds. We have already noticed the peculiar manner adopted by young Coots for concealing themselves under water; and it has been ascertained, by those who have had opportunities of observing the habits of the Black Swan in its wild and natural state, that although it cannot dive, it contrives to immerse itself so deep in the water as to render its body nearly invisible, and thus avoid detection.

We have already noticed the trade carried on in Goose quills ; those of Swans being of course proportionably larger, and less common, are still in request, and preferred by some; consequently a considerable number find their way into the market, and fetch high prices. One of the principal sources of this trade is on the coast of the Black Sea, at its northwestern extremity, in the neighbourhood of Kinbourn, a Russian fortress, nearly opposite to Oczakof, at the point of a tongue of land, deeply indented with creeks and bays; and, as the country round is but thinly inhabited, wild birds abound. Amongst others, it is thronged with Swans, which select the long sandy headlands for the site of their nests. They assemble in numerous flights about these creeks, during the breeding season. Aware of this, the people who collect their feathers start in pursuit of them, the old birds being then busy hatching and breeding their young. The feathers are drifted on shore by the tide, and collected. The produce is sold to dealers, who come from the neighbouring towns of Oczakof and Cherson, and eagerly bid against each other. Sometimes the quills will fetch as much as three pounds per thousand, though the usual price does not exceed twenty-two shillings. They are also an article of trade amongst the people of the Crimea, who live near extensive morasses and marshes, as well as the peasants on the coast of the Sea of Azof, in the direction of Marapot. 


\section{CHAPTER XVII.}

Duck Tribe-Management of-Chinese Mode. - Wild-Ducks building in Trees-Affection of.-Eider Ducks-How Caught. -Duck Shooters.-Danger attending Decoys.

TT would lead us far beyond our limits to notice all the 1 Duck tribes, which are third on the generic list of this division; a few particulars must suffice. Much that has been said upon the treatment of Geese applies equally to Ducks, which, under judicious management, might be made a source of great profit to the cottager; and we are assured, on the authority of a practical rural economist, that water is by no means indispensable; so far from it, indeed, that, instead of being absolutely necessary, it is often injurious to the young, and that, in fact, they should never be suffered to swim till more than a month old; that, instead of allowing young Ducks to go out in the morning to eat slugs and worms, they should be kept up, since this food, notwithstanding their partiality for it, is injurious; and that grass, corn, white cabbages, and lettuces, cut when half ripe, and flung down in the haulm or stalk, will make the finest Ducks for the market and the table. When young, they should be fed upon barley-meal, or curds, and kept in a warm place in the night-time.

By attention and care, much more, we are persuaded, may be done in the general management, as well as improvement, of our domestic birds. We have been assured, for example, that the people in some parts of Buckinghamshire derive considerable profit from their peculiar skill in breeding and rearing Ducks. They contrive to reverse the order of nature, and by a restriction of food, or other means, prevent them from laying till October or 'November. Some weeks before the time they wish them to lay, they feed 
them with stimulating food; and when the eggs are ready, they are put under a hen, who is obliged frequently to continue on the nest till three successive broods have been hatched. When the young Ducks leave the shell, they are placed, near a fire, and nursed with great care. By these means many Ducklings are sent at Christmas to London, where they meet with ready purchasers.

Of all people in the world, the Chinese are said to be the most skilled in the management of poultry, particularly of Ducks, many people at Canton earning their livelihood merely by bringing them up; some buy the eggs and trade with them, others hatch them in ovens, and others attend on the young ones. The following is their plan:- they lay an iron plate on a brick hearth; on this they place a box full of sand, half a foot high, in which the eggs are put in rows; they box the cover with a sieve, over which they hang a mat. To heat them they make use of a particular sort of wood, which burns slowly and uniformly; at first, they give them but little warmth, increasing it gradually, and it becomes a strong heat by the time the eggs are hatched. If the heat is increased too much, the young Ducks are hatched too soon, and in that case they generally die in three or four days. The hatched young ones are sold to those who bring them up; and these try, in the following manner, whether they are hatched too soon or not. They take up the little Ducks by the bill, and let their bodies hang down: if they sprawl and extend their feet and wings, they are hatched in due time; but, if they have had too much heat, they hang without struggling. The latter often live till they are put to the water, which is generally eight days after they are hatched,--this turns them giddy; they get cramped, throw themselves on their back, and die in convulsions. They are carefully fed with boiled rice, mixed up with herbs and little fish, chopped small. When they are older, they are removed into a larger floating-pen, called a sampane, which has a broad bottom of bamboo, with a gallery round, above the river, and a bridge declining towards the water. An old and experienced step-mother is provided to lead them 
down, and attend them when feeding: these old birds are so well trained, that at the given signal in the evening, they return in the utmost haste with their young broods. This signal is a whistle, on the sound of which the whole flock sets itself in motion, waddling in regular order towards their boat. The first Duck that enters is rewarded with some favourite food; the last is whipped as an idler: so that it is a comical sight to see the last birds, as if knowing what will happen to the last of all, making efforts to fly over the backs of others, and get on board the boat in time to escape punishment.

We should be surprised to see our domestic Ducks perch amongst the branches of trees, adjacent to their roostingplaces, and there pass the night; but though this seems impracticable for our species, there are, nevertheless, many others of the wild sort, that not only roost perching, but rear their young in trees. Captain Cook was surprised to find the Whistling-Ducks doing so, near Endeavour River, in New Holland; and in various parts of the world similar nests are found in these unexpected situations.

In America, the Anas sponsa, or Summer-Duck, builds in the hollows of trees, at a considerable height from the ground, from which the young ones, soon after they are hatched, descend and make the best of their way to the water. The Wood-Ducks, also an American species, are continually to be seen, during the breeding season, flying between the upper parts of the Mississippi and the woods where they build. Our common Wild-Duck, in a similar manner (though, according to the general habit of those birds whose young leave the nest as soon as hatched, she generally deposits her eggs upon the ground), at times departs from this practice, and follows the example of the above foreign species.

In Sussex, a nest was found in an oak-tree, five-andtwenty feet from the ground; the old bird was sitting upon nine eggs, supported by some small twigs, laid crossways. 
In Derbyshire, a gentleman's gamekeeper observed a Wild-Duck fly out of a large oak, in which the year preceding had been a Hawk's nest. On examination, she was found to have laid two eggs in the old nest, completely repaired.

Another instance occurred at Madeley, in Staffordshire. In this case, the Wild-Duck took possession of a Rook's nest at the top of an oak-tree. The Drake was also seen to perch on a bough near her, and occasionally in her absence sat on the nest.

This is not a solitary instance of birds usually building on the ground, giving an accidental preference to another and apparently unnatural situation. At Caistor, in Norfolk, a Bantam Hen was observed to fly into the branches of a spruce-fir, and take possession of a Wood-Pigeon's nest, about fourteen feet from the ground; there she laid five eggs, and no doubt would have hatched her brood, had not the nest been unfortunately destroyed; neither would there have been any danger to the young ones, as it is a well-known fact, that chickens, soon after they are hatched, may fall from a height of several feet without sustaining any injury.

In the preserves of the Zoological Gardens, in the Regent's Park, London, we saw the nest of a Wild-Duck on the roof of a thatched cottage by the water-side. The keeper was ordered to keep a good look-out, in order to see how the young ones would contrive to reach the ground; but they eluded his watchfulness by disappearing one morning, when he and his family were absent at church. It is, indeed, difficult to account for the exceptions to the accustomed habits of Wild-Ducks: we should suppose, that naturally they would prefer a convenient spot close to the water, and in such places their nests are usually built. Once, indeed, to our surprise, a nest was found in a patch of high grass, within a few feet of the spot where a boat was drawn up; and either so closely had the Duck sat, or so cleverly had she timed her visits to and fro, that it was not till after 
some time discovered by a carpenter, who had been for three or four days on the spot, repairing the boat. But, from several other circumstances coming under our observation, we have reason to believe that they often build at considerable distances from the waters intended to be the permanent nursery for their brood. About a mile above this very sheet of water on which the boat was repairing, there is a hill covered with heather, fern, and plantations; and more than once at early dawn, about four o'clock, in June, broods of little dark Wild-Ducklings, just hatched, have been seen trotting down the road, leading from the hill to the water; and once we were surprised, on a Summer's morning, at seeing about a dozen of these active little nestlings running before our door; so rapid were their motions, that, notwithstanding every exertion, they contrived to elude observation, till they were tracked in the grass to a small pit about two hundred yards off, in a meadow.

They no doubt had been making for the mere, or larger sheet of water, from the spot above mentioned, but had lost their way. There is one species, however, which, in preference to trees or flat ground, selects a very unaccountable accommodation, namely, a rabbit-hole. This is the Sheldrake,-a bird by no means uncommon on many parts of our coasts. She selects, if possible, a burrow near the water, in which are laid sometimes sixteen eggs, which she carefully covers with the down of her body. The eggs may also be easily reared under hens, and the young ones may be kept in ponds. We have known several thus domesticated; but although many other species of Wild-Duck, under similar confinement, bred regularly, the Sheldrake never was observed to take any steps in preparing a nest.

In a nobleman's menagerie, we have heard, however, that they were induced to do so by simply burrowing holes about three or four feet deep, like rabbit-holes, in the bank, a foot or two above the water. The bird thus found her accustomed accommodation, and lost no time in availing herself of 
it. Ducks, too, like Geese, have a strong sense of affection; we cannot, indeed, produce instances so striking or so interesting as those related of the latter, but the two following instances show a similar tendency towards animal, as well as human beings.

A clergyman had a very fierce and noisy house-dog, within the length of whose chain it would have been dangerous for a stranger to have ventured; but notwithstanding his apparently savage disposition, a brood of Ducklings, reared in the yard in which he was kept, soon became so fond of him, that whenever, from his barking, they apprehended danger, they would rush towards him for protection, and seek shelter in his kennel.

A farmer's wife had a young Duck, which by some accident was deprived of its companions, and from that moment seemed to concentrate all its affections on her. Wherever she moved, it followed her so closely that she was in constant fear of treading upon and crushing it to death. As it grew older, its affections seemed to strengthen rather than diminish; it laid itself by the fire and basked on the hearth, and when noticed, seemed delighted; this continued till some other Ducks were procured, when, being constantly driven out of the house, it gradually associated itself with its more natural companions.

Another case was that of a pair of Muscovy Ducks which were landed at Holyhead, from a Liverpool vessel returning from the coast of Africa. The male was conveyed to a gentleman's house in the neighbourhood, and introduced to a flock of Ducks; but to them he manifested the greatest indifference, and was evidently pining at the loss of his mate, when one day she too was brought up and turned loose; for a short time, being engaged at a distance, he did not see her; but, when, on turning his head accidentally, he caught a glimpse of his well-known companion, he rushed towards her with an earnestness and affection which quite touched those who witnessed the meeting. Nothing from that moment would induce him to quit her, and he manifested his 
joy at the unexpected re-union, by twining his neck on hers, -nestling it under her wing, and gazing at her with eyes expressive of extreme delight and satisfaction.

There is another Wild-Duck deserving of mention from the value of the down upon its breast, which is carefully collected by those who rear these birds, and dispose of their produce at a very high price. The bird we speak of is the Eider Duck. And well may it have a warmer under-clothing than most other Ducks,--born and bred, as it is, amidst the most dreary and desolate region of the Frozen Seas, and abiding either solitary or in pairs near the ice, as far as possible from land, but assembling, at the breeding season, in vast numbers, on most of the islands in the North. As Iceland is one of their favourite haunts, we cannot do better than collect our particulars from a spot where they are probably better known than anywhere else. There, as they are rarely hurt or disturbed, they become surprisingly tame, and allow persons to walk amongst their nests. On approaching them, the Drakes, indeed, often take alarm, and plunge with great precipitancy into the water; but the Ducks generally remain sitting on their nests, or merely fly to the distance of a yard or two, and on an attempt to touch their eggs, return in a rage. Many of them suffer themselves to be handled, and can only be removed by actual force from their nests. In some parts of the island, where they are more particularly attended to, they build their nests on the roofs of the houses, and become quite familiar with the inhabitants. The nests are constructed of sea-weed, and lined with the finest down, plucked from their breasts.

As soon as it is observed that the first eggs are laid, they are removed, and the nests at the same time robbed of the down; and this is repeated a second or a third time; but it is generally found, that if they are robbed more than twice, they begin to desert the place, and if pillaged oftener, they quit it entirely.

A few days after the young Ducks leave the egg, they proceed to the water, under the guidance of their dam, who 
swims with them on her back to some distance, when, making a sudden dive, she abandons them to themselves, and reappearing, tempts them to come towards her; so that, on the first trial, they commonly become expert swimmers. When the breeding-season is over, they generally stand out to sea; yet numbers are seen frequenting the bays and creeks about the coast.

The eggs furnish excellent food to the inhabitants, and the down is bought on the spot at about thirteen or fourteen shillings a pound, by merchants, who send it to different parts of the world. It is used chiefly for making bed coverings, on account of its exceeding lightness as well as warmth ; a large bed-quilt sometimes weighing only five pounds three ounces; of which the linen covering weighs two pounds and a half,-leaving two pounds eleven ounces for the Eiderdown.

Shy and difficult of approach as Wild-Ducks are, and withal so valuable when obtained, we ought not to be surprised that a good deal of human ingenuity has been exerted in inventing the most efficacious modes of catching them; and it is curious to perceive how people in very different parts of the world may hit upon the same expedient. Thus, the Indians, who live in villages built on the shallows, in the midst of the waters of the great lake of Maracaibo, on the north coast of South America, opening into the Caribbean Sea, practise the same mode as the Chinese. They take care that a number of empty calabashes, a sort of large shell, or rind of a fruit, resembling an empty gourd, are continually floating up and down the lake; to these the Ducks get accustomed and allow them to drift down amongst their flocks, without expressing any fear. The Duck-catcher, particularly when, from the state of the wind, or situation of the birds, he observes the calabashes floating near a flock, goes into the lake, with a calabash over his head, having holes in it for seeing and breathing. Nothing is seen above the water except the calabash, the Indian taking care to keep the whole of his body immersed. He now steals slowly and quietly 
towards the unsuspecting birds, and when within arm's length, catches one of them by the leg, and twitches it suddenly under water, before it has time to alarm the rest, by crying or fluttering its wings. He then moves towards another, which he treats in the same way, and so on, till he has collected as many as he can conveniently carry, attached to a belt round his middle, and then he slowly retires, leaving the floating calabashes amongst the Ducks. On another part of the coast the same expedient is practised, excepting that instead of a calabash, they use a sort of cap made of rushes, similar caps being left to float amongst the flocks of Ducks, to which they soon get as much accustomed as those we first mentioned do to the calabashes.

The Sheldrakes, which, as we have seen, build in rabbitburrows, are caught by snares placed before the hole, into which the birds are traced by the marks of their feet on the sand. In this country, our markets are supplied either by those who are in the habit of shooting them, as a livelihood during the Winter season, or from decoys, in which by far the greater number are taken. In shooting, the great difficulty is to get within gunshot, the Duck not only being very watchful and timid, but possessed of so fine a sense of smelling, that but for the precaution of approaching them to leeward, or of holding a piece of smoking turf in the hand, it is no easy matter to get within reasonable distance. The guns, also, which are employed for this purpose, are much longer than those in common use, and will kill at a much greater distance. A Duck-shooter's life is often exposed to great hazard; the sport, if so it may be called, being carried on usually in Winter, late in the evening, or early in the morning, and most frequently in wet and marshy places, or on the shores of wild and solitary estuaries, opening through the lowlands near the sea. On these occasions some of them prefer going without even a dog, the cold being often so severe that no animal could bear it.

Many of the favourite feeding-places consist of those vast muddy flats, covered with green sea-weed, over which 
the fowler may slip and slide in the best way he can, or (were it not for his mud-pattens, flat square pieces of board tied to the feet,) through which he might sink up to the middle waist.

On one of these expeditions, a Duck-shooter, in Hampshire, met with a perilous adventure. Mounted on his mud-pattens, he was traversing one of these oozy plains, and being intent only on his game, suddenly found the water rising with the tide. Aware of his danger, he looked round, but his retreat was already cut off; he was already surrounded with the flowing sea, and death stared him in the face. But in this desperate situation his presence of mind remained, and an idea struck him, which might yet be the means of his preservation. He gazed round to see if any part of this mud desert was higher than the rest; and observing a small portion still a foot or two above the water, he hastened towards it; and when there, striking the barrel of his long gun deep into the ooze, he resolved to hold fast by it, as a prop to secure himself against the buffetings of the waves, which were breaking angrily around him, and had now reached his feet; and at the same time as an anchor, to which he might cling, and not be carried away by the current of the flowing or ebbing tide; or, at all events, that if it was to be his sad fate to perish, his body might be found by those friends who might venture out to search for him. Well acquainted with the usual rise of the tide, he had every reason to suppose that it would not reach above his middle, and that if he could endure the cold of six hours' immersion, he might be saved. Unfortunately, however, he had not taken into account the state of the wind, or some other causes, which had not only brought the waters up more rapidly than usual, but would also add to their height. Accordingly, having first felt the chill and deadly sensation of ripple after ripple, now covering his feet, then bathing him knee-deep, and then advancing beyond his waist, he was horror-struck at finding, that instead of receding, it still crept upwards, and had reached his shoulders; the spray burst over his head; upon another minute's 
rise or fall of tide his life depended; but still, though he gave himself up for lost, he firmly grasped his gun-barrel. The main land was too far distant to admit of his shouts being heard, and it was equally vain to hope that any looker-out could descry such a speck upon the waves as the head of a human being. In this awful moment of suspense, on looking downwards, he thought he saw the uppermost button of his waistcoat beginning to appear. Intensely he watched it, but for some. time without any well-founded assurance that he was right. At length, however, hope increased to certainty, as he saw button after button rising slowly into view, an infallible sign that the height of the tide was over, and that it was now upon the ebb. Though chilled with cold, and almost fainting, this welcome prospect raised his spirits, and, acting like a cordial, enabled him to endure the remaining hours of his fearful imprisonment. This man escaped; but we well remember a case very similar, in which the poor sufferer had to endure an equal horror, though not spared to tell the tale.

Off the north-west point of the hundred of Wirral, in Cheshire, extends a wide tract of sand forming a dangerous shoal, called Hoylebank, which has proved the grave of many a shipwrecked mariner. To this bank, always dry at low water, the fishermen of the neighbourhood are in the frequent habit of going to collect mussels. One evening, a party having ventured as usual, before separating, agreed upon a particular point where they were to meet again when the tide began to come in. Dusk came on, and those who first returned to the boat rowed to the point of rendezvous, there to await the arrival of their comrades; but hour after hour passed, and some were yet missing. The boat-keepers began to fear the worst; the absentees had either lost their way on the wide desert of sand, and were now wandering about hopelessly in darkness, or they had perished in one of the many quicksands which abounded on the shoal. Still they hung upon their anchor, and waited till, at its appointed hour, the tide had covered the whole bank, and not a doubt could re- 
main as to the fate of their friends. They then returned to reveal the sad tidings to their relatives on shore, and at early dawn repaired once more to the bank, now dry as when they first landed. One body alone was found, and he, like the Duck-shooter, had resorted to the same last and forlorn hope. He had firmly fixed a boat-hook on the highest ridge of sand, and having lashed himself to it with his handkerchief, had determined there to await the rising of the last tide he was ever destined to behold. The bodies of his companions were never seen again, and had probably found a resting-place in the deep channels of the surrounding sea.

Not far from the scene of this sad story, on the Cheshire side of the mouth of the river Dee runs a ridge of three small rocky islands, called Great Helbree, Little Helbree, and at the southern extremity, at a somewhat greater distance, forming the termination of the ridge, the Little Eye. At low water, the passage between these rocks and the main land is entirely dry. At this time, therefore, those who were inclined to take the chance of one single shot, for a second loading was out of the question, bent their way to the Little Eye, and took possession of a sort of excavated hovel, where, under cover of a few rough stones piled together, they were prepared to remain till high water; when, if they were fortunate, (but this was by no means to be calculated upon with anything like certainty,) a floating flock of Ducks and other sea-fowl would drift within reach, and a well-directed fire might do prodigious execution.

We have heard of we know not how many dozens of birds killed or disabled by this solitary broadside; whether the birds have retired from this part of the river, or the patience of the Duck-shooters has been exhausted, we cannot say; but of late years the sport seems to have been discontinued.

In the south of England, this mode is, however, still practised. On the coast of Hampshire, the marksman conceals himself till night, and then, listening with attention, directs his course towards the spot on which a flight of seafowl has descended to feed: when he judges himself suffi- 
ciently near, he directs his piece, and fires at a venture, and instantly catching up another gun, discharges it where he supposes the flock to be rising on the wing; he then hastens to the spot with his mud-pattens, and gathers up the profits of his toil.

We suspect, indeed, that the birds have seceded from the whole line of the river Dee; for the flights now seen are not to be compared with those which are spoken of as frequent a few years ago, when a couple of experienced Duck-shooters, we believe from the fens of Lincolnshire, spent some weeks on the coast, and realized a considerable sum by supplying the Chester and Liverpool markets. Their plan was this :-One of them had a small flat-built boat, without any keel, about sixteen feet long, and three feet broad, drawing about three and a half inches water. It was managed by a pole, twelve feet long, made about six inches broad at each end, which the man held in the centre, and dipping each end in, propelled his boat along; and when he got near his prey, used two small paddles, only three feet in length, by which he guided his skiff. His gun, which was fixed on a rest, consisted of two immense barrels, about nine feet long, an inch and a quarter in diameter, requiring three-quarters of a pound of powder and two pounds of shot to load both barrels, which were fired together. His success in one week, was a hundred and three Ducks and eleven Geese, besides smaller birds. At one shot, he had been known to kill two hundred and one Sea-Purres. He earned about ten pounds per week, and his companion rather more, by a similar plan.

But the exploits of our British fowlers are insignificant, when compared with the grand scale on which this warfare is carried on in Mexico, where a great Tiro de Patos, or Duck-shooting, is, we are assured,* one of the most curious scenes that it is possible to witness. The Indians, by whom it is principally conducted, prepare a battery composed of seventy or eighty musket-barrels, arranged in two rows, one

* Ward's Mexico. 
of which sweeps the water, while the other is a little elevated, so as to take the Ducks as they rise upon the wing. The barrels are connected with each other, and fired by a train; but the whole apparatus, as well as the man who has charge of it, are concealed in the rushes until the moment when, after many hours of cautious labour, one of the dense columns of Ducks, which blacken at times the surface of the lake, is driven by the distant canoes of his associates sufficiently near to the fatal spot. The double tier of guns is immediately fired, and the water remains strewed with the bodies of the killed and wounded, whose escape is cut off by the circle of canoes beyond. Twelve hundred Ducks are often brought in as the result of a single attack; and during the whole season they form the ordinary food of the lower classes in the town of Mexico, where they are sold for a trifling sum.

We have alluded to decoys as the great source of profit and supply with respect to wild fowl; and with an account of them we shall conclude the history of Ducks. A decoy is generally situated in a marsh, so as to be surrounded with wood or reeds, and if possible both, to keep the water quiet, and that the repose of the wild fowl may not be interrupted. A certain number of Decoy-Ducks is then provided, consisting of wild ones, which are bred for the purpose, and which, although they fly abroad, regularly return for food to the decoy-waters, and of tame ones which never quit the water, and are regularly trained to act their part. Their food consists of hempseed, oats, and buck-wheat. In what is called working the decoy, the hempseed is thrown in small quantities over screens made of reeds, to allure the birds forward towards the pipes, or wicker channels, of which there are several, leading up a narrow ditch, closing at last with a funnel-net. Over these pipes, which grow narrower from the first entrance, is a continued arch of netting suspended on hoops ; it is necessary to have a pipe for almost every wind that can blow, as upon this circumstance it depends which pipe the Ducks will take to; and the Decoy-man always keeps to leeward of the flock, taking the additional precaution. 
of keeping a piece of turf burning to prevent their scenting him.

Along each pipe at certain intervals are placed the reed screens which hide the decoy-man until the moment when it is necessary for him to show himself, namely, when the birds have passed up the pipe to which they are led by the trained birds, who know the whistle of the decoy-man, or are enticed by the hempseed. A dog which is generally preferred of a reddish colour, is also trained to play backwards and forwards between the screens; and by suddenly appearing and running round a screen, the birds are attracted towards him. When a sufficient number of Ducks have thus fairly passed up the pipe, the decoy-man comes forward from behind the screens, upon which the whole flock, unable to fly upwards on account of the hoop-net above, rush onwards to a funnel-net which opens on the land, where they are caught without difficulty; the trained birds are of course immediately turned loose again. If well managed, a good decoy has been known to produce several hundred pounds a year.

Many birds manifest almost reasoning powers in eluding pursuit, or turning attention from their nests and young; but few perhaps more than the Duck tribe, of which the following may be adduced as an instance, from Captain Back's Narrative of his Arctic Land Expedition, p. 249. One of his companions, Mr. King, having killed a female Duck, fired again, and, as he thought, disabled its companion, a fine Drake. Accordingly, leaving the dead bird, which he had the mortification of seeing, in a few minutes afterwards, carried off by one of the white-headed Eagles, he waded into the water after the Drake, which, far from being fluttered or alarmed, remained motionless, as if waiting to be taken up. Still, as he neared it, it glided easily away through innumerable little nooks and windings. Several times he extended his arm to catch it; and having at last, with great patience, managed to coop it up in a corner, from whence there appeared to be no escape, he was triumphantly bending down to take it, when, to his utter astonishment, after two or three flounders, it looked around, cried "quack," and then 
flew off so strongly, that he was convinced he never hit it at all. The object of the Drake had clearly been to draw Mr. King away from his companion, of whose fate it was unconscious; indeed, so attached are these birds at certain seasons, that it is no uncommon circumstance, when one has been shot, for the other, especially the male, to linger about its struggling partner, exhibiting the greatest distress, until either killed or frightened away.

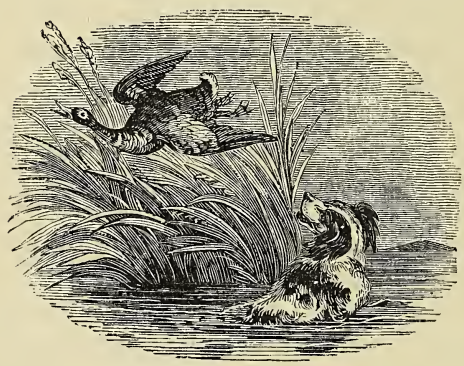




\section{CHAPTER XVIII.}

Pinnipedes; Swimming Feet.-Pelican-Fable of Drawing its Blood explained-Mode of Fishing. - Sea-birds feeding on Fish thrown up by Whales. - Cormorants-Voracity of-May be tamed-Fierceness of.-Frigate Bird.-Solan Goose-Lightness and Buoyancy of-Nests.-Anhingas, or Darters.

\section{TABLE XXVIII. (See page 22.)}

Order 6. Palmipedes. Tribe 2. Pinnipedes.

\section{(Swimming-feet.)}

THEbirds of this Table are, like the preceding, web-footed, 1 but they differ from them in having the back toe so united with the others as to form one continuous web, having, in some instances, a toothed claw on the second toe; and what is very singular, notwithstanding this peculiarity, which it might be supposed, while it ren-

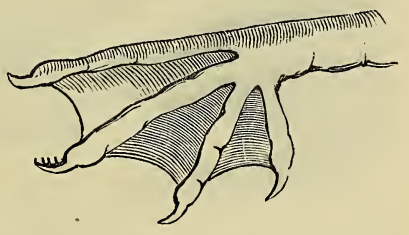
dered them more fit for Toothed Claw of Cormorant's Foot. swimming, would entirely prevent their clinging to a branch, almost all of them can, and do frequently, perch on trees.

The Pelican stands at the head of this list, easily distinguished from all others by his capacious pouch, formed of a naked skin, stretched, or rather suspended from the two bony branches of his lower mandible. We have already given his picture, in speaking of the pouches peculiar to some birds.

Few birds have had more marvellous stories told of them 
than the Pelican, and most of them founded upon some peculiarity, exaggerated by the ignorant. Thus, the old tradition of its drawing blood from its breast to feed its young ones, or as some ancient authors gravely asserted, to bring them to life again, after serpents had squirted venom into the nest and destroyed them,* originated in the bird's habit of pressing its beak to its breast, in order more easily to dis-

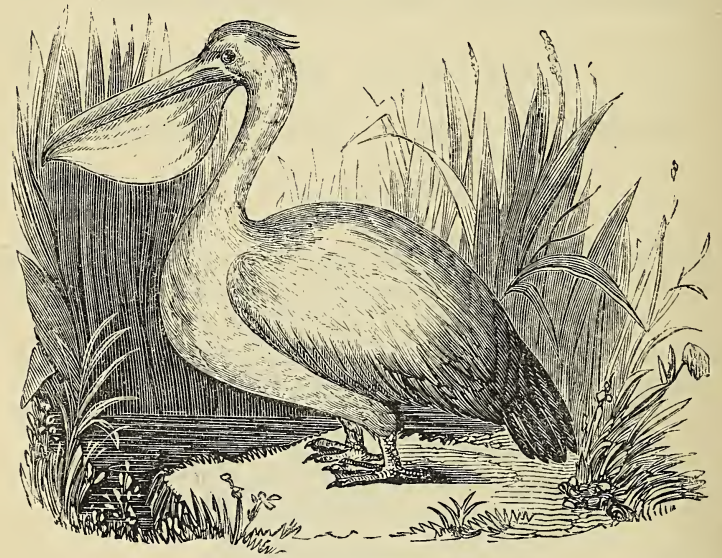

The Pelican.

gorge the food it had prepared for them. They have, again, by others, been considered as purveyors of water to the camels, who instinctively seek in the desert for nests of these birds, which form reservoirs of water, conveyed thither in their pouches, to quench the thirst of their young. True it is, that the pouch of the Pelican is capable of carrying about two gallons, but it is for the conveyance of fish rather than water, that it is serviceable to the bird; and were it ten

* Eusebius on Psalm cii. 
times more capacious, the dry and parched sand of the burning desert would soon suck up a supply so insignificant for an animal which, at one draught, would take up the water imported by a flight of Pelicans.

But without going into fabulous history, this bird has true wonders enough to excite our admiration and astonishment. Looking at its vast dimensions, six feet from the point of the bill to end of the tail, we should suppose that there would be a corresponding weight to be borne upwards by its vast spreading wings, twelve feet from tip to tip, and yet its entire skeleton does not weigh much more than thirty ounces, its bones being so light, as to be nearly transparent. It possesses also, in a high degree, the capacity for containing air, already spoken of,* when we treated of the lightness of some birds; its bones and feathers, as well as the space between the skin and the flesh, being all reservoirs of air. Thus furnished, the Pelicans will frequently, like the other air-supplied birds, rise to an immense height. In one respect, indeed, this lightness operates against its procuring fish; for so large a surface of so light a weight cannot easily be forced under water.

The Pelicans, aware of their inability to catch their prey under water, in consequence of this buoyancy, adopt an equally certain mode of supplying themselves; for assembling in flocks, they unite their forces, and surrounding a shoal of fish, strike the water with their wings; and with the noisy splashing frighten and drive them into a narrower compass, so that the shoal at length becomes much compressed: the upper part is thus raised by the lower, when, at a certain signal, all the Pelicans strike the water again, and in the general confusion fill their pouches, and devour their contents at their leisure.

The Russians, who have ample means of observing their habits, owing to the immense flights arriving annually from the Black Sea and the sea of Azof, and alighting at the mouth of the river Don, assert that the Pelicans take the

Page 52. 
Cormorants into partnership on these occasions; the Pelican extending its wings and flapping the water, while the Cormorant, diving below, drives the fish to the surface; and when, by their joint exertions, the shoal is driven into the shallows, and easily taken by the Pelicans, the Cormorant helps himself' out of his companion's wide pouch. The very respectable writer,* on whose authority we state this latter part, gives some further account of the concealment of their eggs, which, however extraordinary at first sight, is so well borne out by the instinctive habits of some other birds, that there is no reason for doubting its truth. He says, that if disturbed while sitting, they will hide their eggs in the water, taking them out with their bills when they believe the danger to be over.

We can vouch for the fact of sea-birds feeding on fish, forced above the surface by the lower part of the shoal, having witnessed a singular scene off the Hebrides during the herring season. A whale of the smaller species (Delphinus deductor) $\uparrow$ was observed pursuing a shoal of herrings about half a mile off. The fish were evidently in a state of alarm, and it was equally evident that a prodigious flight of Gulls, Gannets, and all the host of sea-birds, were aware of what might happen, as they hovered over the spot screaming, and now and then darting irregularly downwards to within a yard or two of the surface. As the whale closed upon the shoal, agitation seemed to increase, judging by the increased excitement of the birds above. His long black back slowly rose, and disappeared as the huge animal rolled onwards, seldom descending so far below as to bury his back-fin, which rippled along the surface; at length he was in the midst of them, and the confusion was complete. At one moment he disappeared altogether; but though unseen by us, it was very clear, by a momentary elevation of an actual mass of herrings above the

* Dr. E. D. Cluarke's Travels.

$\dagger$ The northern coasts were much frequented by this whale about that time; at Kirkwall Bay, in Orkney, we saw the remains of no less than ninety-two, which had been recently driven on shore in a heavy gale. 
water, that the poor frightened creatures had closed within the smallest compass, and by the upheaving struggles of the lower stratum of the shoal, were thus unwillingly exposed to greater dangers in another element; for, availing themselves of this eventful moment, down came the birds with one simultaneous pounce upon the dense mass. Shortly after, the dark fin would again appear, and a bright jet of glistening foam, rising like a fountain, announced that the animal was under the necessity of breathing or blowing after his labours. Then again he would descend headlong, with a sort of recruited spring, exhibiting nearly his whole body, and giving the water a tremendous lash with his tail as it disappeared. The sound produced by this crash upon the waves was astounding enough in itself, but the effect of the blow was far more so; for whether, by a sort of sculling motion, it scooped and threw a mass of herrings upwards with a jerk, or whether they were fairly driven from the water with the cloud of foam which followed the blow, the air for some feet above the water was spangled with bright specks of herrings, on which the united host of birds again pounced, forming one mingled mass of herrings, sea-fowl, and foam.

In the West Indies, it appears that some of the species of Pelicans are able to immerse their bodies; and, after diving and bringing up their pouches full of fish, will goodnaturedly allow the Parasite Gulls (so called from being in the habit of living on the labour of others), to settle on their heads, and partake of the spoil;* a fact, in great degree corroborating the Russian account of the Cormorants just mentioned. If the Pelicans of the West Indies permit themselves to be made into resting-places for other birds, those of the Eastern world consider themselves equally privileged to make resting-places for themselves on the bodies of animals. On the banks of the river Tigris, in Asia, the favourite resort of a species of Pelican (Pelicanus fuscus), they may be seen in great numbers spreading their silvery wings, quietly settled

* Transatlantic Sletches. 
on the backs of the buffaloes, which are plunging into the water, and patiently accommodating themselves to this incumbrance.* We know that cows will allow of Magpies sitting on their backs, and pecking holes in their hides,-for which they ought to be grateful, as the Magpie is doing the poor beast an essential service, by ridding it of the grub of the Gad-fly (CEstrus bovis), the sound of even one of which will send a herd off at full gallop, with their tails in the air; but as the Pelican's beak is by no means fitted for boring into the tough coat of a buffalo, we cannot account for the apparent satisfaction expressed by the animal on its making this settlement.

Of the voracity and capacious stomach of the Pelican, as well as of his pouch, we have spoken before (p. 44). Of this the Chinese take advantage, and train a species of Pelican or Cormorant, called by them Loo-fou, as fishing-birds. Mr. Smith, an intelligent missionary, gives a detailed account of this mode of fishing, which came under his immediate observation when at Nantai, in China. Generally about the time of low water a boatman might be seen near the arches of the bridge, with four or five Cormorants perched on its gunwale. At a given signal from the owner, one of these birds bounded from the boat into the stream, and after looking about for a few moments, dived to the bottom, becoming invisible, sometimes for two minutes, when it generally arose at forty or fifty yards' distance, to breathe. After another minute, the bird again descended, and repeated the process till it brought a fish to the surface struggling in its beak. This was a signal to the boatman to paddle his little vessel to the spot, where he cast a net into the river, and hauled both bird and fish into the boat. The bird, conscious of its desert, flapped its wings, and by various odd motions, sought the usual reward of a piece of fish or other food for its success. Sometimes two cormorants were fishing at the same time, and were often for many minutes apparently lost. The fisherman, however, easily followed them, his little boat consisting

* Mign.an's Travels. 
merely of half a dozen bamboo.poles, which formed a light raft sufficient for himself and the birds, and was easily paddled with a single oar. During the time Mr. Smith watched their operations, they caught three or four fish, one of which was more than the captor could manage, and weighed down its bill below the stream as it floated towards the raft. It is said that a ring placed round the lower portion of the throat of their fishing Cormorants, disables them from swallowing their prey before the boatman arrives to the rescue.

To the Pelican succeeds the Cormorant; so closely, indeed, . are they allied, that many naturalists have classed them together, and given them the same scientific name; for instance, our common Cormorant is called Pelicanus carbo. The Cormorant, however, may be distinguished by the claw of the middle toe being indented like a saw,* probably to help him in retaining the slippery bodies of small fish, as the toothed claw of the Herons serves for a similar purpose. Possibly it may further serve so awkwardly-shaped a bird, by enabling it to cling to branches; for although they usually frequent rocks and precipices, they can, and very often do, perch on trees. The poet, Milton, seems to have been aware of this, when he describes Satan taking the form of this illfavoured bird, when he first entered Paradise, devising the ruin of our first parents :-

\section{Up he flew, and on the tree of life \\ Sat like a Cormorant-devising death \\ To them that lived.}

The poet could not, indeed, easily have selected a fitter frame for the foul fiend than that of a Cormorant: there is something so unearthly about him, as he is seen reposing on a rock, when gorged with food; his slouching form, his wet and vapid wings dangling from his sides to catch the breeze, while his weird, haggard, wildly-staring, emerald-green eyes scowl about in all directions.

* See figure inserted in page 315. 


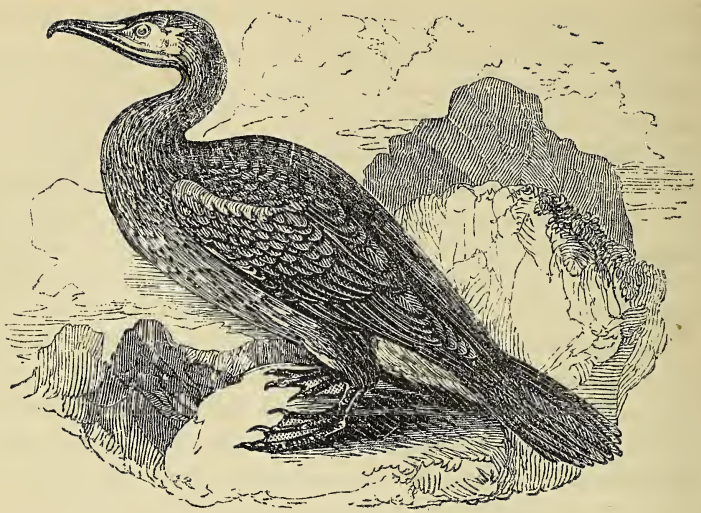

The Cormorant.

The quantity of fish one of these birds will devour is astonishing-three or four pounds a day, or about half their weight, - a Cormorant weighing from six to seven pounds. What should we say of a man eating seventy or eighty pounds of beef or mutton at his daily meals? which he would do were his appetite as great in proportion as that of the Cormorant. The fact is, that, like most birds living on fish, its digestion is extremely rapid, and it therefore requires a proportionably larger supply of food, of which if it is deprived it soon dies, as is often known to be the case. Thus, on the western coast of the Hebrides, these poor birds suffer severely, when, during and after a continued gale, the Atlantic rolls in its enormous billows, dashing them against the headlands, and scouring with their fury the sounds and Creeks. As far as the eye can reach, the ocean boils and heaves, presenting one boundless field of foam, the spray from the summits of the waves sweeping along the waste like drifted snow: no sign of life is to be seen, save when a Gull, labouring hard to bear itself up against the blast, hovers overhead, or darts by like a meteor. If, at such a season, the haunts of the 
Cormorants are visited, they will be found huddled together in their caves and crevices, perishing with hunger, and their numbers daily thinning by death. If, indeed, they could venture out, and bear the buffeting of the storm, they would still fail in procuring food; for, as in fishing, these birds always carry their heads under water, in order that, with their keen, clear, and beautiful eye, they may discover their prey at a greater distance, it is obvious that in such commotions of the air and water, they would need even a quicker glance than they possess. The use they make of their bills in feeding shows remarkable ingenuity, as well as agility : if the fish happens to be a flat one,- - a flounder, for instance,they will turn it, so as to place it in the most commodious position for slipping down the throat; if, on the contrary, it happens to be an eel, which has been seized in an unfavourable position for gorging, they will throw it up, as a cook does a pancake, and catch it in the fall.

Wild and desolate as are the habitations of these birds, and little as they seem to have in common with man, yet, judging from one which was caught young, and reared, they are not only docile, but grateful and affectionate. This bird,* though it had fasted twenty-four hours, during its journey by coach to the place where it was sent as a present, refused every sort of food. It was therefore crammed with raw flesh, as no fish could be procured. It submitted patiently to this forced meat, and was left by the gentleman, who retired to his library after seeing it fed, but who was not a little surprised, in a few minutes, to see the bird walking boldly into the room, and, when before the fire, beginning to plume its feathers, as much at ease as if seated on its native rocks. It was removed to a menagerie, and supplied with water, into which it immediately plunged, and manifested much restlessness, as if disappointed in not finding fish. After this it gradually became more docile, and fed upon whatever was offered; and if let out, never attempted to ramble, but walking direct to the house, would enter the first open door, with- 
out caring either for men or dogs; and, in short, at last becoming troublesomely tame.

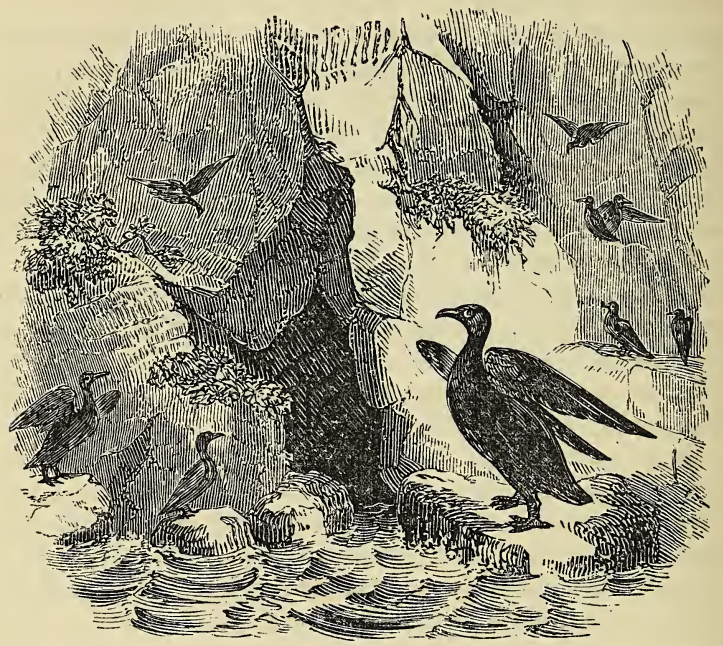

Cormorants.

This is fully corroborated by another account of a couple of these birds, which were brought up from the nest, and kept for nearly two years. The owner found them pleasant pets enough, unless when pressed by hunger, when they became quite outrageous, and screamed violently. But woe to the man or animals that ventured to approach them when hungry. One day a gentleman's servant went in to look at them, wearing, unfortunately for himself, a pair of red plush breeches, which immediately caught their attention, mistaking them, probably, for raw flesh, as they had been accustomed to be fed on raw liver and lights, resembling the plush, in some degree, in colour: the consequence was, they made such 
a furious charge, that the owner was obliged to come to his assistance with a stick, and even then could not keep them off without much difficulty. Their attack on dogs, cats, and poultry, if unprotected, was always fatal. They fought at once with their bills, wings, and claws, screaming frightfully all the time. They were on this account at last parted with, having killed a favourite pointer. The poor dog had incautiously strayed into the place where they were kept, when they immediately flew at him, and attacked him in front and rear : his loud howlings brought his master to his aid, but too late; they had got him down, and inflicted fatal wounds.

The chief difference between Cormorants and the Frigatebirds, so called from their keeping a sharp look-out on other birds, and robbing them of their fish, consists in the latter having forked tails like our Swallows: their spread of wing is also proportionably much larger, and they are altogether of a lighter and more elegant appearance. We know but little of them; indeed, our knowledge is limited to one species only, the Tachypetes aquila, of which we have already spoken (see page 78), when considering the buoyancy of birds and their power of floating in the air. We shall therefore proceed to the next genus, Gannets, or Boobies, as some of them are called by sailors, owing to the stupidity with which they suffer themselves to be attacked and robbed by men and birds.

The Common Gannet (Solan Goose) is the species to which we shall confine our remarks : well known as it must be to those who have sailed on either side of the Scottish coast, as well as several other shores of our island, it will be more familiar to many under the name of the Solan Goose. Like most of the other birds of this tribe, it is profusely-supplied with air-cells; and we refer our readers to the account already given (page 53), of these peculiarities in its formation, merely adding, that from the facility of procuring specimens, a close examination of this species is recommended to those naturalists who wish to acquire more information on the internal economy of air-inflated birds.

In our account of the dismal tempests that so often prove 
fatal to the starving Cormorants, we might have added, that in the way of the Gannet they throw no impediment; buoyant as a bladder, no sea can overwhelm him; there he floats, if so it pleases him, lighter than a cork, on the summit of the most angry waves, without let or hindrance. On their airy, spreading pinions too, they can, in case of disappointment in one place, transport themselves, in an incredibly short time, to another. The inhabitants of St. Kilda assert, that they occasionally go a hundred miles or more for the purpose of fishing; a fact, they say, proved by finding in their nests, hooks of English manufacture, sticking in fish bones.*

Their nests are usually placed on the ledges of apparently inaccessible rocks, in which two eggs only are, for the most part, laid; but, breeding as they do, on so many of the desolate rocks of the northern shores, the number produced is incredible, and in many parts becomes a source of considerable profit to those who catch them. Thus, Mr. Landt, in his account of some islands near the Feroes, says, "The old ones are caught in the middle of April, when they have built their nests, but before they have laid their eggs. The peasants steal upon them in the night-time, or when it is dark, in the places where they sit and sleep, and seize them by griping them in a peculiar manner, which prevents them from emitting any cry ; for if they are suffered to make a noise, all the rest would awaken and take themselves to flight. In the course of a season, those who are successful will catch, of old and young ones, about four hundred brace."

As we shall have occasion to speak of the Gannet again, in giving a general account of the modes of catching the various sea-birds that are found upon our shores, we shall, for the present, take our leave of it, as well as of the two last divisions of this Table, the Phaetons (see page 79), or TropicBirds, and Anhingas, or Darters, both comparatively little known, and inhabitants of remote regions, the former, from its name, being found almost invariably within the tropics, 
and generally at great distances from land; the Anhinga being confined to the savannahs, marshes, and rivers of the hottest parts of the African and American continents.

The long thin neck and beak, the slim body, and large webbed feet of the Anhinga, bespeak at once its real character as an excellent diver, which it certainly is, for on the slightest appearance of danger, it will disappear in an instant, rising again at the distance of many hundred yards, and then only showing its narrow head just above the surface of the water. It is said that when several are surprised perching, according to their practice, on a branch stretuhing over a river, they will all drop down together as if dead, and then dive away beyond pursuit.

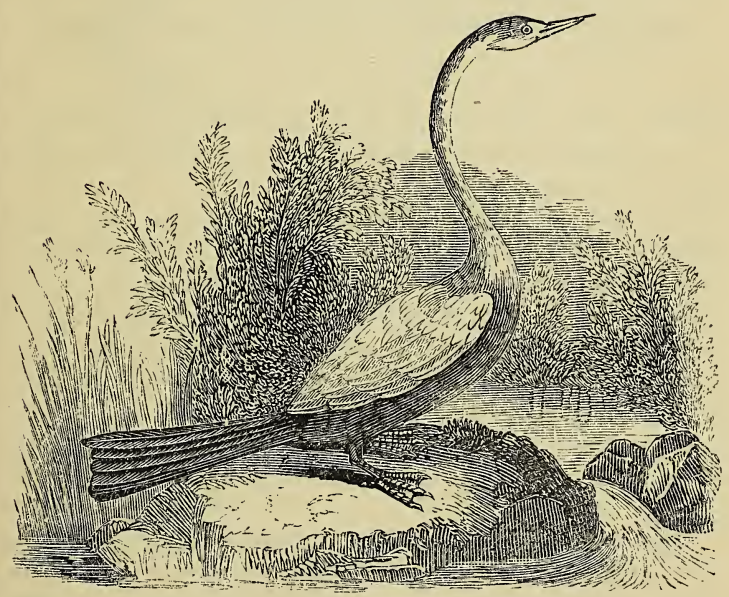

Anhinǵa or I arter. 


\section{CHAPTER XIX.}

Longipennes ; Long-winged._Skimmers._-Singular Bill._-Terns, or Sea-Swallows-Anecdote of.-Gulls-Capacity for enduring Cold-Voracious feeders-Breeding Places.-South Stack described.-Albatross-Roaming Habits.-Tristan D'Acunha -Resort for Breeding-Voracity.-Petrels-Nests-Feed at Night-Superstition of Sailors respecting. - Brevipennes; Short-winged.-Divers. - Crested Glebe-Great Destroyers of Fish.—Guillemots.—Razor-Bills.—Puffins and Auks.

\section{TABLE XXIX. (See p. 23.)}

\section{Order 6. Palmipedfs.-Tribe 3. Longipennes. (Long-winged.)}

THIS tribe comprises:-1. Rhynchops, or Skimmers

1 2. Sterna, Terns; 3. Larus, Gulls ; 4. Diomedea, Alba. tross ; 5. Procellaria, Petrels.

All these are long-winged birds, proper to the main ocean, and, by means of their powers of flight, are spread widely over the world. They may be known by either having no back toe at all, or by that toe being free,that is, not united with the others by a membrane, forming one large web, as in the preceding tribe; and by their bill, without indentations, but bent at the end, as in the Procellaria, or Petrels, the extremity of which seems to consist of a piece fastened on, or pointed, as in all the rest.

The Skimmer (Rhynchops) derives its name from the way in which it feeds, flying generally so close to the water, that the under mandible just skims below the surface, while the upper is kept wide open, so that on its meeting with any floating substance, it closes immediately upon it. It is a bird with little feet, long wings, and a forked tail; but its bill is so extraordinary, that there is no mistaking it for the 
Sea-Swallow's, which in other respects it closely resembles : the lower mandible is the shortest, and the other shuts upon it like the two blades of a pair of scissors.

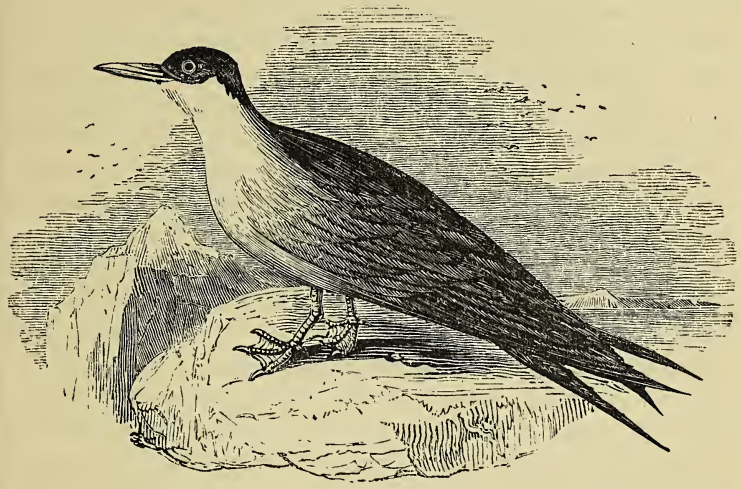

Sea-Swallow.

Terns, or Sea-Swallows, have very long and very pointed wings, with forked tails and short feet, in which they resemble Swallows ; but their mode of flight is very different, not having that darting rapid course, but a sort of graceful gliding motion,--sometimes high in the air, then falling as if they had lost their balance. Though perfectly web-footed, they never swim, but take their food, consisting of small fishes or insects, by descending to the water, and gently touching the surface with their beaks.

We have four species in this country, either residents, or occasional visitors. Those which breed here, generally lay three or four eggs, without any nest, preferring a low shingly shore, on which, we believe, the bird sits in the usual manner; but as it has been ascertained that an American species deposits her eggs in a similar situation, and leaves them to be hatched principally by the heat of the 
sun,- the parent bird only sitting upon them during the night,--it would be worth an observer's while to look after our Terns, and see how far they resemble their American connexions.

They are very tame; and we have approached one of our British species (Sterno hirundo), as it rested on a patch of mud, a boat's buoy, or a piece of floating wood, till we might have almost knocked it down with a stick. They appear, indeed, to have little or no sense of danger : if three or four are in company, and one is shot, the others will usually, instead of hurrying away, come fluttering down to the dead body, uttering their soft, mournful, or, as in this case it might be termed, reproachful cry. Their whole appearance is, in truth, so beautiful and attractive, that we can readily enter into the feeling with which one of these birds was regarded by a forlorn, starving boat's crew, whose vessel, striking on an ice-island, on her passage from Halifax, in North America, to England, foundered, and left her miserable inmates on the wide ocean, hourly expecting to be swallowed up by the heavy seas, which were constantly breaking over the crowded boats. It was on the evening of the sixth day after quitting the wreck,* just before night set in, that a beautiful white bird, "web-footed, and not unlike a Dove in size and plumage, hovered over the mast-head of the cutter; and, notwithstanding the pitching of the boat, frequently attempted to perch on it, and continued fluttering there till dark. Trifling as this circumstance may appear," continues the writer of the narrative, "it was considered by us all as a propitious omen. The impressive manner in which it left us, and returned to gladden us with its presence, awakened in us a superstition, to which sailors are at all times said to be prone. We indulged ourselves, on this occasion, with the most consolatory assurances that the same hand which had provided this solace to our distresses, would extricate us from the dạngers that surrounded us."

We come next to the numerous class of Gulls,-a class

* Narrative of the loss of the Lady Hobart packet. 
which the sailor is sure to find wherever he goes, whether under the burning sun of the tropical regions, or the frozen icebergs of the Arctic circle, and always bearing the same restless, noisy character. They have been named, and justly so, the scavengers of the sea, for nothing comes amiss to their voracious appetite. Loathsome as may be the putrefying carrion left on the beach, to the Gull it is just as acceptable as a meal on the finest and freshest fish. On either they will gorge almost to suffocation; and in that state may be taken up torpid and insensible. Some years ago, in riding with a friend on the sea-shore, we espied a Gull lying motionless on the sand, apparently dead; but, as its eyes were open, life was clearly not extinct. Suspecting it to be a wounded bird, we alighted to examine the extent and nature of the injuries it had received; but not a drop of blood was to be seen, neither was a feather ruffled. Afterhaving, therefore, handled it for several minutes, without its evincing the slightest symptoms of vitality, beyond the opening and shutting of its eyes, we threw it into the air, when, to our inconceivable surprise, the apparently dead bird expanded its wings, and, tucking up its

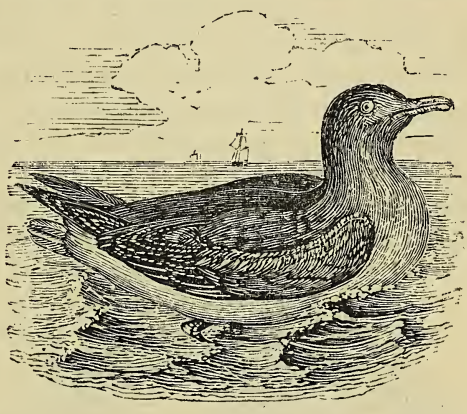

T'he Black-kraclzed Gull. legs, flew off with the utmost composure and steadiness.

Nature has amply provided them with means for their wandering lives. While the Cormorant is pent up in his cavern, and most of the other sea-birds are driven to their rocks and crags, during heavy gales, it matters as little to the Gull as to the Gannet, that the weather be fair or foul. Cold has no effect upon him, provided as he is with a thick coat 
of the softest down : light, too, as he is, he tops and rides over the waves without an effort; and his wide wings insure him a safe conveyance from every peril, save that of the gun, to which he may be exposed.

They are a very numerous tribe, differing a good deal in their habits, if not in their external features. The king of them all seems to be the Burgomaster (Larus glaucus), a name given by the Dutch, being the title of their chief magistrate, to which, by his conduct, he has a fair claim, for no other Gull dares dispute his authority, when he chooses to exert it. A constant attendant on the whale-fishers, whenever they are busied in cutting up a whale, he hovers over the carcase, and having fixed his eye on a choice morsel of blubber or flesh, which some other of the Gull tribe has secured for itself, down he comes, and, forcing it to abandon the prize, carries it off as his own; or, if pressed by hunger, he will sometimes even fall upon one of the smaller sea-birds, and devour it whole. Thus, one of them was shot in the Polar expedition under Sir Edward Parry, which immediately disgorged an Auk, or Greenland Dove ; and, on opening him, another was found undigested in his stomach. But this Burgomaster, tyrant as he is, has a rival quite his equal in tyranny, and, though his inferior in size, surpassing him in courage and activity. The Arctic Gull, or Dung-Hunter

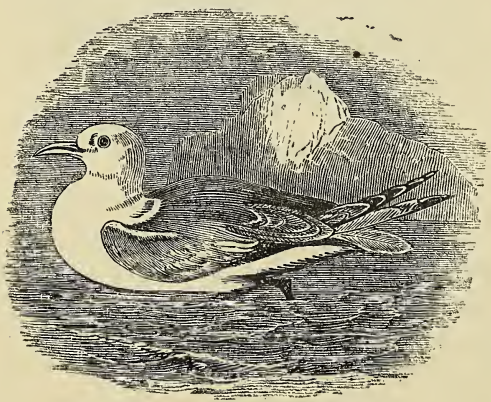

White Gull.
(Lestris parasiticus), fears no bird, nor even hesitates to attack any animal, of whatever size, that comes too near its nest. Where they breed in considerable numbers; neither Hawks, nor even Eagles, are allowed to approach ; for if, either by accident 
or design, any of these birds of prey are seen, the whole assembly attack and compel them to retire. Hence, in some places where they abound, they become the guardians of the young lambs, which the people consider perfectly safe during Summer; and, in return for this protection, the Gull is never molested, being held in no less esteem than the Stork in Holland, or the Ibis in Egypt. The unfortunate birds most exposed to the attacks of these robbers are their brethren, the Herring-Gulls and Kittiwakes, probably because, being the most diligent pursuers of fish, they are sure to find from their exertions a never-failing supply.

Herrings form the chief provision for the immense flocks of these birds, which, in the season, are always found near the shoals. It has been remarked, that they seem to have an instinctive knowledge of the habits of these fish, and act accordingly. In the Shetland Islands, at a particular time of the tide, the herrings descend from the surface; and, during the intervals of their absence, the Gulls, as if fishing was out of the question for the time, generally repair inland, and rest among the heaths. As soon, however, as the tide changes, and the herrings again rise, they quit their retreats, and by loud and discordant screams, seem to express to each other their joy at the approaching feast; and when they take wing, it is a sure sign that the period for fishing is at hand. It is astonishing to see with what precision and regularity the flocks, far removed from the sea, arouse themselves from a state of quiet and repose, and suddenly, full of bustle and activity, betake themselves to the herring-grounds.

The Gulls hitherto mentioned are, more or less, strangers to this country; or may, at all events, be considered as mere casual frequenters of our coasts, preferring solitudes still more wild and lonely than our own. We have, however, several species which breed and remain with us all the year. They build on several parts of our rocky shores; and few scenes present more attractions, to an observer of nature, than a view of one of these wild spots in that season. We shall describe one, that we have often visited, and give, at the same time, 
some particulars relative to the habits of the birds of which we are now speaking.

The spot we allude to is at the back of a mountain near Holyhead, which terminates abruptly in a series of precipices. At the foot of one of these is a small island, called the South Stack, on which a light-house has been erected within the last few years, well known to those who navigate the Irish Channel. Upon this rock, which, before the erection of the light-house, was almost inaccessible, myriads of sea-fowl used to build; but when the works were commenced, in 1808, the unusual appearance of persons on the island, with their noisy operation of blasting, so disturbed the proceedings of the birds recently arrived, that, with the exception of a solitary pair of Gulls, the whole body, including Guillemots and Razor-bills, took to flight, leaving the workmen in full possession of a spot, which the birds, from time unknown, had occupied by a sort of prescriptive right. This solitary pair had taken post on an inaccessible ledge of bare rock, in the face of a precipice, and seemed to be aware that nothing but shot or stones could dislodge them. Their determined confidence in the security of their stronghold met with its due reward, orders being issued that none should molest them. The consequence was, that in a short time they became quite familiarized to the noise and bustle, and remained until their young were reared, and in a condition to shift for themselves.

In the ensuing Spring, the same pair, as was supposed, retook possession of their old post-and strict orders, as before, were given, on no account to disturb them; and, as a further protection, no fire-arms were allowed to be used; nor were strangers who disregarded these rules to be admitted again on the island. In consequence of a rigid attention to these humane regulations, the same pair continued, for five successive years, to visit this ledge, rearing their young, consisting generally of two, and never exceeding three in number. But although only this single pair were observed to breed on the island, a considerable number, at times, as if aware of their security, sought the shelter denied them on the main-land; 
where, notwithstanding the bare and perpendicular character of the precipices, there was scarcely a spot among the clefts and hollows to which the young men and boys of the neighbourhood did not find their way, in search of eggs, for which they found a ready demand.

The main body of Gulls at length finding that these wonted haunts no longer afforded security, either taught by the experience of the above pair, or by their own observation, in the Spring of the sixth year took refuge on the island, chiefly at the south side, on an inclined plane of rock, where they have remained, during the breeding season, ever since; and on this spot, in particular, their artless nests are spread in such numbers, that it is difficult, at times, to avoid treading upon them. It is remarkable, however, that only two pair of the Black-backed Gulls returned, and these, according to their usual habits, not only build apart, but never herd with the rest. Neither have the Razor-bills and Guillemots reestablished themselves in the same abundance, or with the same apparent confidence,-which may, in some degree, be accounted for, by the parts of the rock most suited to their habits having been more or less used as landing-places. But although these poor birds have, contrary to the general rule, found a protector in man, they are not entirely without their troubles and annoyances. Certain Crows (the light-keepers say, a pair only of one particular species, probably the-redlegged, Corvus graculus) come at the same time, and build their nest just opposite the Stack, as if for the express purpose of harassing and stealing their eggs. For no sooner do the Gulls begin to lay, than these two Crows are perpetually on the look-out, frequently hovering over, and watching for an opportunity to carry off a prize.

The moment the thieves appear, the whole Gull colony is in a state of commotion and consternation: those on the nests cowering over their new-laid treasures, while the others, by their screams and menacing attitudes, do thẹir best to frighten and drive the marauders away. But the cunning Crows usually gain their point: watching an opportunity, 
down they pounce, pierce an egg with their sharp beak, and fly off with it in a trice.

A curious circumstance fell under the observation of the light-keeper. A pair of these Crows had, for some years, frequented the same spot, when, in one season, the female was shot, and the male almost immediately disappeared, remaining absent for the space of three or four days, when he returned with another partner, and the business of nidification was carried on as before.

The Gulls, at the breeding season so numerous on the island and adjacent coast, disperse themselves for the rest of the year ; and are never seen congregated in great numbers, except when attracted by shoals of herrings, or some similar cause; but it is positively asserted by the light-keepers as a very extraordinary fact, that they all instinctively return to the South Stack during the same night, on or about the 10th of February ; and retire, with the exception of those that, having been robbed on the main, had resorted to the island to renew the labours of incubation, about the night of the 12th of August. The keepers state, that in the middle of the former night, they are warned of their arrival by a great noise, as it were a mutual greeting and cheering; adding that they look to their return as that of so many old acquaintances, after a long absence, announcing the Winter to be over, and Spring approaching. For a time they appear to congregate together without any order whatever; but in the course of a month begin to pair, and getting their nests in readiness, proceed to lay their eggs. As if confident of protection, they become quite familiar; at least this is the case with the Larus canus, or common Gull.

In one part, a point of rock projects considerably; its extremity commanding a full view of the various ledges, as well as declivities, on which the Gulls have established themselves; and there have we sat, and could have remained for hours, watching these sea-birds, and listening to their wild cry, mingling with the hoarse roar of the waves lashing the rocks below. When resting there, some would fly so near, that the fanning of their wings could almost be felt, while 
others would alight within a few yards, and conning us over with a vacant simple stare, kept repeating their plaintive, melancholy, imploring sort of note. While, on the other hand, a pair or two of the black-backed Gulls (Larus marinus) from time to time sailed by, and then dropping on their inaccessible ledge, reconnoitred us with a scrutinizing look, from their keen, suspicious, penetrating eye. The former, barely opening their comparatively slender beaks enough to give vent to a gentle cry, seemed to say, "We are poor harmless creatures ; do not hurt us." The latter, on the other hand, the moment they had alighted, opening theirs as wide as possible, uttered a loud hearty scream, as much as to say, "This is our territory; you have no business here." Not far from the resting-place of this pair of blackbacked Gulls, a couple of the common sort had, when we last visited this interesting spot, established themselves on a bit of a plateau, that made one giddy to look at, and quite tremble for the fate of their sole offspring, a little gray, downy-covered nestling, with about half an inch between its toes and destruction, for a breath might have blown it over : but there stood the little tottering bird, quite at its ease, so well tutored apparently, that when the old ones successively returned with food, it betrayed none of those emotions common to young birds, which would certainly have thrown it off its balance; no tremulous movement of its flappers, no impatient stretchings of its neck, no gapings of its mouth. There it stood, motionless, as if conscious of the dangers attendant on even the slightest bustling display of satisfaction. It was impossible not to feel something like pity for the dull life it was doomed to lead in such a cradle; it being evident that, from the moment of its quitting its egg-shell, to that hour, the choice of standing on its right or left leg, or a cautious putting forth of one foot before the other, to the extent of a few inches, was the only source of amusement or variety within its reach. It was curious to observe the proceedings of many of the older birds. The din was incessant, and some seemed quite exhausted with screaming, or hearing others scream; for they might be seen flying off 
from the main body to a retired crag or niche, as if to rest awhile in perfect silence.

Now and then, indeed, as if by mutual consent, the uproar entirely ceased, and the whole body settled themselves on a rocky inclined plane, interspersed with grass, just below the light-keepers' dwellings, which formed their grand nursery establishment; for there, in every stage of growth, hundreds of young ones were moving about. No doubt each parent had a perfect knowledge of its own offspring, though, generally speaking, there were no signs of recognition; for, to all appearance, old and young seemed to mingle, without much reference to relationship; and a stranger might have supposed there was a common property in the nestlings. The only sign of parental attachment was, that an old bird would now and then fix its eye in a more pointed manner upon some one of these living gray puff-balls of downy feathers, and then, suddenly opening its mouth, deposit at the feet of the fledgling a crawful of half-digested shrimps and softened crabs.

We cannot quit this account of the Gulls and their breeding-places on the west coast of England without referring to the history of the Laughing Gulls (Larus ridibundus), which annually frequent a particular spot in Norfolk. From time immemorial, these birds have frequented an island in a mere about thirty miles from the sea, at Woodrising, the property of John Weyland, Esq. It contains within its banks about seventy acres, nearly thirty of which are occupied by a large island, consisting of about eighteen acres of remarkably fine reeds (Arundo phragmites), in great request for thatching; two or three acres of broad flag, as much of coarse grass, mixed with a small quantity of fine sedge, and about sixteen in the centre, where the island is firmly attached to the bottom, are occupied by birch brushwood, out of which rise birch-trees, from thirty to forty feet in height, not one of which has ever been blown down by the gales, which often make sad havoc with the oaks and other trees. It is on this island chiefly that the Gulls breed, a few only wandering to smaller pieces of water in the neighbourhood. 
The produce of the island being valuable, is completely cleared off in the course of the Winter, except the brushwood and trees; so that in the early Spring it is in a very convenient state for the accommodation of the birds, the details of whose operations are as follows.

About the middle of February, for an hour or two in the course of the day, their well-known cry may be heard, high in the air, proceeding from a few stragglers. This goes on till about the end of the month, when, and in the first days of March, they appear in detachments of about fifty, flying near to the water, but never alighting upon it, being apparently occupied in reconnoitring, and departing after an hour or two. In a few days the numbers increase to detachments of about three or four hundred, but still departing after they have made their observations. Invariably, however, about the 8th of March, they come in thousands, settle upon the water, and take possession of the island.

The people on the spot have learned from their fathers, and it is confirmed by their own observation, that the day after Hingham fair, which is on the 7th March, is that on which the Scoulton Pies, as they call them, come to the mere. They are, as their English name, "the Laughing Gull," implies, garrulous and noisy birds, being rarely silent for more than one hour out of the twenty-four. In about a. fortnight they pair and begin to build; their nests are very simple, a few cross pieces of the softer remnants of the reeds and grass, and so closely packed together on the favourite spots by the edge of the water, that an outspread hand would touch two or three of them. They lay three thin-shelled eggs, and instantly begin to sit, so that the egg-gatherers are obliged to be on the alert to take them before that process begins. For some time no eggs were allowed to be taken, but on its being ascertained that, in consequence of so many being hatched at once, several were starved, a certain proportion only were preserved, and the remainder are for a few weeks taken, that there may be a succession in the hatches of the broods.

The number of eggs collected annually varies from fifteen 
to twenty thousand, and more might be taken occasionally; for instance, thirty thousand would not have been too large a proportion for this Spring (1837), it having been a wet one. Notwithstanding this drawback, the number of these annual visitants appears to increase. They feed themselves and their young on week days by following the ploughman's heels, pouncing fearlessly upon the grubs and worms turned up by the share, so that they are great favourites with all the farmers within six or seven miles of the mere. On Sundays, when the ploughs are not at work, they betake themselves to the meadows and dry pastures, in search of similar food, foraging over a whole field with the greatest regularity and order.

The eggs are very good eating: the yolk is considered by many equal to the Plover's, but the white less transparent and gelatinous. The young birds being web-footed, take to the water as soon as hatched, but are fed by the old ones till they can fly; when nearly fledged, they are not bad food, though not often brought to table at present. The young birds for the first year are of a brownish grey colour, with partial patches of white, but have neither the black cap, nor black tips of wings, nor the delicate white of the breast, nor the slate-coloured back and wings, which they return with in the following year. They remain till the young birds are strong enough for a long flight, when they assemble in detachments on an open field in the evening, and go off in the night. The first detachments retire about the end of July, and they almost entirely disappear in the course of August.

To what regions the great body resort for their Winter abode is not exactly known; probably they separate, and parties linger in particular spots, as in the Autumn they appear in great abundance on the coast of Carmarthen and Glamorganshire, about the mouths of rivers. In Northumberland they are also common, and for many years have attached themselves to a large pond at Pallinsburn, the seat of A. Askew, Esq., where their habits and punctuality are similar to the account above given, and from whence (in con- 
sequence of the increase produced by the protection afforded during the breeding season) flocks have at different times detached themselves to such other situations in the neighbourhood as were suitable.

The following account of these birds, from Dr. Plot's History of Staffordshire (p. 231, edit. Oxford, 1686), is also worthy of attention, partly from its accuracy, and closely corroborating that just given, and partly as an instance of the credulity of the otherwise talented writer, who so easily fell into the superstitions notions of the neighbourhood, and firmly believed that the attachment of these birds to particular spots depended on the life and death of the proprietors :-

"But the strangest whole-footed water-fowle that frequents this country is a species of Gull; in some counties called the Black-Cap, in others, the Sea or Mire-Crow, here, the Pewitt; which being of the migratory kind, comes annually to certain pooles in the estate of the right worshipfull Sir Charles Skrymsher, knight, to build and breed, and to no other estate in or near the county, but of this family, to which they have belonged ultra hominum memoriam, and never moved from it, though they have changed their station often. They anciently came to an old Pewit poole, about half a mile S. W. of Norbury Church, but it being their strange quality (as the whole family will tell yow; to whom I referr the reader for the following account) to be disturbed and remove upon the death of the head of it, as they did within memory, upon the death of James Skrymsher, Esq., to Offley Moss, near Woods-Eves, which Moss, though containing two gentlemen's land, yet (which is very remarkable) the Pewits did discern betwixt the one and the other, and build only on the land of the next heir, John Skrymsher, Esq., so wholly are they addicted to this family.

"At which Moss they continued about three years, and then removed to the old Pewit poole again, where they continued to the death of the said John Skrymsher, Esq., which happening on the eve to our Lady-day, the very time when they are laying their eggs; yet so concerned were 
they at this gentleman's death, that, notwithstanding this tie of the law of nature, which has been ever held to be universal and perpetual, they left their nests and eggs; and though they made some attempts of laying again at Offley Moss, yet they were still so disturbed that they bred not at all that year.

" The next year after they went to Aqualat, to another gentleman's estate, of the same family, (where, though tempted to stay with all the care imaginable,) yet continued there but two years, and then returned again to another poole of the next heir of John Skrymsher, deceased, called Shebben Poole, in the parish of High Offley, where they continue to this day, and seem to be the propriety, as I may say (though a wild fowle), of the right worshipfull Sir Charles Skrymsher, knight, their present lord and master.

"But, being of the migratory kind, their first appearance is not till about the latter end of February, and then in numbers scarce above six, which come, as it were, as harbingers to the rest, to see whether the hafts or islands in the pooles (upon which they build their nests) be prepared for them; but these never so much as lighten, but fly over the poole, scarce staying an hour. About the sixth of March following, there comes a pretty considerable flight, of a hundred or more, and then they alight on the hafts, and stay all day, but are gone again at night. About our Lady-day, or sooner in a forward spring, they come to stay for good, otherwise not till the beginning of April, when they build their nests, which they make not of stickes, but heath and rushes, making them but shallow, and laying generally but four eggs, three and five more rarely, which are about the bignes of a small Hen egg. The hafts or islands are prepared for them between Michaelmas and Christmas, by cutting down the reeds and rushes, and putting them aside in the nookes and corners of the hafts, and in the valleys to make them level; for should they be permitted to rot on the islands, the Pewits would not endure them.

" After three weeks' sitting, the young ones are hatcht, and about a month after are almost ready to flye, which 
usually happens on the third of June, when the proprietor of the poole orders them to be driven and catch'd, the gentry comeing in from all parts to see the sport; the manner thus. They pitch a rabbit-net on the banke side, in the most convenient place over against the hafts, the net in the middle being about ten yards from the side, but close at the ends in the manner of a bow; then six or seven men wade into the poole beyond the Pewits, over against the net, with long staves, and drive them from the hafts; whence they all swim to the bank side, and landing, run like Lapwings into the net, where people standing ready, take them up, and put them into two penns made within the bow of the net, which are built round, about three yards diameter, and a yard high, or somewhat better, with small stakes driven into the ground in a circle, and interwoven with broom and other raddles; in which manner there have been taken of them in one morning, fifty dozens at a driving, which, at $5 s$. per dozen, (the ancient price for them,) comes to $12 l$. 12s.; but at several drifts that have been anciently made in the same morning, there have been as many taken as have been sold for $30 l$. So that some years the profit of them has amounted to fifty or threescore pounds, besides what the generous proprietor usually presents his relations, and the nobility and gentry of the county withall, which he constantly does in a plentifull manner, sending them to their houses in crates alive, so that feeding them with livers and other entrals of beasts, they may kill them at what distance of time they please, according as occasions present themselves, they being accounted a good dish at the most plentifull tables.

"But they commonly appoint three days of driving them, within fourteen days, or thereabout, of the second or third of June; which, while they are doing, some have observed a certain old one that seems to be somewhat more concerned than the rest, being clamorous, and striking down upon the very heads of the men, which has given ground of suspicion that they have some government amongst them, and that this is their prince, that is so much concerned for its subjects. 
"And 'tis further observed, that when there is great plenty of them, the Lent corn of the country is so much the better, and so the cow pastures too, by reason they pick up all the worms, and the fern flyes, which though bred in the fern, yet nip and feed on the young corn and grass, and hinder their growth."

We next come to the largest sea-bird that flies, the Wandering Albatross (Diomedea exulans), of which we have already partially spoken; but large as they are to the eye, they are not so in reality, for so abundantly covered are they with feathers, that when plucked, they appear not above half their original size, and when cleaned, their weight is comparatively trifling. With this light body, and an immense spread of wing, our surprise is lessened at their being able to venture so far from land; Captain King* having met with them almost a thousand miles from the nearest shore.

It is a pleasing relief to the eye, when sailing over the landless oceans frequented by the Albatross, and where, except now and then a passing sea-bird, nothing meets the sight but a tract of boundless water, to observe this superb bird sailing in the air, in graceful and elegant movements, seemingly under the influence of an invisible power; for, when once elevated in the air, there is scarcely any visible movement of its wide wings. Rising, as if some concealed power guided its various motions, without any muscular exertion of its own, and then descending, it sweeps the air close to the stern of the vessel, with an independence of manner as if it were monarch of all it surveyed.

It has been remarked by an observer, who has given the best account of these birds, $\uparrow$ that they could lower themselves even to the water's edge, and then again rise without any apparent impulse. Whether with or against the wind, seems to be a matter of indifference to them. No tempest troubles the Albatross, for he may be seen, with equal vigour, sportively wheeling in the blast and carousing in the

* KInG's Australia, vol. ii.

$\dagger$ Bennet's Wanderings in New South Wales. 
hurricane. Of this noble bird it may indeed be literally said,

His march is o'er the mountain waye,

His home is on the deep.

In the gale he will sweep, occasionally, the rising billows, and seem to delight in the spray bursting over him. Tired, in truth, they rarely are; but should they be, though never seen to swim, they can, in consequence of their feet being webbed and remarkably large, walk on the surface of the water when it is smooth, with hardly any assistance from their wings; and the noise of their tread may be heard at a great distance.*

They are most voracious birds, and easily caught by baiting a hook with offal and letting it trail after the vessel by a long line; on seizing and swallowing the bait, it will sometimes rise into the air, from whence, by hauling on the line, as a boy does a kite, it is brought on board. Sometimes, however, they break the line and escape, which has afforded a proof of the distance and length of time they will follow a vessel. Thus when hauling in one of large size, the line slipped, and the bird consequently swallowed the hook, and a portion of the line; the remginder of which hung pendant from the beak. From being thus marked, it was ascertained that it followed the ship two days, and might have been doing so for days before ; and in these fortyeight hours, as she sailed at the rate of two hundred miles a day, from the irregular flight of the bird, the space it went over could not have been less than three or four times that distance. Their reason for preferring rough weather to smooth may easily be accounted for, the agitation of the waves no doubt bringing to the surface those marine animals which serve them for food: they will glide down on them with unerring aim and fearful force, transfixing whatever they have aimed at with their large, strong, and trenchant bill.

A poor fellow who fell overboard from a man of war, off

* WEDdelL. 
the Island of St. Paul's in the Southern Indian Ocean, was immediately perceived by two or three Albatrosses; the boat was lowered with all speed, but nothing was found excepting his hat, pierced through and through with the violent stroke of their beaks, the first of which had, most probably, penetrated the skull and caused instant death.

These birds are found round the whole circle of the globe in the Southern Seas, retiring to breed in the most desolate and dreary situations. Captain Weddell, who has penetrated further into these inhospitable southern regions than any other navigator, met with them in great numbers amidst the icy rocks of the New South Shetlands, associating, as we shall hereafter see, with the Penguins; though in the dreary island of Tristan d'Acunha, another traveller, Mr. Earle, describes them as the sole occupants, without any interloper, whether friend or enemy. In the higher regions, amidst the barren and cindery peaks of black rocks composing that dismal island, he found the young ones on the ground completely uncovered, and the old ones stalking around them. Each bird lays but one egg, and after the young one is hatched, it has to remain a year before it can fly.

Their style of courtship, and of selecting their mates, is described as very ludicrous. The couple approach one another with great apparent ceremony, bringing their beaks repeatedly together, swinging their heads, and contemplating each other with very deliberate attention. Sometimes this will continue for two hours together, like a courtship in a pantomime. They have great power in their beaks, and when on the nest they will defend themselves for half an hour against an active dog.

Mr. M'Cormick, surgeon in Sir James Ross's expedition of discovery in the Antarctic regions, corroborates this account, and gives the following more minute description of one of their places of resort for breeding, in Campbell's Island. He sayss, "during our stay in the months of November and December, the Albatrosses were so busily employed in the work of incubation, as to allow themselves to be caught without making "an effort to escape. It was an 
amusing scene to watch a group of these birds, a dozen or more, assembled together on the side of a hill, grotesquely waddling about, selecting their mates; this being settled, they dispersed, and each pair fixed upon a spot for the nest, which consisted of a mound of soil, intermingled with withered leaves and grass, the average dimensions of which were found to be eighteen inches in height, twenty-seven in diameter at the top, and six feet at the base. Like the Petrels, with which genus they are nearly allied, they lay but one egg, of a white colour, averaging seventeen ounces in weight. In one nest only, out of at least a hundred examined, were found two eggs, both of the full size, and one of them unusually elongated in its longest diameter. When forced off the egg, it made a resolute defence, snapping: the mandibles of its beak sharply together in defiance."

Their eggs are inferior to those of Geese, and they have less yolk, and more white, in proportion to their size, weighing generally about one pound and three quarters. All birds of the Albatross and Gull kind on these islands lay their eggs in October; and when new laid they are a great source of refreshment. Voyagers mention another large bird, called the Nelly-bird, also a species of Albatross (Diomedea spadicea), of an unpleasing appearance, and extremely voracious. Their fondness for blubber often induces them to eat so much, that, like the gorged Gull we have described, they are unable to fly. A flock, of perhaps five or six hundred, have been known to devour twenty tons of sea-elephant fat in six or eight hours; that is, upwards of seventy pounds for each: The Albatross will, at one gulp, swallow a salmon of four or five pounds weight; but if more be taken, and the whole will not go into the stomach, the bird is often seen with the last hanging partly out of the mouth. We have noticed (p. 390) the proportion of food consumed by a Cormorant, compared with the weight of the body, but its voracity is as nothing in comparison with that of the Nelly-bird, which appears in the course of twenty-four hours to dispose of nearly three times its own weight of food.

The last genus of this tribe is that of the Petrels, two 
only of which are well known to us, as frequenters of our shores: the Fulmar, which is nearly as large as a Gull, and the Stormy Petrel, better known to sailors by the name of Mother Carey's Chickens, about the size of, and in appearance not unlike, the Swift, or largest Swallow. Their whole bodies seem to be filled and impregnated with oil to such a degree, that in some of the most remote islands of the Hebrides the inhabitants actually form them into candles, by merely passing a rush through the body and out at the beak, which is found to burn as well as if dipped in tallow or any other grease. So full are they of this oil, that the Fulmar uses it as a weapon of defence, and when taken will squirt over the person who handles it a strong jet of pure oily liquid. When shot, if it falls into the sea, a partial calm is created by the quantity ejected from its mouth.

With their quantity of down, which supplies the islanders with warm bedding,-and fat, which is considered an efficacious remedy for wounds; as is their oil, which is preserved in large bunches of long bladders, made of the gorge or stomach of the Solan Geese;-these birds become more valuable to the inhabitants than the poultry tribe to us. The poor people of St. Kilda, in a word, prize them so highly that it is proverbial with them to say, "Deprive us of the Petrel and Fulmar, and St. Kilda is no more."

They build, like most other sea-birds, in holes and chinks of rocks, or on the ledges of precipices ; though upon Norfolk island, in Australia, a species has been discovered which burrows in sand like rabbits, lying hid in the holes by day, and sallying forth in the evening in quest of food. Their reason for concealing themselves appears to be well founded; for no doubt this is the same species met with in the other remote islands of the Southern Indian Seas, spoken of * as living in perpetual dread of another of its own genus, the great Black Petrel (Procellaria equinoctialis); and well it may, for its sable enemies are incessantly looking out for its heart and

* Macartney's Voyage, vol. i. 
liver, on which alone they feed, leaving the rest of the body untouched.

At night, therefore, only, they venture forth, but not with much safety, for then a new danger awaits them, in the shape of the seal-catchers, who attract them by torches, and kill them in multitudes, for the sake of their oil. They probably, however, prefer the darkness of night for other reasons; for our common Stormy Petrels, whose hearts and livers are in no danger from enemies by day, are observed by the people employed in the cod-fisheries of the north, to come forth like the Bat at dusk, when they see them skimming over the water, catching a glimpse of them only by the white spots on their rumps, and the side feathers of their tails. But though apparently so wild and solitary, if caught and taken home, they will become so tame as to suffer themselves, without the least fear, to be touched and handled. One kept in a cage for some time was supported by means of smearing the feathers of the breast with train oil, which the bird afterwards sucked with its bill. When the oil was placed in a saucer in the cage, it would dip its feathers therein, and then suck the oil from them.

Sailors have a superstitious dislike to the Stormy Petrels, or, as they are commonly called, Mother Carey's Chickens, believing that their appearance forebodes storms, with which they are in some way or other connected. That storms do frequently occur when, or soon after, these birds are seen, is certainly true; but the cause probably is, that, instinctively feeling the approach of a gale, they are disquieted, and are anxiously awaiting its arrival, and, therefore, hover round the ship, which they imagine may shelter them from its fury; for, unlike the Albatross, or Gull, they seem to dislike the war of elements; and to this dislike may probably be attributed the otherwise unaccountable circumstance of their being so often found even many miles inland. The fact might be doubted, but for numberless recorded instances; for there is scarcely a county in England in which they have not been seen.

In 1832 upwards of twenty instances occurred, and many 
of them in the midst of crowded towns; thus, after a series of tempestuous weather, one was captured, which had been seen flying up and down the streets of a populous town, about seven or eight feet above the ground, apparently much exhausted; and in October, 1846, one was picked up in Broad Street, Halifax, remaining alive only a few hours, driven inland, no doubt, by recent stormy weather; while others, after severe storms, have been seen flying about the iron-furnaces at Low Moor, near Bradford, in the West Riding of Yorkshire, probably attracted by the blaze of their immense fires.

They do not, however, always follow ships merely for shelter; we suspect that the scraps of food or grease, which occasionally fall overboard, frequently attract them. We have heard of one which accompanied a ship from the Channel to the very shores of America, picking up or examining everything that fell overboard. It was observed to be more clamorous during the night than the day. It appeared, moreover, to those who watched it, to dive, and remain under water for half an hour or more; and we have heard this power of immersion attributed to it by others ; but we are inclined, nevertheless, to doubt even its power of diving at all; its form, lightness, thick coating of feathers, all being: against its remaining under water for any length of time; added to which, such a power would be unnecessary, its food being prepared for it on the surface of the waters, and not below. 


\section{TABLE XXX. (See page 23.)}

Order 6. Palmipedes. Tribe 4. Brenipennes. (Short-winged.)

THE characteristic feature of this, the last tribe of the last 1 order of birds, is the extreme shortness of the wing, which, in many of them, prevents their flying to any distance, and, in some, partakes more of a fin than a feathered wing. Their legs are, moreover, placed far behind ; their plumage is close and glossy, so as to resist water; all which peculiarities fit them for a more exclusively water life. It is divided into four genera :- -1 . Grebes, or Divers; 2. Guillemots; 3. Auks, or Puffins; 4. Penguins.

The Grebes, which take precedence in this list of the shortwinged tribe, are the only birds whose habits lead them to pass comparatively peaceful lives, on the less agitated surfaces of our inland lakes and meres; the others being all, more or less, sea-birds, whose dwelling-place, when on land, is on wild rocks, exposed to storm and tempest, of which they take no heed, defended as they are by a rich coat of glossy plumage, whose smooth and oily surface is impenetrable to water.

The Grebes, though classed amongst the palmated or webfooted families, nevertheless, in some species at least, differ from them in one respect,- -having only partial webs; the toes being flattened and furnished with what is called lobes or membranes, like those of the Coot. They are unsocial solitary birds, seldom more than a pair being seen together; and withal, so shy, that it requires all the address and skill of a keen sportsman to get within shot; though the inexperienced may think it an easy matter so to do, when he sees one of them apparently dozing within a few yards of the rushy confines of a pool of water. But the Grebe is neither sleeping nor off his guard; as the gunner would know, were he near enough to watch the motions of the wary bird. $\mathrm{He}$ would then see its clear penetrating eye glancing in every 
direction, alive to the approach of friend or foe, and, if suspicious of danger, its body gradually sinking, until the upper part of it only remained visible, and its sharp, lance-shaped head thrown back on its slender neck, prepared to plunge at a moment's notice. So rapid indeed are their movements, that, on seeing the flash of a gun, they can dive into security, below the water, before the shot can reach them, as the following account will show :-

"As I was out shooting," writes an eye-witness, "I saw one of these birds swimming towards a point of land, where I could easily conceal myself; so I repaired thither for that purpose. He came onwards with a wild anxious gait, constantly turning his head from side to side, as if to be upon his guard against an enemy. I had arrived at the place, and the bird was approaching. Now and then, as he came on, he stretched his long neck, for several seconds, under the water, looking for small fish; and when he had nothing better to do, he turned his head round, in order to tickle his tail with his bill. Watching the moment when he was so engaged, I fired, at the distance of thirty yards. My gun went quick as lightning, but the Grebe went quicker, and scrambling over, out of sight, came up again in a few seconds perfectly unhurt."

The skins of these birds, from their beautifully soft and silky texture, make valuable tippets for ladies, and form an article of trade from North America, and other countries where they abound. They are chiefly taken by the Indians, who contrive to kill them at great distances, using a large quantity of powder and very little shot; and they have also a way cf enticing them by a particular call, and a red rag at the end of a stick-methods which they practise with great success.

One of the most common in our country, and at the same time one of the most beautiful, is the Crested Grebe (Colymbus cristatus), of whose head we have given a figure (see page 72). The bird has the power of moving the sort of shawl, or tippet, round its neck, as well as the two tufts or crests on its head, which, when erected, appear like two horns. This 
species, as well as some others, such as the Sea-Lark, already mentioned,* when alarmed, carries off its young under the wing. We once saw an old one, basking in the middle of a large sheet of water, with one or two young ones, apparently not long hatched, swimming round her. By the assistance of a telescope, the little downy Divers might be seen, enjoying their new existence; at one moment darting along the surface, and then scrambling on the mother's back, who floated motionless, and continued to plume herself, while the brood gambolled about her. One of the largest of this genus, the Great Northern Diver (Colymbus glacialis), may also be called a British Bird, though but a rare visitant, preferring the more remote shores of the north, where it passes its existence as far as possible beyond the reach of men; not, however, that it can escape the snare of the hunter,-numbers being taken by the persevering efforts of those who know the value of their skins, which, when tanned and dressed, make excellent caps and jackets. But although the poor birds cannot avoid falling a prey to their pursuers, they contrive so effectually to seclude themselves from observation, during the breeding-season, that, in the Orkneys, and other northern islands which they frequent, the inhabitants really believe that they make no nests at all, but, never leaving the sea, hatch their eggs under water, in a hole beneath the wing, prepared by nature for that purpose,- - a belief, no doubt, encouraged by their being seen, like our Crested Grebes, taking their young upon their backs, or under their wings, for protection.

Rare as these birds are, they sometimes, either by choice or stress of weather, wander from their dreary northern abodes, and have been met with, very unexpectedly, not far from the habitations of men. For instance, a few years ago one was shot on Styperson Pool, in Adlington, near Macclesfield: either from the close and glossy texture of its feathers, or its agility in diving, it was fired at nine times before it could be secured, and at length received its death-wound from 
a shot in the head. In the throat, which presented the appearance of a bag appended to the gullet, were found fourteen large perch, quite whole and fresh. Its voracity was such, that even after it was evidently wounded, it continued to bring up fish when diving, remaining at each immersion several minutes under water, and making its way beneath the surface from one end of the pool to the other. Another of these birds was observed for a considerable length of time on a large piece of water at Westwood-park, near Worcester. The situation of this lake was very retired: no boat was upon it, and scarcely any person allowed to approach. This rare visitant seemed to excite as much alarm amongst the other wild fowl on the lake, as surprise amongst those who had the opportunity of seeing it: for, whenever the stranger approached, they hastened out of the way, and at all times kept as far off as possible. No attempt was made to capture it, as the owner of the water would not allow it to be molested. Their extreme shyness and timidity, though on the whole contributing to their preservation, is, in some instances, the cause of their being taken. Thus, the Red-throated Diver, another species near akin to the above, when met with by the natives of the northern inlands, flying, as they often do, from one of the small inland lakes to another, are so terrified by loud shouts, that they will frequently fall down; and if they drop on the grass or heather, are easily caught by hand, as from the awkward position of their legs, which, though well suited for water, are by no means adapted for land, they can neither walk nor take wing again.

The Guillemots constitute a family of sea-birds in many respects resembling the Divers, but with wings still shorter; the chief distinction, however, is their having no hind-toe or thumb; they live on fish and crabs, and when on land frequent ledges of rocks, where they build their nests. The species best known to us is that called the Foolish Guillemot (Colymbus troile), a name probably acquired by its apparent stupidity, in not only allowing a very near approach, but even frequently remaining within shot, although its companions may have been killed close to it. These are the 
birds which so often attract the attention of passengers in steam-boats, by remaining quietly tossing on the waves, without seeming to notice the noise and splashing of the paddles; seldom, if ever, taking flight, but usually diving and rising again at short distances. The bird, however, by no means merits its character for stupidity, as those who are the most experienced fowlers find it a very difficult matter to catch them, except by means of snares laid near their nests.

Closely allied with these, and by many naturalists more or less associated with them, are the Alca tribes, comprising, amongst other birds, our Razor-bills and Puffins, which, although not generally scattered over our shores, are found in prodigious numbers on certain favourite spots, which they have from time immemorial selected for themselves. One of the most frequented spots for the latter is Puffin Island, near Beaumaris ; though further towards the north, they are still more widely spread, and may be found during the breedingseason, in still greater abundance. They are often called SeaParrots, from the peculiar form of the beak, capable of inflicting very severe wounds, and of which they make great use, sometimes to their own disadvantage, as the following singular mode of taking them, which does not seem confined to our own country, will fully prove.

"In Iceland," says Dr. Henderson, in his missionary travels to that island, "they are caught by means of a hook fastened to the end of a stick; and what is singular, when one is dragged out, his companions take hold of him, and endeavour to retain him; by which means they are often caught to the number of three or four at a time."

"In Norway," says Colonel Brooke, "Puffins breed in great numbers on the rocks, and the mode of catching them is precisely the same as that adopted in the northern parts of Great Britain, with the exception that a dog is trained to the sport. The Puffins sitting together in prodigious numbers in the deep holes and clefts of the highest rocks, one of these little dogs is sent in, which seizes the first by the wing. This, to prevent being carried away, lays hold with its strong 
beak of the bird next to it, which in like manner seizes its neighbour, and the dog continuing to draw them out, an extraordinary string of these birds fall into the hands of the fowler. They are in Norway taken for their feathers, which are valuable."

Social as they appear, and attentive to their young, there yet seems to be a curious exception occasionally occurring towards the close of the breeding-season, when, on their departure, the broods of the latter hatches are left a prey for the Peregrine Falcon, who watches at the mouth of the holes, and seizes the poor starving nestlings, when compelled through hunger to quit their inner-chambers, thus escaping the lingering pains of famine by a more violent and immediate death.

With respect to the Razor-bills and Guillemots, we shall again refer our readers to the same rock-scenery of the South Stack, already noticed in our observations on Gulls, where, as on a stage of Nature's theatre, we have often watched their motions from the verge of a projecting little promontory, or arm of rock, immediately facing a precipice beyond the reach of human intrusion, intersected by innumerable fissures, crevices, ledges, and shelves, admirably adapted for tenants requiring such accommodations, and where, accordingly, an army of Razor-bills and Guillemots have taken up their position, almost, though not entirely to the exclusion of the Gulls; and therein, as if conscious of their safety, (it being an inviolable rule never to disturb them, they carry on their usual occupations with the most perfect unconcern, permitting an observer to enter fully into their domestic arrangements.

At our last visit, closely jammed, in a lateral niche, just opposite, sat seventy-two Guillemots, all bowing their heads at each other, with a gravity and solemnity quite unaccountable. On they went for above a quarter of an hour without intermission; each nodding slowly to its neighbour, who, with equal composure, nodded as slowly in return. Now and then, on another ledge, one or two would come in from a 
short excursion, and jostling the whole line, send a dozen or two backwards over the dizzy height, croaking disapprobation at the intruders, who took the vacant places, utterly disregarding the confusion they had caused. It was impossible at first sight to divest oneself of an involuntary shudder, as they tumbled backwards headlong into the abyss, where the sea was roaring and lashing the rocks below them, their squat plump bodies supported only by such comparatively disproportioned wings. One felt at every moment a sort of rising exclamation, " $\mathrm{Ah}$, poor bird, nothing can save it; it must be killed!" when, flapping its little pinions, away it went cleaving the air, making its circuit of a mile or so, skimming now and then over the sea, but never touching the waves, and then rejoining its friends on the ledge, and in its turn jostling the line, and causing a similar ejectment of half a dozen others. In these solitary flights, however, they now and then meet with unpleasant adventures, as certain Hawks inhabiting the mainland occasionally make a dash at them. One day, the light-keepers were witnesses of one of these curious rencontres.

The Hawk was seen in full chase of a Razor-bill, but aware, probably, of the toughness of its skin, instead of assaulting his prey with the usual death-pounce from the beak, he seized the unfortunate bird by the head with both his claws, and made towards the land, his prisoner croaking, screaming, and struggling lustily; and, being a heavy bird, so far incommoded or over-balanced its aggressor, that both descended fast towards the sea, when just as they touched the water, the Hawk let go his hold and ascended,- - the Razor-bill as instantaneously diving below.

Amidst the myriads of old ones, we looked in vain for anything like a corresponding number of young, but scarcely a single individual was to be seen. It is true that the females produce only one egg; but still that could not account for the small number visible: we could only therefore suspect, from certain friendly croakings uttered by the old ones, when turning their heads towards little chinks, 
the extremities of which were invisible, that the infant birds were kept in the back-ground; and well they were so, for otherwise, in the constant disturbances and tumblings incessantly taking place, the whole rising generation must inevitably have broken their necks in the confusion, by falling over before they were able to fly. But a greater surprise was excited by perceiving, in the midst of the bustle, a solitary egg here and there lying on the bare rock, within a few inches of the edge. By what care or instinct was it preserved from falling? It has been said, that if they are removed by a human hand, it is impossible, or at least extremely difficult, to replace them in their former situation; whence it has been inferred, that they are glued by some secret cement to the rock. Some of our ablest naturalists, however, doubt this; but if it is not so, the mystery is rather increased than lessened-for they are in a most hazardous position; but they are preserved, though by what means we have yet to learn.

The Razor-bills were by no means so numerous as the Guillemots, and, generally speaking, did not mix with them; seeming to hold themselves apart as the better bird of the two, peering at one another, and pluming their coats with a sort of dandy satisfaction at their superior brilliancy and glossiness.

Besides these more common species, there are others rarely found in Britain, being chiefly confined to the colder and more inhospitable regions of the northern or southern divisions of the globe, where they exist in numbers almost surpassing our powers of computation. One species in particular, the little Auk, or Greenland Dove (Alca alle), Sir Edward Parry met with by millions, when the ships got amongst the ice in particular spots, and they were killed for sea provisions. But in the southern hemispheres they appear to be even still more abundant.

Adjacent to the islands of Australia, * the Sooty Petrels (Procellaria pacifica), congregate in incredible masses, of 
from fifty to eighty yards in depth, and of three hundred yards or more in breadth, not scattered, but flying as compactly and as close as the free movement of their wings will allow, and passing for a full hour or more with a swiftness little inferior to that of a Pigeon. On these data, it has been calculated that the number in such a flight would amount to one hundred and fifty-one million, five hundred thousand birds! about one fifth of the whole population of the globe. These birds live and breed in burrows, and the number of burrows required to lodge such a flock would not be far short of seventy-six millions; and allowing a square yard for each burrow, the space covered would be something more than twenty-four and a half square miles, or nearly fifteen thousand six hundred and eighty acres of ground!

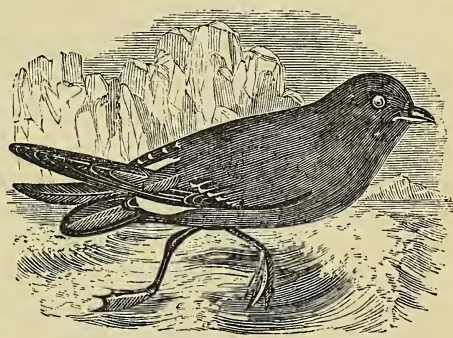

Petrel.

And though in such cheerless solitudes, man would soon perish for want of sustenance, living food seems to be placed there by Providence to a greater extent than in any other known parts of the habitable globe. Countless as are the myriads of these birds, still more countless, by millions and millions of figures, are the lesser marine beings on which they feed. Some idea may be formed of their abundance, by calculating the length of time that would be requisite for a certain number of persons to count the quantity contained in one square mile of sea-water. Allowing that one person could count a million in seven days, which is barely possible, it has been calculated that no less than eighty thousand persons should have started at the creation of the world, nearly six thousand years ago, to complete the calculation to the present time! And if, passing beyond the consideration 
of the actual numbers, we reflect that each of these minute beings has not only life, but a body wonderfully made, with instincts and senses peculiar to each,- -how infinitely beyond the power of our imagination to conceive, is that great and overruling Power, who hath measured the waters in the hollow of his hand, and meted out the heavens with a span. 


\section{CHAPTER XX.}

Penguins-Fin-winged-King Penguin of the Southern Regions described-Breeding-Places-Valuable for Oil.-Sea-Fowler's perilous occupation-Description of, in Shetland, St. Kilda, \&c.-Singular Escapes-Fatal Accidents.

HITHERTO we have considered birds as more or less 1 inhabitants of the air, gifted with wings for that purpose: it remains for us to speak of two families, possessing, indeed, wings, but too small to assist them in flight, and used, therefore, only as fish use their fins, for giving them additional powers on, or beneath, the surface of the water, where they pass the greater part of their existence. They are the Penguins, properly so called, and the Aptenodytes, a word compounded from the Greek, signifying wingless divers; for although the wings of the former scarcely deserve the name, they are nevertheless co-

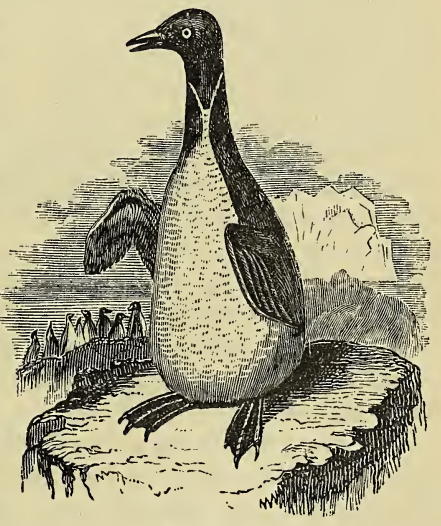

Penguin. vered to a certain degree with feathers, whereas those of the latter are only furnished with vestiges of feathers, at first sight much resembling fish-scales.

The Penguins are chiefly confined to the coldest regions of the northern or southern hemispheres. The rapidity with which these birds fly, if it may be so termed, under 
water after fish, is quite astonishing. One which was caught in the Orkney Islands at first refused all food, and became so weak that it was expected to die; at length, however, it was tempted to eat, and being plentifully supplied with fish, soon resumed its strength and activity. With a cord tied round its leg to prevent its escape, it was permitted to sport in the water; but even with this restraint, which must have very much impeded its motions, it performed the motions of diving and swimming with a speed that set all pursuit from a boat at defiance, affording the most convincing proof that, had it been at full liberty, no fish could have escaped.

The Aptenodytes, which may be called southern Penguins, as they never come beyond the limits of the Southern Ocean, are very numerous on the lonely isles scattered over the dreary wilderness of those seas. The largest of these, the King Penguin, exceeds a Goose in size. As their legs project from their bodies in the same direction with their tails, they walk upright; and when a flock of them are seen moving in file, or arranged along the ledges of the rocks, they appear like a company of soldiers ; for they hold their heads very high, with stretched necks, while their little flappers project like two arms. As the feathers on their breasts are beautifully white, with a line of black running across the crop, they have been by others compared to a row of children, with white aprons tied round their waists with black strings.

The great Albatross, as we have seen, spends the chief part of his life on the wing; the King Penguin, on the other hand, rarely quits the water, with the exception of the breeding season, when in some places, though not always, as we shall see in our account of the Albatross, in Tristan d'Acunha, both unite in vast flocks, and people the rugged rocks for a time. When a sufficient number of these birds are assembled on the shore, they appear, like the Herons, Storks, and some other species we have mentioned in the preceding pages, to pass a day or two in deliberation; on concluding the consultation, they will proceed to the execu- 


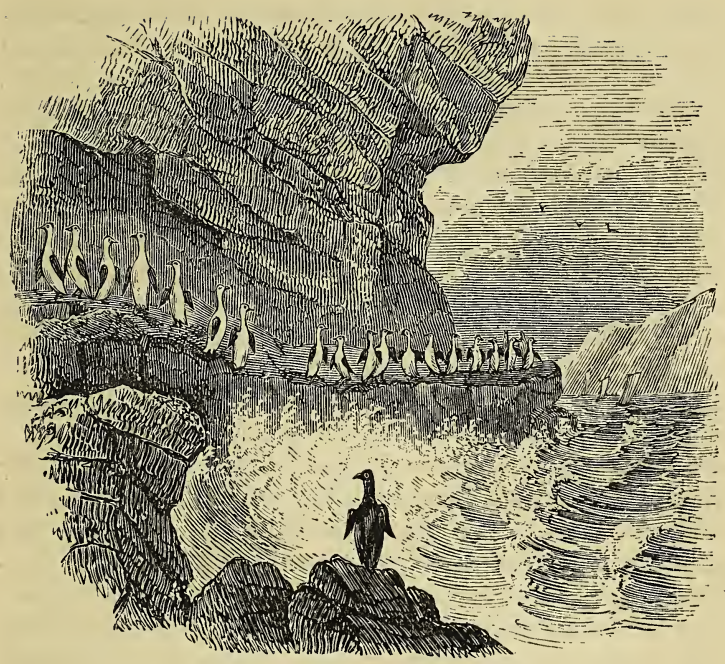

Penǵuins.

tion of the grand purpose for which they are then and there assembled. In the first place, they select* as level a piece of ground as they can find, often comprising four or five acres, and as near the water as possible,-always preferring that which is least encumbered with stones and other hard substances, which might endanger their eggs. As soon as they are satisfied on this point, they proceed to lay out the plan of their intended encampment; which task they commence by tracing a well-defined oblong, large enough to accommodate the whole united parties. One side of this square runs parallel with the water's edge, and is always left open for coming in and going out; the other three sides are differently arranged. 
The next step is to clear all the ground within the space from obstruction of every kind, picking up the stones in their bills, and carefully conveying them outside the lines, until they sometimes raise quite a little wall on three sides of their space. Within the range of stones and rubbish they form a pathway, six or seven feet in width, quite smooth. On this path they all walk by day, and on it the sentinels patrol by night. Having thus finished what may be called their outworks, they next lay out the whole area in little squares of equal size, formed by narrower paths, which cross .each other at right angles, and which are also made very smooth. At each intersection of these paths, an Albatross constructs her nest; while in the centre of each little square is a Penguin's nest.

In this regular manner is the whole space taken up by Penguins and Albatrosses, with the addition of a few other sea-birds, which find places in unoccupied spots. But although these Penguins and Albatrosses are on such intimate terms, and appear to go on so well together, they not only form very different nests, but the Penguin, when she can, will rob her neighbour's. She merely makes a slight hollow in the earth, just deep enough to prevent her single egg rolling out; whereas the Albatross throws up a little mound of earth, grass, and shells, eight or ten inches high, about the size of a small water-bucket, on the top of which she sits. None of their nests are ever left unoccupied for a single moment until the eggs are hatched, and the young ones old enough to take care of themselves. The male goes to sea till he has satisfied his hunger, and then returning, takes the place of his mate, when she flies off for the same purpose,the egg being conveyed to him by the hen placing her toes* together, and rolling it towards the male, the beak being used to place it properly.

During this season the Penguins may be seen marching round, or up and down the pathways of this marine rookery, as it may be termed, while the air is darkened by thousands

* WedDeLL's Voyage to the South Pole. 
of Albatrosses, hovering like a cloud,-some continually alighting and meeting their companions, while others are as continually rising and shaping their course towards the sea.

Many of the birds of the two latter tribes, either from their feathers, skins, oil, or eggs, are considered, as it were, the standard harvest of the poor people, who, like them, are destined to abide amidst the wild and lonely islands of the ocean : it is, therefore, natural to suppose that no means are neglected, no ingenuity left untried, in providing, whether for rent, clothing, food, or the lamp-light of their long and dreary Winter's nights, by laying in a store of each of these important articles, for which they are indebted to their companions, the sea-birds. And as the risks and difficulties which they encounter, and overcome, form leading features in their lives, we shall close our account with a few of the hazardous and interesting details connected with the reaping of this their fearful harvest.

It is chiefly on the most rugged shores of Scotland, or on the more rugged rocks of the several adjacent islands, or still further to the north, in the Shetland or Ferroe Islands, that this "dreadful trade" is carried on in the perfection of its horrors; though in some parts of Wales,-as, for instance, near the South Stack above-mentioned, and the Needle Rocks off the Isle of Wight,-adventurous climbers will occasionally exhibit feats of perilous achievement, quite sufficient to ${ }^{\circ}$ satisfy most beholders. In some parts of the coast, immense mounds or fragments of rocks have been cut off from the main land by terrible convulsions of nature, or the incessant wearing of waves through fissures and narrow channels for successive ages. On a few of these spots, sea-birds, for a time, rested securely, till some bold adventurers devised the means of invading their territories, crossing the space by means of cradles, suspended on ropes thrown across.

At Carrick-a-Reade, near the Giant's Causeway, in Ireland, and in the Shetland Islands, two of these airy conveyances are still in use; and, until a suspension-bridge was erected a few years ago, a third, and tolerably commodious and safe one, existed, connecting the South Staci rock with 
Holyhead mountain, in lieu of an original and far more primitive machine, which was for a time, of necessity, resorted to by those who wished to inspect the works on the island. It consisted of a small box, suspended on two strong ropes swung across a chasm of about a hundred and fifty feet, commencing its journey from a projecting point, about half-way down the precipice of the main land, from which the passenger was vaulted over the gulf, by a rope leading to the island,-a journey which, together with the scrambling down the unprotected face of the precipice, was sufficiently disagreeable and alarming to convey a correct idea of the far more terrific communications adopted in less frequented places; such as that in Shetland, between the headland of Bressa, a sort of column rising out of the sea to the height of three or four hundred feet above its level, and not more than four yards in diameter on its summit. It is said that this cradle, by which the inhabitants pass easily and readily, and, from habit, without any fear of danger, was erected by a bold man in the neighbourhood, who mounted the hitherto supposed inaccessible sides of the rock. A great number of people were assembled, expecting to see him lose his footing, and fall headlong: however, he succeeded, and when at the top waved his hat and cheered his friends; and then having, with their assistance on the opposite side, arranged the ropes and cradle, might have been the first to cross safely and successfully over his own bridge,--but being fool-hardy, and determined to descend by the way he had got up, before he had accomplished a third of the distance, his foot slipped, and he was dashed to pieces.

But though here and there accommodations like this, or others, for facilitating the visits of the bird-catchers to their particular haunts, may be at hand, by far the greater number are taken by enterprising individuals, who have only their own steadiness of head, strength of muscle, and dauntless spirit, to insure success. We will describe the means and proceedings of those in St. Kilda, a small speck of an island, the most westward and distant, (save a still smaller needlepointed uninhabited spot, called Rockall,) in the midst of the 
Atlantic Ocean, containing a few people, who, from infancy accustomed to precipices, drop from crag to crag as fearlessly as the birds themselves. Their great dependence is upon ropes of two sorts ; one made of hides,- the other of hair of cows' tails, all of the same thickness. The former are the most ancient, and still continue in the greatest esteem, as being stronger, and less liable to wear away, or be cut by rubbing against the sharp edges of rocks. These ropes are of various lengths, from ninety to a hundred and twenty and nearly two hundred feet in length, and about three inches in circumference. Those of hide are made of cows' and sheep's hides mixed together. The hide of the sheep, after being cut into narrow slips, is platted over with a broader slip of cow's hide. Two of these are then twisted together; so that the rope, when untwisted, is found to consist of two parts, and each of these contains a length of sheep-skin, covered with cow's hide. For the best they will ask about thirteen pence a fathom, at which price they sell them to each other.

So valuable are these ropes, that one of them forms the marriage portion of a St. Kilda girl; and to this secluded people, to whom monied wealth is little known, an article on which often life itself, and all its comforts, more or less depend, is far beyond gold and jewels.

The favourite resort for sea-fowl, particularly the oily Fulmars, is a tremendous precipice, about thirteen hundred feet high, formed by the abrupt termination of Conachan, the most elevated hill in the island, and supposed to be the loftiest precipitous face of rock in Britain.

\section{. . . . How fearful}

Anḍ dizzy 'tis, to cast one's eyes so low !

The Crows and Choughs, that wing the midway air,

Show scarce so gross as beetles; half-way down

Hangs one that gathers samphire; dreadful trade :

Methinks he seems no bigger than his head:

The fishermen that walk upon the beach

Appear like mice; and yon tall anchoring bark, 
Diminished to her cock; her cock, a buoy,

Almost too small for sight: the murmuring surge,

That on the unnumbered idle pebbles chafes,

Cannot be heard so high. I'll look no more;

Lest my brain turn, and the deficient sight

Topple down headlong.

Such is the beautiful description of Dover Cliff by Shakspeare; but what would he have said, could he have looked down from this precipice in St. Kilda, which is nearly three times higher, and so tremendous, that one who was accustomed to regard such sights with indifference, dared not venture to the edge of it alone? But, held by two of the islanders, he looked over into what might be termed a world of rolling mists and contending clouds. As these occasionally broke and dispersed, the ocean was disclosed below, but at so great a depth, that even the roaring of its surf, dashing with fury against the rocks, and rushing with a noise like thunder into the caverns it had formed, was unheard at this stupendous height. The brink was wet and slippery,-the rocks perpendicular from their summit to their base; and yet, upon this treacherous surface, the St. Kilda people approached, and sat upon the extremest verge; the youngest of them even creeping down a little way from the top, after eggs or birds, building in the higher range, which they take in great numbers, by means of a slender pole like a fishing-rod, at the end of which was fixed a noose of cow-hair, stiffened at one end with the feather of a Solan Goose.

But these pranks of the young are nothing when compared to the fearful feats of the older and more experienced practitioners. Several ropes of hide and hair are first tied together to increase the depth of his descent. One extremity of these ropes, so connected, is of hide, and the end is fastened, like a girdle, round his waist. The other extremity is then let down the precipice, to a considerable depth, by the adventurer himself, standing at the edge: when, giving the middle of the rope to a single man, he 
descends, always holding by one part of the rope, as he lets himself down by the other, and supported from falling only by the man above, who has no part of the rope fastened to him, but holds it merely in his hands, and sometimes supports his comrade by one hand alone, looking at the same time over the precipice, without any stay for his feet, and conversing with the other, as he descends to a depth of nearly four hundred feet. A bird-catcher, on finding himself amongst the Fulmars' nests, took four, and with two in each hand, contrived, nevertheless, to hold the rope as he ascended; and, striking his foot against the rock, threw himself out from the face of the precipice, and returning with a bound, would again fly out, capering and shouting, and playing all sorts of tricks. Frightful as such a display must be to those unaccustomed to it, accidents are extremely rare; and the St. Kildians seem to think the possibility of a fatal termination to these exploits almost out of the question.

It is indeed astonishing to what a degree habit and practice, with steady nerves, may remove danger. From the island of the South Stack above mentioned, boys may be seen frequently scrambling by themselves; or, held on by an urchin or two of their own age, letting themselves down the picturesque precipice opposite the island, by a piece of rope, so slender and apparently rotten, that the wonder is why it does not snap at the first strain. Yet, without a particle of fear, heedless of consequences, they will swing themselves to a ledge barely wide enough to admit the foot of a goat, and thence pick their way with or without the rope, to pillage the nest of a Gull, which, if aware of its own powers, might flap them headlong to the bottom.

Here, too, in St. Kilda, accidents are said to be of rare occurrence, though of course they do occasionally happen; but escapes sufficiently appalling to make the blood run cold to hear of, are common enough.

The first we shall mention happened about two miles from the South Stack, on the rocky coast of Rhoscolin. A lady, living near the spot, sent a boy in search of samphire with 
a trusty servant, to hold the rope at the top. While the boy was dangling midway between sky and water, the servant, who was unused to his situation, whether owing to a sudden dizziness from looking downward on the boy's motions, or misgivings as to his own powers of holding him up, felt a cold, sickly shivering creep over him, accompanied with a certainty that he was about to faint; the inevitable consequence of which, he had sense enough left to know, would be the certain death of the boy, and, in all probability, of himself, as in the act of fainting it was most likely he would fall forward, and follow the rope and boy down the precipice. In this dilemma, he uttered a loud, despairing scream, which was fortunately heard by a woman working in an adjoining field, who, running up, was just in time to catch the rope, as the fainting man fell senseless at her feet.

We shall add two more, equally hazardous and one fatal. Many bird-catchers go on these expeditions without any companion to hold the rope or assist them. It was on such a solitary excursion, that a man, having fastened his rope to a stake on the top, let himself down far below; and, in his ardour for collecting birds and eggs, followed the course of a ledge, beneath a mass of overhanging rock: unfortunately he had omitted to take the usual precaution of tying the rope round his body, but held it carelessly in his hand; when, in a luckless moment, as he was busily engaged in pillaging a nest, it slipped from his grasp, and after swinging backwards and forwards three or four times, without coming within reach, at last became stationary over the ledge of the projecting rock, leaving the bird-catcher apparently without a chance of escape,-for to ascend the precipice without a rope was impossible, and none were near to hear his cries, or afford him help. What was to be done? Death stared him in the face. After a few minutes' pause, he made up his mind. By a desperate leap he might regain the rope, but if he failed, and, at the distance at which it hung, the chances were against him, his fate was certain, amidst the pointed crags ready to receive him, over 
which the waves were dashing far, far below. Collecting, therefore, all his strength, with outstretched arms, he sprang from the rock, and lived to tell the tale-for the rope was caught!

The next occurred at St. Kilda, where, amongst other modes of catching the sea-fowl, that of setting gins or nooses is adopted. They are fixed in various places frequented by the birds. In one of these, set upon a ledge, a hundred and twenty feet above the sea, a bird-catcher entangled his foot, and not being at the moment aware of it, was, on moving onwards, tripped up, and precipitated over the rock, where he hung suspended. He, too, as in the preceding case, had no companion; and, to add to his misfortune, darkness was at hand, leaving little prospect of his being discovered before morning. In vain he exerted himself to bend upwards, so as to reach the noose or grapple the rock. After a few fruitless efforts, his strength was exhausted, and in this dreadful situation, expecting, moreover, that the noose might give way every instant, did he pass a long night. At early dawn, by good fortune, his shouts were heard by a neighbour, who rescued him from his perilous suspension.*

The last we shall relate terminated in a more awful manner. A father and two sons were out together, and, having firmly attached their rope at the summit of a precipice, descended, on their usual occupation. Having collected as many birds and eggs as they could carry, they were all three ascending by the rope,- - the eldest of the sons first,his brother a fathom or two below him; and the father following last. They had made considerable progress, when the elder son, looking upwards, perceived the strands of the rope grinding against a sharp edge of rock, and gradually giving way. He immediately reported the alarming fact. "Will it hold together till we can gain the summit?" asked the father. "It will not hold another minute," was the reply; "our triple weight is loosening it rapidly!" "Will it hold one?" said the father. "It is as much as it 
can do," replied the son,- " even that is but doubtful." "There is then a chance, at least of one of us being saved; draw your knife and cut away below!" was the cool and intrepid order of the parent;-_ "Exert yourself,-you may yet escape, and live to comfort your mother!" There was no time for discussion or further hesitation. The son looked up once more, but the edge of rock was cutting its way, and the rope had nearly severed. The knife was drawn,-the rope was divided,- -and his father and brother were launched into eternity!

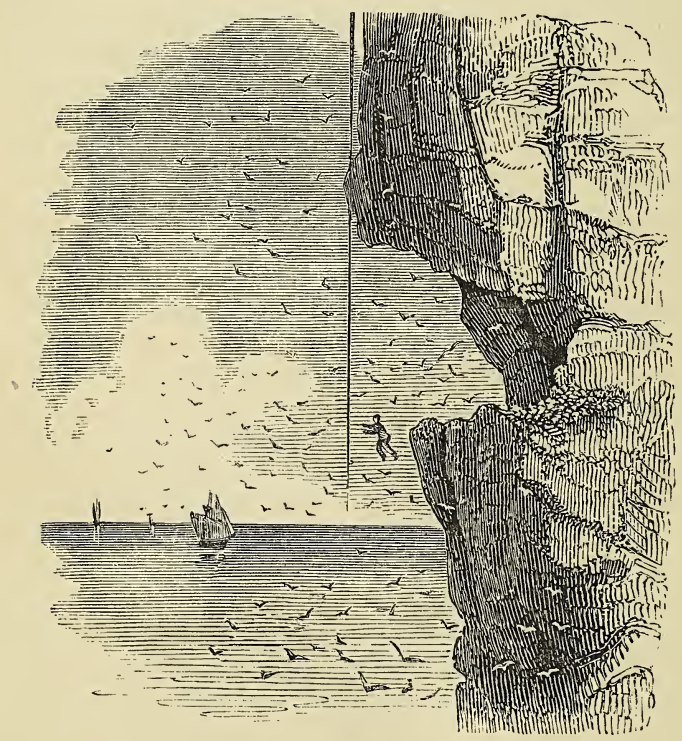

Perilous Leap of a Bird-Catcher. 


\section{N D E X.}

Affectionate disposition of the Ostrich, 300

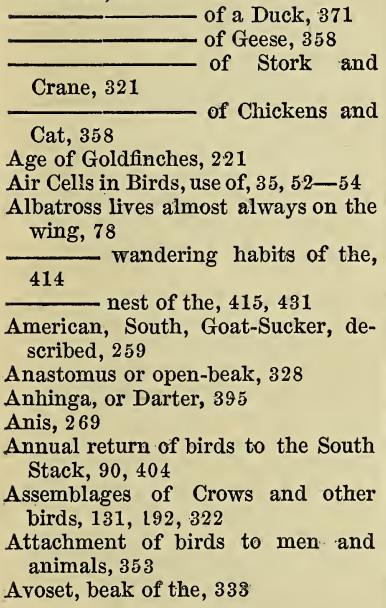

Barn-Owl, habits of the, 150,155

Bee-Eater, 264

Bell Bird, 59

Benefits derived from Rooks, 196 229.

Bird-catchers employ Owls, 155

Bird-catching in Shetland and St. Kilda, 433

Birds, their situation in the natural division of the animal kingdom, 5

Bittern, light in the breast of, 317 Blackbird crowing like a Cock, 57

Bones of birds, 34

Box, feeding, for Pheasants, 287

Breast-bone, 37

- light in that of an American Bittern, 317
Breathing, 52

Breeding - Pheasant with poultry, 285

Bullfinches, how taught to pipe, 222

Burrowing Owl described, 156

Bustards taken by Hawks, 123

courage of the, -284

pouch of the, 299

Butcher-Bird, habits of the, 159

Canada Geese, 356, 359

Canaries, history of, and trade in, 221

Cancroma, or Boat-bill, 329

Caprimulgus, Goat-Sucker, 259

Carrier-Pigeon, its rapid flight, and how used, 75, 279

Cassowary, 302

Cat and Pigeon, anecdote of, 382

Chickens, anecdote of, 385

Catching Wood-Pigeons, mode of, 280,281

Caverns filled with Swallows' eatable nests, 254

Certhia, or Tree-Creeper, 264

Chavana Fidele, capacity for filling itself with air, 54

Children, instances of, carried off by Eagles, 96

Chinese management of Ducks, 368

388

Chough, or Red-legged Crow, 204

Cinereous Crow, depredations of the, 206

Classification, Tables of, 9

Claw of the Goat-Sucker, why toothed, 260

- serrated, of the Heron, 315

Cock, barn-door, courage of, 282

Cold, capacity of birds for enduring severe, 47

Colour of plumage, changes in, 68

Condor, eontest with a man, 118

Constancy of Magpies and other birds, 324

Consumption of food by small birds, 230 
Coots, nest of, 309

Cormorants, habits of, 389

by the Chinese, 388

Frigate-Bird, 393

Corn-Crake, 313

Cotinga, 173

Courage of Swallows, 251

Cranes, 315

- anecdote of a lame, 332

Crocodile, birds feed in mouth of, 337

Cross-Bill, beak described, 28

Crows, 189 peculiarities of the, 195

harassing the Gulls at the

South Stack, 433

Cuckoos, 269

Golden, 25

fed by a Thrush, 171

Cultrirostral, cutting-billed birds, 315

Cuneirostral, wedge-billed birds, 269

Dangerous instinct of Herons and Bitterns in darting at the eye, 327

Dardanelles, incessant flight of a species of Petrel on the, 81

Dates of the arrival and departure of certain birds, 90

Desertion of young, instances of, 180, 424

Desperate leap of a Bird-cateher, 438

Digestive organs, 42

Divers, 421

Dodo, 304

Dormancy of birds considered, 242

Ducks' bills described, 29

_ occasional long flights of, 76

- Chinese management of, 368 affection of, 371

nest of Wild, 370

- Eider, how to obtain the down, 373

- Indian mode of catching, 374

- Shooters, adventures of, 375

- decoy, 380

381

Dunlin, nest and eggs, 335
Eagles, various particulars respecting them, 93

carrying off children, 96

Egg of the Cuckoo, why laid in small birds' nests, 272

Eggs of Nightingales carried, 341

Emu, 302

Eye, insects flying in the, 248

Herons and Bitterns dangerous to the, 327

Falcon, Iceland, valuable, 124

Falconry, 125

land, 128

Familiarity of Crows, anecdote of, 191

Fasting powers of birds, 51

Fatal event to a family of Seafowlers, 439

Feathers of Eagles prized, 111

rapid growth of, 225

Feats of Bird-catchers, 436

Feeding, Thrush's mode of, 168

Feeding-box for Pheasants, 287

Fieldfare, 167

Finches, family of, 217

Flamingo, or Phœnicopterus, s30

singularity of its bill, 330

Africa, 332

Flight, difficulties connected with, s

- of birds, 70,75

Fly-catchers, 171

Food consumed by small birds, 230

Fowl, singular contents of the stomach of a, 50

Frigate-Bird lives almost always on the wing, 79

Frost favourable to insects, 200

Frozen, birds occasionally, 139

Fulmars, 416

Gallinaceous, Poultry tribe, 276

Gallinula, Water Hen, 305

Gannet, 53

- use of its horny mask, 53

- mode of catching, 53 nests, 394

Gastric juice, 46

Geese, rearing of, profitable, 350

management of them in Lincolnshire, 350 
Geese sacred among the ancients, 352 352

- instances of attachment in, 352 various anecdotes of, 352

- Bernacle, or Tree, 362

Gigantic Crane, or Hurgila, 324

Gizzard, functions of the, 48,49

Goat-Sucker, bill of the, 31

- mouth of the, 241, 259 South American, 261

Goldfinches, anecdote of, 217

- sagacity of, 218 sociability of, 219

Grackles, 175, 199 age attained by, 221

Grebe, 419

crested, shot at Adlington, Cheshire, 421

Guillemots, 422, 424

Gulls, 498

— feeding on herrings, 401

- anecdote of a pair, 402

- Laughing,their breeding-place

in Norfolk, 406

Gullet, 45

Hare and Hawk, contest between, 136

Hawk tribe, 93, 121

Hawking, 125

Hawks rearing Chickens, 142

Hen kills mice, 285

- swimming, 285

Herons taken by Hawking, 129

- assemblage of, 194

- legs allure fish, 316

- feathers, 317

- voracity of, 317

Honey-Buzzard feeds on wasps, 140

Hoopoe, 262, 264

Hornbills, bills of, 32

general character, 174

Horned Screamer, Palamadea cornuta, 312

Hospital for Cranes and Storks, 320

Humming.Birds, 262, 266

Hurgila, or Gigantic Crane, 324

Ibis, Sacred, 346

Imitative power of birds, 57
Injuries from Crows and Rooks, 196

- and benefits from small birds, 229

Insects, quantity devoured by Swallows, 248

Looks and Crows destructive to, 189

frost favourable to, 200

Instinct nearly allied to reason, instance in Ducks, 381

Jabiru, 326

Jacamars, 269

Jacana walks on water-plants, 312

Jackdaws, 203

Jays, partial migration of, 83

— killed by Hawks, 137

- general character, 207

Kingfisher, 265

King Penguin, 431

Kites once common in London, 127

Land-birds found far at sea, 77

Language of birds, 61

Lapwing, food of the, 336

Larks, 232

Latirostres, flat-beaked, 329

Laughing Gull, account of, 406

Leg-bones, 38

Legs of Herons allure fish, 316

Levirostral, light-billed, 275

Light on American Bittern's breast, 317

Light-houses a decoy for birds, 91, 334

Linnets' affection for their young, 228

Longipennes, 396

Magpies, 208, 324

- sagacity of, 208

Manakins, 232

nurse young Ravens, 209

Mate, birds choose new ones when the old ones die, 180, 252

Meetings of Crows and other birds, 192,322

Mice killed by a Hen, 285

Migration of Cuckoos, 270

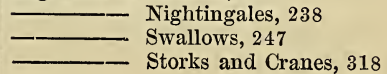


Migration, queries respecting, 82, 237 Mocking-Bird, 58

Muscular power of the wing of a bird, 70,437

Music attracts Nightingales, 239

Narrow-beaked, Pressirostral, 305

Nest, Blackbird's, by a Rabbit's seat, 170

- Eagle's, 104 109 other birds build in Eagles,

- curious, of a Thrush, 167

- rapidity of building, 219 219

curious one of African Finches, - of Sparrows and Redbreast, 224,235

- of Titmouse, singular place for one, 232

- - of a Redstart, 234

- Swallow's, in a lamp, 250 in a bell, 250

- not always of mud,253 eatable, 253

- Pigeons, 281

Ostrich, 300

- Water-Hen, $305,30.8$

- Solan Goose, 393

- Albatross, 412, 431

- same frequented by same birds, season after season, 250

Night, birds sing during, 240

Nightingales, migration of, 230

removal of eggs by, 341

Nuthatch, Sitta Europæa, 263

Oil on feathers, use of, 66

Oriole, Golden, 211

Ostrich, substances found in the stomach of one, 45

- affectionate disposition of the, 300

modes of catching, 301

Oxen destroyed by Eagles, 106

Owls, particulars respecting, 14.5

- remove their young, 341

Oyster-Catchers, 314

Palamadea cornuta, or Horned Screamer, 313
Palmipedes, web-footed, 349,383

Park, Mungo, anecdote of, 1

Parrots, 275

- beak described, 27

Parroquets, 275

Partridge and Turkey associate, 291

— tame, 293

- in North America, 294

296

Paradise, Bird of, 177

Passerine order, 211

Peacocks formerly prized as dainties, 289

Pelican's beak, 33

traditions of, 383

and Cormorant, fishing in

partnership, 38.6

Penguin, 429

- stones swallowed by, 50

place, 431

Petrel, 82, 416

- used as a candle, 416

of, 417 Stormy, sailors' superstition found inland, 426

Sooty, 426

Pheasant attacks a lady, 284

286

Pigeons living peaceably with a Hawk, 141

- Carrier, 75, 279

- Passenger, 276

mode of catching in the Pyrenees, 280

— Wood, 281

282

Platypus, Duck-billed, 30

Ptiloris Paradiscus, plumage of, 64 Plover, Stilted, 40

337

Plumage of Birds considered, 64, 66

- change of colour, 68

Pouch of the Bustard, 299

Emu, 302

Hurgila, use of, 325

Poultry tribe, 276

Pressirostral, or Narrow-beaked, 305 
Ptarmigan,its mode of escaping birds of prey, 149

Puff-backed Shrike, 166

Puffin and Raven, 184 or Sea-Parrot 423 how caught, 423

Purres, 334

Quails, 296

Rails, 313

Rain, why Swallows fly low during, 249

Rapacious birds, 93

Rapidity of flight, 73

Raven, notices of the, 179

- tame, 185
tame, in a wild state, 189
and Jackdaws, 180
and Puffin, 184
attachment to a dog, 187,
Razor-bill, 423

- chased by a Hawk, 425

Rearing Pheasants, 286

Redbreast builds in a dining-room curtain, 235

235

in a school-house,

in a church, 236

frequenting some particu-

lar place, 237

Red-legged Crow, 204, 403

Redpoll and Goldfinch, 218

Redstart's nest in the hinge of a door, 234

Redwing, 167

Ring-Dotterell, 334

Rooks, 189

Rookeries, 201

$$
\text { occasional desertion of, } 201
$$
contentions in, 203

Ropes of hide used in St. Kilda, 435

Sacred Ibis, 346

Sandpipers on the sea-shore, 334

Screamer, Horned, Palamadea, 312

Sea-birds, feeding on fish, 386

- found far out at sea, 78, 418

found inland, 418

trade in, 433

Swallow, or Tern, 397
Senses, acuteness of the; in birds of prey, 115

Sitta Europæa, Nuthatch, 263

Sheldrake builds in rabbit-holes, $\mathbf{3 7 5}$

Shoveller Duck's bill, 30 of New Holland, 30

Shrike, or Butcher-bird, 27, 158

- used for Hawking, 164

Skeleton of a bird, 26, 35

Skimmer (Rhynchops), 396

Snake-eater, Vultur serpentarius, 120

Snipe's attachment to place, 339

- mode of feeding, 28

Snowy Owl, habits of the, 149

Solan Goose, 53, 393

Song in birds pleasurable, 62

South Stack, punctual return of seabirds to the, 91,404

- Lighthouse, birds killed by flying against, 344

mots at the, 424

Sparrow, boldness of, 224

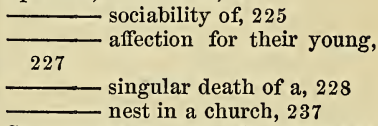

Sparrow-Hawk, mode of catching, 136

geons, 141

Spiders, height to which they ascend

in the air, 249

Spoon-bill, shot at Holyhead, 330

- 's beak, 34

St. Kilda, bird-catchers of, 434

Stanley Crest explained, 92

Starlings, habits of, 212

Stomach, Heron's, 316

Stork, 318

—_ kills its faithless mate, 332

Strength of the Condor, 118

Swallow's bill, 31

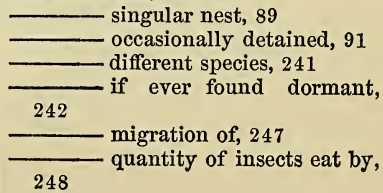


Swallow's nest in a bell,and in a lamp, 250

courage, 251
suit their nests to circum-
stances, 253
nests eatable, 253
scarcity of them in late
Swan, strength of, 365
black, 366
Swiftness of Ostriches, 301
Swimming Hen, 285

Tables of Classification, 9

Tame Hawks, 142

- Partridge, 293

- Raven in wild state, 188

- Woodpecker, 273

Tanagers, 173

Tantalus, 328

Tenuirostral tribes, of Passerine order, 262

Tenuirostres, or slender-billed, of order Waders, 333

Tern, habits of the, 397

Thrush tribe, 166

—_ feeds a Blackbird, 170 : feeds

a Cuckoo, 171

__ feeding on shell-fish, 169

Titmouse found at sea, 77

- nest of the, 232

Todus viridis, 262

Tongue of the Wryneck, 275

Toucan-bill, 31

- mode of killing small birds, 32

37

Tracheas, or windpipes, of Duck tribes, 56

Trap for Eagles, 110

Goshawks, 133

Sparrow-Hawks, 136

Tree-Creeper, 264
Tropic Bird lives almost always on wing, 79

Turkey, wild, anecdote of the, 290

- and Partridge associate, 291 Cock rearing young ones, 292

Turks' veneration for Storks, 319

Turtles, migration of, 86

Voice of birds, 56, 61

Voracity of some birds, 43, 317, 326

Vulture floating on a corpse, 103

—_ particulars of, 113

- mode of catching in South America, 117

— voracity of, 117

Wagtail's nest in a brass-foundry, 233

Warblers, 232

Warmth of Birds, 46, 54

Water-Crow walking under water, 72 Hen, account of, 305

Washington, Bird of, 107

Wedge-billed birds, or Cuneirostral, 269

Weight, comparative, of Birds, 71

Windows, how to prevent Swallows building near, 257

Wing-bones described, 38

Winter, hard, favourable to insects, 200

Wire-worms, destroyed by Rooks, 198

Woodcocks breed in Scotland, 340

- migration of, 342

_ rapid flight proved, 343

345

young, 340

Wood-Pigeon, 281

Woodpecker, 269

Wrens, 232

Wryneck, tongue of the, 275

Young birds carried off by the old ones, 334, 340, 341, 421 




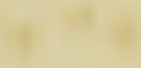

7 
$3 x+9$. हs

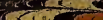




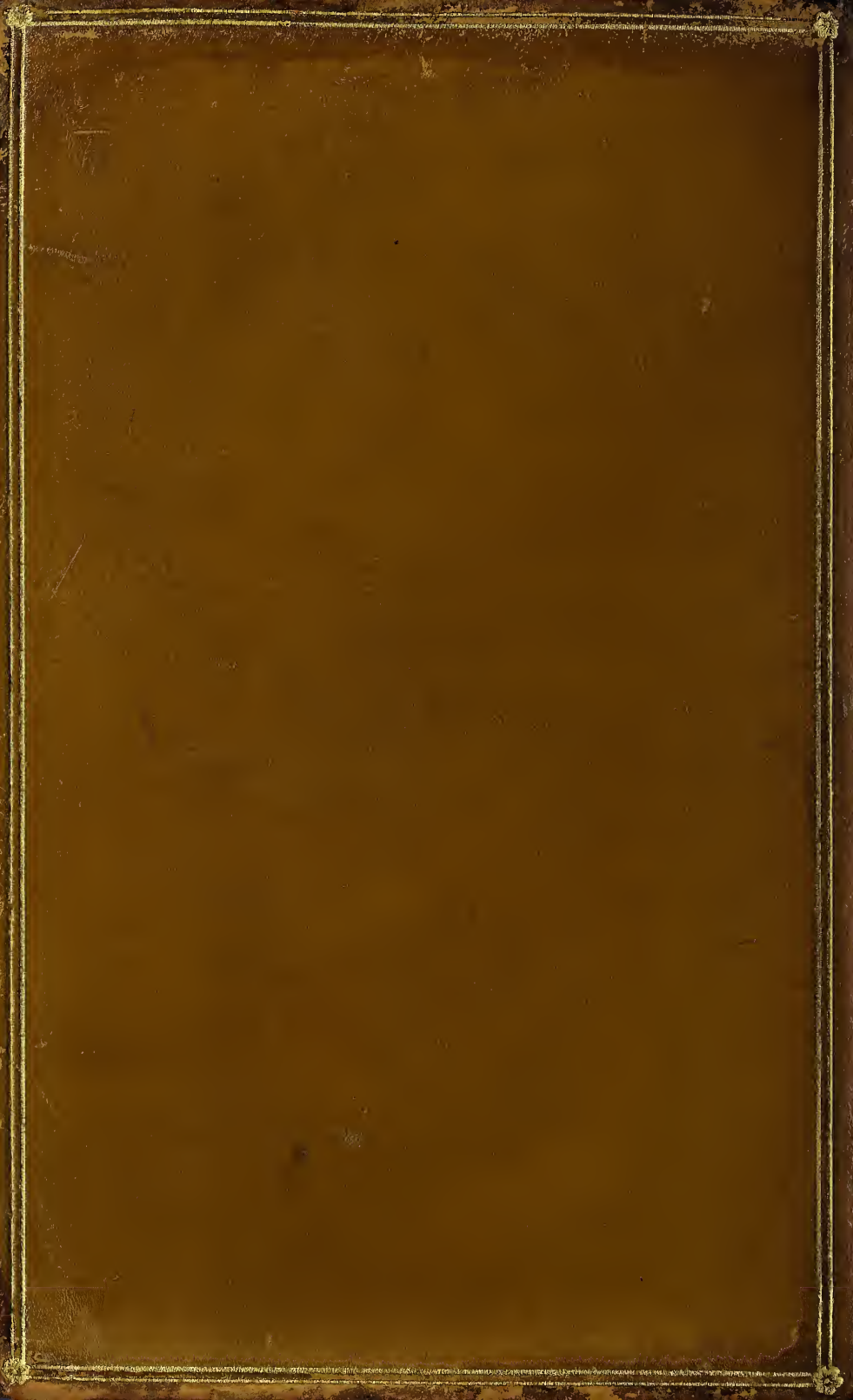

